\title{
Insulin receptor sensitization improves affective pathology in various mouse models
}

Citation for published version (APA):

da Costa Alvares Viegas Nunes, J. P. (2015). Insulin receptor sensitization improves affective pathology in various mouse models. [Doctoral Thesis, Maastricht University]. https://doi.org/10.26481/dis.20151221jc

Document status and date:

Published: 01/01/2015

DOI:

10.26481/dis.20151221jc

Document Version:

Publisher's PDF, also known as Version of record

\section{Please check the document version of this publication:}

- A submitted manuscript is the version of the article upon submission and before peer-review. There can be important differences between the submitted version and the official published version of record.

People interested in the research are advised to contact the author for the final version of the publication, or visit the DOI to the publisher's website.

- The final author version and the galley proof are versions of the publication after peer review.

- The final published version features the final layout of the paper including the volume, issue and page numbers.

Link to publication

\footnotetext{
General rights rights.

- You may freely distribute the URL identifying the publication in the public portal. please follow below link for the End User Agreement:

www.umlib.nl/taverne-license

Take down policy

If you believe that this document breaches copyright please contact us at:

repository@maastrichtuniversity.nl

providing details and we will investigate your claim.
}

Copyright and moral rights for the publications made accessible in the public portal are retained by the authors and/or other copyright owners and it is a condition of accessing publications that users recognise and abide by the legal requirements associated with these

- Users may download and print one copy of any publication from the public portal for the purpose of private study or research.

- You may not further distribute the material or use it for any profit-making activity or commercial gain

If the publication is distributed under the terms of Article $25 \mathrm{fa}$ of the Dutch Copyright Act, indicated by the "Taverne" license above, 
Insulin receptor sensitization improves affective pathology in various mouse models

João Pedro COSTA-NUNES 
๑João Pedro Costa-Nunes, 2015

Lay-out: Andreia Gaspar and João P. Costa-Nunes

Cover: Ana Leonor Nunes

Production: Planeta Colorido - Copy Center, Lisbon, Portugal

The studies described in this thesis were performed as a collaboration between Maastricht University and the University of Lisbon, New University of Lisbon, University of Oxford, University of Würzburg, University of Wisconsin, University of Strasbourg, Claude Bernard University Lyon, and the Russian Academy of Sciences.

The printing of this thesis was financially supported by Maastricht University 


\title{
Insulin receptor sensitization improves affective pathology in various mouse models
}

\author{
Dissertation \\ to obtain the degree of Doctor at Maastricht University, \\ on the authority of the Rector Magnificus \\ Prof. Dr. L. L. G Soete \\ in accordance with the decision of the Board of Deans \\ to be defended in public \\ on Monday, December $21^{\text {st }} 2015$ at 9.45 hrs \\ by
}

João Pedro da Costa Alvares Viegas Nunes 


\section{Supervisor:}

Prof. Dr. Harry W. M. Steinbusch

\section{Co-supervisors:}

Dr. Tatyana Strekalova

Dr. Brandon Cline, Université de Strasbourg, Strasbourg, France Prof. Dr. Klaus-Peter Lesch

Assessment committee:

Prof. Dr. W. Buurman, Chairman

Prof. Dr. A.A.M. Masclee

Prof. Dr. A.I.M. Santos, Universidade Nova de Lisboa, Portugal

Prof. Dr. J.A. Belo, Universidade Nova de Lisboa, Portugal

Dr. D. Van den Hove 
To my grandfather, Rodrigo. 



\section{Contents}

Chapter 1 Introduction

p. 9

Chapter 2 Altered emotionality, hippocampus-dependent performance

p. 53

and expression of NMDA receptor subunit mRNAs in chronically stressed mice.

Costa-Nunes JP* Zubareva $O^{*}$, Araújo-Correia $M^{*}$, Valença $A^{*}$, Schroeter CA, Pawluski JL, Vignisse J, Steinbusch H, Hermes D, Phillipines M, Steinbusch HWM, Strekalova T (2014). Stress. 2014 (1):108-16.

Chapter 3 Dicholine succinate, the neuronal insulin sensitizer, normalizes p. 79 behavior, REM sleep, hippocampal pGSK3 beta and mRNAs of NMDA receptor subunits in mouse models of depression.

Costa-Nunes JP*, Cline BH*, Cespuglio R, Markova N, Santos Al, Bukhman YV, Kubatiev A, Steinbusch HW, Lesch K and Strekalova $T$ (2015). Front. Behav. Neurosci. 9: 37.

Chapter 4 T/r4 upregulation in the brain accompanies depression- and p. 137 anxiety-like behaviors induced by a high-cholesterol diet

Strekalova T, Evans M, Costa-Nunes J, Bachurin S, Yeritsyan N, Couch $Y$, Steinbusch HWM, Köhler ES, Lesch KP, Anthony DC (2015). Brain, Behav Immunity. 48:42-7. 
Chapter 5 Animal models of depression and drug delivery with food as an p.155 effective dosing method: evidences from studies with celecoxib and dicholine succinate.

Costa-Nunes JP* Cline BH*, Araújo-Correia M, Valença A, Markova $N$, Dolgov O, Kubatiev A, Yeritsyan N, Steinbusch HWM, Strekalova T (2015). BioMed Research International, 2015:596126.

Chapter 6 Insulin receptor sensitizer, dicholine succinate, prevents both p. 185 Toll-like receptor 4 (TLR4) upregulation and affective changes induced by a high-cholesterol diet in mice.

Strekalova $T$, Costa-Nunes JP, Veniaminova E, Kubatiev A, Lesch KP, Chekhonin V, Evans M, Steinbusch HWM. J Affect Disord (Submitted 15.09.2015, Revised 25.10.2015).

Chapter 7 Discussion and Impact

p. 231 



\section{Chapter 1}

Introduction 
Insulin is a peptidergic hormone normally secreted by the beta cells at the pancreatic islets of Langerhans (Huang et al., 2010). Discovered in 1922 by Banting and Best, it was initially assumed to be unable to transit the blood-brain barrier (BBB) and consequently have no action in the brain (Pirart, 1978). This supposition has long been proven wrong, when both insulin and its receptor were found in the brain (Havrankova et al., 1978; Unger et al., 1989).

Contrary to what was initially thought (Pirart, 1978), insulin originates in the peripheral tissues and migrates via the cerebrospinal fluid (CSF) into the central nervous system via a saturable insulin receptor-mediated transport process, which is hypothesized to occur through the choroid plexus (Woods et al., 1985; Wallum et al., 1987; Devaskar et al., 1994; Craft and Watson, 2004), whereas central synthesis (e.g. in neurons) is still a controversial subject (reviewed in Blásquez et al., 2014). 
The neuronal or central insulin receptor (IR), discovered in 1978 by Havrankova and colleagues, is a heterotetrameric glycoprotein, comprised of two alpha subunits and two beta subunits of transmembrane proteins with tyrosine kinase activity, linked together by disulphide bonds (Zhao et al., 1999; Huang et al., 2010). Central insulin receptors differ from their peripheral counterparts by having distinctly smaller molecular weights, although reported to have similar signal transducing properties, and are distributed in particularly high concentrations in neurons and to a much lesser extent in glial cells (Heidenreich et al., 1983; Heidenreich and Gilmore, 1985; Schwartz et al., 1992; Zhao et al., 1999).

Ubiquitously distributed in the brain, IR presence is the highest in the olfactory bulb, cerebral cortex, hippocampus, hypothalamus, and amygdala (Havrankova et al., 1978), where it is thought to be associated with, but not limited to synaptic plasticity, cell differentiation, myelination and survival (Chiu et al., 2008; Huang et al., 2010, Lin et al., 2010), metabolic processes (Govind et al., 2001; Zhao and Alkon, 2001; Freude et al., 2008), regulation of dopamine-mediated neurotransmission (Williams et al., 2007) and extracellular levels of norepinephrine and serotonin (Daws et al., 2009).

The robust density of the neuronal insulin receptor in structures such as the hippocampus and cerebral cortex (Mufson et al., 1999; Sun et al., 2010) together with its high structural homology in the activation loop segment with tropomyosin receptor kinase $B$ (TrkB) suggest a prominent role in adaptive stress response (Krishnan et al., 2007; Kikusui et al., 2009; Spencer et al., 2010). Brain insulin levels also have an impact in the modulation of neuroinflammation, both by reducing levels of proinflammatory cytokines as well as minimizing the effects of reactive oxygen species (ROS), thus maintaining tissue integrity (Abbas et al., 2012).

Signalling starts when insulin binds to the extracellular subunits of the insulin receptor, inducing a conformational change that leads to autophosphorylation of the 
cytosolic tyrosine residues (Kahn et al., 1993), enabling the recognition and further tyrosine phosphorylation of adaptor proteins such as insulin receptor substrates (IRS) (Lizcano and Alessi, 2002). A plurality of phosphorylated IRS proteins then couples to their respective effectors and transduce the insulin signal into multiple pathways.

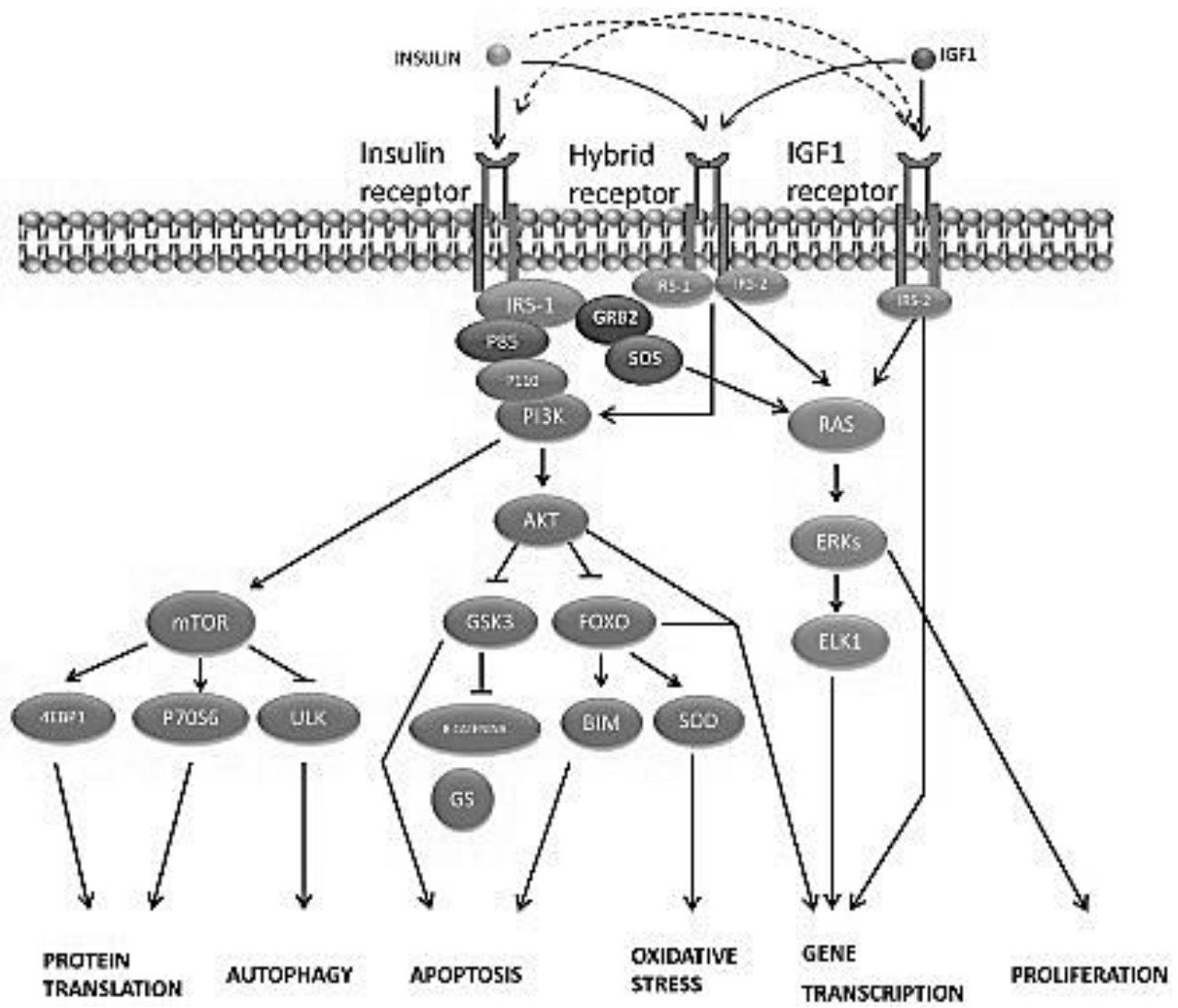

Fig. 1 - Transduction of signals and biological actions induced by Insulin or IGF-1

The pivotal insulin-triggered pathway is the one which, upon activation, creates binding sites for the regulatory subunit of phosphoinositol 3-kinase (PI3K), enabling downstream phosphorylation of phosphatidylinositol 4,5-bisphosphate (PIP2) and assembly of the protein kinase B (PKB/AKT) activator, phosphatidylinositol $(3,4,5)$ trisphosphate (PIP3). Active AKT phosphorylates and inactivates cytosolic forms of glycogen synthase kinase 3 (GSK3), pro-apoptotic regulators, and also modulates 
downstream regulation of transcription and translation. In neurons, the balance between these intricate pathways are critical for survival signalling (Cole and Frautschy, 2007) (See Fig.1).

\section{Insulin resistance}

Insulin resistance is a pathological condition, normally attributed to genetics, obesity and aging (Folli et al., 1993; Saad et al., 1993; Carvalho et al., 1996; Anai et al., 1998, 1999), that may also be precipitated by a so-called Western diet, enriched with highcholesterol, -fat, -sugar or -salt content foods (Ogihara et al., 2001; Pipatpiboon et al., 2012), a growing cause for concern given its synergy with the stressful and modern lifestyle.

A chronic inflammation stage usually precedes the development of peripheral insulin resistance in key metabolic tissues, including the liver (Schenk et al., 2008). Systemic and local cytokines trigger kinases capable of inhibiting key elements of the insulin signalling pathway (Hotamisligil, 2006), leading to an increase in lipid peroxidation, altered high (HDL) and low density lipid (LDL) levels, liver steatosis and hyperinsulinemia (Abbas et al., 2012; Janczyk and Socha, 2012).

Peripheral insulin resistance reduces the transport of insulin into the brain across the BBB. Reduced neuronal insulin receptor signalling either by substrate deficiency or receptor desensitization compromises neuronal survival, plasticity, growth and remodelling, microtubule assembly, energy production, gene expression, white matter integrity through aberrant kinase activity, induces changes in protein levels and structure, endoplasmic reticulum stress, promotes the generation of reactive oxygen and nitrogen species that damage proteins, nucleic acids, and lipids, mitochondrial dysfunction and triggers signalling through pro-inflammatory and proapoptosis cascades (Krogh-Madsen et al., 2004a,b; Watson and Craft, 2006; Hu et al., 2014 - Fig. 2). 

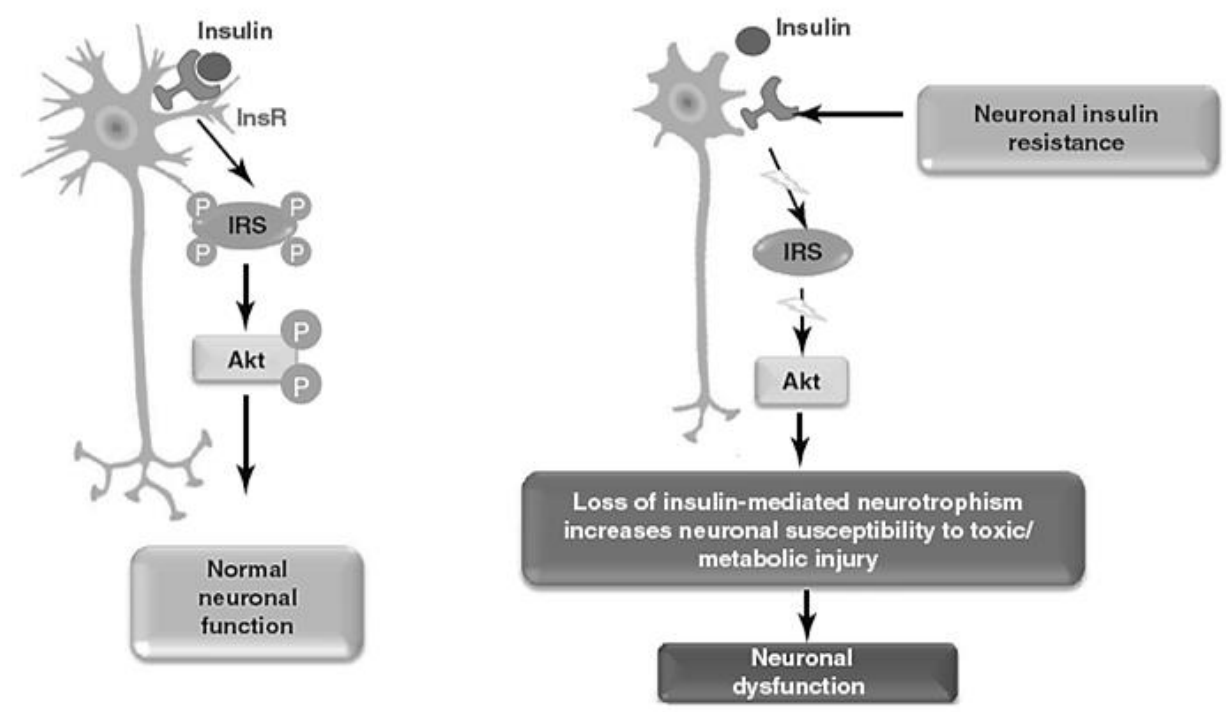

Fig. 2 - Normal insulin signalling (left) vs. insulin resistance (right)

Initially thought to be a cause of insulin resistance (Petersen et al., 2003), mitochondrial dysfunction is considered to be a consequence of this phenomena. In the central nervous system, brain mitochondria play an important role in energydemanding neurotransmission, in controlling calcium homeostasis (Wang et al., 2010) and regulating adenosine triphosphate (ATP) production via oxidative phosphorylation. Insulin stimulates mitochondrial functions at multiple steps including oxidative phosphorylation, gene transcription and protein expression (Stump et al., 2003).

Mitochondrial recycling is an essential process, regulated by autophagy, where damaged mitochondria are degraded and used for energy production through recycling membrane lipids (Zhang and Ye, 2012). Disruption of electron transport chains can lead to decreased ATP with increased reactive oxygen species (ROS) production (Pipatpiboon et al., 2012), normally converted into $\mathrm{H}_{2} \mathrm{O}$ and $\mathrm{CO}_{2}$ by 
functional mitochondria, deleterious to the processes of lipid oxidation, and responsible for protein and DNA damage.

\section{$N$-methyl-D-aspartate receptors and insulin signalling}

The N-methyl-D-aspartic acid receptors (NMDAr) are hetero-oligomeric complexes comprised of two NR1 subunits co-assembled with two subunits of the NR2 (NR2AD) subfamily and, at times, an NR3 subunit (Das et al. 1998; Laube et al. 1998; Schorge and Colquhoun 2003). The different NR2 subunits are differentially expressed throughout the brain and during development (Watanabe et al. 1993; Monyer et al. 1994), and they confer distinct electrophysiological and pharmacological properties to the receptors (Riedel et al. 2003).

These are an important subtype of ionotropic glutamate receptors that function as a ligand-gated ion channel which initiate cation influx upon activation (McBain et al., 1994; Sucher et al., 1996). Then, permeability to $\mathrm{Ca}^{2+}$ rises tenfold, which will act as a second messenger in multiple pathways. NMDA receptors also contains regulatory sites for other ions such as $\mathrm{K}^{+}, \mathrm{Mg}^{2+}, \mathrm{Zn}^{2+}$, for glycine, polyamines, and phencyclidine (Zhang et al., 1998; Salehi-Sadaghiani et al., 2012).

In the central nervous system (CNS), modulation of the NMDA receptors occurs particularly in the hippocampus (Trudeau et al. 2004) and has also been shown to have a role in learning and memory (Zhao and Alkon 2001; Huerta et al., 2000; Nakazawa et al., 2002), including acquisition, consolidation, and reconsolidation (Bank et al., 1988; Olds et al., 1989; Alkon, et al., 1998; Bonini et al., 2007).

The insulin-driven potentiation of NMDA receptor activity is not direct. Instead, potentiation occurs via recruiting new channel molecules to the cell surface by regulated exocytosis (Skeberdis et al., 2001). At post-synaptic sites, the activation of insulin receptors results in tyrosine phosphorylation of insulin receptor substrates 1 
and 2 (IRS- 1 and IRS-2), which bind to effector molecules that activate protein kinases (Zhao and Alkon, 2001), ultimately leading to a positive-feedback phosphorylation of NR2A/NR2B subunits of the NMDA receptor (Christie et al., 1999) thus increasing the opening rate of functional channels (Lin et al., 2006).

NMDA receptor dysfunction has been reported in various CNS disorders including dementia (Zekry and Gold 2010), epilepsy (Metzler 2011), schizophrenia (Kantrowitz and Javitt, 2010), stroke (Cho et al. 2010), Parkinson's disease (Gardoni et al. 2010), and Huntington's disease (Milnerwood and Raymond, 2010), and also depression (Berman et al., 2000; Zarate et al., 2006; Machado-Vieira et al., 2008; Sanacora et al., 2008; Hashimoto, 2009; Salehi-sadaghiani et al., 2012). Insulin receptor sensitizers were demonstrated to have inhibitory effects over NMDA-mediated calcium currents, protecting neurons from excitotocity (Zhao et al., 2006).

\section{Glycogen synthase kinase 3, insulin signalling and brain functions}

The glycogen synthase kinase 3 (GSK-3) was originally identified in 1984 as a key regulator in glycogen synthesis (Woodgett and Cohen, 1984), presenting itself in two isoforms, $\alpha$ and $\beta$ very similar to one another in terms of sequence homology and biochemical characteristics (Woodgett and Cohen 1984; Woodgett, 1990, 1991), each exhibiting a N-terminal inhibitory Ser phosphorylation site and a facilitative Tyr site in their catalytic loop.

GSK3 has several unique features compared with other kinases: (1) it is constitutively activated, (2) phosphorylation at Ser21 ( $\alpha$ ) and Ser9 ( $\beta$ ) inhibits kinase activity; (3) in general, 'primed' phosphorylation of its substrates by other kinases is required, with the exception of b-catenin and Axin; (4) plays a part in a number of physiological processes, such as glycogen metabolism (Welsh and Proud, 1993), gene transcription (Troussard et al., 1999) and apoptosis (Turenne and Price, 2001). GSK3 activity is modulated by insulin and WNT signalling, both pathways act in a negative regulatory 
manner (Lizcano and Alessi, 2002; Saltiel and Kahn, 2001), in contrast with its action on the NFKB signalling pathway (Lee and Kim, 2007).

The beta isoform is ubiquitous in neuronal tissue (Bhat et al., 2004). Under normal conditions, GSK3 inhibits glycogen synthesis by suppressing glycogen synthase (GS) via phosphorylation. In turn, insulin (and IGF-I) keep GSK-3 kinase activity suppressed through IRS-1 and PI3K dependent mechanism via Akt-mediated phosphorylation of the enzyme isoforms at the serine residues. (Sutherland et al., 1993; Yuan et al., 2001; Lee and Kim, 2007; Bhat and Thirumangalakudi, 2013). This neuroprotective effect of GSK-3 inhibition increases cell survival, decreases death signals, inflammatory signals (COX-2), and neutrophil infiltration, reduces brain swelling, and decreases postischemic serum glucose levels related to neuronal cell death (Koh et al., 2008).

High fat and high cholesterol diets have been shown to significantly induce insulin resistance, redcue hippocampal AKT activity and conversely enhancing GSK-3 $\beta$ activity and tau hyperphosphorylation (Hu et al., 2013; Bhat and Thirumangalakudi, 2013). Tau is a microtubule-associated protein, hyperphosphorylated at specific serine residues by abnormal activated state of several proline-directed kinases, such as GSK-3 (Sengupta et al., 2006; de la monte et al., 2012). As a result, tau protein folds in erroneous conformations and self-aggregates into insoluble fibrillary structures (paired helical filaments and straight filaments) that form neurofibrillary tangles, dystrophic neurites, and neuropil threads (Iqbal et al., 2009).

Intraneuronal accumulations of fibrillary tau disrupt cytoskeletal networks and axonal transport, leading to synaptic disconnection, progressive neurodegeneration and necrosis (Iqbal et al., 2009). Besides fibrillary tau, pre-fibrillary tau can also aggregate (Takashima, 2010). The accumulation of insoluble fibrillary tau is also responsible for oxidative stress and ROS generation which promote apoptosis, mitochondrial dysfunction, and neuronal death, present in Alzheimer's disease 
(Mandelkow et al., 2003) recently considered to be a neuronal form of diabetes (Steen et al., 2005).

Studies have implicated GSK-3 $\beta$ in the mechanism of action of mood stabilizers (Chen et al., 1999; Li et al., 2002) and antidepressants (Rosa et al., 2008). Insulin sensitizers were shown to ameliorate intracerebral insulin resistance, and reduce tau-protein hyperphosphorylation via GSK-3 kinase activity inhibition (Rosa et al., 2008; Hu et al., 2013).

\section{Toll-like receptors, inflammatory response and insulin resistance}

Toll-like receptors (TLRs) are a family of transmembrane glycoproteins, located either in the plasma membrane (Lucas et al., 2006; Nataf, 2009; Hanamsagar et al., 2012; Ghasemi et al., 2013; Najjar et al., 2013; Obulesu and Jhansilakshmi, 2013) or in intracellular compartments (Hanke et al., 2011; Konner and Bruning, 2011; Shatz et al., 2012; More et al., 2013), and are widely expressed in the brain (Kim and Sears, 2010, Tanti et al., 2013, Hemmati et al., 2014), liver, adipose tissue, skeletal muscle, vasculature and pancreatic $\beta$ cells (Kim and Sears, 2010; Tanti et al., 2013).

This receptor family recognizes pattern-associated molecular patterns (PAMPs, such as lipids, proteins, lipoproteins, and nucleic acids) derived from bacteria, viruses, fungi, and parasites (McGettrick and O'Neill, 2010; Wang et al., 2011) as well as endogenous danger signals (damage-associated molecular patterns or DAMPs (Liu et al., 2012).

Toll-like receptors and insulin signalling cross paths in numerous ways. TLR activation modulates the PI3K/Akt pathway, which, in turn, limits TLR overactivity (Fukao and Koyasu, 2003; Gelman et al., 2006; Hazeki et al., 2007). Whereas normal activation is needed to repair mitochondrial damage (Bauerfeld et al., 2012), abnormal signalling 
is also shown to increase inflammation (Androulidaki et al., 2009; Chaurasia et al., 2010) and link to insulin resistance.

Perturbation in PI3K/Akt pathway by TLR drives a GSK3 $\beta$ overactivation, associated with insulin resistance (Liu et al., 2010) by the hyperphosphorylation of tau, shown to have an effect on learning and memory deficits (Gong and Iqbal, 2008; Hooper et al., 2008; King et al., 2013) and being related to psychiatric disorders like depression or schizophrenia (Emamian et al., 2004; Wilkinson et al., 2011).

Pathological activation of toll-like receptors triggers two myeloid differentiation primary response gene, 88 (MyD88)-dependent and MyD88-independent pathways, both converging in the activation of the IKK/NF-KB pathway, with release of NFKB and its translocation into the nucleus, promoting inflammation and downstream insulin resistance (Gao et al., 2002; Zuani-Amorim et al., 2002; Kawai and Akira, 2007; Kim and Sears, 2010; Velloso et al., 2015, Zhang et al., 2015], but also via ceramideinduced inhibition of Akt phosphorylation (Holland et al., 2011; Chavez and Summers, 2012).

Cellular stress caused by TLR activation causes ROS production, triggers downstream kinases and promotes interferon-driven inflammation (Mogensen, 2009; Kim and Sears, 2010; Hemmati et al., 2014). Lastly, together with cytokines, TLR also triggers suppressor of cytokine signaling 3 (SOCS-3)-mediated insulin resistance, achieved via targeting of IRS-1 and IRS-2 for proteasomal degradation (Howard and Flier, 2006), and a downregulation of Akt signalling (Zhang et al., 2008).

This large receptor family has been used as sentinel molecules for detection of metabolic disorders such as insulin resistance, obesity and diabetes (Shi et al., 2006; Tsukumo et al., 2007; Jin et al., 2013), where Increased expression is detected in the liver, muscle, brain, adipose tissue, vasculature and pancreatic $\beta$-cells of obese 
subjects (Kim and Sears, 2010), accompanied by increased NFB activity (Reyna et al., 2008; Poulin-Godefroy et al., 2010; Hardy et al., 2013).

Consumption of fat-rich foods is responsible for two mechanisms of insulin resistance. Firstly, there is induction of endoplasmic reticulum (ER) stress by ROS in a TLRindependent pathway, where lipid excess causes a disequilibrium between folding capacity and amount of proteins, generation of IL-1 $\beta$ and inflammasomes (Tsiotra and Tsigos, 2006; Jager et al., 2007; Zhang and Kaufman, 2008; Boden, 2009; Franchi et al., 2009; Deldicque et al., 2010; Wen et al., 2011). Secondly, TLR-4 activation by saturated and free fatty acids elicits metabolic endotoxemia, where alterations in the composition of gut microbiota and an increase in gut permeability (Cani and Delzenne, 2009; Burcelin et al., 2011) promote live Gram-negative enterobacteria translocation mediated by Fetuin-A stimulation of macrophage migration and activation from the gut to the adipose tissue, inducing inflammation (Neal et al., 2006; Amar et al., 2011; Jin et al., 2013) via NFKB/JNK pathways, which also contributes to ER stress (Anghel and Wahli, 2007; Zhang et al., 2008; Raso et al., 2013; Enos et al., 2014).

Notwithstanding the effects in obesity, diabetes and metabolic syndrome, TLRs have also been linked to both Alzheimer (Chen et al., 2006) and Parkinson (Hirsch and Hunot, 2009), where recurrent expression promotes microglial activation, with concomitant release in pro-inflammatory cytokines, leading to neurodegenerative inflammation. Moreover, higher levels of TLRs and inflammatory cytokines have been linked to schizophrenic and bipolar patients and induced behavioural deficits, social withdrawal was reported in (Najjar et al., 2003; DeMiranda et al., 2010; McKernan et al., 2011; Forrest et al., 2012).

Studies show that downregulation, suppression or mutation of TLRs elicit a weak effect on insulin resistance-mediated inflammation (Radin et al., 2008; Saberi et al., 
2009; Amyot et al., 2012; Liang et al., 2013; Jia et al., 2014), preventing activation of IKK (JNK in mice fed a high fat diet (Tsukumo et al., 2008). In the CNS, normal values of TLRs restore normal plasticity, activity and insulin sensitivity (Hennige et al., 2009; Benarroch, 2010; Heni et al., 2011; Sartorius et al., 2012; and Chapter 6).

The use of insulin sensitizers such as pioglitazone (Gurley et al., 2008; Dasu et al., 2009; Takagi et al., 2009), rosiglitazone (Wu et al., 2010, 2011; Pan et al., 2014), troglitazone (Appel et al., 2005; Gurley et al., 2008; Zhao et al., 2011) and dicholine succinate (Chapter 6 ) have shown to be linked to a reduction of TLR expression and associated inflammatory response.

\section{Cyclooxygenase-mediated aberrations in the CNS functions}

Inflammation induces the expression of an array of proteins, among which are the two isoforms of cyclooxygenases (COX), inflammatory response regulators and main target for all non-steroidal anti-inflammatory drugs (NSAID). Whereas COX-1 is constitutively expressed in most tissues and mediates the synthesis of prostaglandin and thromboxane from arachidonic acid (Smith and DeWitt 1996), COX-2 is expressed in inflamed tissues in response to proinflammatory stimuli, responsible for systemic PGE2 production and the generation of reactive oxygen species (ROS) (Diaz et al., 1998; Lipsky, 1999; McAdam et al., 1999; Whelton et al., 2000; Dannenberg et al., 2001; Huang et al., 2005; Lee et al., 2006; Tian et al., 2011), mainly under pathological conditions (Smith and DeWitt, 1996). In the adipose tissue, COX-2 activation crucially up-regulates the expression of MCP-1 in inflamed fat which causes macrophage infiltration and leads to endotoxemia (Hsieh et al., 2010).

Non-steroidal anti-inflammatory drugs target inhibition of both COX isoforms, through blocking the formation of prostaglandins in normal and inflamed tissues. Celecoxib, a selective COX-2 inhibitor has been shown to have neuroprotective effects (Hunter et al., 2007), reduce the risk and delay the onset of various age- 
related diseases, including cancers (Thun et al., 1991; Smalley and DuBois, 1997; Thompson et al., 1997; Fukutake et al., 1998; Hida et al., 1998; Kismet et al., 2004), Alzheimer's disease, and other neurodegenerative diseases ( $t$ ' Veld et al., 2001; Aisen, 2002; Etminan et al., 2003; Asanuma et al., 2004). Similarly, thiazolidinediones have been shown to relieve the inflammatory response, restore mitochondrial function, and reduce cell loss (Hunter et al., 2007).

In high-fat and high-fructose enriched diet models of inflammation, COX-2 inhibition has been shown to attenuate whole body insulin resistance (Hsieh et al., 2008, 2010), suppress fat inflammation and macrophage recruitment (Hsieh et al., 2010), decrease circulating levels of free fatty acids and liver lipid accumulation due to a concomitant reduction in TNF- $\alpha$ expression, diminishes adipocyte hypertrophy and reverses the suppression of differentiation markers of adipocytes (Hsieh et al., 2010), consequently preventing insulin resistance.

\section{Disruption of normal sleep patterns and the impact on insulin sensitivity}

Normal sleep is composed of rapid eye-movement (REM) sleep and stages N1-3 of non-REM (NREM) sleep, with most profound and restorative being N3, also known as slow-wave sleep (SWS). Fluctuations between REM and NREM stages take place every $90 \mathrm{~min}$ and repeat four to six times during the night for a 6-9h total duration (Reutrakul and van Cauter, 2014).

Reductions in self-reported sleep to fewer than 6 hours per night over the last 30 years has overlapped with a marked increase in the prevalence of metabolic disorders over the same period (Knutson and van Cauter, 2008; Buxton et al., 2010), attributable to a decrease in insulin sensitivity rather than to impairments in insulin secretion or glucose effectiveness (Buxton et al., 2010). 
Putative mechanisms by which insulin sensitivity is altered are increased sympathetic activity (Spiegel et al., 1999; Stamatakis and Punjabi, 2010), decreased cerebral glucose utilization, elevated evening cortisol levels, increased growth hormone secretion, increased norepinephrine and epinephrine (Irwin et al., 1999; Nedeltcheva et al., 2009; Buxton et al., 2010), through a dysregulation of the neuroendocrine control of appetite (Sakurai et al., 1998), increased monocyte counts (Boyum et al., 1996; Boudjeltia et al., 2008; Faraut et al., 2011), and of proinflammatory cytokines (Shearer et al., 2001; Vgontzas et al., 2004; Irwin et al., 2006; van Leeuwen et al., 2009), abnormal adipocyte function, stimulation of lipolysis and increased free fatty acid (Hucking et al., 2003).

Sleep curtailment has a similar physiological effect to the administration of lipopolysaccharide (LPS), promptly increasing endotoxin levels (Everson, 2005). LPS acts as a TLR4 agonist, stimulating the innate immune response via activation of macrophages and monocytes, triggering the NFkB pathway and synthesis of proinflammatory cytokines (Shearer et al., 2001; Meier-Ewert et al., 2004; Irwin et al., 2006, 2008; Henning et al., 2014; Venâncio and Suchecki, 2014; see previous sections). Also disrupted is the PI3K-Akt pathway in adipose tissue, with associated perturbation in leptin secretion and lipid metabolism (Broussard et al., 2012).

Suppression of sleep aggravates the phenotype with an approximate decrease of insulin sensitivity by $25 \%$, similar to what is reported in older adults and in populations at high risk for diabetes (van Cauter et al., 2001; Tasali et al., 2009; Tasali et al., 2008). Additionally, sleep deprivation decreases IRS-1 phosphorylation and correlated IL-10 secretion (Kooijman and Coppens, 2004), compromises hippocampus dependent memory and synaptic plasticity by affecting the levels of target of rapamycin (TOR)(Vecsey et al., 2012). 
Chronic sleep perturbations increase the risk for obesity (Ayas et al., 2003; Hasler et al., 2004; Cizza et al., 2005; Gangwisch et al., 2005; Vorona et al., 2005), diabetes (Ayas et al., 2003; Gottlieb et al., 2005; Meisinger et al., 2005; Yaggi et al., 2006; Gangwisch et al., 2007), and metabolic syndrome (Jennings et al., 2007) but also for age-related pathologies hypertension (Gottlieb et al., 2006), cardiovascular disease (Spiegel et al., 1999; Mallon et al., 2002) and early mortality (Hammond, 1964; Kripke et al., 2002; Mallon et al., 2002; Patel et al., 2004; Ferrie et al., 2007; Hublin et al., 2007; Meisinger et al., 2007). Primary sleep disturbance is also observed in depression, with shortened REM latency periods and NREM instabilities (Jones et al., 1987).

\section{Ageing, insulin resistance and mental disorders}

With a progression to old age, decrease in brain mass, atrophy and re-structuration of morphological and chemical balance are associated with impaired memory, a decline in regeneration, plasticity and cognitive ability (Golomb et al., 1994; Smith et al., 2000; Uylings and de Brabander, 2002; Rusinek et al., 2003; Jack Jr. et al., 2005; Wilson et al., 2006).

Premature CNS aging (Biessels et al., 2002) and increased risk of neurodegenerative disorders (Arvanitakis et al., 2004) are associated to long-term insulin resistance, which usually is attributed to an impairment of HPA-axis feedback mechanism (Dallman et al., 1993; McEwen, 1998), COX-mediated inflammation or oxidative stress (Helmersson et al., 2004).

Studies propose the implication of insulin/insulin growth factor 1 (IGF1) receptor signalling as an important factor in invertebrate and vertebrate development, nutrient sensing, growth and aging (Hafen, 2004; Bartke, 2006). IGF-1 promotes cell survival through ERK and PI3-K> AKT (Wei et al., 2002), where Insulin-mediated AKT activation acts as an upstream inhibitory kinase for GSK3 $\beta$ via serine 9, limiting the 
ability to phosphorylate tau (Rickle et al., 2004) and concomitant neurodegeneration (Kahn and Suzuki, 2010).

The Akt signalling pathway likewise downregulates the activity of FOXO (forkhead box) transcription factors (Chen et al., 1989; Chen et al., 2003; Calabrese et al., 2004), involved in the processes of autophagy and proteolysis (Denne et al., 1991; Donati et al., 2001; DiRaison et al., 2003; del Roso et al., 2003).

\section{Reversion of insulin resistance by new therapies with insulin receptor sensitizers}

Reversion of insulin resistance can be achieved through the use of sensitizer molecules, i.e., compounds that increase the bioavailability of insulin in the tissues. Although other compounds were used in the past (Bailey, 1992), the thiazolidinediones (TZD), are the standard therapeutic agents, interacting with cells via peroxisome proliferator-activator receptor (PPAR), where they act as agonists, or directly by binding to the mitochondria and modulating respiratory function (Feinstein, 2004).

Represented by the rosiglitazone (high-affinity to PPARY - Form et al., 1975; Sakamoto et al., 2000) and pioglitazone (partial PPARa and high affinity to PPARY Shinkai et al., 1927; Sakamoto et al., 2000), TZD are responsible for decreasing a release of free fatty acids in peripheral tissues with concomitant increase in the number of adipocytes, subcutaneous adipose tissue mass, and triglyceride storage (Goldstein, 2002; Czaja, 2009; Jain et al., 2013). Simultaneously with the inhibition of pro-inflammatory cytokines, production of adiponectin (Czaja 2009) and increase in glycolysis, thiazolidinediones promote glucose oxidation and a more efficient uptake (Jafari et al., 2007). Taken together, these PPAR agonists protect pancreatic $\beta$ cell integrity, liver and skeletal muscle from toxicity while at the same time increasing insulin sensitivity (Jain et al., 2013). 
In the brain, thiazolidinediones promote insulin sensitivity while reducing both dopaminergic neuronal loss and microglial, astrocytical activation (McGuire et al., 2001; Hong et al., 2012), suppresses phosphorylation of p38 mitogen-activated protein kinase (Ghisletti et al., 2007; Straus and Glass, 2007) and neurotrophic factor kappa B (He et al., 2012), reduces neuroinflammation and enhances endogenous peroxisomal proliferation mitochondrial biogenesis (Balfour and Plosker, 1999; Strum et al., 2007). Curiously, these PPAR agonists show no effect in healthy individuals (Miles et al., 2000; Kiek-Wilk et al., 2005 - Fig.3).

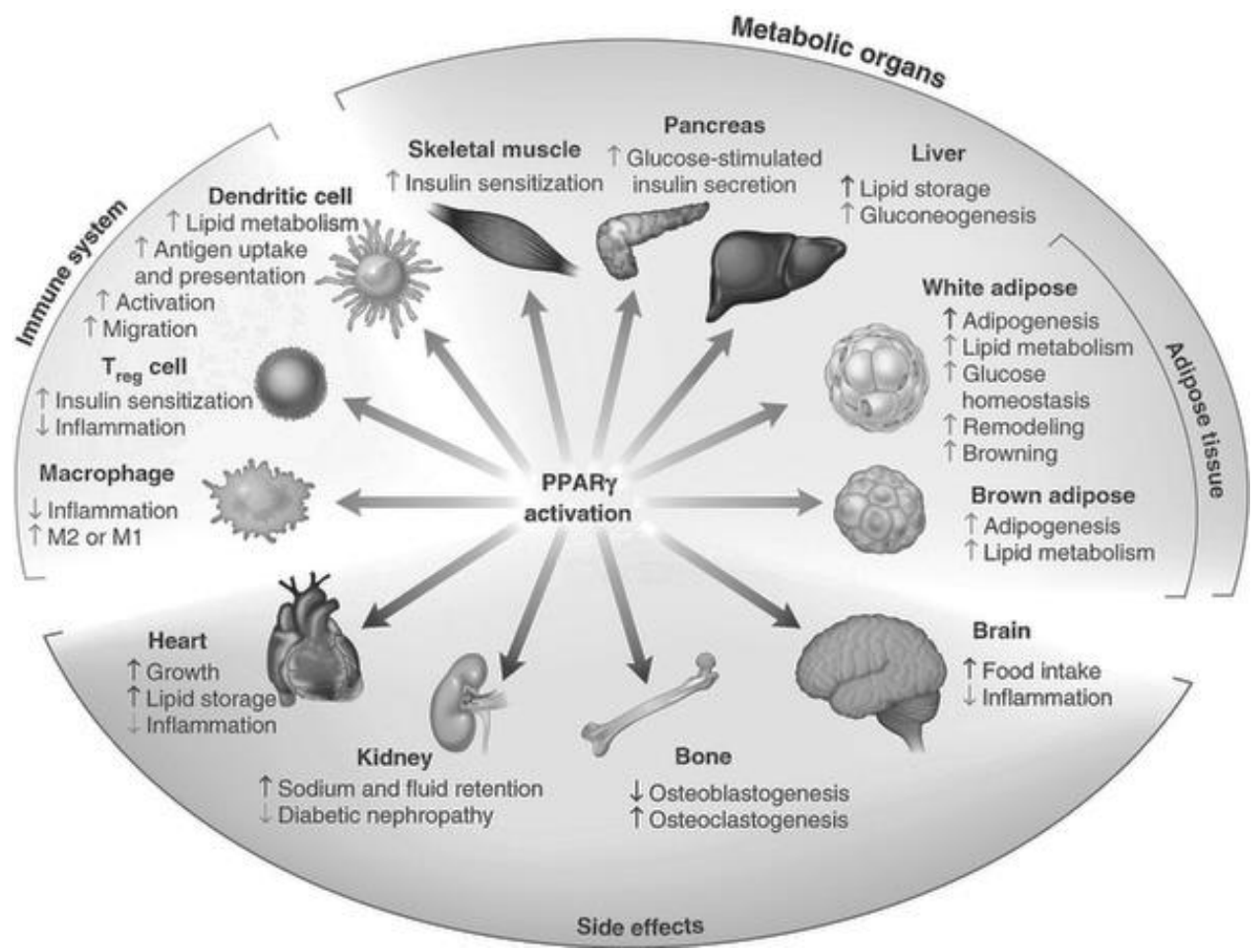

Fig. 3 - Known effects of PPARY activation.

Due to their anti-inflammatory and neuroprotective profile, some authors have used these insulin sensitizers in a variety of medical conditions such as inflammatory bowel disease (Saubermann et al., 2002), psoriasis (Mittal et al., 2009), and atherosclerosis 
(Igarashi et al., 2008), but also in depression (Rosa et al., 2008; Eissa Ahmed et al., 2009; Kemp et al., 2009, 2012; Salehi-Sadaghiani et al., 2012; Sepanjnia et al., 2012), autism (Boris et al., 2007), Alzheimer's Disease (Pershadsingh et al., 2004), and multiple sclerosis (Kaiser et al., 2009), where its ability to reduce microglial and astrocytical activation, decrease neuronal damage, and increase neuronal mitochondrial biogenesis holds promise for treating neuropsychiatric disorders (Heneka et al., 2005; Zhao et al., 2006; Strum et al., 2007).

A mitochondrial complex II substrate from a subfamily of the TZD, dicholine succinate (DS), was found to intervene in a pivotal regulatory event of neuronal insulin receptor function, where it plays a role as an important endogenous sensitizer (Pomytkin, 2008; Cline et al., 2012). This compound, in presence of other respiratory substrates, dose-dependently stimulates insulin-dependent $\mathrm{H}_{2} \mathrm{O}_{2}$ production at the mitochondrial respiratory chain in cerebellar neurons, promoting an enhancement of the central insulin receptor autophosphorylation at the tyrosine residues (Storozhevykh et al., 2007; Storozheva et al., 2008; Shomaker et al., 2010; Persiyantseva et al., 2013 - Fig.4).

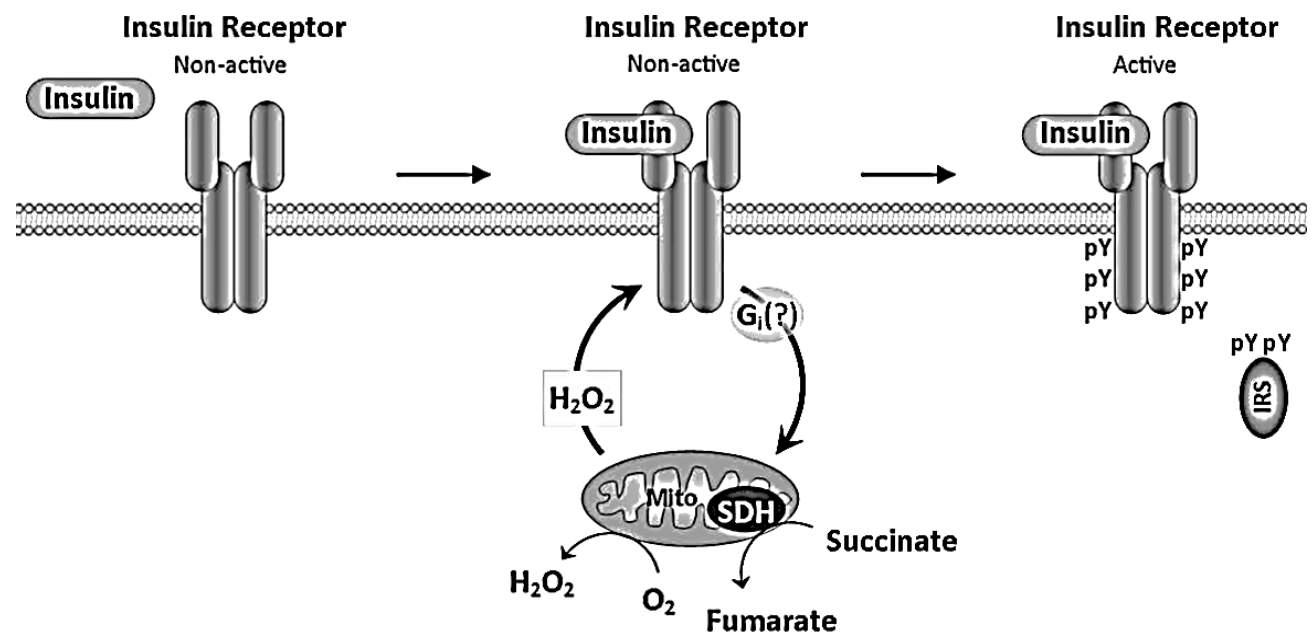

Fig. 4-Mitochondrial central insulin receptor activation. 
Previous studies have shown antidepressant, anxiolytic and memory-preserving effects of DS in CD1 mice (Cline et al., 2012; Costa-Nunes et al., 2012), parallelled with increased hippocampal expression of Insulin-like Growth Factor 2 (IGF-2), a member of the insulin gene family with neurotrophic properties (Chen et al., 2012; Bracko et al., 2012; Basta-Kaim et al., 2014). Moreover, DS has rescued normal neuronal function and viability with maintenance of hippocampus-dependent tasks in rat models (Storozheva et al., 2008).

\section{Objectives}

In this work, we sought to study the role of neuronal insulin receptor signaling in the development of affective changes evoked by different ethopathological origins, in mice. We combined a mixed approach of already established models and validated new methodologies.

First, we validated the use of ethological stressors as an accurate methodology to mimic cognitive and emotional abnormalities associated with human phenotypes, and investigated the hippocampal relative-fold mRNA expression of NMDAr subunits as it mimics clinically relevant situations of stress-related disturbances in learning and emotionality (Chapter 2). This methodology would be one pillar for subsequent studies to evaluate insulin receptor sensitization properties.

Then, we have used chronic stress, elderly and naïve models of induction of depression to assess the effects of a neuronal insulin receptor sensitizer on sleep, behaviour, hippocampal GSK-3 $\beta$ and mRNA expression levels of NMDA receptor subunits (Chapter 3 ). This approach was coupled with Illumina gene expression analysis.

Later, for the first time, we validated the administration of high amounts of dietary cholesterol to naïve mice as a model of affective pathology (Chapter 4). It was shown 
to have an impact in anxiety-, depression-like and impulsive behaviours, levels of hepatic steatosis and inflammation, both central and peripheral.

We were also able to validate the use of an oral route, with food, for the delivery of antidepressant treatment, and the efficacy of a low dose (Chapter 5). These successes are highly important for their translational validity to the human clinic and use as a potential food supplement, as they are to animal welfare, allowing to circumvent invasive techniques.

Lastly, in Chapter 6, we demonstrated the use of a previously established oral delivery of a neuronal insulin receptor sensitizer in successfully abolishing T/r4 overexpression both in brain and liver, improving mouse behaviour in anxiogenic and depressogenic paradigms without effecting hepatic lipid metabolism or dystrophy. In parallel it was also found to normalize the expression of a marker for mitochondrial activity.

Altogether, we validated new methodologies of inducing affective pathologies in mice, sensitive to neuronal insulin sensitization, shown to have ameliorative behavioural and physiological effects, and paralleled with a positive balance in gene expression changes. The use of three different paradigms of depressive-like syndrome: stress-, aging and high cholesterol-diet related conditions, suggested the importance of insulin receptor signalling in their pathogenesis. 


\section{References}

Abbas, A., Blandon, J., Rude, J., Elfar, A., Mukherjee, D. (2012). PPAR- Agonist in Treatment of Diabetes: Cardiovascular Safety Considerations. Cardiovasc Hematol Agents Med Chem. 10, 124-134.

Aisen, P.S. (2002). The potential of anti-inflammatory drugs for the treatment of Alzheimer's disease. Lancet Neurol. 1, 279-284.

Alkon, D.L., Nelson, T., Zhao, W., Cavallaro, S. (1998). Time domains of neuronal Ca2+ signalling and associative memory: steps through a calexcitin, ryanodine receptor, $\mathrm{K}+$ channel cascade. Trends in Neurosci. 21, 529-537.

Amar, J., Chabo, C., Waget, A., Klopp, P., Vachoux, C., Bermudez-Humaran, L.G., Smirnova, N., Bergé, M., Sulpice, T., Lahtinen, S., Ouwehand, A., Langella, P., Rautonen, N., Sansonetti, P.J., Burcelin, R. (2011). Intestinal mucosal adherence and translocation of comensal bactéria at the early onset of type 2 diabetes: molecular mechanisms and probiotic treatment. EMBO Mol. Med. 3, 559-572.

Amyot, J., Semache, M., Ferdaoussi, M., Fontes, G., Poitout, V. (2012). Lipopolysaccharides impair insulin gene expression in isolated islets of Langerhans via Toll-Like Receptor-4 and NF-kappaB signalling. PLoS One. 7:e36200.

Anai, M., Funaki, M., Ogihara, T., Kanda, A., Onishi, Y., Sakoda, H., Inukai, K., Nawano, M., Fukushima, Y., Yazaki, Y., Kikuchi, M., Oka, Y., Asano, T. (1999). Enhanced insulin-stimulated activation of phosphatidylinositol 3-kinase in the liver of high-fat-fed rats. Diabetes. 48, 158-169.

Anai, M., Funaki, M., Ogihara, T., Terasaki, J., Inukai, K., Katagiri, H., Fukushima, Y., Yazaki, Y., Kikuchi, M., Oka, Y., Asano, T. (1998). Altered expression levels and impaired steps in the pathway to phosphatidylinositol 3-kinase activation via insulin receptor substrates 1 and 2 in Zucker fatty rats. Diabetes. 47, 13-23.

Androulidaki, A., Iliopoulos, D., Arranz, A., Doxaki, C., Schworer, S., Zacharioudaki, V., Margioris, A.N., Tsichlis, P.N., Tsatsanis, C. (2009). The kinase Akt1 controls macrophage response to lipopolysaccharide by regulating microRNAs. Immunity. 31, 220-231.

Anghel, S.I., Wahli, W. (2007). Fat poetry: a kingdom for PPAR gamma. Cell Res., 17, 486-511.

Appel, S., Mirakaj, V., Bringmann, A., Weck, M.M., Grünebach, F., Brossart, P. (2015). PPAR- $\gamma$ agonists inhibit toll-like receptor-mediated activation of dendritic cells via the MAP kinase and NF- kappaB pathways. Blood. 106, 3888-3894.

Arvanitakis, Z., Wilson, R.S., Bienias, J.L., Evans, D.A., Bennett, D.A. (2004). Diabetes mellitus and risk of Alzheimer disease and decline in cognitive function. Arch Neurol. 61, 661-666.

Asanuma, M., Miyazaki, I., Ogawa, N. (2004). Neuroprotective effects of nonsteroidal anti-inflammatory drugs on neurodegenerative diseases. Curr. Pharm. Des. 10, 695-700.

Ayas, N.T., White, D.P., Al-Delaimy, W.K., Manson, J.E., Stampfer, M.J., Speizer, F.E., Patel, S., Hu, F.B. (2003). A prospective study of self-reported sleep duration and incident diabetes in women. Diabetes Care. 26, 380-384.

Bailey, C.J. (1992). Biguanides and NIDDM. Diabetes Care. 15, 755-772.

Balfour, J.A., Plosker, G.L. (1999). Rosiglitazone. Drugs. 57, 921-930. 
Bank, B., DeWeer, A., Kuzirian, A.M., Rasmussen, H., Alkon, D.L. (1988). Classical conditioning induces long-term translocation of protein kinase $\mathrm{C}$ in rabbit hippocampal CA1 cells. Proc. Natl. Acad. Sci. U. S. A. 85, 1988-1992.

Banting, F.G., Best, C.H. (1922). The internal secretion of the pancreas. J Lab Clin Med. 7, 256-271.

Bartke, A. (2006). Long-lived Klotho mice: new insights into the roles of IGF-1 and insulin in aging. Trends Endocrinol. Metab. 17, 33-35.

Basta-Kaim, A., Szczesny, E., Glombik, K., Stachowicz, K., Slusarczyk, J., Nalepa, I., Zelek-Molik, A., RafaZablocka, K., Budziszewska, B., Kubera, M., Leskiewicz, M, Lason, W. (2014). Prenatal stress affects insulin-like growth factor-1 (IGF-1) level and IGF-1 receptor phosphorylation in the brain of adult rats. Eur. Neuropsychopharmacol. 24, 1546-1556.

Bauerfeld, C.P., Rastogi, R., Pirockinaite, G., Lee, I., Huttemann, M., Monks, B., Birnbaum, M.J., Franchi, L., Nunez, G., Samavati, L. (2012). TLR4-mediated AKT activation is MyD88/TRIF dependent and critical for induction of oxidative phosphorylation and mitochondrial transcription factor $A$ in murine macrophages. J Immunol (Baltimore, Md: 1950). 188, 2847-2857.

Benarroch, E. E. (2010). Glycogen metabolism: metabolic coupling between astrocytes and neurons. Neurology. 74, 919-923.

Berman, R.M., Cappiello, A., Anand, A., Oren, D.A., Heninger, G.R., Charney, D.S., Krystal, J.H. (2000). Antidepressant effects of ketamine in depressed patients. Biol Psychiatry 47, 351-354.

Bhat RV, Budd Haeberlein S.L., Avila J. (2004). Glycogen synthase kinase 3: a drug target for CNS therapies. J Neurochem. 89, 1313-1317.

Bhat, N.R., Thirumangalakudi, L. (2013). Increased Tau Phosphorylation and Impaired Brain Insulin/IGF Signalling in Mice Fed a High Fat/High Cholesterol Diet. J Alzheimers Dis. 36, 781-789.

Biessels, G.J., van der Heide, L.P., Kamal, A., Bleys, R.L., Gispen, W.H. (2002). Ageing and diabetes: implications for brain function, Eur. J. Pharmacol. 441, 1-14.

Blázquez, E., Velázquez, E., Hurtado-Carneiro, V., Ruiz-Albusac, J.M. (2014). Insulin in the brain: its pathophysiological implications for States related with central insulin resistance, type 2 diabetes and Alzheimer's disease. Front Endocrinol (Lausanne). 5, 161.

Boden, G. (2009). Endoplasmic reticulum stress: another link between obesity and insulin resistance/inflammation? Diabetes. 58, 518-519.

Bonini, J.S., Da Silva, W.C.,Bevilaqua, L.R., Medina, J.H., Izquierdo, I.,Cammarota, M. (2007). On the participation of hippocampal PKC in acquisition, consolidation and reconsolidation of spatial memory. Neuroscience. 147, 37-45.

Boris, M., Kaiser, C.C., Goldblatt, A., Elice, M.W., Edelson, S.M., Adams, J.B., Feinstein, D.L. (2007). Effect of pioglitazone treatment on behavioral symptoms in autistic children. J. Neuroinflammation. $4,3$.

Boudjeltia, K.Z., Faraut, B., Stenuit, P., Esposito, M.J., Dyzma, M., Brohée, D., Ducobu, J., Vanhaeverbeek, M., Kerkhofs, M. (2008). Sleep restriction increases white blood cells, mainly neutrophil count, in young healthy men: a pilot study. Vasc. Health Risk Manag. 4, 1467-1470. 
Boyum, A., Wiik, P., Gustavsson, E., Veiby, O.P., Reseland, J., Haugen, A.H., Opstad, P.K. (1996). The effect of strenuous exercise, calorie deficiency and sleep deprivation on white blood cells, plasma immunoglobulins and cytokines. Scand. J. Immunol. 43, 228-235.

Bracko, O., Singer, T., Aigner, S., Knobloch, M., Winner, B., Ray, J., Clemenson, G.D. Jr, Suh, H., CouillardDespres, S., Aigner, L., Gage, F.H., Jessberger, S. (2012). Gene expression profiling of neural stem cells and their neuronal progeny reveals IGF2 as a regulator of adult hippocampal neurogenesis. J. Neurosci. 32, 3376-3387.

Broussard, J.L., Ehrmann, D.A., van Cauter, E., Tasali, E., Brady, M.J. (2012). Impaired insulin signalling in human adipocytes after experimental sleep restriction: a randomized, crossover study. Ann Intern Med. 157, 549-557.

Burcelin, R., Serino, M., Chabo, C., Blasco-Baque, V., Amar, J. (2011). Gut microbiota and diabetes: from pathogenesis to therapeutic perspective. Acta Diabetol. 48, 257-273.

Buxton, O.M., Pavlova, M., Reid, E.W., Wang, W., Simonson, D.C., Adler, G.K. (2010). Sleep restriction for 1 week reduces insulin sensitivity in healthy men. Diabetes. 59, 2126-2133.

Calabrese, V., Scapagnini, G., Ravagna, A., Colombrita, C., Spadaro, F., Butterfield, D.A., Guffrida Stella, A.M. (2004). Increased expression of heat shock proteins in rat brain during aging: relationship with mitochondrial function and glutathione redox state. Mech Ageing Dev. 125, 325-335.

Cani, P.D., Delzenne, N.M. (2009). The role of the gut microbiota in energy metabolism and metabolic disease. Curr. Pharm. Des.15, 1546-1558.

Carvalho, C.R., Brenelli, S.L., Silva, A.C., Nunes, A.L., Velloso, L.A., Saad, M.J. (1996). Effect of aging on insulin receptor, insulin receptor substrate-1, and phosphatidylinositol 3-kinase in liver and muscle of rats. Endocrinology. 137, 151-159

Chaurasia, B., Mauer, J., Koch, L., Goldau, J., Kock, A.S., Bruning, J.C. (2010). Phosphoinositidedependent kinase 1 provides negative feedback inhibition to Toll-like receptor-mediated NF-kappaB activation in macrophages. Mol Cell Biol. 30, 4354-4366.

Chavez, J.A., Summers, S.A. (2012). A ceramide-centric view of insulin resistance. Cell Metab. 15, 585594.

Chen, F., Castranova, V., Shi, X., Demers, L.M. (1999). New insights into the role of nuclear factor-kappaB, a ubiquitous transcription factor in the initiation of diseases. Clin. Chem. 45, 7-17.

Chen, K., Iribarren, P., Hu, J., Chen, J., Gong, W., Cho, E.H., Lockett, S., Dunlop, N.M., Wang, J.M. (2006). Activation of Toll-like receptor 2 on microglia promotes cell uptake of Alzheimer disease-associated amyloid beta peptide. J Biol Chem. 281, 3651-3659.

Chen, T.S., Richie, J.P., Lang, C.A. (1989). The effect of aging on glutathione and cysteine levels in different regions of the mouse brain. Proc Soc Exp Biol Med. 190, 399-402.

Chen, X., Margolis, K.J., Gershon, M.D., Schwartz, G.J., Sze, J.Y. (2012). Reduced Serotonin Reuptake Transporter (SERT) Function Causes Insulin Resistance and Hepatic Steatosis Independent of Food Intake. PLoS One. 7, e32511.

Chen, X., Scholl, T.O., Leskiw, M.J., Donaldson, M.R., Stein, T.P. (2003). Association of glutathione peroxidase activity with insulin resistance and dietary fat intake during normal pregnancy. J Clin Endocrinol Metab. 88, 5963-5968. 
Chiu, S., Chen, C., Cline, H.T. (2008). Insulin Receptor Signalling Regulates Synapse Number, Dendritic Plasticity, and Circuit Function In Vivo. Neuron. 58, 708-719.

Cho, S.I., Park, U.J., Chung, J.M., Gwag, B.J. (2010). Neu 2000, an NR2B selective, moderate NMDA receptor antagonist and potent spin trapping molecule for stroke. Drug News Perspect. 23, 549-556.

Christie, J.M., Wenthold, R.J., Monaghan, D.T. (1999). Insulin causes a transient tyrosine phosphorylation of NR2A and NR2B NMDA receptor subunits in rat hippocampus. J. Neurochem. 72, 1523-1528.

Cizza, G., Skarulis, M., Mignot, E. (2005). A link between short sleep and obesity: building the evidence for causation. Sleep. 28, 1217-1220.

Cline, B.H., Steinbusch, H.W.M., Malin, D., Revishchin, A. V, Pavlova, G. V, Cespuglio, R., Strekalova, T. (2012). The neuronal insulin sensitizer dicholine succinate reduces stress-induced depressive traits and memory deficit: possible role of insulin-like growth factor 2. BMC Neurosci. 13, 110.

Cole, G.M., Frautschy, S.A. (2007). The role of insulin and neurotrophic factor signalling in brain aging and Alzheimer's Disease. Exp Gerontol. 42, 10-21.

Costa-Nunes, J.P., Couch, Y., Cline, B.H., Cespuglio, R., Anthony, D.C., Steinbusch, H.W.M., et al. (2012). The neuronal insulin sensitizer dicholine succinate reduces stress-induced depressive traits, changes in sleep and gene expression in the brain. Presented at the $8^{\text {th }}$ annual meeting for the FENS; July 14-18; Barcelona, Spain.

Craft, S., Watson, G.S. (2004). Insulin and neurodegenerative disease: shared and specific mechanisms. Lancet Neurol. 3, 169-178.

Czaja, M.J. (2009). Pioglitazone: More than Just an Insulin Sensitizer. Hepatology. 49, 1427-1430.

Dallman, M.F., Strack, A.L., Akana, S.F., Bradbury, M.J., Hanson, E.S., Scribner, K.A., Smith, M. (1993). Feast and famine: critical role of glucocorticoids with insulin in daily energy flow. Front Neuroendocrinol. $14,303-347$.

Dannenberg, A.J., Altorki, N.K., Boyle, J.O., Dang, C., Howe, L.R., Weksler, B.B., Subbaramaiah, K. (2001). Cyclo-oxygenase 2: a pharmacological target for the prevention of cancer. Lancet Oncol. 2, 544-551.

Das, S., Sasaki, Y. F., Rothe, T. Premkumar, L.S., Takasu, M., Crandall, J.E., Dikkes, P., Conner, D.A., Rayudu, P.V., Cheung, W., Chen, H.S., Lipton, S.A., Nakanishi, N. (1998). Increased NMDA current and spine density in mice lacking the NMDA receptor subunit NR3A. Nature. 393, 377-381.

Dasu, M.R., Park, S., Devaraj, S., Jialal, I. (2009). Pioglitazone inhibits Toll-like receptor expression and activity in human monocytes and db/db mice. Endocrinology. 150, 3457-3464.

Daws, L.W., Owens, A., Campos, P., Gould, G., Galli, A., France, C. (2009). Regulation of biogenic amine transporters by insulin: Implications for antidepressant drug efficacy. Presented at the 48th Annual Meeting of the American College of Neuropsychopharmacology; December 6-10; Hollywood, FL.

de la Monte, S.M. (2012). Brain Insulin Resistance and Deficiency as Therapeutic Targets in Alzheimer's Disease. Curr Alzheimer Res. 9, 35-66. 
Del Roso, A., Vittorini, S., Cavallini, G., Donati, A., Gori, Z., Masini, M., Pollera, M., Bergamini, E. (2003). Ageing-related changes in the in vivo function of rat liver macroautophagy and proteolysis. Exp Gerontol. 38: 519-527.

Deldicque, L., Cani, P.D., Philp, A., Raymackers, J.M., Meakin, P.J. Ashford, M.L., Delzenne, N.M., Francaux, M., Baar, K. (2010). The unfolded protein response is activated in skeletal muscle by high-fat feeding: potential role in the downregulation of protein synthesis. Am J Physiol Endocrinol Metab. 299, E695-E705.

DeMiranda, J., Yaddanapudi, K., Hornig, M., Villar, G., Serge, R., Lipkin, W.I. (2010). Induction of Toll-like receptor 3-mediated immunity during gestation inhibits cortical neurogenesis and causes behavioral disturbances. mBio. pii: e00176-10. doi: 10.1128/mBio.00176-10.

Denne, S.C., Liechty, E.A., Liu, Y.M., Brechtel, G., Baron, A.D. (1991). Proteolysis in skeletal muscle and whole body response to euglycemic hyperinsulinemia in normal adults. Am J Physiol. 261, E809-E814.

Devaskar, S.U., Giddings, S.J., Rajakumar, P.A., Carnaghi, L.R., Menon, R.K., Zahm, D.S. (1994). Insulin gene expression and insulin synthesis in mammalian neuronal cells. J. Biol. Chem. 269, 8445-8454.

Diraison, F., Moulin, P., Beylot, M. (2003). Contribution of hepatic de novo lipogenesis and reesterification of plasma nonesterified fatty acids to plasma triglyceride synthesis during non-alcoholic fatty liver disease. Diabetes Metab. 29, 478-485.

Donati, A., Cavallini, G., Paradiso, C., Vittorini, S., Pollera, M., Gori, Z., Bergamini, E. (2001). Age-related changes in the autophagic proteolysis of rat isolated liver cells: Effects of anti-aging dietary restrictions. J Gerontol Sci Med Sci. 56, B375-B383.

Eissa Ahmed, A.A., Al-Rasheed, N.M., Al-Rasheed, N.M. (2009). Antidepressant-like effects of rosiglitazone, a PPARy agonist, in the rat forced swim and mouse tail suspension tests. Behav Pharmacol. 20, 635-642.

Emamian, E.S., Hall, D., Birnbaum, M.J., Karayiorgou, M., Gogos, J.A. (2004). Convergent evidence for impaired AKT1-GSK3beta signalling in schizophrenia. Nat Genet. 36, 131-137.

Enos, R.T., Velázquez, K.T., Murphy, E.A. (2014). Insight into the impact of dietary saturated fat on tissuespecific cellular processes underlying obesity-related diseases. J. Nutr. Biochem. 25, 600-612.

Etminan, M., Gill, S., Samii, A. (2003). Effect of non-steroidal anti-inflammatory drugs on risk of Alzheimer's disease: systematic review and meta-analysis of observational studies. BMJ 327, 128.

Everson, C.A. (2005). Clinical assessment of blood leukocytes, serum cytokines, and 629 serum immunoglobulins as responses to sleep deprivation in laboratory rats. $630 \mathrm{Am}$. J. Physiol. Regul. Integr. Comp. Physiol. 289, R1054-1063.

Faraut, B., Boudjeltia, K.Z., Dyzma, M., Rousseau, A., David, E., Stenuit, P., Franck, T., van Antwerpen, P., Vanhaeverbeek, M., Kerkhofs, M. (2011). Benefits of napping and an extended duration of recovery sleep on alertness and immune cells after acute sleep restriction. Brain Behav. Immun. 25, 16-24.

Feinstein, D.L. (2004). Contrasting the neuroprotective and gliotoxic effects of PPAR g agonists Drug Discovery Today: Therapeutic Strategies. 1, 29-34.

Ferrie, J.E., Shipley, M.J., Cappuccio, F.P., Brunner, E., Miller, M.A., Kumari, M., Marmot, M.G. (2007). A prospective study of change in sleep duration: associations with mortality in the Whitehall II cohort. Sleep. 30, $1659-1666$. 
Folli, F., Saad, M.J., Backer, J.M., Kahn, C.R. (1993). Regulation of phosphatidylinositol 3-kinase activity in liver and muscle of animal models of insulin-resistant and insulin-deficient diabetes mellitus. J Clin Invest. 92, 1787-1794.

Form, G.R., Raper, E.S. Downie, T.C. (1975). The crystal and molecular structure of thiazolidine-2,4-dione. Acta Cyrstallogr. B31, 2181.

Forrest, C.M., Khalil, O.S., Pisar, M., Smith, R.A., Darlington, L.G., Stone, T.W. (2012). Prenatal activation of Toll-like receptors-3 by administration of the viral mimetic poly-(I:C) changes synaptic proteins, $\mathrm{N}$ methyl-D-aspartate receptors and neurogenesis markers in offspring. Mol Brain. 5, 22.

Franchi, L., Eigenbrod, T., Munoz-Planillo, R., Nunez, G. (2009). The inflammasome: a caspase-1activation platform that regulates immune responses and disease pathogenesis. Nat Immunol. 10, 241247.

Freude, S., Leeser, U., Muller, M., Hettich, M.M., Udelhoven, M., Schilbach, K., Tobe, K., Kadowaki, T., Köhler, C., Schröder, H., Krone, W., Brüning, J.C., Schubert, M. (2008). IRS-2 branch of IGF-1 receptor signalling is essential for appropriate timing of myelination. J. Neurochem. 107, 907-917.

Fukao, T., Koyasu, S. (2003). PI3K and negative regulation of TLR signalling. Trends Immunol. 24, 358363.

Fukutake, M., Nakatsugi, S., Isoi, T., Takahashi, M., Ohta, T., Mamiya, S., Taniguchi, Y., Sato, H., Fukuda, K., Sugimura, T., Wakabayashi, K. (1998). Suppressive effects of nimesulide, a selective inhibitor of cyclooxygenase-2, on azoxymethane-induced colon carcinogenesis in mice. Carcinogenesis. 19, 19391942.

Gangwisch, J.E., Heymsfield, S.B., Boden-Albala, B., Buijs, R.M., Kreier, F., Pickering, T.G., Rundle, A.G., Zammit, G.K., Malaspina, D. (2007). Sleep duration as a risk factor for diabetes incidence in a large U.S. sample. Sleep. 30, 1667-1673.

Gangwisch, J.E., Malaspina, D., Boden-Albala, B., Heymsfield, S.B. (2005). Inadequate sleep as a risk factor for obesity: analyses of the NHANES I. Sleep. 28, 1289-1296.

Gao, Z., Hwang, D., Bataille, F., Lefevre, M., York, D., Quon, M.J., Ye, J. (2002). Serine phosphorylation of insulin receptor substrate 1 by inhibitor kappa B kinase complex. J Biol Chem 277, 48115-48121.

García-bueno, B., Madrigal, J.L.M., Lizasoain, I., Moro, M.A., Lorenzo, P., Leza, J.C. (2005). Peroxisome Proliferator-Activated Receptor Gamma Activation Decreases Neuroinflammation in Brain After Stress in Rats. Biol Psychiatry. 57, 885-894.

Gardoni, F., Ghiglieri, V., Luca, M., Calabresi, P. (2010). Assemblies of glutamate receptor subunits with post-synaptic density proteins and their alterations in Parkinson's disease. Prog Brain Res. 183, 169-182.

Gelman, A.E., LaRosa, D.F., Zhang, J., Walsh, P.T., Choi, Y., Sunyer, J.O., Turka, L.A. (2006). The adaptor molecule MyD88 activates PI-3 kinase signalling in CD4+ T cells and enables CpG-oligodeoxynucleotidemediated co-stimulation. Immunity. 25, 783-793.

Ghasemi, R., Haeri, A., Dargahi, L., Mohamed, Z., Ahmadiani, A. (2013). Insulin in the brain: sources, localization and functions. Mol Neurobiol. 47, 145-171.

Ghisletti, S., Huang, W., Ogawa, S., Pascual, G., Lin, M.E., Willson, T.M., Rosenfeld, M.G., Glass, C.K. (2007). Parallel SUMOylation-dependent pathways mediate gene- and signal-specific transrepression by LXRs and PPAR- $\gamma$. Mol Cell. 25, 57-70. 
Goldstein, B.J. (2002). Insulin Resistance as the Core Defect in Type 2 Diabetes Mellitus. Am J Cardiol. 90, 3G-10G.

Golomb, J., Kluger, A., de Leon M.J., Ferris, S.H., Convit, A., Mittelman, M.S., Cohen, J., Rusinek, H., de Santi, S., George, A.E. (1994). Hippocampal formation size in normal human aging: a correlate of delayed secondary memory performance, Learn. Mem. 1, 45-54.

Gong, C.X., Iqbal, K. (2008). Hyper-phosphorylation of microtubule-associated protein tau: a promising therapeutic target for Alzheimer disease. Curr Med Chem. 15, 2321-2328.

Gottlieb, D.J., Punjabi, N.M., Newman, A.B., Resnick, H.E., Redline, S., Baldwin, C.M., Nieto, F.J. (2005). Association of sleep time with diabetes mellitus and impaired glucose tolerance. Arch Intern Med. 165, 863-867.

Gottlieb, D.J., Redline, S., Nieto, F.J., Baldwin, C.M., Newman, A.B., Resnick, H.E., Punjabi, N.M. (2006). Association of usual sleep duration with hypertension: the Sleep Heart Health Study. Sleep. 29, 10091014.

Govind, S., Kozma, R., Monfries, C., Lim, L. Ahmed, S. (2001). Cdc42Hs facilitates cytoskeletal reorganization and neurite outgrowth by localizing the $58-\mathrm{kD}$ insulin receptor substrate to filamentous actin. J. Cell Biol. 152, 579-594.

Gurley, C., Nichols, J., Liu, S., Phulwani, N.K., Esen, N., Kielian, T. (2008). Microglia and Astrocyte Activation by Toll-Like Receptor Ligands: Modulation by PPAR- $>$ Agonists. PPAR Res. 2008, 453120.

Hafen, E. (2004). Cancer, type 2 diabetes, and ageing: news from flies and worms. Swiss Med. Wkly. 134, 711-719.

Hammond, E.C. (1964). Some preliminary findings of physical complaints from a prospective study of 1,064,004 men and women. Am J Public Health. 54, 11-23.

Hanamsagar, R., Hanke, M.L., Kielian, T. (2012). Toll-like receptor TLR) and inflammasome actions in the central nervous system. Trends Immunol. 33, 333-342.

Hanke, M.L., Kielian, T. (2011). Toll-like receptors in health and disease in the brain: mechanisms and therapeutic potential. Clin Sci (London, England: 1979). 121, 367-387.

Hardy, O.T., Kim, A., Ciccarelli, C., Hayman, L.L., Wiecha, J. (2013). Increased Toll-like receptor (TLR) mRNA expression in monocytes is a feature of metabolic syndrome in adolescents. Pediatric obesity. 8, e19-e23.

Hashimoto, K. (2009). Emerging role of glutamate in the pathophysiology of major depressive disorder. Brain Res Rev. 61, 105-123.

Hasler, G., Buysse, D.J., Klaghofer, R., Gamma, A., Ajdacic, V., Eich, D., Rossler, W., Angst, J. (2004). The association between short sleep duration and obesity in young adults: a 13-year prospective study. Sleep. 27, 661-666.

Havrankova, J., Roth. J., Brownstein, M. (1978). Insulin receptors are widely distributed in the central nervous system of the rat. Nature. 272, 827-829.

Hazeki, K., Nigorikawa, K., Hazeki, O. (2007). Role of phosphoinositide 3-kinase in innate immunity. Biol Pharm Bull. 30, 1617-1623. 
He, X., Feng, L., Meng, H., Wang, X., Liu, S. (2012). Rosiglitazone protects dopaminergic neurons against lipopolysaccharide-induced neurotoxicity through inhibition of microglia activation. Int J Neurosci. 122, 532-540.

Heidenreich, K.A., Gilmore, P.R. (1985). Structural and functional characteristics of insulin receptors in rat neuroblastoma cells. J. Neurochem. 45, 1642-1648.

Heidenreich, K.A., Zahniser, N.R., Berhanu, P., Brandenburg, D., Olefsky, J.M. (1983). Structural differences between insulin receptors in the brain and peripheral target tissues. J. Biol. Chem. 258, 8527-8530.

Helmersson, J., Vessby, B., Larsson, A., Basu, S. (2004). Association of type 2 diabetes with cyclooxygenase-mediated inflammation and oxidative stress in an elderly population. Circulation. 109, 1729-1734.

Hemmati, F., Ghasemi, R., Ibrahim, N.M. (2014). Crosstalk Between Insulin and Toll-like Receptor Signalling Pathways in the Central Nervous system. Mol Neurobiol. 50, 979-810.

Heneka, M.T., Sastre, M., Dumitrescu-Ozimek, L., Hanke, A., Dewachter, I., Kuiperi, C., O'Banion, K., Klockgether, T., Van Leuven, F., Landreth, G.E. (2005). Acute treatment with the PPARgamma agonist pioglitazone and ibuprofen reduces glial inflammation and Abeta1-42 levels in APPV717I transgenic mice. Brain. 128, 1442-1453.

Heni, M., Hennige, A. M., Peter, A., Siegel-Axel, D., Ordelheide, A. M., Krebs, N., Machicao, F., Fritsche, A., Haring, H. U., Staiger, H. (2011). Insulin promotes glycogen storage and cell proliferation in primary human astrocytes. PLoS One. 6, e21594.

Hennige, A.M., Sartorius, T., Lutz, S.Z., Tschritter, O., Preissl, H., Hopp, S., Fritsche, A., Rammensee, H.G., Ruth, P., Haring, H.U. (2009). Insulin-mediated cortical activity in the slow frequency range is diminished in obese mice and promotes physical inactivity. Diabetologia. 52, 2416-2424.

Henning, P.C., Scofield, D.E., Spiering, B.A., Staab, J.S., Matheny, R.W., Smith, M.A., Bhasin, S., Nindl, B.C. (2014). Recovery of endocrine and inflammatory mediators following an extended energy deficit. J Clin Endocrinol Metab. 99, 956-964.

Hida, T., Leyton, J., Makheja, A. N., Ben-Av, P., Hla, T., Martinez, A., Mulshine, J., Malkani, S., Chung, P., Moody, T.W. (1998). Non-small cell lung cancer cycloxygenase activity and proliferation are inhibited by non-steroidal anti-inflammatory drugs. Anticancer Res. 18, 775-782.

Hirsch, E.C., Hunot, S. (2009). Neuroinflammation in Parkinson's disease: a target for neuroprotection? Lancet Neurol. 8,382-397.

Holland, W.L., Bikman, B.T., Wang, L.P., Yuguang, G., Sargent, K.M., Bulchand, S., Knotts, T.A., Shui, G., Clegg, D.J., Wenk, M.R., Pagliassotti, M.J., Scherer, P.E., Summers, S.A. (2011). Lipid-induced insulin resistance mediated by the proinflammatory receptor TLR4 requires saturated fatty acid-induced ceramide biosynthesis in mice. J Clin Invest. 121, 1858-1870.

Hong, S., Xin, Y., Haiqin, W., Guilian, Z. (2012). The PPARy agonist rosiglitazone prevents cognitive impairment by inhibiting astrocyte activation and oxidative stress following pilocarpine-induced status epilepticus. Neurol Sci. 33, 559-566.

Hooper, C., Killick, R., Lovestone, S. (2008). The GSK3 hypothesis of Alzheimer's disease. J Neurochem, 104,1433-1439.

Hotamisligil, G.S. (2006). Inflammation and metabolic disorders. Nature. 444, 860-867. 
Howard, J.K., Flier, J.S. (2006). Attenuation of leptin and insulin signalling by SOCS proteins. TEM. 17, 365-371.

Hsieh, P., Lu, K., Chiang, C., Chen, C. (2010). Suppressive effect of COX2 inhibitor on the progression of adipose inflammation in high-fat-induced obese rats. Eur J Clin Invest. 40, 164-171.

Hsieh, P.S., Tsai, H.C., Kuo, C.H., Chan, J.Y., Shyu, J.F., Cheng, W.T., Liu, T.T. (2008). Selective COX2 inhibition improves whole body and muscular insulin resistance in fructose-fed rats. Eur I Clin Invest. 38, 812-819.

Hu, X., Wang, T., Luo, J., Liang, S., Li, W., Wu, X., Jin, F., Wang, L. (2014). Age-dependent effect of high cholesterol diets on anxiety-like behavior in elevated plus maze test in rats. Behav Brain Funct. 10, 30.

Huang, C., Lee, C., Hsu, K. (2010). The Role of Insulin Receptor Signalling in Synaptic Plasticity and Cognitive Function. Chang Gung Med J. 33, 115-125.

Huang, Y., Liu, J., Wang, L-Z., Zhang, W-Y., Zhu, X-Z. (2005). Neuroprotective effects of cyclooxygenase2 inhibitor celecoxib against toxicity of LPS-stimulated macrophages toward motor neurons. Acta Pharmacol Sin. 26, 952-958.

Hublin, C., Partinen, M., Koskenvuo, M., Kaprio, J. (2007). Sleep and mortality: a population-based 22year follow-up study. Sleep. 30, 1245-1253.

Hucking, K., Hamilton-Wessler, M., Ellmerer, M., Bergman, R.N. (2003). Burst-like control of lipolysis by the sympathetic nervous system in vivo. J. Clin. Invest. 111, 257-264.

Huerta, P.T., Sun, L.D., Wilson, M.A., Tonegawa, S. (2000). Formation of temporal memory requires NMDA receptors within CA1 pyramidal neurons. Neuron. 25, 473-480.

Hunter, R.L., Dragicevic, N., Seifert, K., Choi, D.Y., Liu, M., Kim, H., Cass, W.A., Sullivan, P.G., Bing, G. (2007). Inflammation induces mitochondrial dysfunction and dopaminergic neurodegeneration in the nigrostriatal system. J Neurochem. 100, 1375-1386.

Igarashi, M., Hirata, A., Yamaguchi, H., Jimbu, Y., Tominaga, M. (2008). Pioglitazone reduces atherogenic outcomes in type 2 diabetic patients. J. Atheroscler. Thromb. 15, 34-40.

Iqbal, K., Liu, F., Gong, C.X., Alonso Adel, C., Grundke-lqbal, I. (2009). Mechanisms of tau-induced neurodegeneration. Acta Neuropathol 118, 53-69.

Irwin, M., Thompson, J., Miller, C., Gillin, J.C., Ziegler, M. (1999). Effects of sleep and sleep deprivation on catecholamine and interleukin-2 levels in humans: clinical implications. J. Clin. Endocrinol. Metab. 84, 1979-1985.

Irwin, M.R., Wang, M., Campomayor, C.O., Collado-Hidalgo, A., Cole, S. (2006). Sleep deprivation and activation of morning levels of cellular and genomic markers of inflammation. Arch Intern Med. 166, 1756-1762.

Irwin, M.R., Wang, M., Ribeiro, D., Cho, H.J., Olmstead, R., Breen, E.C., Martinez-Maza, O., Cole, S. (2008). Sleep loss activates cellular inflammatory signalling. Biol Psychiatry. 64, 538-540.

Jack Jr., C.R., Shiung, M.M., Weigand, S.D., O'Brien, P.C., Gunter, J.L., Boeve, B.F., Knopman, D.S., Smith, G.E., Ivnik, R.J., Tangalos, E.G., Petersen, R.C. (2005). Brain atrophy rates predict subsequent clinical conversion in normal elderly and amnestic MCl, Neurology. 65, 1227-1231. 
Jafari, M., Khodayari, B., Felgner, J., Bussel, I.I., Rose, M.R., Mueller, L.D. (2007). Pioglitazone: an antidiabetic compound with anti-aging properties. Biogerontology. 8, 639-651.

Jager, J., Gremeaux, T., Cormont, M., Le, Marchand-Brustel, Y., Tanti, J.F. (2007). Interleukin-1betainduced insulin resistance in adipocytes through down-regulation of insulin receptor substrate-1 expression. Endocrinology. 148, 241-251.

Jain, V.S., Vora, D.K., Ramaa C.S. (2013). Thiazolidine-2,4-diones: Progress towards multifarious applications. Bioorg Med Chem. 21, 1599-1620.

Jain, V.S., Vora, D.K., Ramaa C.S. (2013). Thiazolidine-2,4-diones: Progress towards multifarious applications. Bioorg Med Chem. 21, 1599-1620.

Janczyk, W., Socha, P. (2012). Non-alcoholic fatty liver disease in children. Clin Res Hepatol Gastroenterol. 36, 297-300.

Jennings, J.R., Muldoon, M.F., Hall, M., Buysse, D.J., Manuck, S.B. (2007). Self-reported sleep quality is associated with the metabolic syndrome. Sleep. 30, 219-223.

Jia L, Vianna CR, Fukuda M, Berglund ED, Liu C, Tao C., Sun, K., Liu, T., Harper, M.J., Lee, C.E., Lee, S., Scherer, P.E., Elmquist, J.K. (2014). Hepatocyte Toll-like receptor 4 regulates obesity-induced inflammation and insulin resistance. Nature communications. 5, 3878.

Jin, C., Henao-Mejia, J., Flavell, R.A. (2013). Innate immune receptors: key regulators of metabolic disease progression. Cell metab. 17, 873-882.

Jones, D., Gershon, S., Sitaram, N., Keshavan, M. (1987). Sleep and depression. Psychopathology. 20, 2031.

Kahn, C.R., Suzuki, R. Insulin Action in the Brain and the Pathogenesis of Alzheimer's Disease. In: Craft, S., Christen, Y. (2010). Diabetes, Insulin and Alzheimer's Disease, Research and Perspectives in Alzheimer's Disease. Springer-Verlag (Berlin).

Kahn, C.R., White, M.F., Shoelson, S.E., Backer, J.M., Araki, E., Cheatham, B., Csermely, P., Folli, F., Goldstein, B.J., Huertas, P., Rothenberg, P.L., Saad, M.J.A., Siddle, K., Sun, X-J., Wilden, P.A., Yamada, K., Kahn, S.A. (1993). The insulin receptor and its substrate: molecular determinants of early events in insulin action. Recent Prog Horm Res. 48, 291-339.

Kaiser, C.C., Shukla, D.K., Stebbins, G.T., Skias, D.D., Jeffery, D.R., Stefoski, D., Katsamakis, G., Feinstein, D.L. (2009). A pilot test of pioglitazone as an add-on in patients with relapsing remitting multiple sclerosis. J. Neuroimmunol. 211, 124-130.

Kantrowitz, J.T., Javitt, D.C. (2010). Thinking glutamatergically: changing concepts of Schizophrenia based upon changing neurochemical models. Clin Schizophr Relat Psychoses. 4, 189-200,

Kawai, T., Akira, S. (2007). Signalling to NF-kappaB by Toll-like receptors. Trends Mol Med. 13, 460-469.

Kemp, D.E., Ismail-Beigi, F., Calabrese, J.R. (2009). Antidepressant response associated with pioglitazone: support for an overlapping pathophysiology between major depression and metabolic syndrome. Am J Psychiatry. 166, 619.

Kemp, D.E., Ismail-beigi, F., Ganocy, S.J., Conroy, C., Gao, K., Obral, S., Fein, E., Findling, R.L., Calabrese, J.R. (2012). Use of insulin sensitizers for the treatment of major depressive disorder: A pilot study of pioglitazone for major depression accompanied by abdominal obesity. J. Affect. Disord. 136, 1164-1173. 
Kiec-Wilk, B., Dembinska-Kiec, A., Olszanecka, A., Bodzioch, M., Kawecka-Jaszcz, K. (2005). The selected pathophysiological aspects of PPARs activation. J Physiol Pharmacol. 56, 149-162.

Kikusui, T., Ichikawa, S., Mori, Y. (2009). Maternal deprivation by early weaning increases corticosterone and decreases hippocampal BDNF and neurogenesis in mice. Psychoneuroendocrinology. 34, 762-772.

Kim, J.J., Sears, D.D. (2010). TLR4 and Insulin Resistance. Gastroenterol Res Pract. pii: 212563, doi: $10.1155 / 2010 / 212563$.

King, M.R., Anderson, N.J., Guernsey, L.S., Jolivalt, C.G. (2013). Glycogen synthase kinase-3 inhibition prevents learning deficits in diabetic mice. J Neurosci Res. 91, 506-514.

Kismet, K., Akay, M.T., Abbasoglu, O., Ercan, A. (2004). Celecoxib: a potent cyclooxygenase-2 inhibitor in cancer prevention. Cancer Detect. Prev. 28, 127-142.

Knutson, K.L., van Cauter, E. (2008). Associations between sleep loss and increased risk of obesity and diabetes. Ann N Y Acad Sci. 1129, 287-304.

Koh, S., Yoo, A.R., Chang, D., Hwang, S.J., Kim, S.H. (2008). Inhibition of GSK-3 reduces infarct volume and improves neurobehavioral functions. Biochem Biophys Res Commun. 371, 894-899.

Konner, A.C., Bruning, J.C. (2011). Toll-like receptors: linking inflammation to metabolism. TEM. 22, 1623.

Koo, J.W., Russo, S.J., Ferguson, D., Nestler, E.J., Duman, R. S. (2010). Nuclear factor kappaB is a critical mediator of stress-impaired neurogenesis and depressive behavior. Proc. Natl. Acad. Sci. U.S.A. 107, 2669-2674

Kooijman, R., Coppens, A. (2004). Insulin-like growth factor-I stimulates IL-10 production in human T cells. J Leukoc Biol. 76, 862-867.

Kripke, D.F., Garfinkel, L., Wingard, D.L., Klauber, M.R., Marler, M. (2002). Mortality associated with sleep duration and insomnia. Arch Gen Psychiatry. 59, 131-136.

Krishnan, V., Han, M.H., Graham, D.L., Berton, O., Renthal, W., Russo, S.J., Laplant, Q., Graham, A., Lutter, M., Lagace, D.C., Ghose, S., Reister, R., Tannous, P., Green, T.A., Neve, R.L., Chakravarty, S., Kumar, A., Eisch, A.J., Self, D.W., Lee, F.S., Tamminga, C.A., Cooper, D.C., Gershenfeld, H.K., Nestler, E.J. (2007). Molecular adaptations underlying susceptibility and resistance to social defeat in brain reward regions. Cell. 131, 391-404.

Krogh-Madsen, R., Moller, K., Dela, F., Kronborg, G., Jauffred, S., Pedersen, B.K. (2004b). Effect of hyperglycemia and hyperinsulinemia on the response of IL-6, TNF-alpha, and FFAs to low-dose endotoxemia in humans. Am. J. Physiol. Endocrinol. Metab. 286, E766-E772.

Krogh-Madsen, R., Plomgaard, P., Keller, P., Keller, C., Pedersen, B.K. (2004a). Insulin stimulates interleukin-6 and tumor necrosis factor alpha gene expression in human subcutaneous adipose tissue. Am. J. Physiol. Endocrinol. Metab. 286, E234-E238.

Laube, B., Kuhse, J., Betz, H. (1998). Evidence for a tetrameric structure of recombinant NMDA receptors. J. Neurosci. 18, 2954-2961.

Lee, E., Choi, M-K., Youk, H-J., Kim, C., Han, I-O., Yoo, B-C., Lee, M.K., Lim, S.J. (2006). 5-(4-Chlorophenyl)1-(4-methoxyphenyl)-3-trifluoromethylpyrazole acts in a reactive oxygen species-dependent manner to suppress human lung cancer growth. J Cancer Res Clin Oncol, 132, 223-233. 
Lee, J., Kim, M. (2007). The role of GSK3 in glucose homeostasis and the development of insulin resistance. Diabetes Res Clin Pract. 77, S49-S57.

Li, X., Bijur, G.N., Jope, R.S. (2002). Glycogen synthase kinase-3beta, mood stabilizers, and neuroprotection. Bipolar Dis. 4, 137-144.

Liang, H., Hussey, S.E., Sanchez-Avila, A., Tantiwong, P., Musi, N. (2013). Effect of lipopolysaccharide on inflammation and insulin action in human muscle. PloS one. 8, e63983.

Lin, C.H., Tomioka, M., Pereira, S., Sellings, L., lino, Y., van der Kooy, D. (2010). Insulin signalling plays a dual role in Caenorhabditis elegans memory acquisition and memory retrieval. J. Neurosci. 30, 80018011.

Lipsky, P.E. (1999). Specific COX-2 inhibitors in arthritis, oncology, and beyond: where is the science headed? J. Rheumatol. Suppl. 56, 25-30.

Liu, T., Gao, Y.J., Ji, R.R. (2012). Emerging role of Toll-like receptors in the control of pain and itch. Neurosci Bull. 28, 131-144.

Liu, Y., Tanabe, K., Baronnier, D., Patel, S., Woodgett, J., Cras-Meneur, C., Permutt, M.A. (2010). Conditional ablation of Gsk-3beta in islet beta cells results in expanded mass and resistance to fat feeding-induced diabetes in mice. Diabetologia. 53, 2600-2610.

Lizcano, J.M., Alessi, D.R. (2002). The insulin signalling pathway. Curr. Biol. 12, R236-R238.

Lucas, S.M., Rothwell, N.J., Gibson, R.M. (2006). The role of inflammation in CNS injury and disease. Br J Pharmacol. 147, S232-S240.

Machado-Vieira, R., Salvadore, G., Luckenbaugh, D.A., Manji, H.K., Zarate Jr, C.A. (2008). Rapid onset of antidepressant action: a new paradigm in the research and treatment of major depressive disorder. J Clin Psychiatry. 69, 946-958.

Mallon, L., Broman, J.E., Hetta, J. (2002). Sleep complaints predict coronary artery disease mortality in males: a 12-year follow-up study of a middle-aged Swedish population. J Int Med. 251, 207-216.

Mandelkow, E.M., Stamer, K., Vogel, R., Thies, E., Mandelkow, E. (2003). Clogging of axons by tau, inhibition of axonal traffic and starvation of synapses. Neurobiol Aging. 24, 1079-1085.

McAdam, B.F., Catella-Lawson, F., Mardini, I.A., Kapoor, S., Lawson, J.A., FitzGerald, G.A. (1999). Systemic biosynthesis of prostacyclin by cyclooxygenase (COX)-2: The human pharmacology of a selective inhibitor of COX-2. Proc Natl Acad Sci USA. 96, 272-277.

McBain, C. J., Mayer, M. L. (1994). N-methyl-D-aspartic acid receptor structure and function. Physiol. Rev. 74, 723-760.

McEwen, B.S. (1998). Protective and damaging effects of stress mediators. N Engl J Med. 338, 171-179.

McGettrick, A.F., O'Neill, L.A. (2010). Localization and trafficking of Toll-like receptors: an important mode of regulation. Curr Opin Immunol. 22, 20-27.

McGuire, S.O., Ling, Z.D., Lipton, J.W., Sortwell, C.E., Collier, T.J., Carvey, P.M. (2001). Tumor necrosis factor alpha is toxic to embryonic mesencephalic dopamine neurons. Exp Neurol. 169, 219-230. 
McKernan, D.P., Dennison, U., Gaszner, G., Cryan, J.F., Dinan, T.G. (2011). Enhanced peripheral toll-like receptor responses in psychosis: further evidence of a pro-inflammatory phenotype. Transl Psychiatry. $1: \mathrm{e} 36$.

Meier-Ewert, H.K., Ridker, P.M., Rifai, N., Regan, M.M., Price, N.J., Dinges, D.F., Mullington, J.M. (2004). Effect of sleep loss on C-reactive protein, an inflammatory marker of cardiovascular risk. J. Am. Coll. Cardiol. 43, 678-683.

Meisinger, C., Heier, M., Loewel, H. (2005). Sleep disturbance as a predictor of type 2 diabetes mellitus in men and women from the general population. Diabetologia. 48, 235-241.

Meisinger, C., Heier, M., Lowel, H., Schneider, A., Doring, A. (2007). Sleep duration and sleep complaints and risk of myocardial infarction in middle-aged men and women from the general population: the MONICA/KORA Augsburg Cohort study. Sleep. 30, 1121-1127.

Metzler, M. (2011). Mutations in NMDA receptors influence neurodevelopmental disorders causing epilepsy and intellectual disability. Clin Genet. 79, 219-220.

Miles, P.D., Barak, Y., He, W., Evans, R.M., Olefsky, J.M. (2000). Improved insulin-sensitivity in mice heterozygous for PPAR-gamma deficiency. J Clin Invest. 105, 287-292.

Milnerwood, A.J., Raymond, L.A. (2010). Early synaptic pathophysiology in neurodegeneration: insights from Huntington's disease. Trends Neurosci. 33, 513-523.

Mittal, R., Malhotra, S., Pandhi, P., Kaur, I., Dogra, S. (2009). Efficacy and safety of combination Acitretin and Pioglitazone therapy in patients with moderate to severe chronic plaque-type psoriasis: a randomized, double-blind, placebo-controlled clinical trial. Arch. Dermatol. 145, 387-393.

Mogensen, T.H. (2009). Pathogen recognition and inflammatory signalling in innate immune defenses. Clin. Microbiol Rev. 22, 240-273.

Monyer, H., Burnashev, N., Laurie, D.J., Sakmann, B., Seeburg, P.H. (1994). Developmental and regional expression in the rat brain and functional properties of four NMDA receptors. Neuron. 12, 529-540.

More, S.V., Kumar, H., Kim, I.S., Song, S.Y., Choi, D.K. (2013). Cellular and molecular mediators of neuroinflammation in the pathogenesis of Parkinson's disease. Mediat Inflamm. 2013, 952375.

Mufson, E.J., Kroin, J.S., Sendera, T.J., Sobreviela, T. (1999). Distribution and retrograde transport of trophic factors in the central nervous system: functional implications for the treatment of neurodegenerative diseases. Prog. Neurobiol. 57, 451-484.

Najjar, S., Pearlman, D.M., Alper, K., Najjar, A., Devinsky, O. (2013). Neuroinflammation and psychiatric illness. J Neuroinflammation. 10, 43.

Nakazawa, K., Quirk, M.C., Chitwood, R.A., Watanabe, M., Yeckel, M.F., Sun, L.D., Kato, A., Carr, C.A., Johnston, D., Wilson, M.A., Tonegawa, S. (2002). Requirement for hippocampal CA3 NMDA receptors in associative memory recall. Science. 297, $211-218$.

Nataf, S. (2009). Neuroinflammation responses and neurodegeneration in multiple sclerosis. Rev Neurol. $165,1023-1028$.

Neal, M.D., Leaphart, C., Levy, R., Prince, J., Billiar, T.R., Watkins, S., Li, J., Cetin, S., Ford, H., Schreiber, A., Hackam, D.J. (2006). Enterocyte TLR4 mediates phagocytosis and translocation of bacteria across the intestinal barrier. J Immunol. 176, 3070-3079. 
Nedeltcheva, A.V., Kessler, L., Imperial, J. Penev, P.D. (2009). Exposure to recurrent sleep restriction in the setting of high caloric intake and physical inactivity results in increased insulin resistance and reduced glucose tolerance. J. Clin. Endocrinol. Metab. 94, 3242-3250.

Obulesu, M., Jhansilakshmi, M. (2013). Neuroinflammation in Alzheimer's disease: an understanding of physiology and pathology. Int J Neurosci. 124, 227-235.

Ogihara, T., Asano, T., Ando, K., Chiba, Y., Sekine, N., Sakoda, H., Anai, M., Onishi, Y., Fujishiro, M., Ono, H., Shojima, N., Inukai, K., Fukushima, Y., Kikuchi, M., Fujita, T. (2001). Insulin Resistance With Enhanced Insulin Signalling in High-Salt Diet-Fed Rats. Diabetes, 50, 573-583.

Olds, J.L., Anderson, M.L., McPhie, D.L., Staten, L.D., Alkon, D.L. (1989). Imaging of memory-specific changes in the distribution of protein kinase C in the hippocampus. Science. 245, 866-869.

Pan, Y., Hong, Y., Zhang, Q.Y., Kong, L.D. (2013). Impaired hypothalamic insulin signalling in CUMS rats: restored by icariin and fluoxetine through inhibiting CRF system. Psychoneuroendocrinology. 38, 122134.

Parsons, R.G., Gafford, G.M., Helmstetter, F.J. (2006). Translational control via the mammalian target of rapamycin pathway is critical for the formation and stability of longterm fear memory in amygdala neurons. J Neurosci. 26, 12977-12983.

Patel, S.R., Ayas, N.T., Malhotra, M.R., White, D.P., Schernhammer, E.S., Speizer, F.E., Stampfer, M.J., Hu, F.B. (2004). A prospective study of sleep duration and mortality risk in women. Sleep. 27, 440-444.

Pershadsingh, H.A., Heneka, M.T., Saini, R., Amin, N.M., Broeske, D.J., Feinstein, D.L. (2004). Effect of pioglitazone treatment in a patient with secondary multiple sclerosis. J. Neuroinflammation 1, 3.

Persiyantseva, N.A., Storozhevykh, T.P., Senilova, Y.E., Gorbacheva, L.R., Pinelis, V.G., Pomytkin, I.A. (2013). Mitochondrial H2O2 as an enable signal for triggering autophosphorylation of insulin receptor in neurons. J Mol Signal. 8, 11.

Petersen, K.F., Befroy, D., Dufour, S., Dziura, J., Ariyan, C., Rothman, D.L., DiPietro, L., Cline, G.W., Shulman, G.I. (2003). Mitochondrial dysfunction in the elderly: possible role in insulin resistance. Science. $300,1140-1142$.

Petersen, K.F., Befroy, D., Dufour, S., Dziura, J., Ariyan, C., Rothman, D.L., DiPietro, L., Cline, G.W., Shulman, G.I. (2003). Mitochondrial dysfunction in the elderly: possible role in insulin resistance. Science. 300, 1140-1142.

Pipatpiboon, N., Pratchayasakul, W., Chattipakorn, N., Chattipakorn, S.C. (2012). PPARy agonist improves neuronal insulin receptor function in hippocampus and brain mitochondria function in rats with insulin resistance induced by long term high-fat diets. Endocrinology. 153, 329-338.

Pirart, J. (1978) Diabetes mellitus and its degenerative complications: A prospective study of 4,400 patients observed between 1947 and 1973 (Pt 1). Diabetes Care. 1, 168-188.

Pomytkin, I.A. (2008). Choline salts of succinic acid for the treatment of depression, anxiety, schizophrenia, sleep disorder and epilepsy. Patent ID: US008673977B2, Mar. 18, 2014.

Poulain-Godefroy, O., Le Bacquer, O., Plancq, P., Lecoeur, C., Pattou, F., Fruhbeck, G., Froguel, P. (2010). Inflammatory role of Toll-like receptors in human and murine adipose tissue. Mediators Inflamm. 2010, 823486. 
Radin, M.S., Sinha, S., Bhatt, B.A., Dedousis, N., O'Doherty, R.M. (2008). Inhibition or deletion of the lipopolysaccharide receptor Toll-like receptor-4 confers partial protection against lipid-induced insulin resistance in rodent skeletal muscle. Diabetologia. 51, 336-346.

Raso, G.M., Simeoli, R., lacono, A., Santoro, A., Amero, P., Paciello, O., Russo, R., D'Agostino, G., Di Costanzo, M., Canani, R.B., Calignano, A., Meli R. (2014). Effects of a Lactobacillus paracasei B21060 based synbiotic on steatosis, insulin signalling and toll-like receptor expression in rats fed a high-fat diet. J Nutr Biochem. 25, 81-90.

Reutrakul, S., van Cauter, E. (2014). Interactions between sleep, circadian function, and glucose metabolism: implications for risk and severity. Ann N Y Acad Sci. 151-173.

Reyna, S.M., Ghosh, S., Tantiwong, P., Meka, C.S., Eagan, P., Jenkinson, C.P., Cersosimo, E., Defronzo, R.A., Coletta, D.K., Sriwijitkamol, A., Musi, N. (2008). Elevated toll-like receptor 4 expression and signalling in muscle from insulin-resistant subjects. Diabetes. 57, 2595-2602.

Rickle, A., Bogdanovic, N., Volkman, I., Winblad, B., Ravid, R., Cowburn, R.F. (2004). Akt activity in Alzheimer's disease and other neurodegenerative disorders. Neuroreport. 15, 955-959.

Riedel, G., Platt, B., Micheau, J. (2003). Glutamate receptor function in learning and memory. Behav. Brain Res. 140, 1-47.

Rosa, A.O., Kaster, M.P., Binfaré, R.W., Morales, S., Martín-aparicio, E., Navarro-rico, M.L., Martinez, A., Medina, M., García, A.G., López, M.G., Lúcia, A., Rodrigues, S. (2008). Antidepressant-like effect of the novel thiadiazolidinone NP031115 in mice. Prog Neuropsychopharmacol Biol Psychiatry. 32, 1549-1556.

Rusinek, H., de Santi, S., Frid, D., Tsui, W.H., Tarshish, C.Y., Convit, A., de Leon, M.J. (2003). Regional brain atrophy rate predicts future cognitive decline: 6-year longitudinal MR imaging study of normal aging, Radiology. 229, 691-696.

Saad, M.J., Folli, F., Kahn, J.A., Kahn, C.R. (1993). Modulation of insulin receptor, insulin receptor substrate-1, and phosphatidylinositol 3-kinase in liver and muscle of dexamethasone-treated rats. J Clin Invest. 92, 2065-2072.

Saberi, M., Woods, N.B., de Luca, C., Schenk, S., Lu, J.C., Bandyopadhyay, G., Verma, I.M., Olefsky, J.M. (2009). Hematopoietic cell-specific deletion of toll-like receptor 4 ameliorates hepatic and adipose tissue insulin resistance in high-fat-fed mice. Cell Metab. 10, 419-429.

Sakamoto, J., Kimura, H., Moriyama, S., Odaka, H., Momose, Y., Sugiyama, Y., Sawada, H. (2000). Activation of human peroxisome proliferator-activated receptor (PPAR) subtypes by pioglitazone. Biochem Biophys Res Commun. 278, 704-711.

Sakurai, T., Amemiya, A., Ishii, M., Matsuzaki, I., Chemelli, R.M., Tanaka, H., Williams, S.C., Richarson, J.A., Kozlowski, G.P., Wilson, S., Arch, J.R., Buckingham, R.E., Haynes, A.C., Carr, S.A., Annan, R.S., McNulty, D.E., Liu, W.S., Terrett, J.A., Elshourbagy, N.A., Bergsma, D.J., Yanagisawa, M. (1998). Orexins and orexin receptors: a family of hypothalamic neuropeptides and $\mathrm{G}$ protein-coupled receptors that regulate feeding behavior. Cell. 92, 573-585.

Salehi-Sadaghiani, M., Javadi-Paydar, M., Gharedaghi, M.H., Zandieh, A., Heydarpour, P., YousefzadehFard, Y., Dehpour, A.R. (2012). NMDA receptor involvement in antidepressant-like effect of pioglitazone in the forced swimming test in mice. Psychopharmacology (Berl). 223, 345-355.

Saltiel, A.R., Kahn, C.R. (2001). Insulin signalling and the regulation of glucose and lipid metabolism. Nature 414, 799-806. 
Sanacora, G., Zarate, C.A., Krystal, J.H., Manji, H.K. (2008). Targeting the glutamatergic system to develop novel, improved therapeutics for mood disorders. Nat Rev Drug Discov. 7, 426-437.

Sartorius, T., Lutz, S.Z., Hoene, M., Waak, J., Peter, A., Weigert, C., Rammensee, H.G., Kahle, P.J., Haring, H.U., Hennige, A.M. (2012). Toll-like receptors 2 and 4 impair insulin-mediated brain activity by interleukin-6 and osteopontin and alter sleep architecture. FASEB J Off Publ Fed Am Soc Exp Biol. 26, 1799-1809.

Saubermann, L.J., Nakajima, A., Wada, K., Zhao, S., Terauchi, Y., Kadowaki, T., Aburatani, H., Matsuhashi, N., Nagai, R., Blumberg, R.S. (2002). Peroxisome proliferator-activated receptor gamma agonist ligands stimulate a Th2 cytokine response and prevent acute colitis. Inflamm. Bowel. Dis. 8, 330-339.

Schenk, S., Saberi, M., Olefsky, J.M. (2008). Insulin sensitivity: modulation by nutrients and inflammation. J Clin Invest, 118, 2992-3002.

Schorge, S., Colquhoun, D. (2003). Studies of NMDA receptor function and stoichiometry with truncated and tandem subunits. J. Neurosci. 23, 1151-1158.

Schwartz, M.W., Figlewicz, D.P., Baskin, D.G., Woods, S.C., Porte, D. (1992). Insulin in the brain: a hormonal regulator of energy balance. Endocr Rev. 13, 387-414.

Sen, R., Baltimore, D. (1986). Inducibility of k immunoglobulin enhancer-binding protein NFkB by a posttranslational mechanism. Cell. 47, 921-928.

Sengupta, A., Novak, M., Grundke-lqbal, I., Iqbal, K. (2006). Regulation of phosphorylation of tau by cyclin-dependent kinase 5 and glycogen synthase kinase-3 at substrate level. FEBS Lett 580, 5925-5933.

Sepanjnia, K., Modabbernia, A., Ashrafi, M., Modabbernia, M.J., Akhondzadeh, S. (2012). Pioglitazone adjunctive therapy for moderate to severe major depressive disorder: randomized double-blind placebo-controlled trial. Neuropsychopharmacology. 37, 2093-2100.

Shatz, M., Menendez, D., Resnick, M.A. (2012). The human TLR innate immune gene family is differentially influenced by DNA stress and p53 status in cancer cells. Cancer Res. 72, 3948-3957.

Shearer, W.T., Reuben, J.M., Mullington, J.M., Price, N.J., Lee, B.N., Smith, E.O., Szuba, M.P., van Dongen, H.P., Dinges, D.F. (2001). Soluble TNF-alpha receptor 1 and IL-6 plasma levels in humans subjected to the sleep deprivation model of spaceflight. J. Allergy Clin. Immunol. 107, 165-170.

Shi, X., Dong, Z., Huang, C., Ma, W., Liu, J., Ye, J., Chen, F. Leonard, S.S., Ding, M., Castranova, V., Vallyathan, V. (1999). The role of hydroxyl radical as a messenger in the activation of nuclear transcription factor NF-KB. Mol Cell Biochem, 194, 63-70.

Shinkai, H., Onogi, S., Tanaka, M., Shibata, T., Iwao, M., Wakitani, K., Uchida, I. (1998). Isoxazolidine-3,5dione and noncyclic 1,3-dicarbonyl compounds as hypoglycemic agents. J Med Chem. 41, 1927-1933.

Shomaker, L. B., Tanofsky-Kraff, M., Young-Hyman, D., Han, J.C., Yanoff, L. B., Brady, S.M., Yanovski, S.Z., Yanovski, J.A. (2010). Psychological symptoms and insulin sensitivity in adolescents. Pediatr. Diabetes. $11,417-423$.

Skeberdis, V.A., Lan, J., Zheng, X., Zukin, R.S., Bennett, M.V.L. (2001). Insulin promotes rapid delivery of $\mathrm{N}$-methyl-D-aspartate receptors to the cell surface by exocytosis. Proc Natl Acad Sci U S A. 98, 35613566. 
Smalley, W.E., DuBois, R.N. (1997). Colorectal cancer and nonsteroidal anti-inflammatory drugs. Adv. Pharmacol. 39, 1-20.

Smith, T.D., Adams, M.M., Gallagher, M., Morrison, J.H., Rapp, P.R. (2000). Circuit-specific alterations in hippocampal synaptophysin immunoreactivity predict spatial learning impairment in aged rats, J. Neurosci. 20, 6587-6593.

Smith, W.L., Dewitt, D.L. (1996). Prostaglandin endoperoxide h synthases-1 and -2. Adv Immunol. 62, 167-215.

Spencer, J.L., Waters, E.M., Milner, T.A., Lee, F.S., McEwen, B.S. (2010). BDNF variant Val66Met interacts with estrous cycle in the control of hippocampal function. Proc Natl Acad Sci U S A. 107:4395-4400. doi: 10.1073/pnas.0915105107.

Spiegel, K., Leproult, R., van Cauter, E. (1999). Impact of sleep debt on metabolic and endocrine function. Lancet. 354, 1435-1439.

Stamatakis, K.A., Punjabi, N.M. (2010). Effects of sleep fragmentation on glucose metabolism in normal subjects. Chest. 137, 95-101.

Steen, E., Terry, B.M., Rivera, E.J., Cannon, J.L., Neely, T.R., Tavares, R., Xu, X.J., Wands, J.R., de la Monte, S.M. (2005). Impaired insulin and insulin-like growth factor expression and signalling mechanisms in Alzheimer's disease: is this type 3 diabetes? J Alzheimers Dis. 7, 63-80.

Storozheva, Z.I., Proshin, A.T., Sherstnev, V. V, Storozhevykh, T.P., Senilova, Y.E., Persiyantseva, N.A., Pinelis, V.G., Semenova, N.A., Zakharova, E.I., Pomytkin, I.A. (2008). Dicholine salt of succinic acid, a neuronal insulin sensitizer, ameliorates cognitive deficits in rodent models of normal aging, chronic cerebral hypoperfusion, and beta-amyloid peptide-(25-35)-induced amnesia. BMC Pharmacol. 8, 1.

Storozhevykh, T.P., Senilova, Y.E., Persiyantseva, N.A., Pinelis, V.G., Pomytkin, I.A. (2007). Mitochondrial respiratory chain is involved in insulin-stimulated hydrogen peroxide production and plays an integral role in insulin receptor autophosphorylation in neurons. BMC Neurosci. 8, 84.

Straus, D.S., Glass, C.K. (2007). Anti-inflammatory actions of PPAR ligands: new insights on cellular and molecular mechanisms. Trends Immunol. 28, 551-558.

Strum, J.C., Shehee, R., Virley, D., Richardson, J., Mattie, M., Selley, P., Ghosh, S., Nock, C., Saunders, A., Roses A. (2007). Rosiglitazone induces mitochondrial biogenesis in mouse brain. J Alzheimers Dis. 11, 45-51.

Stump, C.S., Short, K.R., Bigelow, M.L., Schimke, J.M., Nair, K.S. (2003). Effect of insulin on human skeletal muscle mitochondrial ATP production, protein synthesis, and mrna transcripts. Proc Natl Acad Sci USA. 100, 7996-8001.

Sucher, N. J., Awobuluyi, M., Choi, Y. B., Lipton, S. A. (1996). NMDA receptors: from genes to channels. Trends Pharmacol. Sci. 17, 348-355.

Sun, X., Yao, H., Douglas, R.M., Gu, X.Q., Wang, J., Haddad, G.G. (2010). Insulin/PI3K signalling protects dentate neurons from oxygen-glucose deprivation in organotypic slice cultures. J. Neurochem. 112, 377388.

Sutherland, C., Leighton, I. A., Cohen, P. (1993). Inactivation of glycogen synthase kinase-3 $\beta$ by phosphorylation; new kinase connections in insulin and growth factor signalling. Biochem. J. 296, 1519. 
t’ Veld, B.A., Ruitenberg, A., Hofman, A., Launer, L.J., van Duijn, C.M., Stijnen, T., Breteler, M.M., Stricker, B.H. (2001). Nonsteroidal anti-inflammatory drugs and the risk of Alzheimer's disease. N. Engl. J. Med. $345,1515-1521$.

Takagi, T., Okura, H., Kobayashi, Y., Kataoka, T., Taguchi, H., Toda, I., Tamita, K., Yamamuro, A., Sakanoue, Y., Ito, A., Yanagi, S., Shimeno, K., Waseda, K., Yamasaki, M., Fitzgerald, P.J., Ikeno, F., Honda, Y., Yoshiyama, M., Yoshikawa, J., Investigators, P. (2009). A Prospective, Multicenter, Randomized Trial to Assess Efficacy of Pioglitazone on In-Stent Neointimal Suppression in Type 2 Diabetes. JACC Cardiovasc Interv. 2, 524-531.

Takashima A. (2010). Drug development for tauopathy and Alzheimer's disease. Nihon Shinkei Seishin Yakurigaku Zasshi. 30, 177-180.

Tanti, J., Ceppo, F., Jager, J., Berthou, F. (2013). Implication of inflammatory signalling pathways in obesity-induced insulin resistance. Front Endocrinol (Lausanne). 3, 1-15.

Tasali, E., Leproult, R., Ehrmann, D.A., van Cauter, E. (2008). Slow-wave sleep and the risk of type 2 diabetes in humans. Proc Natl Acad Sci U S A. 105, 1044-1049.

Tasali, E., Leproult, R., Spiegel, K. (2009). Reduced Sleep Duration or Quality: Relationships With Insulin Resistance and Type 2 Diabetes. Prog. Cardiovasc. Dis. 51, 381-391.

Thompson, H.J., Jiang, C., Lu, J., Mehta, R.G., Piazza, G.A., Paranka, N.S., Pamukcu, R., Ahnen, D.J. (1997). Sulfone metabolite of sulindac inhibits mammary carcinogenesis. Cancer Res. 57, 267-271.

Thun, M.J., Namboodiri, M.M., Heath, C.W. Jr. (1991). Aspirin use and reduced risk of fatal colon cancer. N. Engl. J. Med. 325, 1593-1596.

Tian, Y., Hsia, T., Hsieh, C., Huang, D. (2011). The importance of cyclooxygenase 2-mediated oxidative stress in obesity-induced muscular insulin resistance in high-fat-fed rats. Life Sci. 89, 107-114.

Troussard, A.A., Tan, C., Yoganathan, T.N., Dedhar, S. (1999). Cell extracellular matrix interactions stimulate the AP-1 transcription factor in an integrin-linked kinase- and glycogen synthase kinase 3dependent manner. Mol. Cell. Biol. 19, 7420-7427.

Trudeau, F., Gagnon, S., Massicotte, G. (2004). Hippocampal synaptic plasticity and glutamate receptor regulation: influences of diabetes mellitus. Eur. J. Pharmacol. 490, 177-186.

Tsiotra, P.C., Tsigos, C. (2006). Stress, the endoplasmic reticulum, and insulin resistance. Ann N Y Acad Sci. 1083, 63-76.

Tsukumo, D.M., Carvalho-Filho, M.A., Carvalheira, J.B., Prada, P.O., Hirabara, S.M., Schenka, A.A., Araujo, E.P., Vassallo, J., Curi, R., Velloso, L.A., Saad, M.J. (2007). Loss-of-function mutation in Toll-like receptor 4 prevents diet-induced obesity and insulin resistance. Diabetes. 56, 1986-1998.

Turenne, G.A., Price, B.D. (2001). Glycogen synthase kinase3 beta phosphorylates serine 33 of p53 and activates p53's transcriptional activity. BMC Cell Biol. 2, 12.

Unger, J., McNeill, T.H., Moxley, R.T., 3rd, White, M., Moss, A., Livingston, J.N. (1989). Distribution of insulin receptor-like immunoreactivity in the rat forebrain. Neuroscience. 31, 143-157.

Uylings, H.B., de Brabander, J.M. (2002). Neuronal changes in normal human aging and Alzheimer's disease, Brain Cogn. 49, 268-276. 
van Cauter, E., Blackman, J.D., Roland, D., Spire, J.P., Refetoff, S., Polonsky, K.S. (2001). Modulation of glucose regulation and insulin secretion by circadian rhythmicity and sleep. J Clin Invest. 88, 934-942.

van Leeuwen, W.M., Lehto, M., Karisola, P., Lindholm, H., Luukkonen, R., Sallinen, M., Härmä, M., Porkka-Heiskanen, T., Alenius, H. (2009). Sleep restriction increases the risk of developing cardiovascular diseases by augmenting proinflammatory responses through II-17 and Crp. PLoS One. 4, e4589.

Vecsey, C.G., Baillie, G.S., Jaganath, D., Havekes, R., Daniels, A., Wimmer, M., Huang, T., Brown, K.M., Li, X.Y., Descalzi, G., Kim, S.S., Chen, T., Shang, Y.Z., Zhuo, M., Houslay, M.D., Abel, T. (2009). Sleep deprivation impairs cAMP signalling in the hippocampus. Nature. 461, 1122-1125.

Velloso, L.A., Folli, F., Saad, M.J. (2015). TLR4 at the Crossroads of Nutrients, Gut Microbiota, and Metabolic Inflammation. Endocr Rev. 36, 245-271.

Venancio, D.P., Suchecki, D. (2015). Prolonged REM sleep restriction induces metabolic syndromerelated changes: Mediation by pro-inflammatory cytokines. Brain Behav Immun. 47, 109-117.

Vgontzas, A.N., Zoumakis, E., Bixler, E.O., Lin, H.M., Follett, H., Kales, A., Chrousos, G.P. (2004). Adverse effects of modest sleep restriction on sleepiness, performance, and inflammatory cytokines. J. Clin. Endocrinol. Metab. 89, 2119-2126.

Vorona, R.D., Winn, M.P., Babineau, T.W., Eng, B.P., Feldman, H.R., Ware, J.C. (2005). Overweight and obese patients in a primary care population report less sleep than patients with a normal body mass index. Arch Intern Med. 165, 25-30.

Wallum, B.J., Taborsky, G.J., Porte, D., Figlewicz, D.P., Jacobson, L., Beard, J.C., Ward, W.K., Dorsa, D. (1987). Cerebrospinal fluid insulin levels increase during intravenous insulin infusions in man. J Clin Endocrinol Metab. 64, 190-194.

Wang, C.H., Wang, C.C., Wei, Y.H. (2010) Mitochondrial dysfunction in insulin insensitivity: implication of mitochondrial role in type 2 diabetes. Ann N Y Acad Sci. 1201, 157-165.

Wang, Y.C., Lin, S., Yang, Q.W. (2011). Toll-like receptors in cerebral ischemic inflammatory injury. J Neuroinflammation. 8, 134.

Watanabe M., Inoue Y., Sakimura K. and Mishina M. (1993). Distinct spatio-temporal distributions of the NMDA receptor channel subunit mRNAs in the brain. Ann. NY Acad. Sci. 707, 463-466.

Watson, G.S., Craft, S. (2006). Insulin resistance, inflammation, and cognition in Alzheimer's Disease: lessons for multiple sclerosis. J. Neurol. Sci., 245, 21-33.

Wei, W., Wang, X., Kusiak, J.W. (2002). Signalling events in amyloid betapeptide- induced neuronal death and insulin-like growth factor I protection. J. Biol. Chem. 277, 17649-17656.

Welsh, G.I., Proud, C.G. (1993). Glycogen synthase kinase-3 is rapidly inactivated in response to insulin and phosphorylates eukaryotic initiation factor elF-2B. Biochem. J. 294, 625-629.

Wen, H., Gris, D., Lei, Y., Jha, S., Zhang, L., Huang, M.T., Brickey, W.J., Ting, J.P. (2011). Fatty acid-induced NLRP3-ASC inflammasome activation interferes with insulin signalling. Nat Immunol. 12, 408-415.

Whelton, A., Schulman, G., Wallemark, C., Drower, E.J., Isakson, P.C., Verburg, K.M., Geis, G.S. (2000). Effects of celecoxib and naproxen on renal function in the elderly. Arch Intern Med. 160, 1465-1470.

Wilkinson, M.B., Dias, C., Magida, J., Mazei-Robison, M., Lobo, M., Kennedy, P., Dietz, D., Covington, H. 3rd, Russo, S., Neve, R., Ghose, S., Tamminga, C., Nestler, E.J. (2011). A novel role of the WNT- 
dishevelled-GSK3beta signalling cascade in the mouse nucleus accumbens in a social defeat model of depression. J Neurosci Off J Soc Neurosci. 31, 9084-9092.

Williams, J.M., Owens, W.A., Turner, G.H., Saunders, C., Dipace, C., Blakely, R.D., France CP, Gore, J.C., Daws, L.C., Avison, M.J., Galli, A. (2007). Hypoinsulinemia regulates amphetamine-induced reverse transport of dopamine. PLoS. Biol. 5, e274.

Wilson, I.A., Gallagher, M., Eichenbaum, H., Tanila, H. (2006). Neurocognitive aging: prior memories hinder new hippocampal encoding, Trends Neurosci. 29, 662-670.

Woodgett, J.R. (1990). Molecular cloning and expression of glycogen synthase kinase-3/factor a, EMBO J. 9, 2431-2438.

Woodgett, J.R. (1991). Cdna cloning and properties of glycogen synthase kinase-3, Methods Enzymol. 200, 564-577.

Woodgett, J.R., Cohen, P. (1984). Multisite phosphorylation of glycogen synthase. Molecular basis for the substrate specificity of glycogen synthase kinase-3 and casein kinase-ii (glycogen synthase kinase-5), Biochim. Biophys. Acta. 788, 339-347.

Woods, S.C., Porte, D. Jr., Bobbioni, E., Ionescu, E., Sauter, J.F., Rohner-Jeanrenaud, F., Jeanrenaud, B. (1985). Insulin: its relationship to the central nervous system and to the control of food intake and body weight. Am. J. Clin. Nutr. 42, 1063-1071.

Wu, Y., Tang, K., Huang, R., Zhuang, Z., Cheng, H., Yin, H., Shi, J. (2011). Therapeutic potential of peroxisome proliferator-activated receptor gamma agonist rosiglitazone in cerebral vasospasm after a rat experimental subarachnoid hemorrhage model. J Neurol Sci. 305, 85-91.

Wu, Y., Zhao, X., Zhuang, Z., Xue, Y., Cheng, H., Yin, H., Shi, J. (2010). Peroxisome proliferator-activated receptor gamma agonist rosiglitazone attenuates oxyhemoglobin-induced Toll-like receptor 4 expression in vascular smooth muscle cells. Brain Res. 1322, 102-108.

Yaggi, H.K., Araujo, A.B., McKinlay, J.B. (2006). Sleep duration as a risk factor for the development of type 2 diabetes. Diabetes Care. 29, 657-661.

Yuan, M., Konstantopoulos, N., Lee, J., Hansen, L., Li, Z.W., Karin, M., Shoelson, S.E. (2001). Reversal of obesity- and diet-induced insulin resistance with salicylates or targeted disruption of Ikkbeta. Science. 293, 1673-1677.

Zarate Jr, C.A., Singh, J.B., Carlson, P.J., Brutsche, N.E., Ameli, R., Luckenbaugh, D.A., Charney, D.S., Manji, H.K. (2006). A randomized trial of an N-methyl-D-aspartate antagonist in treatment-resistant major depression. Arch Gen Psychiatry. 63, 856-864.

Zekry, D., Gold, G. (2010). Management of mixed dementia. Drugs Aging. 27, 715-728.

Zhang, F.X., Rubin, R., Rooney, T.A. (1998). N-Methyl-D-aspartate Inhibits Apoptosis through Activation of Phosphatidylinositol 3-Kinase in Cerebellar Granule Neurons. J Biol Chem. 273, 26596-26602.

Zhang, K., Kaufman, R.J. (2008). From endoplasmic-reticulum stress to the inflammatory response. Nature. 454, 455-462.

Zhang, N., Liang, H., Farese, R. V, Li, J., Musi, N. (2015). Pharmacological TLR4 Inhibition Protects against Acute and Chronic Fat-Induced Insulin Resistance in Rats. PLoS One. 10, e0132575. 
Zhang, X., Zhang, G., Zhang, H., Karin, M., Bai, H., Cai, D. (2008). Hypothalamic IKKbeta/NF-kappaB and ER stress link overnutrition to energy imbalance and obesity. Cell. 135, 61-73.

Zhang, Y., Ye, J. (2012). Mitochondrial inhibitor as a new class of insulin sensitizer. Acta Pharm Sin B. 2, 341-349.

Zhao, W., Alkon, D.L. (2001). Role of insulin and insulin receptor in learning and memory. Mol Cell Endocrinol. 177, 125-134.

Zhao, W., Chen, H., Xu, H., Moore, E., Meiri, N., Quon, M.J., Alkon, D.L. (1999). Brain insulin receptors and spatial memory. Correlated changes in gene expression, tyrosine phosphorylation, and signalling molecules in the hippocampus of water maze trained rats. j Biol Chem. 274, 34893-34902.

Zhao, W., Wang, L., Zhang, M., Wang, P., Zhang, L., Yuan, C., Qi, J., Qiao, Y., Kuo, P.C., Gao, C. (2011). Peroxisome proliferator-activated receptor gamma negatively regulates IFN-beta production in Toll-like receptor (TLR)3- and TLR4-stimulated macrophages by preventing interferon regulatory factor 3 binding to the IFN-beta promoter. J Biol Chem. 286, 5519-5528.

Zhao, Y., Patzer, A., Herdegen, T., Gohlke, P., Culman, J. (2006). Activation of cerebral peroxisome proliferator-activated receptors gamma promotes neuroprotection by attenuation of neuronal cyclooxygenase-2 overexpression after focal cerebral ischemia in rats. FASEB. J. 20, 1162-1175.

Zuany-Amorim, C., Hastewell, J., Walker, C. (2002). Toll-like receptors as potential therapeutic targets for multiple diseases. Nat. Rev. Drug Discov. 1, 797-807.

\section{Figure references}

Fig. 1. - Adapted from Blásquez. E. et al., 2014, see above

Fig. 2. - Adapted from Kim, B., Feldman, E.L. (2012). Insulin resistance in the nervous system. Trends Endocrinol Metab. 23, 133-141.

Fig. 3. - Ahmadian, M., Suh, J.M., Hah, N., Liddle, C., Atkins, A.R., Downes, M., Evans, R.M. (2013). PPARy signaling and metabolism: the good, the bad and the future. Nat Med. 19, 557-566.

Fig. 4. - Persiyantseva, N.A., et al., 2013, see above. 



\title{
Chapter 2
}

\section{Altered emotionality, hippocampus-dependent performance and expression of NMDA receptor subunit mRNAs in chronically stressed mice.}

\author{
Costa-Nunes $\mathrm{JP}^{1,3,{ }^{*}}$, Zubareva $\mathrm{O}^{1,{ }^{*}}$, Araújo-Correia $\mathrm{M}^{1,{ }^{*}}$, Valença $\mathrm{A}^{1,{ }^{*}}$, Schroeter \\ $\mathrm{CA}^{4}$, Pawluski $\mathrm{JL}^{1,5}$, Vignisse $\mathrm{J}^{1,5}$, Steinbusch $\mathrm{H}^{1}$, Hermes $\mathrm{D}^{1}$, Phillipines $\mathrm{M}^{1}$, \\ Steinbusch $\mathrm{HWM}^{1}$, Strekalova $\mathrm{T}^{1,2,4,{ }^{*} \text {. }}$ \\ * Authors contributed equally to this work
}

${ }^{1}$ Department of Neuroscience, School for Mental Health and Neuroscience, Maastricht University, Maastricht, the Netherlands, ${ }^{2}$ Institute for Hygiene and Tropical Medicine, New University of Lisbon and Centre of Environmental Biology, University of Lisbon, Lisbon, Portugal, ${ }^{3}$ Institute of Experimental Medicine, Russian Academy of Medical Sciences, St. Petersburg, Russia, ${ }^{4}$ Maastricht Medical Centre in Annadal, Maastricht, the Netherlands, and ${ }^{5}$ GIGA Neuroscience, Liège University, Liège, Belgium

Stress. 2014 Jan;17(1):108-16. 


\section{Abstract}

$\mathrm{N}$-methyl-D-aspartate receptor (NMDAR)-mediated neurotransmission in the hippocampus is implicated in cognitive and emotional disturbances during stressrelated disorders. Here, using quantitative RT-PCR, we investigated the hippocampal expression of NR2A, NR2B and NR1 subunit mRNAs in a mouse stress paradigm that mimics clinically relevant conditions of simultaneously affected emotionality and hippocampus-dependent functions. A two-week stress procedure, which comprised ethologically valid stressors, exposure to a rat and social defeat, was applied to male $\mathrm{C} 57 \mathrm{BL} / 6 \mathrm{~J}$ mice. For predation stress, mice were introduced into transparent containers that were placed in a rat home cage during the night; social defeat was applied during the daytime using aggressive CD1 mice. This treatment impaired hippocampus-dependent performance during contextual fear conditioning. A correlation between this behaviour and food displacement performance was demonstrated, suggesting that burrowing behavior is affected by the stress procedure and is hippocampus-dependent. Stressed mice $(n=22)$ showed behavioural invigoration and anomalous anxiolytic-like profiles in the O-maze and brightly illuminated open field, unaltered short-term memory in the step-down avoidance task and enhanced aggressive traits, as compared to non-stressed mice $(n=10)$. Stressed mice showed increased basal serum corticosterone concentrations, hippocampal mRNA expression for the NR2A subunit of the NMDAR and in the NR2A/NR2B ratio; mRNA expression of NR2B and NR1 was unchanged. Thus, stressinduced aberrations in both hippocampal-dependent performance and emotional abnormalities are associated with alterations in hippocampal mRNA NR2A levels and the NR2A/NR2B ratio and not with mRNA expression of NR2B or NR1.

Key words: burrowing behavior; contextual fear memory; hippocampus; N-methylD-aspartate receptor; predator stress; social defeat 


\section{Introduction}

$\mathrm{N}$-methyl-D-aspartate receptor (NMDAR)-mediated neurotransmission is involved in the aetiology of stress-related cognitive deficits and behavioural abnormalities (CullCandy et al., 2001). This particularly implicates altered expression of the two NR1 (GluN1) and two NR2 (GluN2) subunits (NR2A and NR2B) of NMDAR tetramers, which are the most abundant in the hippocampal formation, a brain structure that mediates stress-induced aberrations in both learning and emotional behaviour ( Li and Ju, 2012). Both NR2A and NR2B were shown to have distinct pharmacology and a role in the regulation of NMDAR, and have been suggested to be differentially involved in the mechanisms of learning and emotionality (Fleischman et al., 2003; Li and Tsien, 2009). A body of evidence has demonstrated the involvement of NR2A, NR2B and NR1 subunits in the neurobiology of neuropsychiatric conditions such as anxiety, psychosis, impulsivity, Alzheimer's disease and major depression (Tsang et al., 2008; Geissler and Lesch, 2011; Davies et al., 2012).

Most experiments investigating the roles of NMDAR subunits in neuropsychiatric symptoms target selective subunits of this receptor using pharmacological and genetic manipulations that are frequently applied in vitro (Boyce-Rustay and Holmes, 2006; Longordo et al., 2009; Cui et al., 2013). However, fewer studies have addressed the changes in NMDAR subunit expression in disease-modeling conditions. Understanding changes in relative-fold mRNA expression of NMDAR subunits in animal models of cognitive and emotional disturbances related to chronic stress is important for the identification of new pharmacological interventions and therapies that effectively alter glutamatergic transmission (Vignisse et al., 2013). Previous work on gene expression (Strekalova et al., 2011) has highlighted abnormal hippocampal expression of NMDAR subunits in mice subjected to repeated stressors. We have hypothesized that in male $\mathrm{C} 57 \mathrm{BL} / 6 \mathrm{~J}$ mice, a novel two-week stress procedure, comprised of ethologically valid stressors, exposure to a rat and social defeat, results 
in concomitant cognitive, emotional and NMDA receptor expression abnormalities in the hippocampus. Thus, the current study specifically investigated the hippocampal relative-fold mRNA expression of NR2A, NR2B and NR1 subunits in the abovementioned chronic stress procedure in mice that mimics clinically relevant situations of stress-related disturbances in learning and emotionality (Strekalova and Steinbusch, 2010; Cline et al., 2012).

\section{Materials and methods}

\section{Animals and housing}

Male C57BL/6J and CD1 mice were 3 months-old, Wistar rats of 3-5 months age were used for predator stress; mice and rats were provided by Harlan, the Netherlands and Charles River, France, respectively. 14 days before the behavioural experiments, mice were single housed under a reverse 12h:12h light-dark cycle (lights on: 21:00 h) in standard laboratory conditions $\left(22 \pm 1^{\circ} \mathrm{C}, 55 \%\right.$ humidity, food and water ad libitum). All experiments were carried out in accordance with the European Committees Council Directives and had been approved by the ethics committee of Maastricht University for animal research (CPV, DEC-UM 2009-109).

\section{Experimental conditions and study outline}

This study applied only ethological stressors to male C57BL/6J mice, for 14 days, based on previous work (adapted from Cline et al., 2012; Couch et al., 2013). The stress procedure consisted of dark-cycle rat exposure between the hours of 09:00 $\mathrm{h}$ and 18:00 $\mathrm{h}$ and light-cycle application of a social defeat paradigm, combined with exposure to an aggressive CD1 mouse. Body weight and parameters of social behaviour were determined one week before the chronic stress procedure in a social interaction test as described elsewhere (Strekalova et al., 2004). The experimental and control groups were balanced for these parameters. Ethological stressors were applied to a stress group for 14 days, as described below. The control group received 
daily handling only. At the end of the stress experiment, $12 \mathrm{~h}$ after the application of the last stressor, short-term memory in the step-down avoidance task (Vignisse et al., 2011) and aggressive behaviour in a resident-intruder test (Strekalova et al., 2004) were investigated in stressed and control mice. At this time, body weight was also assessed. The next day (Day 1), mice were tested in the elevated O-maze and food displacement tube tests (Strekalova and Steinbusch, 2010). On Days 2 and 3, respectively, contextual fear conditioning training and testing for recall (Vignisse et al., 2013) were performed. The open field testing was carried out on Day 4 (under red light) and on day 5 (under white light). All behavioural tests were recorded on video.

We used a battery of behavioural tests based on previous literature (Calabrese et al., 2012). Although it is possible that the different behavioural tests may affect subsequent tests, previously published test batteries with similarly employed paradigms have revealed an absence of any testing effects in C57BI/6 mice (Strekalova and Steinbusch, 2009, 2010; Vignisse et al., 2011, 2013; Malatynska et al., 2012). Hence, we considered possible interfering effects of multiple behavioural test to be minimal in the current study.

A separate cohort of mice from both groups was pre-exposed to a mixture of $\mathrm{CO}_{2}$ and $\mathrm{O}_{2}$ and euthanized via cervical dislocation (according to Dutch law), for gene expression analysis 24 hours after the termination of the stress procedure.

\section{Chronic stress procedure}

Rat exposure while in a small container. Mice were introduced into cylindrical containers, which were placed into a rat home cage for $15 \mathrm{~h}$ (over-night, from 18:00 $\mathrm{h}$ to 9:00 h). Containers $(15 \mathrm{~cm} \times \varnothing 8 \mathrm{~cm}$ ) were made from customized transparent plastic with holes in the covers $(\varnothing<0.5 \mathrm{~cm})$. This ensured protection of the mouse 
from the rat, but allowed visual and odour contact. During the weekends, mice were kept in their home cages, situated on top of the rat cages.

Social defeat stress. Social defeat procedures took place during the dark phase of the light cycle (between 12:00 $\mathrm{h}$ and 16:00 h). To enable visual control by the experimenter over the resident-intruder confrontation, the test was carried out under red light. In a preliminary test, aggressive CD1 mice that were able to attack the counter-partners in less than $60 \mathrm{sec}$, without injuring them, were selected for this procedure; these mice were introduced into the home cages of mice from the stress group during social defeat sessions for $5 \mathrm{~min}$. During social defeat stress, test mice typically showed flight responses, submissive postures and vocalizations. Pairs of mice were carefully observed in order to prevent physical harm. In rare cases, aggressive mice were immediately removed from the cage of resident mice. After a 5-min period of social defeat, $\mathrm{C} 57 \mathrm{BL} / 6$ mice were placed into small containers and put inside a CD1 mouse cage, where they stayed for a $3 \mathrm{~h}$-period. After the $3 \mathrm{~h}$ period, the 5-min social defeat procedure was repeated. In order to randomize the procedure, the same pairs of $\mathrm{C} 57 \mathrm{BL} / 6$ and $\mathrm{CD} 1$ mice were never put together.

\section{Behavioural procedures}

Step-down passive avoidance model. The step-down passive avoidance test was used as described elsewhere (Strekalova et al., 2001; Vignisse et al., 2011, 2013). The stepdown apparatus (Evolocus LLC Tarrytown, NY, USA and Technosmart, Rome, Italy) was a transparent plastic cubicle $(25 \mathrm{~cm} \times 25 \mathrm{~cm} \times 48 \mathrm{~cm}$ ) with a stainless-steel grid floor (33 rods $2 \mathrm{~mm}$ in diameter), onto which a square wooden platform (7 cm $\times 7$ $\mathrm{cm} \times 1.5 \mathrm{~cm}$ ) was placed. The illumination strength was 25 Lux. A shocker was used to deliver an alternating electric current $(A C, 50 \mathrm{~Hz}$ ). In this paradigm, mice are trained to avoid an electric shock by staying on the platform above the grid floor. During the training session, mice were placed on the platform inside a transparent cylinder for $30 \mathrm{~s}$ to prevent them from stepping down immediately. After removal of 
the cylinder, the time until the mouse left the platform, with all four paws, was measured as baseline latency of step-down. Immediately after step-down, mice received a single electric foot shock $(0.5 \mathrm{~mA}, 2 \mathrm{sec})$ and were returned to their home cages. One hour later, during the recall trial session, mice were exposed to the apparatus again by being handled in the same way as in the training session; no foot shock was delivered. Latency of step-down with all four paws was measured until 180 s had elapsed.

Elevated O-maze. Testing on the elevated O-maze was carried out as described elsewhere (Strekalova et al., 2005). The O-maze consisted of a black circular path (runway width $5.5 \mathrm{~cm}, \varnothing=46 \mathrm{~cm}$ ) with two opposing compartments protected by walls made of polyvinyl-chloride (height $=10 \mathrm{~cm}$ ) and two open sectors of equal size. The maze was elevated $20 \mathrm{~cm}$ above the ground and illuminated from the top with red light. At the start of the testing session, mice were placed inside one of the two closed compartments. The test was recorded with a web camera. The latency to the first entry into the anxiety-related open arms of the maze, total number of entries into the open arms and total duration of time spent in open arms were scored for 5 $\min$.

Food pellet displacement (burrowing) behaviour in a tube test. In order to further assess hippocampal function, all experimental groups were tested for burrowing behaviour. Burrowing behaviour, a tendency to displace small objects, e.g., small stones or food pellets, from a tube inside the home cage, is species-specific in mice and has been demonstrated to depend on an intact hippocampal formation. Using a paper tube (internal diameter $4 \mathrm{~cm}$, length $10 \mathrm{~cm}$ ), filled with 20 food pellets and placed in the middle of a mouse home cage, the latency to displacement of the first food pellet, time required to empty the tube, number of pellets removed after $1 \mathrm{~h}$ and 1h 30 min were assessed in stressed and control mice during the dark phase 
(Strekalova and Steinbusch, 2009, 2010). Time elapsed was 90 min.

Contextual fear-conditioning paradigm. The contextual fear-conditioning test procedure was adapted from previously described protocols (Strekalova et al., 2003; Vignisse et al., 2013). The apparatus (Evolocus LLC Tarrytown, NY, USA and Technosmart, Rome, Italy) consisted of a transparent plastic cubicle $(25 \mathrm{~cm} \times 25 \mathrm{~cm}$ $x 50 \mathrm{~cm}$ ) with a stainless-steel grid floor (33 rods $2 \mathrm{~mm}$ in diameter). A shocker was used to deliver an alternating electric current ( $A C, 50 \mathrm{~Hz} ; 0.7 \mathrm{~mA}, 2 \mathrm{sec}$ ) after a 2-min acclimatization of a mouse to the chamber. After delivery of the current, the mouse was immediately placed back in the home cage. Freezing behaviour was scored by visual observation during a test of memory recall that was carried out $24 \mathrm{~h}$ later. The occurrence of freezing behaviour in the chamber was assessed every $10 \mathrm{sec}$ for 180 sec; each 10-sec score was assigned to a freezing or non-freezing period, and the percentage of time spent in freezing was calculated.

Open field. The open-field apparatus consisted of four square arenas $(25 \mathrm{~cm} \times 25 \mathrm{~cm} \times$ $40 \mathrm{~cm}$ ), made of wood covered with white resopal. Mice were put in the center of one of the four square open field arenas, and their behaviour was video recorded for 10 min. The open field was illuminated with white light (25 Lux) or red light. Behaviour was analyzed off-line using the Any-maze software (Stoelting Co, Wood Dale, IL, USA). Among other parameters, time spent immobile was analyzed in the central (area 20 $x 20 \mathrm{~cm}$ ) and peripheral (remaining part of the apparatus) zones.

Resident-intruder test. The resident-intruder test procedure was performed as described elsewhere (Strekalova et al., 2004). In this paradigm, the C57BL/6J mice were placed individually in an observation cage $(30 \mathrm{~cm} \times 60 \mathrm{~cm} \times 30 \mathrm{~cm})$ for $30 \mathrm{~min}$. Thereafter, a male CD1 mouse, which was group housed before the test, was introduced as an intruder to the same cage and left with the resident mouse for 8 min. During the observation period, resident and intruder mice were scored for 
aggressive social behaviours. Latency of the first attack and number of attacks were scored.

Brain dissection and blood collection. On the day following the termination of the stress procedure, a cohort of mice from both groups was euthanized as described above, their hippocampi were dissected and trunk blood was collected for corticosterone evaluation.

Corticosterone concentration. To assay serum corticosterone, trunk blood was stored at $4^{\circ} \mathrm{C}$ overnight and centrifuged at $10 \mathrm{xg}$ for 10 minutes; the assay was performed as previously described (Pawluski et al., 2012). Serum was collected and stored a $80^{\circ} \mathrm{C}$ until use. All samples were run in duplicate. For total serum corticosterone concentrations, a commercially available RIA kit for rat corticosterone from MP Biomedicals (Corticosterone 125 for rats and mice, MP Biomedicals, LLC, Orangeburg, NY, USA) was used. Average intra- and inter-assay coefficients of variation for all corticosterone assays were below $10 \%$. Assay sensitivity was $7.7 \mathrm{ng} / \mathrm{mL}$.

RNA isolation and RT PCR. RNA was extracted as previously described (Couch et al., 2013) using the RNeasy RNA extraction kit (Qiagen, Hilden, Germany) and first strand cDNA synthesis was performed using random primers and Superscript III transcriptase (Invitrogen, Darmstadt, Germany); 1 mg total RNA was converted into cDNA. Quantitative RT-PCR (qPCR) for NR2A, NR2B, NR1 genes and the housekeeping gene glyceraldehyde-3-phosphate dehydrogenase (GAPDH) was performed using TaqMan probes and the CFX96 Real-time System (BioRad, Hercules, CA, USA). Cycling conditions and sequences of primers used are indicated in Table 1 of Supplementary data. Results were normalised to GAPDH mRNA expression and calculated as relativefold changes compared to control mice as described elsewhere (Couch et al., 2013). Results of the GPCR measurements were expressed as Ct values, where $\mathrm{Ct}$ is defined as the threshold cycle of PCR at which amplified product was $0.05 \%$ of normalized 
maximal signal. We used the comparative $\mathrm{Ct}$ method and computed the difference between the expression of the gene of interest and GAPDH expression in each cDNA sample (2- $\Delta \Delta \mathrm{Ct}$ method). Results are given as expression-folds compared to the mean expression values in non-stressed control mice (Couch et al., 2013, adapted from Livak and Schmittgen 2001).

\section{Statistical analysis}

GraphPad Prism 5.00 (San Diego, CA, USA) was used for analyses. A comparison of normally distributed independent variables was carried out using unpaired two-tailed $t$-tests. Independent measurements that were not normally distributed were analysed via the non-parametric Mann-Whitney test, and repeated measurements were compared by the Wilcoxon non-parametric test. The Pearson test was applied for correlation analysis. The level of confidence was set at 95\% $(p<0.05)$.

\section{Results}

Stressed mice showed a significant loss of body weight compared to the control mice $(p<0.0001, t=6.801, \mathrm{df}=21$; unpaired $t$-test; Fig.1A) and a significant elevation of circulating corticosterone concentration ( $p=0.030, U=39$; Mann-Whitney test, Fig.1B), indicating a profound impact of the two-week stress procedure. In comparison to control mice, the open-field activity of the stressed mice was significantly higher both in the peripheral ( $p=0.040, U=61.00$, Mann-Whitney test) and even more notably, in the central zones $(p=0.011 ; U=73.50)$ of the apparatus, when white lighting was employed (Fig.1C), but not when activity was scored under red light ( $p=0.15, U=68.00$ and $p=0.64, U=97.50$, respectively). There was a significantly lower latency to the first exit in the elevated O-maze ( $p=0.010, U=49.50$, Mann-Whitney test), increased time spent in the open arms $(p=0.020, U=55.50)$ and number of entries into the open arms ( $p=0.028, U=58.50 ;$ Fig.1D) in stressed versus control mice. Together, these data indicate differences in the brightly lit open field induced by stress: behavioural 
invigoration and an anomalous "anxiolytic-like" profile. In addition, chronically stressed mice displayed a significant increase in the number of attacks and no change in the latency to the first attack in the resident-intruder test ( $p=0.049, t=1.698, \mathrm{df}=30$ and $p=0.12, t=1.78, \mathrm{df}=23$; unpaired $t$-test; Fig.1E).

Both stressed and control mice showed a significant increase in the latency of step down $1 \mathrm{~h}$ after training, in comparison to baseline latencies $(p=0.033, W=-37.00$ and $p=0.05, W=-51.00$, respectively, Wilcoxon test). There was no significant difference between stressed and control mice in the latencies for step-down evaluated at baseline conditions ( $p=1.0, U=71.50$ ) or $1 \mathrm{~h}$ after training ( $p=0.98, U=71.00$; Fig.2A), indicating similar scores of anxiety-like behaviour and short-term memory in these groups. In the contextual fear-conditioning paradigm, stressed mice spent a significantly shorter time freezing during a recall session than the control group ( $p=0.021, U=50.00$, Mann-Whitney test; Fig.2B), which demonstrates impaired hippocampus-dependent contextual memory in this group. Stressed mice showed no significant inhibition of burrowing behaviour in comparison to the control group, as assessed by latency for the first pellet displacement ( $p=0.18, U=73.00$; Figure $2 \mathrm{C}$ ) and number of pellets displaced over time intervals of $0-60 \min (p=0.14, U=53.50)$ and 60-90 $\min (p=0.34, U=47.50$, Mann-Whitney test). Nonetheless, there was a significant correlation between the two latter measures and contextual freezing ( $r=$ $0.36, p=0.046$ and $r=0.36, p=0.048$, respectively). There was no significant correlation between the duration of freezing and the latency for pellet displacement $(r=-0.16 p$ $=0.39$, Pearson correlation).

Concerning mRNA levels of NMDA receptor subunits in the hippocampus, in comparison to control mice, the stressed group had a significant increase in expression of NR2A ( $p=0.029, t=2.050, \mathrm{df}=15$, unpaired $t$-test; Fig.3A) and no significant change in the expression of NR2B ( $p=0.27, t=0.6431, d f=15$, Fig.3B). The 
ratio of NR2A/NR2B was significantly increased ( $p=0.015, t=2.452, \mathrm{df}=13$; Fig.3C) but the expression of the NR1 subunit was unaltered ( $p=0.64, t=0.4665, d f=14 ;$ Fig.3D).

\section{Discussion}

In accordance with our hypothesis and in line with the literature (Cull-Candy et al., 2001; Fleischman et al., 2003; Li and Ju, 2012; Calabrese et al., 2013), the current study implicates altered expression of NMDAR subunits of the hippocampus in stress-induced deficits in both cognitive and emotional traits. The present study showed that in C57BL/6J mice, a two-week ethological stress paradigm, comprised of exposure to a rat and social defeat, resulted in the impairment of contextual fear conditioning, as well as behavioural disinhibition in the open field test and increased aggressive behaviour. These cognitive and emotional abnormalities were accompanied by increases in the hippocampal mRNA expression of the NR2A subunit of the NMDAR and in the NR2A/NR2B ratio, while the mRNA expression of NR2B and NR1 was unchanged.

A significant reduction in body weight and increase in basal serum corticosterone concentration of stressed mice demonstrated the impact of the two-week stress procedure (Fig.1A,1B). Stressed mice displayed behavioural hyperarousal under stressful testing conditions, as shown by a significant decrease in the time spent immobile in the central and peripheral parts of the brightly illuminated open field, but a lack of these changes during stress-free open field testing under red light (Fig.1C). Behavioural alterations of the stressed group in the open field illuminated with white light are in agreement with behavioural changes in these mice in the elevated O-maze. In the O-maze test, stressed mice showed a significant shortening of the latency to enter the open arms, an increase in the time spent and the number of entries into the open arms (Fig.1D). Together, these findings indicate that the stress procedure evoked anomalous "anxiolytic-like" traits and behavioural 
invigoration in mice. In our experiments, these changes were accompanied by a significant increase in the number of attacks by stressed mice in the resident-intruder paradigm, which is an indicator of enhanced aggressive traits (Fig.1E). This is in agreement with previous work showing that increased anxiety levels typically correlate with increased scores of aggressive behaviour in C57BL/6J male mice (Willner, 2005).

In line with our findings, different chronic stress procedures have been reported to cause an increase in time spent in anxiety-related compartments of the elevated plus maze and the dark/light box in rodents, which was interpreted as a sign of "anxiolyticlike" effects (D’Aquila et al., 1994; Cancela et al., 1995; Sanchez, 1997; Hata et al., 1999). Such phenomena, also considered as manifestations of impulsivity and disinhibition, are well-known consequences of chronic stress in rodents (Strekalova et al., 2005; Willner, 2005; Belujon and Grace, 2011). It is commonly accepted that the limbic system, in general, and the hippocampus, in particular, have a central role in the behavioural inhibition system (Gray and McNaughton, 1983; Rawlins et al., 1985; McNaughton et al., 1997; McNaughton and Gray, 2000; Geissler and Lesch, 2011; Abela and Chudasama, 2013), while the crucial role of the hippocampus for memory was established much earlier (Squire, 1992). Behavioural invigoration, such as during stress, is likely to be associated with alterations of other hippocampal functions, which may include learning processes and molecular changes related to gene expression regulating glutamatergic neurotransmission (Geissler and Lesch, 2011; Belujon and Grace, 2011; Calabrese et al., 2012). Thus, these potential changes were investigated in the present study.

Stressed mice had a normal acquisition of the short-term step-down avoidance task, a form of cortex-dependent learning, which was shown by their unaltered latencies to step-down (Fig.2A). However, a lower percentage of freezing during the recall session of the fear-conditioning test in stressed mice indicates a deficiency in their 
long-term hippocampus-dependent memory (Fig.2B). The possibility that a hyperactivity of chronically stressed mice in our study interferes with scoring of freezing was largely ruled out by a lack of differences in locomotor activity during a two-minute acclimatization pre-training period between stressed and control mice (Strekalova et al., 2003). Also, both groups had similar values for the baseline latencies of step down behaviour (Fig.2A) suggesting their comparable scores of anxiety-like traits that was assessed under testing conditions which were used to assess contextual learning. Baseline step-down behaviour was previously reported as a highly sensitive measure of subtle changes in anxiety and locomotion in C57BL/6J mice (Strekalova and Steinbusch, 2009, 2010; Vignisse et al., 2011, 2013).

The changes in contextual freezing significantly correlated with decreased burrowing behaviour, although burrowing parameters were not altered significantly (Figure 2C). A tendency to displace food pellets is often regarded as not a fully specific indicator of hippocampal dysfunction in rodents (Tarr et al., 2012; Hart et al., 2012; Kaczmarczyk et al., 2013) and its neurobiology is debatable. Hence the finding of a correlation between this behaviour and hippocampus-dependent learning in the present study might be potentially important in relating the burrowing behaviour to the dorsal hippocampus, as originally proposed (Deacon et al., 2002).

This study revealed stress-induced increases in the hippocampal expression of NR2A and the NR2A/NR2B ratio (Figure $3 A, C$ ), which were previously shown to accompany elevated anxiety (Boyce-Rustay and Holmes, 2006; Gao et al., 2010; Calabrese et al., 2013), impulsivity and aggression (Meyer et al., 2004; Bortolato et al., 2012), home cage hyperactivity and a stress-induced increase in peripheral concentrations of corticosterone (Longordo et al., 2009, 2011; Huang et al., 2010) in various conditions. A limitation of our study, however, is the need for confirmation that the mRNA changes result in corresponding changes in subunit protein levels and in altered synaptic function in the hippocampus. In agreement with our data, separate studies 
have reported that molecular changes such as we found are associated with a disruption of long-term memory, but not short-term learning (Huang et al., 2010; Cui et al., 2013; Calabrese et al., 2013). In the present experiment, mRNA expression of NR2B and the NR1 in the hippocampus was not significantly changed by stress (Fig.3). However, previous work has reported a significant decrease in NR2B expression in several brain areas during stress (Cull-Candy et al., 2001; Huang et al., 2010), aging (Dere et al., 2003) and compromised plasticity (Bortolato et al., 2012). Previous work has also reported a decrease in NR1 mRNA after stress (Cull-Candy et al., 2001; Schenberg et al., 2006). Discrepancies between our findings and others may be due to the different stress paradigms employed. However, previous work we have done in a gene expression profiling Illumina study (Integragen, Evry, France and Northwestern Chicago University, USA and Ingenuity Systems, Redwood city, CA, USA), using hippocampi obtained in a similar chronic stress model (Strekalova et al., 2011), suggests diminished expression of NR1 receptor subunit mRNA in stressed mice in particular, and speaks for systemic differences in the hippocampal glutamatergic receptors expression in these mice in general. In addition to NR1 expression results, these microarray data pointed to statistically significant changes in several elements of the glutamatergic system in the hippocampal formation of chronically stressed mice: NR2B receptor, AMPA receptor, glutamate metabotropic receptor 5, and in NR2A/NR2B ratio, which changes are overall in line with the outcome from mRNA evaluation in the current study. Remarkably, a segregation of stress-susceptible and stress-resilient individuals in the microarray study revealed differential expression of the above genes between the sub-groups that additionally supports functional importance of molecular changes in response to stress, obtained both in the microarray and mRNA experiments

In summary, this study demonstrates that elevated hippocampal expression in stressed mice of mRNAs for NR2A and of the NR2A/NR2B ratio, but not forNR2B and 
NR1, is associated with concomitant abnormalities in both cognitive and emotional elements that mimic one of the most characteristic consequences of experiencing chronic stress in humans. These data suggest that a paradigm comprising ethological stressors evokes behavioural disinhibition and molecular changes that likely mimic epidemiologically spread human syndromes associated with stress-related emotional and cognitive deficits. Thus, the stress paradigm employed in the present study can be useful for translational studies in the search for pharmacological compensation of these combined symptoms of stress-related pathologies.

\section{Acknowledgements}

We thank FP7 (AGGRESSOTYPE), ISAO 9051 to TS, RFBR 11-04-1411 as well as Dr. Claudia Oliveira (CBA, University of Lisbon) and Prof. Klimenko (RAS) for a support of this study. JLP holds a Chargé de Recherche position with Fonds de la Recherche Scientifique.

\section{Conflict of interests declaration}

All other authors declare that they have no conflicts of interest. 


\section{References}

Abela AR, Chudasama Y. 2013 Dissociable contributions of the ventral hippocampus and orbitofrontal cortex to decision-making with a delayed or uncertain outcome. Eur. J. Neurosci. 37: 640-647.

Belujon P, Grace AA. 2011 Hippocampus, amygdala, and stress: interacting systems that affect susceptibility to addiction. Ann N Y Acad Sci. 1216: 114-121.

Bortolato M, Godar SC, Melis M, Soggiu A, Roncada P, Casu A, Flore G, Chen K, Frau R, Urbani A, Castelli MP, Devoto P, Shih JC. 2012 NMDARs mediate the role of monoamine oxidase A in pathological aggression. J. Neurosci. 32: 8574-8582.

Boyce-Rustay JM, Holmes A. 2006 Genetic inactivation of the NMDA receptor NR2A subunit has anxiolytic- and antidepressant-like effects in mice. Neuropsychopharmacology 31: 2405-2414.

Calabrese F, Guidotti G, Molteni R, Racagni G, Mancini M, Riva MA. 2012 Stress-induced changes of hippocampal NMDA receptors: modulation by duloxetine treatment. PLoS One 7:e37916.

Cancela LM, Bregonzio C, Molina VA. 1995 Anxiolytic-like effect induced by chronic stress is reversed by naloxone pretreatment. Brain Res. Bull. 36: 209-213.

Cline BH, Steinbusch HW, Malin D, Revishchin AV, Pavlova GV, Cespuglio R, Strekalova T. 2012 The neuronal insulin sensitizer dicholine succinate reduces stress-induced depressive traits and memory deficit: possible role of insulin-like growth factor 2. BMC Neurosci. 13: 110.

Couch Y, Anthony DC, Dolgov O, Revischin A, Festoff B, Santos Al, Steinbusch HW, Strekalova T. 2013 Microglial activation, increased TNF and SERT expression in the prefrontal cortex define stress-altered behaviour in mice susceptible to anhedonia. Brain Behav. Immun. 29: 136-146.

Cui Z, Feng R, Jacobs S, Duan Y, Wang H, Cao X, Tsien JZ. 2013 Increased NR2A:NR2B ratio compresses long-term depression range and constrains long-term memory. Sci. Rep. 3:1036.

Cull-Candy S, Brickley S, Farrant M. 2001 NMDA receptor subunits: diversity, development and disease. Curr. Opin. Neurobiol. 11: 327-335.

D'Aquila P, Brain P, Willner P. 1994 Effects of chronic mild stress on performance in behavioral tests relevant to anxiety and depression. Physiol. Behav. 56: 861-867.

Davies DJ, Crowe M, Lucas N, Quinn J, Miller DD, Pritchard S, Grose D, Bettini E, Calcinaghi N, Virginio C, Abberley L, Goldsmith P, Michel AD, Chessell IP, Kew JN, Miller ND, Gunthorpe MJ. 2012 A novel series of benzimidazole NR2B-selective NMDA receptor antagonists. Bioorg. Med. Chem. Lett. 22: 2620-2623.

Deacon RM, Croucher A, Rawlins JN. 2002 Hippocampal cytotoxic lesion effects on species-typical behaviours in mice. Behav. Brain Res. 132: 203-213.

Dere E, Topic B, De Souza Silva MA, Fink H, Buddenberg T, Huston JP. 2003. NMDA-receptor antagonism via dextromethorphan and ifenprodil modulates graded anxiety test performance of C57BL/6 mice. Behav. Pharmacol. 14: 245-249.

Fleischmann A, Hvalby O, Jensen V, Strekalova T, Zacher C, Layer LE, Kvello A, Reschke M, Spanagel R, Sprengel R, Wagner EF, Gass P. 2003 Impaired long-term memory and NR2A-type NMDA receptordependent synaptic plasticity in mice lacking c-Fos in the CNS. J Neurosci. 23: 9116-9122. 
Gao C, Gill MB, Tronson NC, Guedea AL, Guzmán YF, Huh KH, Corcoran KA, Swanson GT, Radulovic J. 2010 Hippocampal NMDA receptor subunits differentially regulate fear memory formation and neuronal signal propagation. Hippocampus 20:1072-1082.

Geissler J, Lesch KP. 2011 A lifetime of attention-deficit/hyperactivity disorder: diagnostic challenges, treatment and neurobiological mechanisms. Expert Rev. Neurother. 11: 1467-1484.

Gray JA, McNaughton N. 1983 Comparison between the behavioural effects of septal and hippocampal lesions: a review. Neurosci. Biobehav. Rev. 7:119-188.

Hart AD, Wyttenbach A, Perry VH, Teeling JL. 2012 Age related changes in microglial phenotype vary between CNS regions: grey versus white matter differences. Brain Behav. Immun. 26: 754-765.

Hata T, Nishikawa H, Itoh E, Funakami Y. 2001 Anxiety-like behavior in elevated plus-maze in repeatedly cold stressed mice. Jpn. J. Pharmacol. 85: 189-196.

Huang Y, Shi X, Xu H, Yang H, Chen T, Chen S, Chen X. 2010 Chronic Unpredictable Stress Before pregnancy reduce the expression of BDNF and NMDAr in hippocampus of offspring rats associated with impairment of memory. Neurochem. Res. 35:1038-1049.

Kaczmarczyk MM, Machaj AS, Chiu GS, Lawson MA, Gainey SJ, York JM, Meling DD, Martin SA, Kwakwa KA, Newman AF, Woods JA, Kelley KW, Wang Y, Miller MJ, Freund GG. 2013 Methylphenidate prevents high-fat diet (HFD)-induced learning/memory impairment in juvenile mice. Psychoneuroendocrinology 38: 1553-1564.

Li F, Tsien JZ. 2009 Memory and the NMDA receptors. N. Engl. J. Med. 361: 302-303., 2012 Functional roles of synaptic and extrasynaptic NMDA receptors in physiological and pathological neuronal activities. Curr. Drug. Targets 13: 207-221.

Livak KJ, Schmittgen TD. 2001 Analysis of relative gene expression data using real-time quantitative

Longordo F, Kopp C, Mishina M, Luján R, Lüthi A. 2009 NR2A at CA1 synapses is obligatory for the susceptibility of hippocampal plasticity to sleep loss. J. Neurosci. 29: 9026-9041.

Malatynska E, Steinbusch HW, Redkozubova O, Bolkunov A, Kubatiev A, Yeritsyan NB, Vignisse J, Bachurin S, Strekalova T. 2012 Anhedonic-like traits and lack of affective deficits in 18-month-old C57BL/6 mice: Implications for modeling elderly depression. Exp. Gerontol. 47: 552-564.

McNaughton N, Gray JA. 2000 Anxiolytic action on the behavioural inhibition system implies multiple types of arousal contribute to anxiety. J. Affect Disord. 61:161-176.

McNaughton NC, Leach MJ, Hainsworth AH, Randall AD. 1997 Inhibition of human N-type voltage-gated Ca2+ channels by the neuroprotective agent BW619C89. Neuropharmacology 36: 1795-1798.

Meyer WN, Korzan WJ, Summers CH. 2004 Social stress and corticosterone regionally upregulate limbic $\mathrm{N}$-methyl-D-aspartatereceptor (NR) subunit type NR(2A) and NR(2B) in the lizard Anolis carolinensis. Neuroscience 128: 675-684.

Pawluski JL, Valença A, Santos Al, Costa-Nunes JP, Steinbusch HW, Strekalova T. 2012 Pregnancy or stress decrease complexity of CA3 pyramidal neurons in the hippocampus of adult female rats. Neuroscience 227: 201-210.

Rawlins JN, Feldon J, Ursin H, Gray JA. 1985 Resistance to extinction after schedules of partial delay or partial reinforcement in rats with hippocampal lesions. Exp. Brain Res. 59: 273-281. 
Sanchez C. 1997 Acute stress enhances anxiolytic-like drug responses of mice tested in a black and white test box. Eur. Neuropsychopharmacol. 7: 283-288.

Schenberg EE, Ferreira TL, Figueiredo LZ, Hipólide DC, Nóbrega JN, Oliveira MG. 2006 Fear conditioning and NMDA receptor subtypes: NR2A differential expression in the striatum. Brain Res. Bull. 69: 440-446.

Squire LR. 1992 Memory and the hippocampus: a synthesis from findings with rats, monkeys, and humans. Psychol. Rev. 99: 195-231.

Strekalova T, Wotjak CT, Schachner M. 2001 Intrahippocampal administration of an antibody against the HNK-1 carbohydrate impairs memory consolidation in an inhibitory learning task in mice. Mol. Cell. Neurosci. 17: 1102-1113.

Strekalova T, Zörner B, Zacher C, Sadovska G, Herdegen T, Gass P. 2003 Memory retrieval after contextual fear conditioning induces c-Fos and JunB expression in CA1 hippocampus. Genes Brain Behav. 2: 3-10.

Strekalova T, Spanagel R, Bartsch D, Henn FA, Gass P. 2004 Stress-induced anhedonia in mice is associated with deficits in forced swimming and exploration. Neuropsychopharmacology 29: 2007-2017.

Strekalova T, Spanagel R, Dolgov O, Bartsch D. 2005 Stress-induced hyperlocomotion as a confounding factor in anxiety and depression models in mice. Behav. Pharmacol. 16: 171-180.

Strekalova T, Steinbusch H. 2009 Factors of reproducibility of stress-induced anhedonia in chronic stress depression models in mice. In: Mood and Anxiety related phenotypes in mice: characterization using behavioral tests. T. Gould (Ed). Humana Press, Totowa, NJ. Pp. 153-176.

Strekalova T, Steinbusch HW. 2010 Measuring behavior in mice with chronic stress depression paradigm. Prog. Neuropsychopharmacol Biol. Psychiatry 34: 348-361.

Strekalova T, Couch Y, Kholod N, Boyks M, Malin D, Leprince P, Steinbusch HWM. 2011 Update in the methodology of the chronic stress paradigm: internal control matters. Behav. Brain Funct. 7: 9.

Tarr AJ, Chen Q, Wang Y, Sheridan JF, Quan N. 2012 Neural and behavioral responses to low-grade inflammation. Behav. Brain Res. 235: 334-341.

Tsang SW, Vinters HV, Cummings JL, Wong PT, Chen CP, Lai MK. 2008 Alterations in NMDA receptor subunit densities and ligand binding to glycine recognition sites are associated with chronic anxiety in Alzheimer's disease. Neurobiol. Aging 29: 1524-1532.

Vignisse J, Steinbusch HW, Bolkunov A, Nunes J, Santos Al, Grandfils C, Bachurin S, Strekalova T. 2011 Dimebon enhances hippocampus-dependent learning in both appetitive and inhibitory memory tasks in mice. Prog Neuropsychopharmacol Biol Psychiatry 35: 510-522.

Vignisse J, Steinbusch HWM, Grigoriev V, Bolkunov A, Proshin A, Bettendorff L, Bachurin S, Strekalova T. 2013 Concomitant manipulation of NMDA- and AMPA-receptors to produce pro-cognitive drug effects in mice. Eur. Neuropsychopharmacol. (in press).

Willner P. 2005 Chronic mild stress (CMS) revisited: consistency and behavioural neurobiological concordance in the effects of CMS. Neuropsychobiology 52: 90-110. 


\section{Figure legends}

Figure 1. Exposure of mice to stressors for two weeks affects body weight, serum corticosterone and parameters of emotionality. (A) Weight loss and (B) increased serum corticosterone concentration in the stress group. (C) Stressed mice showed a reduced total time spent immobile at the periphery and in the centre of the open field lit with white light. There were no significant differences in locomotor behaviour between groups tested under red light. (D) Stressed mice displayed decreased latency of entries into the open arms, an increased time spent therein and increased number of entries. (E) Elevated aggressive behavior (number of attacks) in stressed mice. ${ }^{*} p<0.05$ vs. control (A,E: unpaired $t$-test, B-D: Mann-Whitney test). Control group, $n=10$; stress group, $n=22$. All data are means \pm standard error of the mean (SEM).

Figure 2. Hippocampus-dependent performance in stressed mice. (A) Stressed and control mice showed a significant increase in the latency for step down $1 \mathrm{~h}$ after training, in comparison to baseline latencies; ${ }^{*} p>0.05$ vs. baseline, Wilcoxon test; there were no differences between groups. (B) Stressed mice spent a significantly shorter time freezing, during a recall session in the fear-conditioning paradigm; (C) there were no significant differences for latency to food displacement or number of pellets displaced at 0-60 min and 60-90 $\mathrm{min}$ in the tube test. ${ }^{*} p<0.05$ vs. control; Mann-Whitney test. Control group, $\mathrm{n}=10$; stress group, $n=22$. All data are means \pm the standard error of the mean (SEM).

Figure 3. Hippocampal expression of mRNAs for N-methyl-D-aspartate receptor (NMDAR) subunits in stressed mice. In the stressed group, relative to controls: (A) mRNA expression of the NR2A subunit of the NMDAR was significantly greater; (B) mRNA expression of NR2B was not altered; (C) the ratio of mRNAs for NR2A/NR2B was significantly increased; (D) mRNA expression of the NR1 subunit of NMDAR was not altered; ${ }^{*} p<0.05$ vs. control; unpaired $t$ test. Control group, $n=9$; stress group, $n=12$. Data are means \pm the standard error of the mean (SEM). 
A BODY WEIGHT

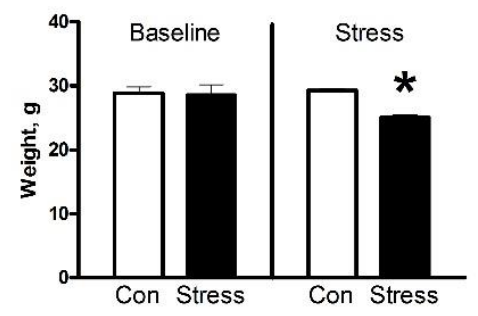

C OPEN FIELD 25 LUX

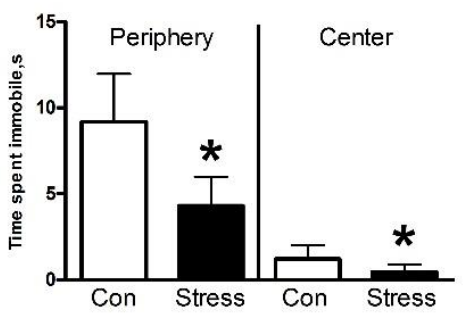

\section{B PLASMA CORT}

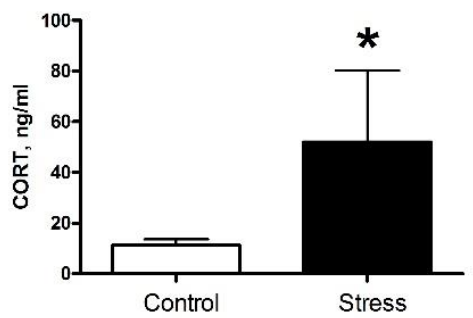

\section{OPEN FIELD RED LIGHT}

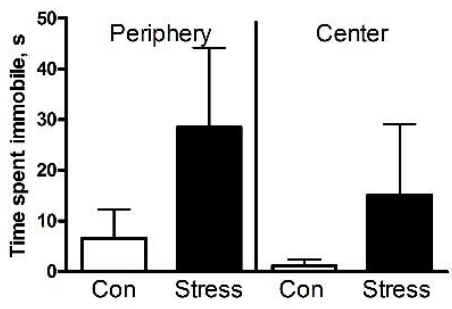

D elevated O-MAZE
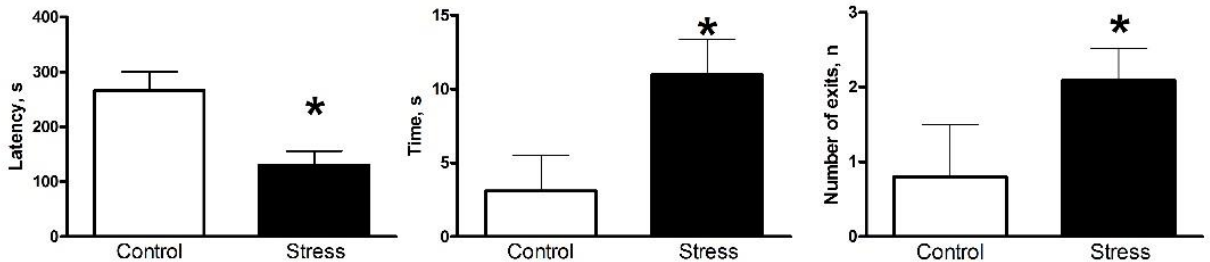

E RESIDENT-INTRUDER TEST
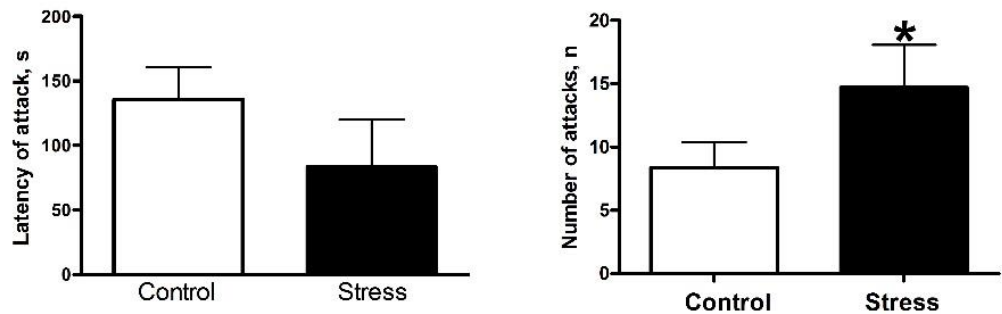

Figure 1 
A STEP-DOWN AVOIDANCE

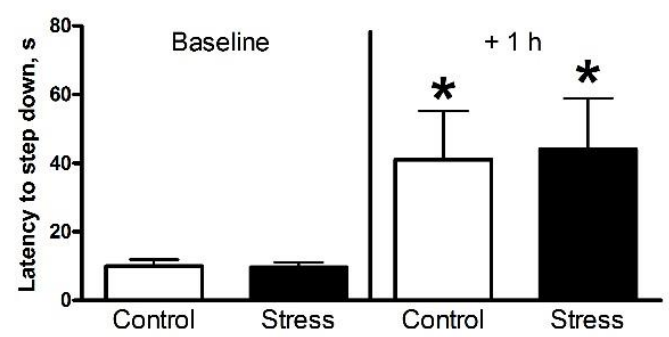

C tubetest
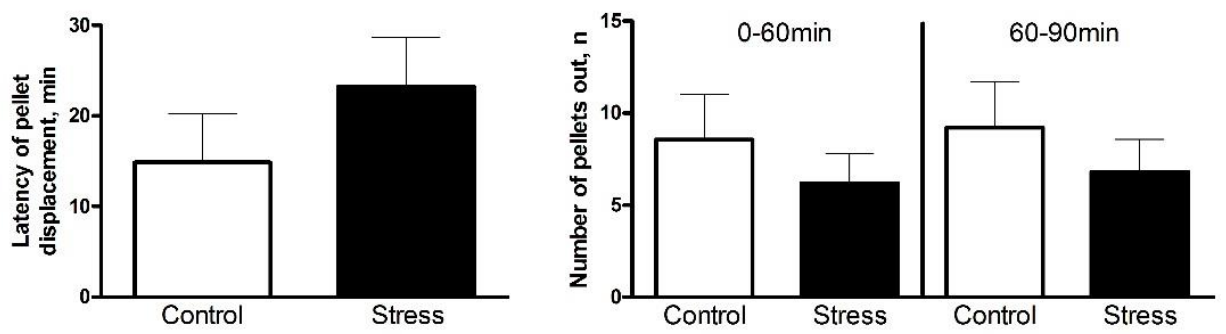

Figure 2
B FEAR CONDITIONING

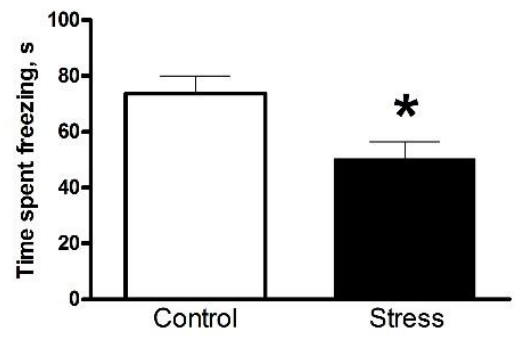


A NR2A

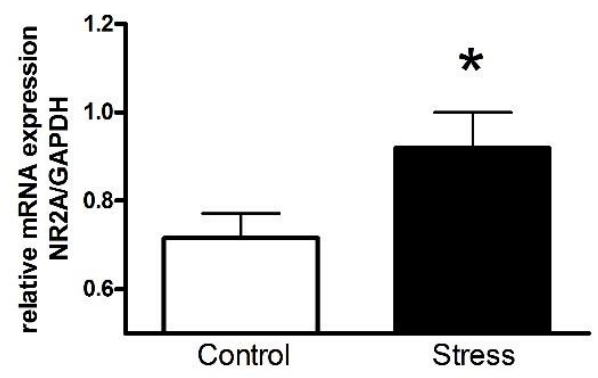

C NR2A/NR2B

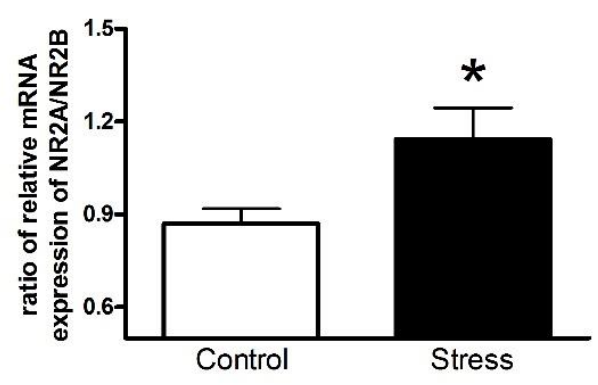

B NR2B

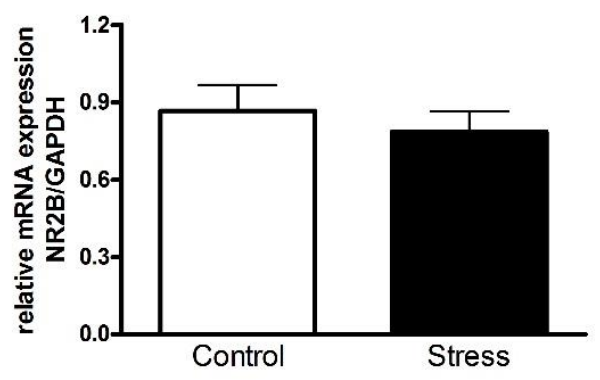

D NR1

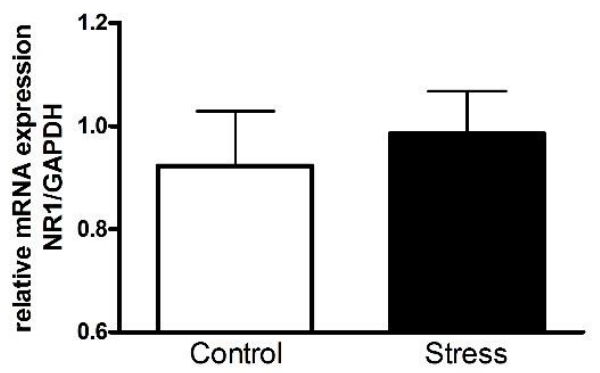

Figure 3 


\section{Supplementary material}

Table 1 - Cycling conditions and sequences of primers used in the RT PCR assay.

\begin{tabular}{|c|c|c|c|}
\hline $\begin{array}{l}\text { mRNA } \\
\text { target }\end{array}$ & Primer sequen & $\left.\rightarrow 3^{\prime}\right)$ & $\begin{array}{l}\text { Annealing } \\
\text { Temperature }\left(C^{\circ}\right)\end{array}$ \\
\hline \multirow[t]{3}{*}{ NR1 } & Forward & GTTCTTCCGCTCCGGCTTTG & \multirow[t]{3}{*}{58} \\
\hline & Reverse & AGGGACACATTTTGCTTCCA & \\
\hline & TaqManProbe & 6-FAM CGGCATGCGCAAGGACAGCC BHQ-1 & \\
\hline \multirow[t]{3}{*}{ NR2A } & Forward & GCTACACACTCTGCACCAATT & \multirow[t]{3}{*}{64} \\
\hline & Reverse & CACCTGATAGCCTTCCTCAGTGA & \\
\hline & TaqManProbe & 6-FAM TGGTCAATGTGACTTGGGATGGCAABHQ-1 & \\
\hline \multirow[t]{3}{*}{ NR2B } & Forward & CTGCATGCGGAATACAGTC & \multirow[t]{3}{*}{56} \\
\hline & Reverse & TTGATGTAGCCTGGTTCCT & \\
\hline & TaqManProbe & 6-FAM CAGAAGCGCATCATCTCTGAGAATBHQ-1 & \\
\hline \multirow[t]{3}{*}{ GAPDH } & Forward & TGCACCACCAACTGCTTAG & \multirow[t]{3}{*}{54} \\
\hline & Reverse & GGATGCAGGGATGATGTTC & \\
\hline & TaqManProbe & HEX ATCACGCCACAGCTTTCCAGA BHQ-1 & \\
\hline
\end{tabular}

The qPCR was performed in a $25 \mu \mathrm{l}$ reaction volume containing a 10xPCR Buffer $(2.5 \mu \mathrm{l}), 25$ $\mathrm{mmol} \mathrm{MgCl2}(4 \mu \mathrm{l}), 10 \mathrm{mmol}$ dNTPs $(2 \mu \mathrm{l})$, specific forward and reverse primers at $20 \mathrm{pmol} / \mathrm{l}$ concentration $(1 \mu \mathrm{l})$, $5 \mathrm{pmol} / \mathrm{I}$ Taq Man probe $(1.5 \mu \mathrm{l})$, cDNA (2 $\mu \mathrm{l}), 5 \mathrm{u} / \mathrm{l}$ Taq DNA polymerase $(1 \mu l)$ (Beagle, st. Petersburg, Russia), and ddH2O (10 I). All samples were run in duplicate. Cycling was performed at $95 \mathrm{C}^{\circ}$ for $5 \mathrm{~min}$ followed by a 45 -cycle amplification at $95^{\circ} \mathrm{C}$ for $10 \mathrm{~s}$, then at the annealing temperature for $15 \mathrm{~s}$ and at the temperature $72^{\circ} \mathrm{C}$ for $20 \mathrm{~s}$. 
Chapter 3. 



\section{Chapter 3}

\section{Dicholine succinate, the neuronal insulin sensitizer, normalizes behaviour, REM sleep, hippocampal pGSK3B and mRNAs of NMDA receptor subunits in mouse models of depression}

Costa-Nunes $\mathrm{JP}^{1,2^{*}}$, Cline $\mathrm{BH}^{3,{ }^{*}}$, Cespuglio $\mathrm{R}^{4}$, Markova $\mathrm{N}^{5,6}$, Santos $\mathrm{Al}^{7}$, Bukhman $\mathrm{YV}^{6}$, Kubatiev $A^{6,7}$, Steinbusch $\mathrm{HWM}^{1}$, Lesch $\mathrm{K}^{1,9}$, Strekalova $\mathrm{T}^{1,2,5}$.

*Co-first authorship

${ }^{1}$ Department of Neuroscience, Maastricht University Maastricht, Netherlands; 'Group of Behavioural Neuroscience and Pharmacology, Institute for Hygiene and Tropical Medicine, New University of Lisbon Lisbon, Portugal.; ${ }^{3}$ Faculté de Médecine, INSERM U1119, Université de Strasbourg Strasbourg, France. ${ }^{4}$ Faculty of Medicine, INSERM U1028, C. Bernard University, Lyon, France. ${ }^{5}$ Institute of Physiologically Active Compounds, Russian Academy of Sciences, Moscow, Russia; ${ }^{6}$ Institute of General Pathology and Pathophysiology, Russian Academy of Medical Sciences Moscow, Russia; ${ }^{7}$ Faculdade de Ciências Médicas, NOVA Medical School, Universidade Nova de Lisboa Lisboa, Portugal. ${ }^{8}$ Great Lakes Bioenergy Research Center, University of Wisconsin, Madison, USA. ${ }^{9}$ Division of Molecular Psychiatry, Centre of Mental Health, University of Wuerzburg Wuerzburg, Germany

Frontiers in. Behavioural. Neuroscience 2015, 9:37. 


\section{Abstract}

Central insulin receptor-mediated signalling is attracting the growing attention of researchers because of rapidly accumulating evidence implicating it in the mechanisms of plasticity, stress response and neuropsychiatric disorders including depression. Dicholine succinate (DS), a mitochondrial complex II substrate, was shown to enhance insulin-receptor mediated signaling in neurons and is regarded as a sensitizer of the neuronal insulin receptor. Compounds enhancing neuronal insulin receptor-mediated transmission exert an antidepressant-like effect in several preclinical paradigms of depression; similarly, such properties for DS were found with a stress-induced anhedonia model. Here, we additionally studied the effects of DS on several variables which were ameliorated by other insulin receptor sensitizers in mice. Pre-treatment with DS of chronically stressed C57BL6 mice rescued normal contextual fear conditioning, hippocampal gene expression of NMDA receptor subunit NR2A, the NR2A/NR2B ratio and increased REM sleep rebound after acute predation. In 18-month-old C57BL6 mice, a model of elderly depression, DS restored normal sucrose preference and activated the expression of neural plasticity factors in the hippocampus as shown by Illumina microarray. Finally, young naïve DS-treated C57BL6 mice had reduced depressive- and anxiety-like behaviours and, similarly to imipramine-treated mice, preserved hippocampal levels of the phosphorylated (inactive) form of GSK-3 $\beta$ that was lowered by forced swimming in pharmacologically naïve animals. Thus, DS can ameliorate behavioural and molecular outcomes under a variety of stress- and depression-related conditions. This further highlights neuronal insulin signalling as a new factor of pathogenesis and a potential pharmacotherapy of affective pathologies.

Key words: chronic stress; insulin receptor; dicholine succinate; phosphorylated glycogen synthase kinase-3beta ( $p$ GSK-3 $\beta$ ); NMDA receptor subunits NR2A and NR2B; sleep EEG; aging; hippocampal plasticity. 


\section{Introduction}

Central insulin receptor signalling is important in brain function/dysfunction including cognitive disorders, stress response and depression. As a member of a subfamily of receptor tyrosine kinases, the neuronal insulin receptor has been shown to be involved in synaptic plasticity, cell differentiation, myelination and survival (Chiu et al., 2008; Huang et al., 2010a, Lin et al., 2010) and metabolic processes (Govind et al., 2001; Zhao and Alkon, 2001; Freude et al., 2008). Insulin signalling has been found to regulate dopamine-mediated neurotransmission (Williams et al., 2007) and extracellular levels of norepinephrine and serotonin (Daws et al., 2009). The robust density of the neuronal insulin receptor in the hippocampus and cerebral cortex (Mufson et al., 1999; Sun et al., 2010) and its high structural homology in the activation loop segment with TrkB suggest its role in stress response (Krishnan et al., 2007; Kikusui et al., 2009; Spencer et al., 2010). Compromised insulin signalling can result in cognitive deficits (van der Heide et al., 2006; Kuhad et al., 2009), neurodegeneration (Pomytkin, 2012) and depressive-like syndrome (Banks et al., 2012; Gold et al., 2013; Pan et al., 2013).

The latest clinical and translational studies have revealed antidepressant-like effects, increased neuronal mitochondrial biogenesis, decreased neuronal damage and antiinflammatory properties for compounds that potentiate the binding of insulin to its receptor or its immediate molecular consequences via various mechanisms and are therefore called "sensitizers of the neuronal insulin receptor" (Igarashi et al., 2008; Storozheva et al., 2008; Storozhevykh et al., 2008; Eissa Ahmed et al., 2009; Mittal et al., 2009; Rasgon et al., 2010; Kemp et al., 2011). Such effects were reported for the thiazolidinediones rosiglitazone and pioglitazone (Saubermann et al., 2002; Ali et al., 2006; Zhao et al., 2006; Asghar et al., 2007; Strum et al., 2007; Eissa Ahmed et al., 2009; Mittal et al., 2009; Rasgon et al., 2010; Kemp et al., 2011). For instance, rosiglitazone, one of the insulin sensitizers of the thiazolidinedione class, induces an 
antidepressant-like effect in the tail suspension and forced swim tests in mice, reducing immobilization and floating behaviour (Eissa-Ahmed et al., 2009). Similar effects were found for pioglitazone, another insulin receptor sensitizer, which were shown to be NMDA receptor-dependent (Sharma et al., 2012; Salehi-Sadaghiani et al., 2012). Rosiglitazone and pioglitazone were reported to be effective in the treatment of major depressive disorder that was refractory to standard antidepressant treatment and accompanied by insulin resistance (Rasgon et al., 2010; Kemp et al., 2011).

The antidepressant-like effects were also reported for a mitochondrial complex II substrate, Dicholine Succinate (DS) (Cline et al., 2012; Costa-Nunes et al., 2012, 2015). DS was found to dose-dependently stimulate insulin-dependent $\mathrm{H}_{2} \mathrm{O}_{2}$ production of the mitochondrial respiratory chain in cerebellar neurons leading to an enhancement of the insulin receptor via insulin-stimulated autophosphorylation of the insulin receptor kinase at tyrosine residues in neurons, which is a key regulatory event of the insulin receptor function. The effect of DS is dependent on the presence of insulin (Storozheva et al., 2008; Storozhevykh et al., 2008; Shomaker et al., 2010; Persiyantseva et al., 2013).

Our previous studies utilizing a mouse depression model where a depressive-like state is induced by chronic stress and defined by a reduction in reward sensitivity, anhedonia, showed the antidepressant- and anti-anxiety effects of DS in CD1 mice (Cline et al., 2012). As for instance, chronic intraperitoneal administration of DS for seven days, at $25 \mathrm{mg} / \mathrm{kg} /$ day before the onset of a 10-day stress, rescued normal sucrose preference, floating and step-down avoidance learning, as well as hippocampal expression of Insulin-like Growth Factor 2 (IGF-2), a member of the insulin gene family with neurotrophic properties (Chen et al., 2011; Bracko et al., 2012; Basta-Kaim et al., 2014). In other experiments, administration of DS for seven days in mice at similar doses rescued aging-related decreases of brain $\mathrm{N}$ - 
acetylaspartate/creatine, a marker of neuronal function and viability and the acquisition of hippocampus-dependent tasks in rat models of chronic cerebral hypoperfusion and beta-amyloid peptide-(25-35)-induced toxicity (Storozheva et al., 2008).

Meanwhile, the antidepressant effects of DS were not assessed in other than chronic stress depression model, e.g., in models that mimic a state of learned helplessness which is distinct from hedonic deficit and an important feature of depression (Porsolt and Papp, 1998). Moreover, the possibility might exist that the antidepressant effects of DS could be limited by the conditions induced by stress and will not preclude other origins / manifestations of a depressive-like syndrome. However, the above mentioned efficacy of other insulin receptor sensitizers with regard to measures of helpless behaviour, e.g., in the tail suspension and forced swim test, and the ameliorative effects of DS in aged rodents suggest the efficacy of DS in a variety of experimental conditions. Based on this, the current study's objectives were to examine the effects of DS on several behavioural, molecular and EEG variables that were previously characterized as biological correlates of depressive state and adaptive response to stress in mice.

In the first experiment, using a model of stress-induced anhedonia (Cline et al., 2014; Costa-Nunes et al., 2014) we investigated whether a pre-treatment in C57BL6J mice with DS, at the dose of $25 \mathrm{mg} / \mathrm{kg} /$ day intraperitoneally for seven days, would improve normal sleep rebound (augmentation) following acute stress, a sign of adaptive stress response (Marinesco et al., 1999; Suchecki et al., 2012; Keshavarzy et al., 2014; Albu et al., 2014), as well as contextual fear conditioning learning that is regarded to be related to the adaptive sleep function (Rolls et al., 2013; Barnes and Wilson, 2014). Also, we studied hippocampal gene expression of NMDA receptor subunit NR2A and the ratio of NR2A/NR2B, whose increases were previously demonstrated to accompany a development of stress-induced anhedonia in the here applied chronic 
stress model (Costa-Nunes et al., 2014). Notably, changes in the NMDA-receptor mediated transmission were shown to underlie the antidepressant effects of the neuronal insulin sensitizer pioglitazone (Salehi-Sadaghiami et al., 2012).

Next, we have examined the potential antidepressant-like effects of DS in a recently validated model of elderly depression, where naïve 18-month-old C57BL6 exhibit hedonic deficit in a sucrose test, which is reversible by drugs with antidepressant and neuroprotective activity (Malatynska et al., 2012). The effects of 7-day intraperitoneal injections of DS at the dose of $25 \mathrm{mg} / \mathrm{kg} /$ day to aged mice were assessed in the sucrose test and Illumina assay of gene expression profiling of the hippocampus and prefrontal cortex.

Finally, we applied a two-week administration of DS via drinking water at two doses of 25 and $75 \mathrm{mg} / \mathrm{kg} / \mathrm{day}$, in young naïve C57BL6J mice, and tested them in two-day forced swim test. The latter treatment group of mice was also investigated in the novel cage and elevated O-maze, to assess potential changes in their depressive- and anxiety-like behaviours, as well as locomotion / exploration. A two-week dosing with imipramine via drinking water ( 2.5 and $15 \mathrm{mg} / \mathrm{kg} /$ day) was used as a reference antidepressant treatment in the forced swim test. Additionally, hippocampal levels of the phosphorylated (inactive) form of Glycogen synthase kinase-3beta ( $p$ GSK-3ß), a previously determined marker of depressive-like behaviour and antidepressant activity in the forced swim test (Markova et al., 2013a, 2014), were evaluated after the exposure of mice to forced swimming and treatment with DS at the dose of 75 $\mathrm{mg} / \mathrm{kg} /$ day or imipramine at the dose of $15 \mathrm{mg} / \mathrm{kg} /$ day.

\section{Materials and Methods}

\section{Animals}

Studies were performed using 3.5-month-old male C57BL/6J mice. 3.5-month-old male CD1 mice were used for resident-intruder for social defeat paradigms and 2-5- 
month-old Wistar rats were used for predator stress. All animals were from the Gulbenkian Institute of Science, Oeiras, Portugal. C57BL/6J mice were housed individually for fourteen days before the start of experiments; CD1 mice and rats were housed in groups of five before the experiment and then individually. All animals were under a reversed 12-hour light-dark cycle (lights on: 21:00 h) starting from the day of animals' transportation in the laboratory, with food and water ad libitum, under controllable laboratory conditions $\left(22 \pm 1^{\circ} \mathrm{C}, 55 \%\right.$ humidity).

All studies were carried out in accordance with the European Communities Council Directive for the care and use of laboratory animals. A licence BH-2007 had been issued by the Ethics Committee on Animal Experimentation of Claude Bernard University of Lyon, in compliance with the decree No.: 03-505-2008 of the French Agriculture Ministry; permission 0421/000/000/2013 was issued by General Directory of Ethical Committee of the New University of Lisbon, in accordance with Portuguese Law-Decrees DL129/92 (July 6th), DL197/96 (October 16th) and Ordinance Port.131/97 (November 7th). This study had been also approved by the ethics committee of Maastricht University for animal research: CPV, DEC-UM 2009109.

Study design with chronic stress depression model and EEG analysis of sleep Chronic Stress Procedure and Behavioural Testing: Chronic stress and behavioural tests associated with its analysis were performed as described previously (Strekalova et al., 2011, 2014; Couch et al., 2013). Mice assigned to the stress group were injected with DS ( $n=20 ; 25 \mathrm{mg} / \mathrm{kg} /$ day, i.p.) or vehicle ( $\mathrm{n}=19$; see below) during 1 week prior the stress procedure as described elsewhere (Cline et al., 2012). Control mice $(n=7)$ were not treated. Animals were assigned to three experimental conditions and had similar body weight and baseline sucrose preference (Fig.2A). Briefly, animals were exposed to 10 days of chronic unpredictable stress followed by behavioural testing using a two-bottle sucrose preference test (performed on Day 11; see below), 
as well as a contextual fear conditioning learning task (performed on Days 12 and 13) that was carried out as described previously (Strekalova et al., 2003; Vignisse et al., 2014; see below). 24 hrs after the termination of behavioural testing, on Day 14, a fraction of stressed vehicle- $(n=8)$, DS-treated $(n=6)$ and control $(n=7)$ mice, were sacrificed for brain dissection and subsequent RT PCR analysis of NMDA receptor subunits NR2A and NR2B. Another fraction of stressed vehicle- $(n=7)$, DS-treated $(n=6)$ mice were subjected to a sleep rebound paradigm and EEG recording (see below, Fig.1A). Remaining mice were used for other assays not reported in the current work. In addition, non-stressed mice that either received DS or not ( $\mathrm{n}=15$ in each group) were studied in a sucrose preference test before and after ten days following the dosing with DS was performed as described above.

The chronic stress procedure employed in this study comprised night time rat exposure and day time application of two of three stressors: a social defeat, restraint stress and tail suspension, a combination of which was applied in a semi-random manner (Fig.1B; Couch et al., 2013). Briefly, between the hours of 09:00 and 18:00 two stressors per day were employed in the following sequence: social defeat for 30 minutes, restraint stress for 2 hours and tail suspension for 40 minutes with an intersession interval of at least 4 hours. This procedure induces anhedonia in a considerably shorter time than previously validated models by increasing the daytime stress load. Details of rat exposure and chronic stressors can be found in supplementary materials.

Sleep rebound paradigm and EEG recording: One week after the termination of stress procedure, another fraction of vehicle-injected control and chronically stressed animals received surgically implanted electrodes. Animals were anaesthetised using a ketamine-xylazine mixture (respectively, 4 and $75 \mathrm{mg} / \mathrm{kg}$, i.p.), placed in a stereotaxic frame and body temperature was maintained at $36.5-37^{\circ} \mathrm{C}$ by use of a homoeothermic blanket. Two electrodes (length, $2 \mathrm{~mm}$; diameter, $500 \mu \mathrm{m}$; both 
stainless steel and connected to Teflon-insulated wires) were placed into the left and right frontal cortices ( $2 \mathrm{~mm}$ lateral and anterior to Bregma (Cespuglio et al., 1999). Two additive electrodes were placed into the left and right parietal cortices ( $2 \mathrm{~mm}$ lateral to the midline at the midpoint between Bregma and lambda (Cespuglio et al., 1999) for electroencephalographic recordings (EEGs). To obtain electromyograms (EMGs), three electrodes (active length, $1 \mathrm{~mm}$; diameter, $500 \mu \mathrm{m}$, all stainless steel and connected to Teflon-insulated iron wires) were inserted between two neck muscle layers. After placement, all electrodes were soldered to two miniature fivepin connectors (Sei 3D, Lyon, France) and the entire assembly anchored to the skull using Super-Bond glue (Sun Medical, Co., Shiga, Japan) and dental acrylic resin (Ivoclar, Lyon, France). Together, four electrodes were implanted within the frontal and parietal cortex, and one electrode in the neck muscle.

After one week of recovery that was combined with an acclimatization procedure to the EEG recording chambers, where mice were connected to recording cables and placed individually in plastic cages in a sound-insulated room (ambient temperature, $22 \pm 1^{\circ} \mathrm{C}$; light-dark cycle $12 \mathrm{~h}-12 \mathrm{~h}$, water and food ad libitum). Thereafter, starting at 16.00, 48-h EEG polysomnographic recordings (Embla, Medcare, Iceland) were performed in these mice during baseline conditions and immediately following the 6-h rat exposure stress (from 10.00 to 16.00) as previously described (Couch et al., under revision).

For acute predation stress, mice were introduced into specialized cylindrical containers allowing visual and odour contact (Costa-Nunes et al., 2014), which were placed into the rat home cage. Visual scoring of digitized EEG and EMG traces (EEG filtering 0.5-49.9 Hz and EMG filtering 15-49.9 Hz) was performed over 10 second bins to quantify the number and duration of sleep-wake episodes and the circadian scheduling of sleep-wake states as described elsewhere (Cespuglio et al., 2012; Strekalova et al., 2014). EEG power spectra (Somnologica software, Medcare, Iceland) 
were also characterized. To this end, EEG traces sampled at $100 \mathrm{~Hz}$ were subjected to fast-Fourier transformation (256 points, computational window 2.56s, and 50\% overlap). Spectra were averaged over 10 second bins and divided into five adjacent bands: delta, $0.5-4 \mathrm{~Hz}$; theta, $4-8 \mathrm{~Hz}$, alpha, $8-11.5 \mathrm{~Hz}$, sigma, $11.5-14.5 \mathrm{~Hz}$; beta-1, $14.5-18.6 \mathrm{~Hz}$, and beta-2, $18.6-30 \mathrm{~Hz}$, and expressed as percentages of total band power $(0-49.9 \mathrm{~Hz})$.

The duration of slow wave sleep (SWS) and Rapid Eye Movement (REM) sleep was averaged for 48-h baseline and 48-h after-challenge periods for each animal. Because of well-known inter-individual variability in sleep parameters of rodents, to evaluate the effects of a predation stress, the EEG data for that period were expressed in percent from the averaged baseline for each mouse, as described earlier (Cespuglio et al., 2012; Strekalova et al., 2014).

\section{Study design with model of elderly depression}

In this experiment, we examined the potential effects of DS on the consumption of palatable $1 \%$-sucrose solution by old mice using a two-bottle sucrose preference test. A decrease in sucrose intake and preference over water is generally taken as a putative sign of anhedonia in rodents (Willner, 2005; Harro et al., 2011) and was shown to be decreased in 18-month-old C57BL6 mice; imipramine and the neuroprotective drug dimebon were shown to reverse this deficit (Malatynska et al., 2012). It was investigated whether DS administered to 18-month-old mice ( $n=9)$ for 1 week at the dose $25 \mathrm{mg} / \mathrm{kg} /$ day would affect the parameters of the sucrose preference test, in comparison with a group of mice of the same age that did not receive such a treatment $(n=8)$. The dose of DS was based on previous studies with CD1 mice, in which its administration, with the above-indicated dosing scheme, effectively reduced the stress-induced decrease in sucrose intake and preference, floating behaviour and alteration of hippocampal gene expression typical of the subgroup of mice susceptible to anhedonia (Cline et al., 2012). $24 \mathrm{~h}$ after the 
termination of the sucrose test, mice were sacrificed and their hippocampal formation and prefrontal cortex were isolated for subsequent gene expression profiling using Illumina assay as described elsewhere (Markova et al., 2013b; see also below and Supplementary Material; Fig.1C).

Study design with tests for anxiety-and depressive like behaviour in naïve mice Three-months-old male C57BL/6J mice received normal water (control group), imipramine (2.5 or $15 \mathrm{mg} / \mathrm{kg} /$ day) or dicholine succinate (DS, 25 or $75 \mathrm{mg} / \mathrm{kg} / \mathrm{day}$; Buddha Biopharma Ltd, Helsinki, Finland; both compounds were dissolved in drinking water) for two weeks ( $n=15$ in each group), and were tested for a depressive-like behaviour in a two-day forced swim test (Malatynska et al., 2012; Markova et al. 2013a, 2014; Costa-Nunes et al., 2015). Prior this testing, mice that received DS at the dose $75 \mathrm{mg} / \mathrm{kg} /$ day were additionally compared with control animals in a novel cage test (Strekalova et al. 2004) and elevated O-maze (Malatynska et al., 2012; Cline et al. 2012), in order, in particular, to rule out potential confounds in the assessment of floating behaviour ( $n=10$ from each group was tested; Fig.1D). Because other studies on mice revealed no effects at the dose of $25 \mathrm{mg} / \mathrm{kg} /$ day of DS on the parameters of anxiety and locomotion (Cline et al., 2012), animals from the current experiment treated with this dose were not examined in additional assays.

Since previous studies revealed a decrease of hippocampal $p$ GSK-3 $\beta$ levels to be a marker of depressive-like behaviour in a two-day forced swim test that was preserved by an antidepressant treatment including imipramine (Markova et al., 2014), we have chosen to study whether this variable is sensitive to the effects of DS treatment as well. Therefore, mice subjected to a two-day FST test and received DS at the dose 75 $\mathrm{mg} / \mathrm{kg} / \mathrm{day}$, or imipramine at the dose $15 \mathrm{mg} / \mathrm{kg} /$ day or remaining untreated, were sacrificed $10 \mathrm{~min}$ after the second swimming session for subsequent isolation of the hippocampus and ELISA assay (see below and Supplementary Material, Fig.1D). An 
additional group of naïve control animals that were not subjected to FST, was sacrificed and analyzed as well.

\section{Behavioural tests}

Sucrose test. In order to assess the hedonic state of mice, they were given a free choice for $8 \mathrm{~h}$ (between $9.00-17.00 \mathrm{~h}$ ) of two drinking bottles; one with 1\%-sucrose solution, and another with tap water, as described elsewhere (Strekalova et al., 2011, 2014). To prevent possible effects of side-preference in drinking behaviour, the position of the bottles in the cage was switched after $4 \mathrm{~h}$. Special precautions have been made in order to minimize the spillage of liquids and error of measurement during sucrose test. The consumption of water, sucrose solution and total intake of liquids was estimated simultaneously in the control and experimental groups by weighing the bottles. Percentage preference for sucrose was calculated using the following formula:

$$
\text { Sucrose Preference }=\left(\frac{V_{\text {Sucrose solution }}}{\left(V_{\text {Sucrose solution }}+V_{\text {Water }}\right)}\right) \times 100 \%
$$

Fear Conditioning test. The test procedure was adapted from a previously described protocol (Strekalova et al., 2003; Vignisse et al., 2014). The apparatus (Evolocus LLC Tarrytown, NY, USA and Technosmart, Rome, Italy) consisted of a transparent plastic cubicle $(25 \mathrm{~cm} \times 25 \mathrm{~cm} \times 50 \mathrm{~cm}$ ) with a stainless-steel grid floor (33 rods $2 \mathrm{~mm}$ in diameter). A single alternating electric current ( $A C, 50 \mathrm{~Hz} ; 0.7 \mathrm{~mA}$ ) was delivered after a 2-min acclimatization period. Freezing behaviour was scored by visual observation during an acclimatization phase and a test of memory recall that was carried out 24 $\mathrm{h}$ later. The freezing episode was defined by a complete lack of movement other than respiration accompanied by the occurrence of a specific posture of tension with the tail in a straight and tense position, as described previously (Strekalova et al., 2003; Fleischmann et al., 2003; Vignisse et al., 2014). The occurrence of freezing behaviour was assessed every $10 \mathrm{sec}$ for $180 \mathrm{sec}$; each 10-sec score was assigned to a freezing 
or non-freezing period, and the percentage of time spent in freezing was calculated. During delivery of foot shocks, the reaction of the animals was closely observed and rated using a 3-grade score system as maximal (jumping and squeaking), intermediate (jumping only), or modest (running). After delivery of the current, the mouse was immediately placed back in the home cage.

Forced swim test. The Porsolt forced swim test has been used as described elsewhere (Malatynska et al., 2012; Couch et al., 2013). Mice were subjected to two 6-min swimming sessions spaced $24 \mathrm{~h}$ apart in a transparent cylinder $(\varnothing 17 \mathrm{~cm})$ filled with water $\left(+23^{\circ} \mathrm{C}\right.$, water height $13 \mathrm{~cm}$, height of cylinder $20 \mathrm{~cm}$, illumination intensity 25 Lux). Floating was defined by the absence of any directed movements of the animals' head and body and was scored manually; criteria of scoring were previously validated using Noldus EthoVision XT 8.5 (Noldus Information Technology, Wageningen, The Netherlands) and CleverSys (CleverSys, Reston, VA, USA). Using this method, the latency of the first episode of floating and the duration of floating behaviour were recorded during the 6-min swimming session on the second day of the test. Latency to begin floating was scored as time between introduction of the animal into the pool and the first moment of complete immobility of the entire body for a duration of $>3$ seconds. The total time spent floating was scored for the entire duration of the test using post-test video footage.

Elevated O-maze. The apparatus (Technosmart, Rome, Italy), which consisted of a circular path (runway width $5.5 \mathrm{~cm}$, diameter $46 \mathrm{~cm}$ ), was placed $20 \mathrm{~cm}$ above the floor. Two opposing arms were protected by walls (height $10 \mathrm{~cm}$ ), and the illumination strength was 5 Lux. The apparatus was placed on a dark surface in order to reduce reflection and maintain control over lighting conditions during testing. Anxiety-like behaviour was assessed using previously validated parameters that were scored manually as described elsewhere (Cline et al., 2014; Costa-Nunes et al., 2014). Mice were placed in one of the closed-arm compartments of the apparatus. The 
latency of the first exit to the anxiety-related open compartments of the maze, the total duration of time spent therein, the number of risk assessment exploratory events and the number of exits to the open arms were scored during a 5-min observation period. The risk assessment exploratory events were defined by the stretching of the head and a body out of the area protected by the walls towards open arm zone, combined with exploratory pose and movements, directed to the edges of the maze. Half of the body and back limbs of a mouse stayed in the close arm area during these events.

Novel cage test. The novel cage test was performed to assess vertical activity in a new environment (Couch et al., 2013). Mice were introduced into a standard plastic cage $(21 \mathrm{~cm} \times 21 \mathrm{~cm} \times 15 \mathrm{~cm}$ ) filled with fresh sawdust. The number of exploratory rears per each minute was counted under red light during a 5-minute period.

\section{Dosing}

The current reference antidepressant treatment was selected because of its effects in lowering the rate of stress-induced anhedonia over other methods of delivery and doses of antidepressants (Cline et al., 2014; Costa-Nunes et al., 2012, 2014). Previous experiments revealed an antidepressant-like effect of one-week pre-treatment with daily i.p. injections of DS ( $25 \mathrm{mg} / \mathrm{kg} /$ day) in CD1 mice for stress-induced depressivelike changes (Cline et al., 2012). Likewise, here DS was administrated during 7 consecutive days to young mice preceding chronic stress or to 18-months-old mice preceding sucrose test, at the above-indicated dose. DS, provided by Buddha Biopharma Ltd (Helsinki, Finland), was dissolved in water for injections. The volume of DS and vehicle injections was $0.01 \mathrm{ml} / \mathrm{g}$ body weight $0.01 \mathrm{ml} / \mathrm{kg}$.

In a study of young non-stressed mice exposed to a battery of tests for emotionality, DS was applied via drinking water at the doses of 25 and $75 \mathrm{mg} / \mathrm{kg} /$ day. In this study, imipramine (Sigma-Aldrich, St. Louis, MO, US) was administrated via drinking as well. 
It was dissolved in tap water; the solution was freshly prepared every 2-3 days. Dosage for imipramine was set at 2.5 or $15 \mathrm{mg} / \mathrm{kg} /$ day. Since imipramine is light sensitive, bottles were protected by aluminium covers. The calculation of the concentration of DS and imipramine in drinking water was based on the previously evaluated mean volume of daily water consumption in C57BL6J mice that was about $3.0 \mathrm{ml}$ and on the dosage of treatment.

\section{Brain dissection and quantitative RT-PCR ( $q P C R$ )}

Mice were killed by cervical dislocation and their brains were dissected. RNA extraction was performed from microdissected snap-frozen hippocampi using RNeasy RNA extraction kit with DNase I treatment, as previously described (Qiagen, Hilden, Germany; Couch et al., 2013; Costa-Nunes, 2014). Using random primers and Superscript III transcriptase (Invitrogen, Darmstadt, Germany), $1 \mu \mathrm{g}$ total RNA was converted into cDNA. The expression levels of NR2A and NR2B as well as the housekeeping gene glyceraldehyde-3-phosphate dehydrogenase (GAPDH), that was used as a reference gene for quantification, were evaluated with TaqMan probes and the CFX96 Real-time System (BioRad, Hercules, CA, USA). Cycling conditions and sequences of primers used are indicated in the Supplementary data.

\section{Illumina assay}

Gene expression profiling was performed using Illumina technology (Northwestern Chicago University, USA) with the hippocampi obtained from 18-months old mice (drug-naïve or treated with DS); five animals per group were analysed. Total RNA samples were hybridized to IlluminaBeadChips (MouseRef-8 v2 Expression BeadChip; Illumina, Inc. San Diego, CA, USA) which were prepared using the IlluminaTotalPrep RNA Amplification kit (Applied Biosystems/Ambion, Carlsbad, CA, USA); the samples were assigned to the chips in random order with the constraint that no two samples from the same group were assigned to the same chip, to avoid confounding of experimental groups with the chips. Microarray data were analysed using standard 
analysis procedures, which included assessment of the overall quality of array data and statistical evaluation of differentially expressed genes. Once the quality of array data was confirmed, the Gene Chip Operating System (Illumina, Inc. San Diego, CA, USA) was used to calculate signal intensities, detection calls, and their associated $P$ values for each transcript on the array. Gene expression was normalized to the expression of the housekeeping gene, beta-actin, due to its stable expression, and calculated as percent mean of the control group of young mice. Differences in gene expression between groups were evaluated using unpaired two-tailed t-test.

Illumina data were imported into Partek Genomics Suite and quantile-normalized. Arrays that appeared as outliers on PCA were removed from the dataset. Comparisons between experimental groups were carried out in Partek-GS using ANOVA with appropriate contrasts. P values were adjusted for multiple testing using step-up False Discovery Rate (FDR). The following criteria were used to select differentially expressed genes at different stringency levels: Strict: FDR $<0.05$ and |fold change | $>$ 2; Medium: FDR < 0.1 and |fold change | $>1.5$; Loose: unadjusted $p$ value $<0.001$ and | fold change $\mid>1.3$, Very loose: unadjusted $p$ values $<0.01$ and no fold change threshold (only used when more stringent selection criteria yielded zero or very few hits). In the current analysis, "medium" criteria were applied.

\section{ELISA of $\mathrm{pGSK}-3 \beta$}

Hippocampus was homogenized in buffer containing $10 \mathrm{mM}$ Tris $(\mathrm{pH7}, 4), 100 \mathrm{mM}$ $\mathrm{NaCl}, 1 \mathrm{mM}$ EDTA, $1 \mathrm{mM}$ EGTA, $1 \mathrm{mM} \mathrm{NaF}, 20 \mathrm{mM} \mathrm{Na}{ }_{4} \mathrm{P}_{2} \mathrm{O}_{7}, 10 \%$ glycerol, $2 \mathrm{mM}$ Na3VO4 in the presence of a protease inhibitor cocktail (Sigma, USA). The GSK-3 $\beta$ [pS9] ELISA kit (Invitrogen Corporation, USA) was used for detection and to quantify the level of GSK-3 $\beta$ protein phosphorylated at serine residue 9. After three incubations according the instruction manual, a signal intensity provided by monoclonal capture antibody specific for GSK-3 $\beta$ that has been coated onto the wells, was evaluated at $450 \mathrm{~nm}$ using a plate reader (Wallac 1420 VICTOR, USA). The 
results were normalized to total protein level in tissues homogenates, which was determined by the biuret assay; bovine serum albumin was used as a standard (for further details, see Supplementary data).

\section{Statistics}

Data were analysed with GraphPad Prism version 5.0 for Windows (San Diego, CA). Unpaired two-tailed test was used to compare two groups; one-way ANOVA was used followed by Tukey's, or Dunnett's post-hoc comparison tests was applied to compare three or more groups. Repeated measurements with non-parametric data were evaluated with Wilcoxon test. The level of confidence was set at $95 \%(p<0.05)$ and data are shown as mean \pm SEM.

\section{Results}

Dosing with Dicholine Succinate preserves normal hedonic status and fear conditioning in a chronic stress paradigm

At the baseline, there was no difference in sucrose preference between the groups ( $p>0.05, q=0.25$, Tukey, Fig.2A). Following a chronic stress paradigm, ANOVA revealed a significant difference for sucrose preference $(F(5,87)=8.608, p<0.0001)$. Post-hoc analysis showed that only the vehicle-treated stressed group had a significant reduction in sucrose preference compared to controls ( $p<0.001, q=5.53$, Tukey) as well as to their DS-treated stressed counterparts ( $p<0.05, q=4.55$, Tukey, Fig.2A), indicating that treatment with DS was able to preclude a hedonic deficit. Sucrose preference was similar in non-treated non-stressed mice (76.22 $\pm 2.84 \%)$ and DStreated non-stressed mice $(82.01 \pm 3.1 ; p=0.193 ; t(12)=1.381 ;$ unpaired two-tailed $t$ test).

During training in the fear conditioning model, control, vehicle-treated stressed and DS-treated stressed groups had a similar percent of mice expressing responses to foot shock: maximal (45, 50 and 55\%, respectively), intermediate (30, 25 and $25 \%$, 
respectively), and a modest response to the foot-shock $(25,25$ and $20 \%$, respectively; $p>0.05$, exact Fischer test). Baseline rates of freezing behaviour measured during training were minimal and did not differ between the three groups either (control vs vehicle: $p>0.05 q=0.25$, control vs DS: $p>0.05, q=2.09$; data not shown, Tukey); together, suggesting their similar behaviour under untrained conditions.

Analysis of freezing behaviour during a recall session using ANOVA and Tukey posthoc test revealed a significant difference between the groups $(F(5,68)=4.724$, $p=0.0009$ ) and showed that the vehicle-treated stressed group had significantly less freezing as compared to their counter parts control ( $p<0.01, q=5.56$, Fig.2B) and DStreated stressed mice ( $p<0.01, q=5.27$, Fig.2B).

Effects of dosing with Dicholine Succinate on sleep parameters of chronically stressed mice in acute-stress sleep rebound paradigm

A fraction of mice exposed to chronic stress, was implanted with electrodes and, after a recovery period, was habituated to the recording chamber and connection to the cables and then subjected to a forty-eight hour EEG registration. In order to assess the effects of acute stress on chronically stressed mice that were either treated with DS, or remained pharmacologically naïve, the recording procedure was interrupted for a 6-h rat exposure stress and then re-started for another $48 \mathrm{~h}$. The duration of SWS and REM sleep was averaged for 48-h baseline and after-predation periods for each animal. Because of well-known inter-individual variability in sleep parameters of rodents, EEG data that were obtained after the predation period, were expressed as percent from the averaged baseline values.

Both groups had an increase of the duration of SWS and REM sleep after acute predation stress in comparison to baseline values (stressed non-treated group: $p=0.0158, W=28.0$ and $p=0.0469, W=24.0$, stressed DS-treated group: $p=0.0313$, $W=21.0$ and $p=0.0255, W=28.0$, Wilcoxon). The duration of REM sleep, normalized 
to baseline, was significantly longer in the DS-treated stressed group compared with the pharmacologically naive stressed group $(\mathrm{t}(10)=2.478, p=0.0327$, unpaired twotailed $t$-test); however, no differences were seen for SW sleep $(t(11)=0.3451$, $p=0.7366$, unpaired two-tailed $t$-test, Fig.2C, 2D). Thus, DS-treated stressed mice demonstrated enhanced REM sleep rebound following acute stress, a sign of adaptive stress response, in comparison with vehicle-treated stressed animals. Power spectra analysis revealed no changes in comparison to baseline measures in both challenged groups ( $p>0.05$, Wilcoxon) and no differences between the groups challenged with a predator stress ( $p>0.05$, unpaired two-tailed $t$-test), during SWS nor during REM sleep stages, as expressed in percent from initial baseline values for these animals (Fig.2C, 2D; power spectra data for baseline and after-predation conditions can be found in Supplementary Table 2).

Dosing with Dicholine Succinate prevents stress-induced increases of mRNA of NMDA receptor subunits in the hippocampus of chronically stressed mice Since changes in the NMDA-receptor mediated transmission were shown to underlie the antidepressant effects of other neuronal insulin sensitizers, we studied hippocampal gene expression of NMDA receptor subunit NR2A and the ratio of NR2A/NR2B, whose increases were previously demonstrated to accompany a susceptibility to stress-induced anhedonia in the here applied chronic stress model (Costa-Nunes et al., 2014). Twenty-four hours after the last behavoural test, i.e., on the $5^{\text {th }}$ day after the termination of chronic stress, in accordance with previously established protocols (Strekalova et al., 2011; Cline et al., 2012), animals were sacrificed for the study of hippocampal gene expression of NMDA receptor subunits. The mRNA levels of NR2A were significantly increased in chronically stressed animals which were not treated with DS following chronic stress $(p<0.05, q=379$, Tukey, $F(2,17)=4.010, p=0.0375$, ANOVA, Fig.2E). There was no overall significant changes in the NR2B mRNA expression levels between the groups following chronic stress 
$(F(2,21)=0.8881, p=0.4264$, ANOVA, Fig.2F). Untreated stressed mice had an increased ratio of NR2A/NR2B as compared to both controls ( $p<0.05, q=4.70$, Tukey) and the DS stressed groups $(p<0.05, q=4.62$, Tukey, $F(2,17)=7.625, p=0.0043$, ANOVA Fig.2G).

Effect of dosing with Dicholine Succinate on sucrose preference of old mice At the baseline, there was no difference in sucrose preference between the groups $(t(7)=0.4509, p=0.6657$, unpaired $t$-test). Animals, which did not receive treatment, aged 18 months showed no differences in preference for sucrose $(t(7)=0.4509$, $p=0.6657$, paired two-tail t-test Fig. $3 \mathrm{~A})$ or in sucrose intake $(t(7)=0.8845, p=0.4058$, paired two-tailed $t$-test, Fig.3B) between two repeated assays of sucrose test. However, sucrose preference and intake of sucrose was significantly increased after dosing with $\mathrm{DS}(t(7)=2.656, p=0.0327$, Fig.3A and $t(8)=2.359, p=0.0461$, paired twotailed $t$-test, Fig.3B; respectively). None of the groups showed any differences for water intake $(t(8)=1.099, p=0.3038$, control; $t(8)=1.850, p=0.1015$, DS, paired twotailed $t$-test, Fig.3C). Total liquid consumption was also not changed in any of the groups $(t(8)=0.8135, p=0.4395$, control; $t(8)=0.7358, p=0.2414$, DS, paired twotailed $t$-test, Fig.3D).

Gene expression profiling of the hippocampus and prefrontal cortex of old mice treated with Dicholine Succinate

Gene expression profiling of the hippocampus of DS-treated 18-month-old mice revealed expression changes in 27 genes, in comparison to a control group, for over 1.5 fold, and FDR was <0.1. Among these genes are those involved in neuronal synaptic plasticity: Arc and Nptx2, SGK1, Taf15, Vgf, Egr1, Gatad2b; all of them were up regulated (Fig.4A, Supplementary Table 3). Apart from them, genes encoding ascorbate transporter SIc23a3, regulator of axonal transport Dctn1, serine protease Htra1, serine proteases inhibitor: Slpi were up-regulated as well. The functions of the proteins encoded by 6430548M08Rik and 6030419C18Rik genes were not described 
in the literature. Functional categories of down-regulated genes in DS-treated old animals constitute genes that regulate sleep and circadian rhythm: Gm129, Cirbp and Dbp, as well as ascorbate transporter SIc23a2, fatty acids transporter SIc27a1.

As for the prefrontal cortex, four genes whose expressions were significantly changed according to the criterion described above were detected. One gene was up regulated (Inhba) while three were down regulated (Fig.4B, Supplementary Table 3).

Effects of dosing with Dicholine Succinate of naive mice: changes in depressive-, anxiety-like behaviours and hippocampal levels of phosphorylated GSK-3 $\beta$

In the forced swim test (FST), a one-way ANOVA revealed no changes between the groups in the latency to float and a significant effect over the total time spent floating $(F(4,70)=1,371, p=0.2528 ; F(4,70)=6.36, p=0.0002$, respectively; Fig.5A). A post-hoc Dunnett's test showed no significant differences between treated animals and a control group for the latency to swim, whereas the duration of immobility was significantly decreased in animals receiving higher doses of imipramine (15 $\mathrm{mg} / \mathrm{kg} /$ day) and dicholine succinate $(75 \mathrm{mg} / \mathrm{kg} /$ day) in comparison with controls $(p<0.01, q=3.79 ; p<0.05, q=2-81$, respectively; Fig.4A). In the elevated O-maze test mice treated with a dose of $75 \mathrm{mg} / \mathrm{kg} /$ day of dicholine succinate, displayed significantly longer duration in the open arms, with no significant changes to a latency to exit, total number of exits, or risk assessment behaviour in comparison with control animals $(p=0.038, t(18)=1.88 ; p=0.28, t(18)=0.59 ; p=0.15, t(18)=1.07 ; p=0.34$, $t(18)=0.99$, respectively; unpaired two tailed $t$-test; Fig.5B). In the novel cage test for locomotion / exploration, animals treated with dicholine succinate exhibited unchanged number of rearings in comparison to a control group ( $1^{\text {st }} \min : p=0.61$, $t(17)=0.52 ; 2^{\text {nd }} \min : p=0.40, t(17)=0.86 ; 3^{\text {rd }} \min : p=0.89, t(17)=0.13 ; 4^{\text {th }} \min : p=0.20$, $t(17)=1.34 ; 5^{\text {th }}$ min: $p=0.49, t(17)=0.71$; total rearings: $p=0.27, t(17)=1.13$; unpaired two-tailed t-test; Fig.5C). 
A one-way ANOVA reveals significant group differences in the levels of phosphorylated GSK-3 $\beta$ in the hippocampus of mice subjected to the forced swim test $(p=0.0145 ; \mathrm{F}=4.130)$. A post-hoc Tukey test showed a significant reduction in GSK-3 $\beta$ in untreated animals as compared with to intact control mice $(p<0.05$, $q=3.85)$. No such decrease was found in animals tested in the forced swim test that were treated with either imipramine or dicholine succinate (imipramine: $p>0.05$, $q=0.21$ and dicholine succinate: $p>0.05, q=0.43 ;$ Fig.5D). Untreated animals subjected to the forced swim test had significantly lower levels of the hippocampal $p$ GSK-3 $\beta$ levels in comparison to imipramine- and DS-treated animals ( $p<0.05, q=3.95$ and $p<0.05, q=4.03$, respectively; Tukey post-hoc test; Fig.5D).

\section{Discussion}

Effects of Dicholine Succinate in a chronic stress model

In the current work, stress exposure lowered sucrose preference in agreement with other reports (Willner et al., 1987; Harro et al., 2001; Krishnan et al., 2007). Stressed mice treated with DS showed no significant change in sucrose preference measured after the $10^{\text {th }}$ day of stress as compared to control animals (Fig.2A), similarly to the effects of classical antidepressants (Cline et al., 2014; Costa-Nunes et al., 2014; Strekalova et al., 2014). Earlier, we have shown in a model of stress-induced anhedonia that the decrease in sucrose preference is paralleled by a reduction in sucrose intake (Strekalova et al., 2004, 2006). Importantly, administration of DS did not alter sucrose test parameters in non-stressed animals ruling out any possible confounding artefacts for sucrose test measurements which could be related to treatment. Thus, the partial preclusion of the stress-induced reduction for sucrose preference by treatment with DS manifests their antidepressant-like activity in our study that is in line with previous findings obtained in a similar model on CD1 mice (Cline et al., 2012). 
Treatment with DS prevented stress-induced memory impairment in the fear conditioning task (Fig.2B). Similar freezing scores at baseline and the responses to foot shock in all experimental groups suggest that the deficits, revealed here in the contextual memory performance in mice subjected to stress and their rescue in the DS-treated stressed animals, are unlikely to be due to any distinct sensitivity to the foot-shock or to basal differences in the emotionality in the groups. While a similarity in these parameters in tested mice is a prerequisite of their unaltered acquisition of fear conditioning, the here employed study design does not exclude the ameliorative effect of DS on either or both learning phase(s), acquisition or / and consolidation of contextual memories. Of interest, the stimulation of neuronal insulin receptor is implicated both in memory acquisition and consolidation (Moosavi et al., 2007) suggesting that DS can be involved in two of these processes.

The effects of DS in the mouse fear conditioning paradigm, as previously validated in our model studies of hippocampus-dependent performance in mice (Strekalova et al., 2003, Vignisse et al., 2014), are in line with the ameliorative effects of DS on hippocampus- and cortex-dependent learning in step-though, step-down and Morris water maze paradigms which this drug exerted under pathological conditions of diverse origins (Storozheva et al., 2008; Storozhevykh et al., 2008). Previously reported effects of DS on increased levels of hippocampal IGF-2, brain Nacetylaspartate/creatine, choline acetyltransferase activity (Storozheva et al., 2008; Cline et al., 2012) can attest for the here observed memory preserving effects of DS. Interestingly, choline acetyltransferase activity in the brain was shown to be regulated by neuronal insulin receptor-mediated mechanisms (Hoyer, 2003). Recent evidence for a critical role of IGF2 in inhibitory avoidance learning and adult neurogenesis as shown in the fear conditioning paradigm (Agis-Balboa et al., 2011; Chen et al., 2011; Bracko et al., 2012) can additionally explain the beneficial effects of DS on memory performance in chronically stressed mice. Finally, recently shown 
activation of insulin receptor-mediated transmission a newly discovered mechanism of augmented neurogenesis (Ziegler et al., 2014), can per se result in proneurogenetic and neuroprotective activities that are characteristic for the antidepressants of various classes (Duman and Li, 2012), and, thus, can underlie procognitive and antidepressant effects of DS.

In the present study, we found significantly longer duration of REM but not SWS sleep in chronically stressed DS-treated mice subjected to acute stress of predation (Fig.2C). It is well established that acute stress of various natures, as for instance, immobilization or predation, induces an adaptive effect of sleep rebound, consisting in an increase of the REM stage of sleep and to a lesser extent SWS, this is regarded as one of the important anti-stress mechanisms (Cespuglio et al., 1995; Marinesco et al., 1999; Koehl et al., 2002; Tang et al., 2007; Tiba et al., 2008; Couch et al., under revision). It was shown that stress-induced sleep rebound is decreased during aging (Descamps and Cespuglio, 2010, Clement et al., 2003), development of anhedonia during stress (Couch et al., under revision) and various neurochemical abnormalities associated with neuropsychiatric conditions (Bonnet et al., 2000; Boutrel et al., 2002; Meerlo et al., 2002; Vázquez-Palacios et al., 2004; Albu et al., 2014). While the exact functions of each of the stages of sleep are, as yet unclear, it is claimed that normal REM sleep is a crucial factor of memory consolidation (Rolls et al., 2013; Barnes and Wilson, 2014). Additionally, insulin receptor mediated signalling is regarded as one of the regulatory mechanisms of sleep (Valatx et al., 1999; Kashyap and Defronzo, 2007).

While recent studies suggest that challenging insulin receptor mediated transmission in the brain might have long-term effects lasting for weeks (Hoyer, 2003), we trust that the ameliorative action of DS reported here on sleep rebound is likely to be related to reduced manifestations of depressive-like changes and stress response in chronically stressed mice that was found to be elevated for weeks in the model 
applied here when no antidepressant therapies are used (Cline et al., 2014). At the same time, power spectra activity was not changed in DS-treated mice (Fig.2C, Table 2) ruling out non-specific general changes in EEG activity of the treatment and suggesting preserved cerebral homeostasis in DS-treated mice that can be compromised by some antidepressants or aging (Cespuglio et al., 1995, Clement et al., 2003).

Our study evidenced preventive effects of DS on stress-induced increases of hippocampal gene expression of NMDA receptor subunits NR2A and the NR2A/NR2B ratio (Fig.2E-2G). The increases of these measures were previously shown to accompany elevated anxiety and occurrence of hedonic deficit during stress (BoyceRustay and Holmes, 2006; Gao et al., 2010; Pochwat et al., 2013; Calabrese et al., 2013; Costa-Nunes et al., 2014), impulsivity and aggression (Meyer et al., 2004; Bortolato et al., 2012), home cage hyperactivity and a stress-induced elevation in peripheral concentrations of corticosterone (Longordo et al., 2009, 2011; Huang et al., 2010b). A number of findings evidence that hippocampal NR2A and NR2B subunits of the NMDA receptor display fast kinetics in response to CORT and adverse experiences, where changes in gene expression parallel rapid alterations in total and surface protein levels as well as receptor trafficking (Zhang et al., 1997; Tse et al., 2011; Pochwat et al., 2013) suggesting that the changes reported in this study for mRNA levels of the NMDA-receptor subunits reflect its functional alterations.

Other studies demonstrate the importance of NMDA-receptor mediated currents in the antidepressant effects of pioglitazone, as it was discussed above (SalehiSadaghiani et al., 2012), which allows speculation that amelioration of depressivelike conditions via enhancement of insulin receptor mediated signalling by different drugs might commonly implicate glutamatergic neurotransmission via this receptor. 
Effects of Dicholine Succinate in a model of elderly depression

DS-treated 18-month old mice displayed higher sucrose intake and preference than pharmacologically naïve mice of this age, suggesting a normalization of hedonic state by the treatment. Comparable to these changes, similar effects were also demonstrated for treatment with imipramine or the neuroprotective drug dimebon (Malatynska et al., 2012). There was a non-significant reduction of water intake in the DS-treated group that was obviously accounted for compensatory changes in drinking behaviour, while total liquid intake was not altered by the treatment (Figs. $3 A-D)$. Together, the current findings may be interpreted as a manifestation of an antidepressant-like activity of DS in a model of elderly depression that is in line with previous reports showing that chronic administration of DS counteracts the development of aging-related neurochemical and cognitive deficits in mice (Storozheva et al., 2008) and preserves normal sucrose preference in chronically stressed mice.

Interestingly, Illumina gene expression study showed that among 27 significantly changed genes in accordance to the criterion applied here, 17 were up-regulated: 7 genes from this cohort (41.2\%) constituted genes encoding factors of synaptic plasticity (Fig.4A and Supplementary Table 3A). These functions are well established for most of them, such as for immediate early gene Arc, whose activity is regulated by stimulation of insulin receptor in neurons (Kremerskothen et al., 2002; Chen et al., 2014), suppressed by chronic stress (Elizalde et al., 2008, 2010) and increased by antidepressants (Molteni et al.,2008; Alme et al., 2007), immediate-early gene Nptx2 encoding neuronal activity-regulated pentraxin (Narp) that modulates AMPAreceptor functions (O'Brien, et al., 1999; Chang et al., 2010), SGK1, which regulates hippocampal postsynaptic density-95 and dendritic growth (Ma 2006; Yang 2006). Also, TAF15 was shown to be implicated in the trafficking of NMDA glutamate receptor (Ibrahim F, 2013). VGF and Egr1 were found to enhance hippocampal 
synaptic plasticity and neurogenesis (Thakker-Varia and Alder, 2009). GATAD2B was shown to be required for normal cognitive performance and synapse development (Willemsen, 2013).

Another cohort of altered genes in DS-treated mice whose function is well established constitute genes that are involved in the regulation of sleep and circadian activity. These genes include Gm129, a novel regulator of the feedback loop that involves activators and suppressors of circadian regulation (Annayev et al., 2014), Cirbp, a factor of cytokine-regulated expression of clock genes (Lopez et al., 2014) and $\mathrm{Dbp}$, a putative clock-controlled transcription factor, which is increased under sleep deprivation (Wisor et al., 2002).

Remarkably, many of these altered genes are functionally associated with insulin receptor signalling. As for instance, activation of Arc is regulated by insulin receptor in neurons through IRS/Grb2/Raf/Mek/Erk pathway (Kremerskothen et al., 2002); Sgk1 is encoding a kinase that is activated by insulin via PI3-kinase (Lang F, 2010). Vgf is encoding a neuropeptide, which expression is up regulated by BDNF and insulin (Salton et al., 2000; Busse et al., 2012); Rsg4 plays a role as a negative regulator of insulin-stimulated GLUT4 translocation in adipocytes (Kanzaki et al., 2000). Finally, Htra1 is encoding a protease that regulates the availability of insulin-like growth factors (IGFs) by cleaving IGF-binding proteins (Zumbrunn et al., 1996); FosB is encoding a transcription factor, which its periphery expression is up-regulated by insulin (Coletta et al., 2008).

Notably, DS evoked limited changes in gene expression in the prefrontal cortex. Among four genes, whose expression was significantly changed in this study is at least one factor that was shown to be implicated in the morphological plasticity of the brain and antidepressant response. Inhba encodes a beta A subunit that is shared by glycoprotein families Activins and Inhibins, that were shown to have opposite 
functions concerning antidepressant mechanisms (Ganea et al., 2012). Activin A, the homodimer of beta $A$, was shown to exert and acute antidepressant-like effect and increase the formation of synaptic contacts by modulating the dynamics of actin in the neuronal spines (Shoji-Kasai et al., 2007; Ganea et al., 2012). Expression of other genes belonging to various classes of regulators whose functions in the CNS are not well defined are associated with autophagy (Gabarapl1), other structural functions (Opalin) and myelin organization (Stmn4) were also significantly changed. Other significantly altered genes encode molecules whose functions in the brain are not well defined and mostly associated with structural functions and myelin organization (Fig.4B and Supplementary Table 3B).

While gene expression profiling data in this study need verification using additional methods, it is remarkable that many changes are associated with activation of brain plasticity factors and changes in sleep / circadian regulation that are known to be implicated in the pathogenesis of depression and antidepressant treatment (Mellman et al., 2002; Wainwright and Galea, 2013). Moreover, a number of highlighted gene changes were also shown to affect the elements of insulin receptormediated signalling that could be expected with the use of compounds that like DS stimulate this processes.

Effects of Dicholine Succinate on behaviour and hippocampal pGSK-3 $\beta$ in naïve mice While the effects of either treatment on the latency to the first episode of floating were not significant, mice treated with higher doses of imipramine and DS had significantly shorter duration of this behaviour (Fig.5A). This is in line with recent findings treated with DS via food and tested in the tail suspension and FST and together suggests that this treatment diminishes the symptoms of learned helplessness (Costa-Nunes et al., 2015). Coinciding with these results, another insulin sensitizer, rosiglitazone, was reported to reduce immobilization and floating behaviours in mouse tail suspension and forced swim tests respectively (Eissa Ahmed 
et al., 2009). Such effects well documented for other antidepressants and are regarded as a manifestation of antidepressant-like activity (Porsolt, 1998, Willner, 2005).

Treatment with DS decreased anxiety scores as shown by increased time spent in the open arms of the elevated O-maze indicating its anxiolytic and anti-stress effect (Fig.5B). Such effects are well documented for compounds with anxiolytic activity (Willner, 2005). Elevated anxiety was found to parallel induction of a depressive-like syndrome (Willner et al., 1987; Willner, 2005; Krishnan et al., 2007; Strekalova et al., 2011). No changes in vertical activity were found in the DS-treated group at no time period of the observation in the novel cage test, suggesting a lack of general effects on locomotion and a specificity of the above-described effects on measures of depression- and anxiety-like behaviours (Fig.5C).

Because on one hand, insulin, via the IRS/PI3K/Akt pathway, regulates GSK-3ß activity (Cross et al., 1995) and on another hand, mice exposed to a two-day forced swimming revealed decreased hippocampal levels of phosphorylated at Ser9 (inactive) form of GSK-3ß (Markova et al., 2014), we assessed potential effects of DS on the latter measure as well. We found that DS at the dose in which it exerted an antidepressant effect in this test, precluded stress-induced reduction of $p$ GSK-3 $\beta$ in this study that was comparable to the effect of imipramine. The present finding is in line with an inhibitory effect of insulin on GSK-3 $\beta$ activity. Given accumulating evidence for similar effects of other antidepressant interventions and, in general, for the role of elevated function of GSK-3 $\beta$ in promoting mood disorders and neurodegeneration (Doble et al., 2003; Li and Jope, 2010), these results suggest that the above-described effects on $p G S K-3 \beta$ can underlie an antidepressant and procognitive action of DS. As GSK-3 $\beta$ plays a key role in the induction of NMDA-receptordependent LTD (Peineau et al., 2009; Bradley et al., 2012) the effects of DS on 
hippocampal gene expression of NR2A subunit of this receptor can be related to the changes in the $p \mathrm{GSK}-3 \beta$ levels in this study.

\section{Conclusions}

Although a link between DS treatment and its mechanism of action in the distinct mouse models applied here remains to be determined, the present study argues for the potential of DS to generate an antidepressant-like effect in various conditions, including those in which the mechanisms of action of other sensitizers of the insulin receptor are effective. A lack of signs of toxicity of choline succinate in mammals (Shivapurkar et al., 1986; Maekawa et al., 1990) at the dosage ranges of DS found effective in our study favours its potential practical use.

We conclude that the insulin receptor sensitizer DS ameliorates depressive-like features in mice whose induction was associated with chronic stress as well those which were not. In a model of stress-induced anhedonia, DS preserved normal contextual fear conditioning, hippocampal gene expression of NMDA receptor subunit NR2A, the NR2A/NR2B ratio and increased REM sleep rebound after acute predation. In a model of elderly depression, DS restored normal sucrose preference and altered gene expression of 27 genes of the hippocampus and the prefrontal cortex most of which are involved in brain plasticity and sleep/circadian regulation. Finally, young DS-treated C57BL6 mice had reduced signs of learned helplessness through lowered scores of floating, similarly to the imipramine-treated group. Also, like imipramine-treated mice, DS-treated mice demonstrated preserved hippocampal levels of the phosphorylated (inactive) form of GSK-3 $\beta$ that was lowered by forced swimming in pharmacologically naïve animals. Thus, even though a variety of experimental techniques and determined physiological, behavioural and molecular read-outs of a depressive-like state dose not quite allow a connection these findings to each other, they all point towards an antidepressant-like role for DS 
at different levels and in different contexts. Consequently, this further highlights the enhancement of insulin receptor signalling as a potential target of pharmacotherapy of depressive disorder, while exactly how this mechanism results due to the effects of DS reported here, remains to be discovered.

\section{Conflict of Interest}

The research was conducted in the absence of any commercial or financial relationships that could be construed as a potential conflict of interest. The authors declare no conflict of interest.

\section{Authors' Contributions}

B.C. and J.C.N. carried out the chronic stress experiment, tissue collection, statistical analysis, prepared the figures and took part in drafting of the manuscript; R.C. and A.S. organised and carried out EEG study on chronically stressed mice; Y.B. performed gene expression Illumina analysis; N.M. and A.K. performed study in old mice and participated in the ELISA and RT PCR assays; H.S. participated in the design of the study and coordination; K.P.L. participated in the coordination of the study and contributed to the drafting of the manuscript; T.S. conceived of the study, participated in its design and coordination and drafted the manuscript. All authors read and approved the final manuscript.

\section{Acknowledgements}

We thank DFG (SFB TRR 58/A5) to KPL, the Neuroscience Research Center of Lyon (CNRL) to RC, RFBR 15-04-03602 to TS for a support of this study YVB was supported by the US Department of Energy (DOE BER Office of Science DE-FC02-07ER64494). The authors' work reported here was also supported by the European Community (EC: AGGRESSOTYPE FP7/No. 602805). 


\section{References}

Agis-Balboa, R.C., Arcos-Diaz, D., Wittnam, J., Govindarajan, N., Blom K., Burkhardt S., et al. (2011). A hippocampal insulin-growth factor 2 pathway regulates the extinction of fear memories. EMBO J. 30:4071-4083. doi: 10.1038/emboj.2011.293.

Albu, S., Romanowski, C.P., Curzi L.M., Jakubcakova, V., Flachskamm, C., Gassen, N.C. et al. (2014). Deficiency of FK506-binding protein (FKBP) 51 alters sleep architecture and recovery sleep responses to stress in mice. J. Sleep. Res. 23:176-185. doi: 10.1111/jsr.12112.

Ali, S., Stone, M.A., Peters, J.L., Davies, M.J., Khunti, K. (2006). The prevalence of co-morbid depression in adults with Type 2 diabetes: a systematic review and meta-analysis. Diabet. Med. 23:1165-1173.

Alme, M.N., Wibrand, K., Dagestad, G., Bramham, C.R. (2007). Chronic fluoxetine treatment induces brain region-specific upregulation of genes associated with BDNF-induced long-term potentiation. Neural. Plast. 2007:26496. doi: 10.1155/2007/26496.

Annayev, Y., Adar. S., Chiou, Y.Y., Lieb, J.D., Sancar, A.Y.R. (2014). Gene model 129 (Gm129) encodes a novel transcriptional repressor that modulates circadian gene expression. J. Biol. Chem. 289:5013-5024. doi: 10.1074/jbc.M113.534651.

Asghar, S., Hussain, A., Ali, S.M., Khan, A.K., Magnusson, A. (2007). Prevalence of depression and diabetes: a population-based study from rural Bangladesh. Diabet Med 24:872-877.

Banks, W.A., Owen, J.B., Erickson, M.A. (2012). Insulin in the brain: there and back again. Pharmacol. Ther. 136:82-93. doi: 10.1016/j.pharmthera.2012.07.006.

Barnes, D.C., Wilson, D.A. (2014). Slow-wave sleep-imposed replay modulates both strength and precision of memory. J. Neurosci. 34:5134-5142. doi: 10.1523/JNEUROSCI.5274-13.2014.

Basta-Kaim, A., Szczesny, E., Glombik, K., Stachowicz, K., Slusarczyk, J., Nalepa, I., et al. (2014). Prenatal stress affects insulin-like growth factor-1 (IGF-1) level and IGF-1 receptor phosphorylation in the brain of adult rats. Eur. Neuropsychopharmacol. 24:1546-1556. doi: 10.1016/j.euroneuro.2014.07.002.

Bonnet, C., Marinesco, S., Debilly, G., Kovalzon, V., Cespuglio, R. (2000). Influence of a 1-h immobilization stress on sleep and CLIP (ACTH(18-39)) brain contents in adrenalectomized rats. Brain. Res. 853:323329.

Bortolato, M., Godar, S.C., Melis, M., Soggiu, A., Roncada, P., Casu, A., et al. (2012) NMDARs mediate the role of monoamine oxidase $A$ in pathological aggression. J. Neurosci. 32: 8574-8582. doi: 10.1523/JNEUROSCI.0225-12.2012.

Boutrel, B., Monaca, C., Hen, R., Hamon, M., Adrien, J. (2002). Involvement of 5-HT1A receptors in homeostatic and stress-induced adaptive regulations of paradoxical sleep: studies in 5-HT1A knock-out mice. J. Neurosci. 22:4686-4692.

Boyce-Rustay, J.M., Holmes, A. (2006). Genetic inactivation of the NMDA receptor NR2A subunit has anxiolytic- and antidepressant-like effects in mice. Neuropsychopharmacology. 31: 2405-2414. 
Bracko, O., Singer, T., Aigner, S., Knobloch, M., Winner, B., Ray, J., et al. 2012. Gene expression profiling of neural stem cells and their neuronal progeny reveals IGF2 as a regulator of adult hippocampal neurogenesis. J. Neurosci. 32:3376-3387. doi: 10.1523/JNEUROSCI.4248-11.2012.

Bradley, C.A., Peineau, S., Taghibiglou, C., Nicolas, C.S., Whitcomb, D.J., Bortolotto, Z.A., et al. (2012). A pivotal role of GSK-3 in synaptic plasticity. Front. Mol. Neurosci. 5:13. doi: 10.3389/fnmol.2012.00013.

Busse, S., Bernstein, H.G., Busse, M., Bielau, H., Brisch, R., Mawrin, C., et al. (2012). Reduced density of hypothalamic VGF-immunoreactive neurons in schizophrenia: a potential link to impaired growth factor signaling and energy homeostasis. Eur. Arch. Psychiatry. Clin. Neurosci. 262:365-374. doi: 10.1007/s00406-011-0282-7.

Calabrese, F., Guidotti, G., Molteni, R., Racagni, G., Mancini, M., Riva, M.A. (2012). Stress-induced changes of hippocampal NMDA receptors: modulation by duloxetine treatment. PLoS. One. 7:e37916. doi: 10.1371/journal.pone.0037916.

Cespuglio, R., Amrouni, D., Meiller, A., Buguet, A., Gautier-Sauvigné, S. (2012). Nitric oxide in the regulation of the sleep-wake states. Sleep. Med. Rev. 16:265-279. doi: 10.1016/j.smrv.2012.01.006.

Cespuglio, R., Marinesco, S., Baubet, V., Bonnet, C., el Kafi, B. (1995). Evidence for a sleep-promoting influence of stress. Adv. Neuroimmunol. 5:145-154.

Chang, M.C., Park, J.M., Pelkey, K.A., Grabenstatter, H.L., Xu, D., Linden, D.J., et al., (2010). Narp regulates homeostatic scaling of excitatory synapses on parvalbumin-expressing interneurons. Nat. Neurosci. 13:1090-1097. doi: 10.1038/nn.2621.

Chen, D.Y., Stern, S.A., Garcia-Osta, A., Saunier-Rebori, B., Pollonini, G., Bambah-Mukku, D., et al. (2011). A critical role for IGF-II in memory consolidation and enhancement. Nature. 469:491-497. doi: 10.1038/nature09667.

Chen, T.J., Wang, D.C., Hung, H.S., Ho, H.F. (2014). Insulin can induce the expression of a memory-related synaptic protein through facilitating AMPA receptor endocytosis in rat cortical neurons. Cell. Mol. Life. Sci. 71:4069-4080. doi: 10.1007/s00018-014-1620-5.

Chiu, S.L., Chen, C.M., Cline, H.T. (2008). Insulin receptor signaling regulates synapse number, dendritic plasticity, and circuit function in vivo. Neuron. 58:708-719. doi: 10.1016/j.neuron.2008.04.014.

Clement, P., Gharib, A., Cespuglio, R., Sarda, N. (2003). Changes in the sleep-wake cycle architecture and cortical nitric oxide release during ageing in the rat. Neuroscience 116: 863-870.

Cline, B.H., Anthony, D.C., Lysko, A., Dolgov, O., Anokhin, K., Schroeter, C., et al. (2014). Lasting downregulation of the lipid peroxidation enzymes in the prefrontal cortex of mice susceptible to stressinduced anhedonia. Behav. Brain. Res. pii: S0166-4328(14)00255-1. doi: 10.1016/j.bbr.2014.04.037.

Cline, B.H., Steinbusch, H.W., Malin, D., Revishchin, A.V., Pavlova, G.V., Cespuglio, R., et al. (2012). The neuronal insulin sensitizer dicholine succinate reduces stress-induced depressive traits and memory deficit: possible role of insulin-like growth factor 2. BMC. Neurosci. 2012 13:110. doi: 10.1186/14712202-13-110. 
Coletta, D.K., Balas, B., Chavez, A.O., Baig, M., Abdul-Ghani, M., Kashyap, S.R., et al. (2008). Effect of acute physiological hyperinsulinemia on gene expression in human skeletal muscle in vivo. Am. J. Physiol. Endocrinol. Metab. 294:E910-917. doi: 10.1152/ajpendo.00607.2007.

Costa-Nunes J.P., Cline B.C., Araújo-Correia M., Valença A., Markova N., Dolgov O., Kubatiev A., Yeritsyanh N., Steinbusch H.W., Strekalova T. (2015). Animal models of depression and drug delivery with food as an effective dosing method: evidences from studies with celecoxib and dicholine succinate. BioMed Research International. (in press).

Costa-Nunes, J., Zubareva, O., Araújo-Correia, M., Valença, A., Schroeter, C.A., Pawluski, J.L., et al. (2014). Altered emotionality, hippocampus-dependent performance and expression of NMDA receptor subunit mRNAs in chronically stressed mice. Stress. 17:108-116. doi: 10.3109/10253890.2013.872619.

Costa-Nunes, J.P., Couch, Y., Cline, B.H., Cespuglio, R., Anthony, D.C., Steinbusch, H.W.M., et al. (2012). The neuronal insulin sensitizer dicholine succinate reduces stress-induced depressive traits, changes in sleep and gene expression in the brain. Presented at the $8^{\text {th }}$ annual meeting for the FENS; July 14-18; Barcelona, Spain.

Couch, Y., Anthony, D.C., Dolgov, O., Revischin, A., Festoff, B., Santos, A.I., et al. (2013). Microglial activation, increased TNF and SERT expression in the prefrontal cortex define stress-altered behaviour in mice susceptible to anhedonia. Brain. Behav. Immun. 29: 136-146. doi: 10.1016/j.bbi.2012.12.017.

Couch, Y., Raymond, C., Kubatiev A., Chernopiatko A., Stratford M., Steinbusch H.W., Anthony, D.C. Strekalova, T. Sleep architecture is altered in distinct ways by stress and inflammation. Molecular Brain. (under revision).

Cowen, P., and Sherwood, A.C. (2013). The role of serotonin in cognitive function: evidence from recent studies and implications for understanding depression. J Psychopharmacol 27: 575-583.

Cross, D.A., Alessi, D.R., Cohen, P., Andjelkovich, M., Hemmings, B.A. (1995). Inhibition of glycogen synthase kinase-3 by insulin mediated by protein kinase B. Nature. 378:785-789.

Daws, L.W., Owens, A., Campos, P., Gould, G., Galli, A., France, C. (2009). Regulation of biogenic amine transporters by insulin: Implications for antidepressant drug efficacy. Presented at the 48th Annual Meeting of the American College of Neuropsychopharmacology; December 6-10; Hollywood, FL.

Descamps, A., Cespuglio, R. (2010). Influence of aging on the sleep rebound induced by immobilization stress in the rat. Brain. Res. 1335:14-23. doi: 10.1016/j.brainres.2010.03.087.

Doble, B.W., Woodgett, J.R. (2003). GSK-3:tricks of the trade for a multi-tasking kinase. J. Cell. Sci. 116:1175-1186.

Duman, R.S., and Li, N. (2012). A neurotrophic hypothesis of depression: role of synaptogenesis in the actions of NMDA receptor antagonists. Philos Trans R Soc Lond B Biol Sci 367: 2475-2484.

Eissa Ahmed, A.A, Al-Rasheed, N.M. (2009). Antidepressant-like effects of rosiglitazone, a PPARgamma agonist, in the rat forced swim and mouse tail suspension tests. Behav. Pharmacol. 20:635-642. doi: 10.1097/FBP.0b013e328331b9bf. 
Fleischmann, A., Hvalby, O., Jensen, V., Strekalova, T., Zacher, C., Layer, L.E., Kvello, A., Reschke, M., Spanagel, R., Sprengel, R., Wagner, E.F., and Gass, P. (2003). Impaired long-term memory and NR2Atype NMDA receptor-dependent synaptic plasticity in mice lacking c-Fos in the CNS. J Neurosci 23: 91169122.

Elizalde, N., Gil-Bea, F.J., Ramirez, M.J., Aisa, B., Lasheras, B., Del Rio, J., and Tordera, R.M. (2008). Longlasting behavioural effects and recognition memory deficit induced by chronic mild stress in mice: effect of antidepressant treatment. Psychopharmacology (Berl) 199: 1-14.

Elizalde. N, Pastor, P.M., Garcia-Garcia, A.L., Serres, F., Venzala, E., Huarte, J., et al. (2010). Regulation of markers of synaptic function in mouse models of depression: chronic mild stress and decreased expression of VGLUT1. J. Neurochem. 114:1302-1314. doi: 10.1111/j.1471-4159.2010.06854.x.

Freude, S., Leeser, U., Muller, M., Hettich, M.M., Udelhoven, M., Schilbach, K., et al. (2008). IRS-2 branch of IGF-1 receptor signaling is essential for appropriate timing of myelination. J. Neurochem. 107:907917. doi: 10.1111/j.1471-4159.2008.05631.

Ganea K., Menke A., Schmidt M.V., Lucae S., Rammes G., Liebl C., et al. (2012). Convergent animal and human evidence suggests the activin/inhibin pathway to be involved in antidepressant response. Transl Psychiatry. 23. 2:e177.

Gao, C., Gill, M.B., Tronson, N.C., Guedea, A.L., Guzmán, Y.F., Huh, K.H., et al. (2010). Hippocampal NMDA receptor subunits differentially regulate fear memory formation and neuronal signal propagation. Hippocampus. 20:1072-1082. doi: 10.1002/hipo.20705.

Gold, P.W., Licinio, J., Pavlatou, M.G. (2013). Pathological parainflammation and endoplasmic reticulum stress in depression: potential translational targets through the CNS insulin, klotho and PPAR- $\gamma$ systems. Mol. Psychiatry. 18:154-165. doi: 10.1038/mp.2012.167.

Govind, S., Kozma, R., Monfries, C., Lim, L., Ahmed, S. (2001). Cdc42Hs facilitates cytoskeletal reorganization and neurite outgrowth by localizing the $58-\mathrm{kD}$ insulin receptor substrate to filamentous actin. J. Cell. Biol. 152:579-594.

Harro, J., Tonissaar, M., Eller, M., Kask, A., Oreland, L. (2001). Chronic variable stress and partial 5-HT denervation by parachloroamphetamine treatment in the rat: effects on behaviour and monoamine neurochemistry. Brain. Res. 899:227-239.

Hoyer S Memory function and brain glucose metabolism. Pharmacopsychiatry. (2003). Jun;36 Suppl 1:S62-7.

Huang, C.C., Lee, C.C., Hsu, K.S. (2010a). The role of insulin receptor signaling in synaptic plasticity and cognitive function. Chang. Gung. Med. J. 33:115-125.

Huang, Y., Shi, X., Xu, H., Yang, H., Chen, T., Chen, S., et al. (2010b). Chronic Unpredictable Stress Before pregnancy reduce the expression of BDNF and NMDAr in hippocampus of offspring rats associated with impairment of memory. Neurochem. Res. 35:1038-1049. doi: 10.1007/s11064-010-0152-0.

Ibrahim, F., Maragkakis, M., Alexiou, P., Maronski, M.A., Dichter, M.A., Mourelatos, Z. (2013). Identification of in vivo, conserved, TAF15 RNA binding sites reveals the impact of TAF15 on the neuronal transcriptome. Cell. Rep. 3:301-308. doi: 10.1016/j.celrep.2013.01.021. 
Igarashi, M., Hirata, A., Yamaguchi, H., Jimbu, Y., Tominaga, M. (2008). Pioglitazone reduces atherogenic outcomes in type 2 diabetic patients. J. Atheroscler. Thromb. 15:34-40.

Kanzaki, M., Watson, R.T., Artemyev, N.O., Pessin, J.E. (2000). The trimeric GTP-binding protein $(G(q) / G(11))$ alpha subunit is required for insulin-stimulated GLUT4 translocation in 3T3L1 adipocytes. J. Biol. Chem. 275:7167-7175.

Kashyap, S.R., Defronzo, R.A. (2007). The insulin resistance syndrome: physiological considerations. Diab Vasc Dis Res. 4:13-19.

Keefe, R.S., Mcclintock, S.M., Roth, R.M., Doraiswamy, P.M., Tiger, S., and Madhoo, M. (2014). Cognitive effects of pharmacotherapy for major depressive disorder: a systematic review. J Clin Psychiatry 75: 864-876.

Kemp, D.E., Ismail-Beigi, F., Ganocy, S.J., Conroy, C., Gao, K., Obral, S., et al. (2011). Use of insulin sensitizers for the treatment of major depressive disorder: A pilot study of pioglitazone for major depression accompanied by abdominal obesity. J. Affect. Disord. 136:1164-1173. doi: 10.1016/j.jad.2011.06.033.

Keshavarzy, F., Bonnet, C., Bezhadi, G., Cespuglio, R. (2014). Expression patterns of c-Fos early gene and phosphorylated ERK in the rat brain following 1-h immobilization stress: concomitant changes induced in association with stress-related sleep rebound. Brain. Struct. Funct.

Kikusui, T., Ichikawa, S., Mori, Y. (2009). Maternal deprivation by early weaning increases corticosterone and decreases hippocampal BDNF and neurogenesis in mice. Psychoneuroendocrinol. 34:762-772. doi: 10.1016/j.psyneuen.2008.12.009.

Koehl, M., Bouyer, J.J., Darnaudéry, M., Le Moal, M., Mayo, W. (2002). The effect of restraint stress on paradoxical sleep is influenced by the circadian cycle. Brain. Res. 937:45-50.

Kremerskothen, J., Wendholt, D., Teber, I., Barnekow, A. (2002). Insulin-induced expression of the activity-regulated cytoskeleton-associated gene (ARC) in human neuroblastoma cells requires p21(ras), mitogen-activated protein kinase/extracellular regulated kinase and src tyrosine kinases but is protein kinase C-independent. Neurosci. Lett. 321:153-156.

Krishnan, V., Han, M.H., Graham, D.L., Berton, O., Renthal, W., Russo, S.J., et al. (2007). Molecular adaptations underlying susceptibility and resistance to social defeat in brain reward regions. Cell. 131:391-404.

Kuhad, A., Bishnoi, M., Tiwari, V., Chopra, K. (2009). Suppression of NF-kappabeta signaling pathway by tocotrienol can prevent diabetes associated cognitive deficits. Pharmacol. Biochem. Behav. 92:251-259. doi: 10.1016/j.pbb.2008.12.012

Lang, F., Strutz-Seebohm, N., Seebohm, G., Lang, U.E. (2010). Significance of SGK1 in the regulation of neuronal function. J. Physiol. 588:3349-3354. doi: 10.1113/jphysiol.2010.190926

Li, X., Jope, R.S. (2010). Is glycogen synthase kinase-3 a central modulator in mood regulation? Neuropsychopharmacology. 35:2143-2154. doi: 10.1038/npp.2010.105. 
Lin, C.H., Tomioka, M., Pereira, S., Sellings, L., lino, Y., van der Kooy, D. (2010). Insulin signaling plays a dual role in Caenorhabditis elegans memory acquisition and memory retrieval. J. Neurosci. 30:80018011. doi: 10.1523/JNEUROSCI.4636-09.2010.

Longordo, F., Fan, J., Steimer, T., Kopp, C., Lüthi, A. (2011). Do mice habituate to "gentle handling?" A comparison of resting behaviour, corticosterone levels and synaptic function in handled and undisturbed C57BL/6J mice. Sleep. 34:679-681.

Longordo, F., Kopp, C., Mishina, M., Luján, R., Lüthi, A. (2009). NR2A at CA1 synapses is obligatory for the susceptibility of hippocampal plasticity to sleep loss. J. Neurosci. 29: 9026-9041. doi: 10.1523/JNEUROSCI.1215-09.2009.

Lopez, M., Meier, D., Müller, A., Franken, P., Fujita, J., Fontana, A. (2014). Tumor necrosis factor and transforming growth factor $\beta$ regulate clock genes by controlling the expression of the cold inducible RNA-binding protein (CIRBP). J. Biol. Chem. 289:2736-2744. doi: 10.1074/jbc.M113.508200.

Ma, Y.L., Tsai, M.C., Hsu, W.L., Lee, E.H. (2006). SGK protein kinase facilitates the expression of longterm potentiation in hippocampal neurons. Learn. Mem. 13:114-118.

Maekawa, A., Todate, A., Onodera, H., Matsushima, Y., Nagaoka, T., Shibutani, M., Ogasawara, H., Kodama, Y., Hayashi, Y. (1990). Lack of toxicity/carcinogenicity of monosodium succinate in F344 rats. Food Chem Toxicol.4:235-241.

Malatynska, E., Steinbusch, H.W., Redkozubova, O., Bolkunov, A., Kubatiev, A., Yeritsyan, N.B., et al. (2012). Anhedonic-like traits and lack of affective deficits in 18-month-old C57BL/6 mice: Implications for modeling elderly depression. Exp. Gerontol. 47:552-564. doi: 10.1016/j.exger.2012.04.010.

Marinesco, S., Bonnet, C., Cespuglio, R. (1999). Influence of stress duration on the sleep rebound induced by immobilization in the rat: a possible role for corticosterone. Neuroscience. 92:921-933.

Markova, N., Chernopiatko, A., Schroeter, C.A., Malin, D., Kubatiev, A., Bachurin, S., et al. (2013b). Hippocampal gene expression of deiodinases 2 and 3 and effects of 3,5-diiodo-L-thyronine T2 in mouse depression paradigms. Biomed. Res. Int. 2013:565218. doi: 10.1155/2013/565218.

Markova, N., Shevtsova, E., Bachurin, S., Steinbusch, H.M., Strekalova, T. (2013a) Individual susceptibility to depressive-like traits in two mouse models of depression and hippocampal levels of GSK3 beta. FEBS. J. 280:219-220.

Markova, N., Shevtsova, E., Vignisse, J., Zubareva, O., Trofimov, A., Steinbusch, H., et al. (2014). Thiamine and benfotiamine improve memory, decrease depressive-like behaviour and reduce brain expression of GSK3 beta in mice. Proceedings of the 8th International Conference on Thiamine 'From Catalysis to Pathology'. May 2014. Liege, Belgium, p. 12.

Mcintyre, R.S., Cha, D.S., Soczynska, J.K., Woldeyohannes, H.O., Gallaugher, L.A., Kudlow, P., Alsuwaidan, M., Baskaran, A. (2013). Cognitive deficits and functional outcomes in major depressive disorder: determinants, substrates, and treatment interventions. Depress Anxiety 30: 515-527.

Meerlo, P., de Bruin, E.A., Strijkstra, A.M., Daan, S. (2001). A social conflict increases EEG slow-wave activity during subsequent sleep. Physiol. Behav. 73:331-335. 
Mellman, T.A., Bustamante, V., Fins, A.I., Pigeon, W.R., Nolan, B. (2002). REM sleep and the early development of posttraumatic stress disorder. Am. J. Psychiatry. 159:1696-1701.

Meyer, W.N., Korzan, W.J., Summers, C.H. (2004). Social stress and corticosterone regionally upregulate limbic N-methyl-D-aspartatereceptor (NR) subunit type $N R(2 A)$ and $N R(2 B)$ in the lizard Anolis carolinensis. Neuroscience. 128: 675-684.

Mittal, R., Malhotra, S., Pandhi, P., Kaur, I., Dogra, S. (2009). Efficacy and safety of combination Acitretin and Pioglitazone therapy in patients with moderate to severe chronic plaque-type psoriasis: a randomized, double-blind, placebo-controlled clinical trial. Arch. Dermatol. 145:387-393. doi: 10.1001/archdermatol.2009.5.

Moosavi, M., Naghdi, N., Choopani, S. (2007). Intra CA1 insulin microinjection improves memory consolidation and retrieval. Peptides 28: 1029-1034.

Molteni, R., Calabrese, F., Mancini, M., Racagni, G., Riva, M.A. (2008). Basal and stress-induced modulation of activity-regulated cytoskeletal associated protein $(\mathrm{Arc})$ in the rat brain following duloxetine treatment. Psychopharmacology (Berl) 201:285-292. doi: 10.1007/s00213-008-1276-7.

Mufson, E.J., Kroin, J.S., Sendera, T.J., Sobreviela, T. (1999). Distribution and retrograde transport of trophic factors in the central nervous system: functional implications for the treatment of neurodegenerative diseases. Prog. Neurobiol. 57:451-484.

Nunes, J., Correia, M., Valenca, A., Gorenkova, N., Bolkunov, A., Redkozubova, O., et al. (2010). Behavioural Effects of Chronic Administration of Imipramine With Food and Water in Tests for Depression and Anxiety in Naïve C57BL/6N Mice. Abstracts of EURON School for Mental Health and Neuroscience: Drugs in Neuropsychopharmacology., p 10.

O'Brien, R.J., Xu, D., Petralia, R.S., Steward, O., Huganir, R.L., Worley, P. (1999). Synaptic clustering of AMPA receptors by the extracellular immediate-early gene product Narp. Neuron. 23:309-323.

Pan, Y., Hong, Y., Zhang, Q.Y., Kong, L.D. (2013). Impaired hypothalamic insulin signaling in CUMS rats: restored by icariin and fluoxetine through inhibiting CRF system. Psychoneuroendocrinol. 38:122-134. doi: 10.1016/j.psyneuen.2012.05.007.

Peineau, S., Nicolas, C.S., Bortolotto, Z.A., Bhat, R.V., Ryves, W.J., Harwood, A.J., et al. (2009). A systematic investigation of the protein kinases involved in NMDA receptor-dependent LTD: evidence for a role of GSK-3 but not other serine/threonine kinases. Mol. Brain. 2:22. doi: 10.1186/1756-6606-2-22.

Persiyantseva, N.A., Storozhevykh, T.P., Senilova, Y.E., Gorbacheva, L.R., Pinelis, V.G., Pomytkin, I.A. (2013). Mitochondrial H2O2 as an enable signal for triggering autophosphorylation of insulin receptor in neurons. J. Mol. Signal. 8:11. doi: 10.1186/1750-2187-8-11.

Pochwat, B., Szewczyk, B., Sowa-Kucma, M., Siwek, A., Doboszewska, U., Piekoszewski, W., Gruca, P., Papp, M., and Nowak, G. (2014). Antidepressant-like activity of magnesium in the chronic mild stress model in rats: alterations in the NMDA receptor subunits. Int J Neuropsychopharmacol 17: 393-405.

Pomytkin, I.A. (2012). H2O2 Signalling Pathway: A Possible Bridge between Insulin Receptor and Mitochondria. Curr. Neuropharmacol. 10:311-320. doi: 10.2174/157015912804143559. 
Porsolt, R, Papp, M. (1998). CNS - Psychiatric models of disease: Depression. In Current Protocols in Pharmacology. Ed. M. Williams, S.J. Enna, T. Kenakin, J.W. Ferkany (New York: Wiley), 591-598.

Rasgon, N.L., Kenna, H.A., Williams, K.E., Powers, B., Wroolie, T., Schatzberg, A.F. (2010). Rosiglitazone add-on in treatment of depressed patients with insulin resistance: a pilot study. Sci. World. J. 10:321328. doi: 10.1100/tsw.2010.32.

Rolls, A., Makam, M., Kroeger, D., Colas, D., de Lecea, L., Heller, H.C. (2013). Sleep to forget: interference of fear memories during sleep. Mol. Psychiatry. 18:1166-1170. doi: 10.1038/mp.2013.121.

Salehi-Sadaghiani, M., Javadi-Paydar, M., Gharedaghi, M.H., Zandieh, A., Heydarpour, P., YousefzadehFard, Y., et al. (2012). NMDA receptor involvement in antidepressant-like effect of pioglitazone in the forced swimming test in mice. Psychopharmacology (Berl). 223:345-355. doi: 10.1007/s00213-0122722-0.

Salton, S.R., Ferri, G.L., Hahm, S., Snyder, S.E., Wilson, A.J., Possenti, R., et al. (2000). VGF: a novel role for this neuronal and neuroendocrine polypeptide in the regulation of energy balance. Front. Neuroendocrinol. 21:199-219.

Saubermann, L.J., Nakajima, A., Wada, K., Zhao, S., Terauchi, Y., Kadowaki, T., et al. (2002). Peroxisome proliferator-activated receptor gamma agonist ligands stimulate a Th2 cytokine response and prevent acute colitis. Inflamm. Bowel. Dis. 8:330-339.

Sharma, A.N., Elased, K.M., Lucot, J.B. (2012). Rosiglitazone treatment reversed depression- but not psychosis-like behaviour of $\mathrm{db} / \mathrm{db}$ diabetic mice. J. Psychopharmacol. 26:724-732. doi: 10.1177/0269881111434620.

Shivapurkar, N., Hoover, K.L., Poirier, L.A. (1986). Effect of methionine and choline on liver tumor promotion by phenobarbital and DDT in diethylnitrosamine-initiated rats. Carcinogenesis 7: 547-550.

Shoji-Kasai Y., Ageta H., Hasegawa Y., Tsuchida K., Sugino H., Inokuchi K. (2007). Activin increases the number of synaptic contacts and the length of dendritic spine necks by modulating spinal actin dynamics. J Cell Sci 120:3830-3837.

Shomaker, L.B., Tanofsky-Kraff, M., Young-Hyman, D., Han, J.C., Yanoff, L.B., Brady, S.M., et al. (2010). Psychological symptoms and insulin sensitivity in adolescents. Pediatr. Diabetes. 11:417-423. doi: 10.1111/j.1399-5448.2009.00606.x.

Spencer, J.L., Waters, E.M., Milner, T.A., Lee, F.S., McEwen, B.S. (2010). BDNF variant Val66Met interacts with estrous cycle in the control of hippocampal function. Proc Natl Acad Sci U S A. 107:4395-4400. doi: 10.1073/pnas.0915105107.

Storozheva, Z.I., Proshin, A.T., Sherstnev, V.V., Storozhevykh, T.P., Senilova, Y.E., Persiyantseva, N.A., et al. (2008). Dicholine salt of succinic acid, a neuronal insulin sensitizer, ameliorates cognitive deficits in rodent models of normal aging, chronic cerebral hypoperfusion, and beta-amyloid peptide-(25-35)induced amnesia. BMC. Pharmacol 8:1. doi: 10.1186/1471-2210-8-1.

Storozhevykh, T.P., Senilova, Y.E., Persiyantseva, N.A., Pinelis, V.G., Pomytkin, I.A. (2007). Mitochondrial respiratory chain is involved in insulin-stimulated hydrogen peroxide production and plays an integral role in insulin receptor autophosphorylation in neurons. BMC. Neurosci. 8:84. 
Strekalova, T., Anthony, D.C., Dolgov, O., Anokhin, K., Kubatiev, A., Steinbusch, H.M., et al. (2013). The differential effects of chronic imipramine or citalopram administration on physiological and behavioural outcomes in naïve mice. Behav. Brain. Res. 245:101-106. doi: 10.1016/j.bbr.2013.02.015.

Strekalova, T., Couch, Y., Kholod, N., Boyks, M., Malin, D., Leprince, P., et al. (2011). Update in the methodology of the chronic stress paradigm: internal control matters. Behav. Brain. Funct. 7:9. doi: 10.1186/1744-9081-7-9.

Strekalova, T., Evans, M., Chernopiatko, A., Couch, Y., Costa-Nunes, J., Cespuglio, R., et al. (2014). Deuterium content of water increases depression susceptibility: The potential role of a serotoninrelated mechanism. Behav. Brain. Res. pii: S0166-4328(14)00488-4. doi: 10.1016/j.bbr.2014.07.039.

Strekalova, T., Gorenkova, N., Schunk, E., Dolgov, O., Bartsch, D. (2006). Selective effects of citalopram in a mouse model of stress-induced anhedonia with a control for chronic stress. Behav. Pharmacol. $17: 271-287$.

Strekalova, T., Spanagel, R., Bartsch, D., Henn, F.A., Gass, P. (2004). Stress-induced anhedonia in mice is associated with deficits in forced swimming and exploration. Neuropsychopharmacology. 29:2007-2017.

Strekalova, T., Steinbusch, H.W. (2010). Measuring behaviour in mice with chronic stress depression paradigm. Prog. Neuropsychopharmacol. Biol. Psychiatry 34: 348-361. doi: 10.1016/j.pnpbp.2009.12.014.

Strekalova, T., Wotjak, C.T., Schachner, M. (2001). Intrahippocampal administration of an antibody against the HNK-1 carbohydrate impairs memory consolidation in an inhibitory learning task in mice. Mol. Cell. Neurosci. 17:1102-1113.

Strekalova, T., Zörner, B., Zacher, C., Sadovska, G., Herdegen, T., Gass, P. (2003). Memory retrieval after contextual fear conditioning induces c-Fos and JunB expression in CA1 hippocampus. Genes. Brain. Behav. 2:3-10.

Strum, J.C., Shehee, R., Virley, D., Richardson, J., Mattie, M., Selley, P., et al. (2007). Rosiglitazone induces mitochondrial biogenesis in mouse brain. J. Alzheimers. Dis. 11:45-51.

Suchecki, D., Tiba, P.A., Machado, R.B. (2012). REM Sleep Rebound as an Adaptive Response to Stressful Situations. Front. Neurol. 3:41. doi: 10.3389/fneur.2012.00041. doi: 10.3389/fneur.2012.00041.

Sun, X., Yao, H., Douglas, R.M., Gu, X.Q., Wang, J., Haddad, G.G. (2010). Insulin/PI3K signaling protects dentate neurons from oxygen-glucose deprivation in organotypic slice cultures. J. Neurochem. 112:377388. doi: 10.1111/j.1471-4159.2009.06450.x.

Tang, X., Yang, L., Sanford, L.D. (2007). Interactions between brief restraint, novelty and footshock stress on subsequent sleep and EEG power in rats. Brain. Res. 1142:110-118.

Thakker-Varia, S., Alder, J. (2009). Neuropeptides in depression: role of VGF. Behav. Brain. Res. 197:262278. doi: 10.1016/j.bbr.2008.10.006.

Tiba, P.A., Tufik, S., Suchecki, D. (2008). Long lasting alteration in REM sleep of female rats submitted to long maternal separation. Physiol. Behav. 93:444-452. 
Tse, Y.C., Bagot, R.C., Hutter, J.A., Wong, A.S., Wong, T.P. (2011). Modulation of synaptic plasticity by stress hormone associates with plastic alteration of synaptic NMDA receptor in the adult hippocampus. PLoS One 6, e27215.

Valatx, J.L., Douhet, P., Bucchini, D. (1999). Human insulin gene insertion in mice. Effects on the sleepwake cycle? J. Sleep. Res. 8:65-68.

van der Heide, L.P., Ramakers, G.M., Smidt, M.P. (2006). Insulin signaling in the central nervous system: learning to survive. Prog. Neurobiol. 79:205-221.

Vazquez-Palacios, G., Bonilla-Jaime, H., Velazquez-Moctezuma, J. (2004). Antidepressant-like effects of the acute and chronic administration of nicotine in the rat forced swimming test and its interaction with fluoxetine. Pharmacol. Biochem. Behav. 78:165-169.

Vignisse, J., Steinbusch, H.W., Grigoriev, V., Bolkunov, A., Proshin, A., Bettendorff, L., et al. (2014). Concomitant manipulation of murine NMDA- and AMPA-receptors to produce pro-cognitive drug effects in mice. Eur. Neuropsychopharmacol. 24:309-320. doi: 10.1016/j.euroneuro.2013.06.010.

Wainwright, S.R., Galea, L.A. (2013). The neural plasticity theory of depression: assessing the roles of adult neurogenesis and PSA-NCAM within the hippocampus. Neural. Plast. 2013:805497. doi: $10.1155 / 2013 / 805497$.

Willemsen, M.H., Nijhof, B., Fenckova, M., Nillesen, W.M., Bongers, E.M., Castells-Nobau, A., et al. (2013). GATAD2B loss-of-function mutations cause a recognisable syndrome with intellectual disability and are associated with learning deficits and synaptic undergrowth in Drosophila. J. Med. Genet. 50:507514. doi: 10.1136/jmedgenet-2012-101490.

Williams, J.M., Owens, W.A., Turner, G.H., Saunders, C., Dipace, C., Blakely, R.D., et al. (2007). Hypoinsulinemia regulates amphetamine-induced reverse transport of dopamine. PLoS. Biol. 5:e274.

Willner, P. (2005). Chronic mild stress (CMS) revisited: consistency and behavioural-neurobiological concordance in the effects of CMS. Neuropsychobiol. 2005, 52:90-110.

Willner, P., Towell, A., Sampson, D., Sophokleous, S., Muscat, R. (1987). Reduction of sucrose preference by chronic unpredictable mild stress, and its restoration by a tricyclic antidepressant. Psychopharmacology (Berl) 93:358-364.

Wisor, J.P., O'Hara, B.F., Terao, A., Selby, C.P., Kilduff, T.S., Sancar, A., et al. (2002). A role for cryptochromes in sleep regulation. BMC. Neurosci. 3:20.

Yang, Y.C., Lin, C.H., Lee, E.H. (2006). Serum- and glucocorticoid-inducible kinase 1 (SGK1) increases neurite formation through microtubule depolymerization by SGK1 and by SGK1 phosphorylation of tau. Mol. Cell. Biol. 26:8357-8370.

Zhao, W.Q., Alkon, D.L. (2001). Role of insulin and insulin receptor in learning and memory. Mol. Cell. Endocrinol. 177:125-134.

Zhao, Y., Patzer, A., Herdegen, T., Gohlke, P., Culman, J. (2006). Activation of cerebral peroxisome proliferator-activated receptors gamma promotes neuroprotection by attenuation of neuronal cyclooxygenase-2 overexpression after focal cerebral ischemia in rats. FASEB. J. 20:1162-1175. 
Zhang, L., Hsu, J.C., Takagi, N., Gurd, J.W., Wallace, M.C., and Eubanks, J.H. (1997). Transient global ischemia alters NMDA receptor expression in rat hippocampus: correlation with decreased immunoreactive protein levels of the NR2A/2B subunits, and an altered NMDA receptor functionality. J Neurochem 69: 1983-1994.

Ziegler, A.N., Chidambaram, S., Forbes, B.E., Wood, T.L., and Levison, S.W. (2014). Insulin-like growth factor-II (IGF-II) and IGF-II analogs with enhanced insulin receptor-a binding affinity promote neural stem cell expansion. J Biol Chem 289: 4626-4633.

Zumbrunn, J., Trueb, B. (1996). Primary structure of a putative serine protease specific for IGF-binding proteins. FEBS Lett. 398:187-192. 


\section{Figure legends}

Figure 1. Study flows. (A) Study of the effects of Dicholine Succinate in a chronic stress model. Abbreviations: DS: dicholine succinate-treated; ST: sucrose test; FC: fear conditioning; T: training; R: recall test; B: baseline; S: stress; D: day of experiment. (B) Schematic of the 10-day chronic stress procedure. Abbreviatons: TS: tail suspension stress, R: restraint stress, D: day, N: night Rat: rat exposure stress (C) Study of the effects of Dicholine Succinate in a model of elderly depression; D: day of experiment. Abbreviations: ST: sucrose test (D) Study of the effects of Dicholine Succinate in naïve mice. Abbreviations: NC: novel cage test; OM: O-maze test; FST D1: forced swim test day 1; FST D2: forced swim test day 2; D: day of experiment.

Figure 2. Effects of Dicholine Succinate in a chronic stress model. (A) Sucrose preference was significantly lowered in stressed vehicle treated animals as compared to their controls as well as to DS-treated stressed mice ( $p<0.001$ vs control and DS respectively). (B) In contextual fear conditioning, the percentage of time spent with freezing during a baseline (pre-training) period was similarly low in all experimental groups $(p>0.05)$. The vehicle stressed group showed memory loss as indicated by significantly lesser freezing compared to both nonstressed controls $(p<0.01)$ and DS treated stressed mice $(p<0.01$. (C) Slow wave sleep was not different between the not treated stressed or DS treated stressed (groups ( $p>0.05)$. Power spectra analysis revealed no differences between the groups ( $p>0.05$ ) (D) REM sleep was significantly increased in stressed DS treated mice as compared to stressed not treated animals $(p<0.05)$; number of animals per group as indicated above. Power spectra analysis revealed no differences between the groups ( $p>0.05)$. (E) mRNA expression of NR2A, as well as the NR2A/NR2B ratio were elevated in the non-treated stress group, as compared to controls ( $p<0.05, N R 2 A$; and $p<0.01$ NR2A/NR2B ratio), but not in stressed DS-treated mice ( $p>0.05)$. No changes were observed for NR2B mRNA expression. Abbreviations: Con: control group; VEH: vehicle-treated; DS: dicholine succinate-treated; B: baseline conditions; S: stressed. ${ }^{*} p<0.05$ vs controls, $\# p<0.05$ vs. DS-treated group.

Figure 3. Effects of Dicholine Succinate in a model of elderly depression. (A) In 18 month aged animals, only the DS treated group showed an increase in sucrose preference $(p<0.05)$ while non-treated animals had no increased sucrose preference ( $p>0.05)$. (B) Total sucrose intake 
was not changed in animals without treatment $(p>0.05)$ while DS-treated animals had an increase in total sucrose intake $(p<0.05)$. (C) No groups showed any difference for total water intake ( $p>0.05$, not treated and $p>0.05$, DS). (D) Also there were no differences in the total liquid consumption for the not treated animals nor for the DS treatment group ( $p>0.05)$.

Figure 4. Gene expression profiling of brain of old mice treated with Dicholine Succinate. A significant change in over 1.5 folds from vehicle-treated aged control as found with 27 genes in the (A) hippocampus and 4 genes in the (B) prefrontal cortex. For the criteria of gene selection, see the text.

Figure 5. Study of the effects of Dicholine Succinate in naïve mice. (A) No differences were observed in the latency to float for any group ( $p>0.05)$ while there was a significant effect of total time spent floating $(p<0.005)$. Tukey's revealed that groups receiving higher treatment does had significantly less floating ( $p<0.01$, imipramine and $p<0.05$, DS). (B) In the elevated O-maze test mice treated with a dose of $75 \mathrm{mg} / \mathrm{kg} /$ day of dicholine succinate, displayed significantly longer duration in the open arms, with no significant changes to a latency to exit, total number of exits, or risk assessment behaviour in comparison with control animals $(p<0.05)$. (C) No changes were observed between DS treated animals and controls at any time point ( $p>0.05$, see the text) or for total rearings ( $p>0.05$ ). (D) Tukey's revealed a significant reduction in $p$ GSK-3 $\beta$ for untreated animals subjected to FST compared to naive control $(p<0.05)$. There was no difference for imipramine-treated mice subjected to FST $(p>0.05)$ or DS-treated mice subjected to FST ( $p>0.05$ ), in comparison with naive control group. $p$ GSK-3 $\beta$ levels were also significantly lower in untreated animals exposed to FST as compared to imipramine treated subjected to FST $(p<0.05)$ and DS treated subjected to FST $(p<0.05)$ groups. Abbreviations: DS: dicholine succinate-treated; FST: subjected to a forced swim test. $*_{p}<0.05$ vs controls, \#p<0.05 vs. FST non-treated group. 
A

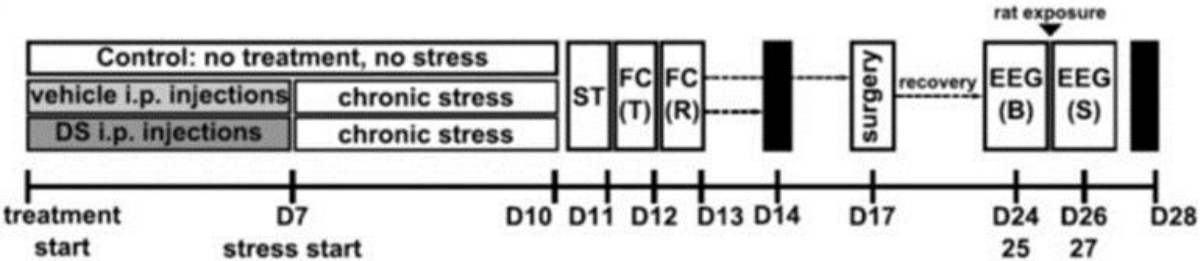

B

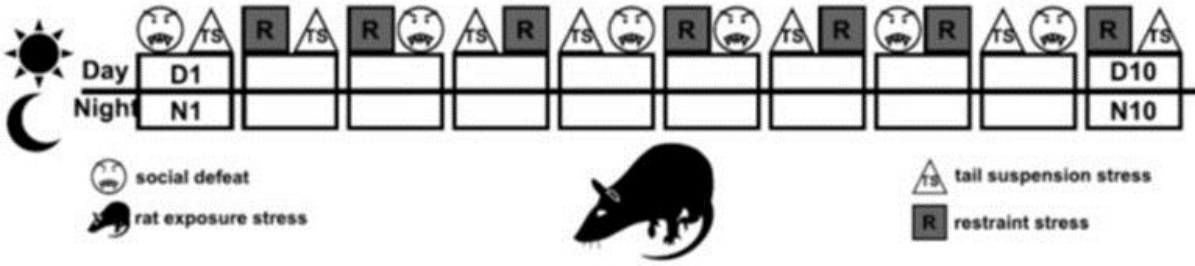

C

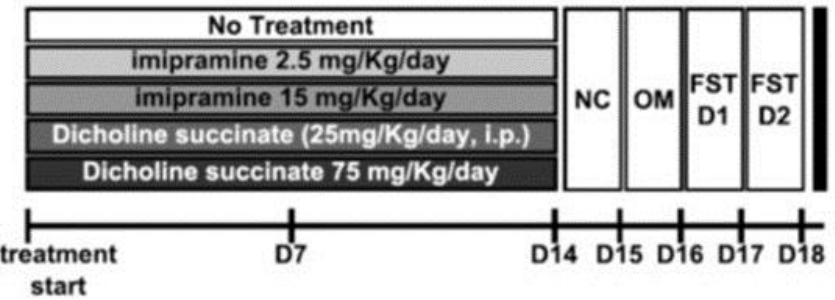

D

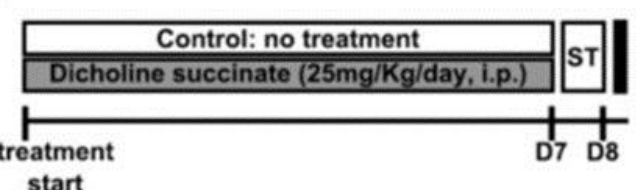

Figure 1 
A

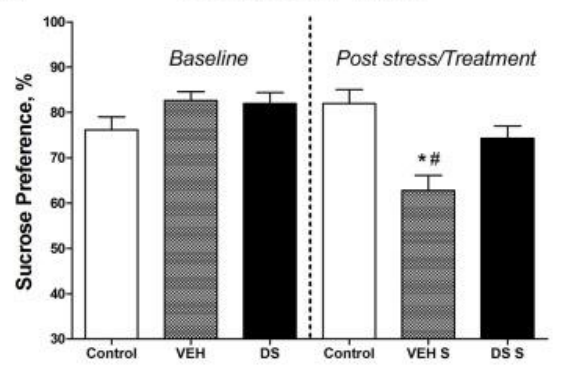

C

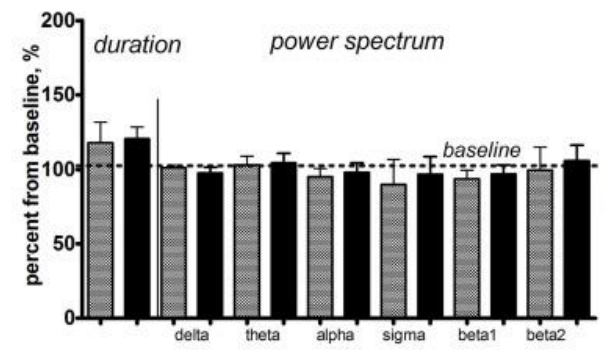

E

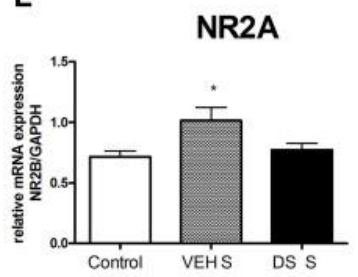

$\mathbf{F}$

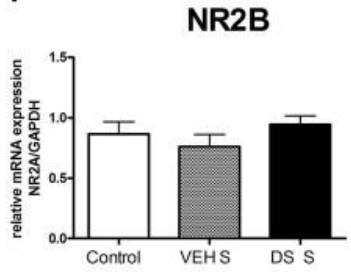

CONTEXTUAL FREEZING

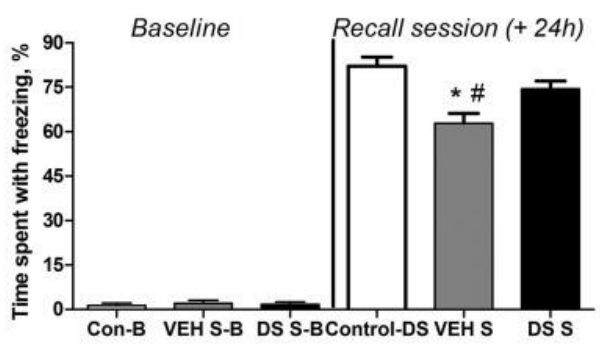

D

REM SLEEP

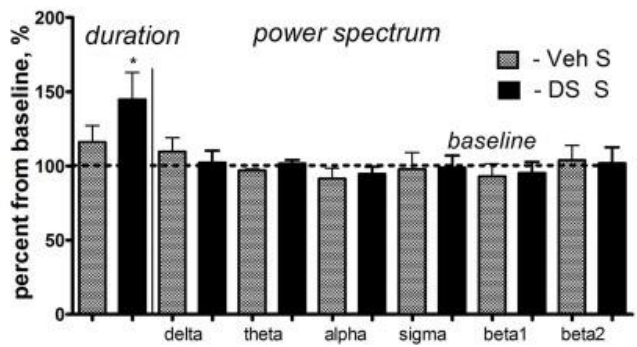

G

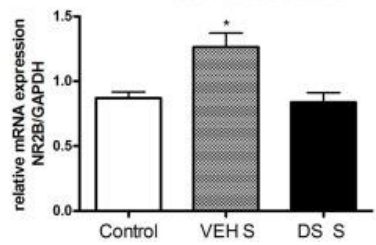

Figure 2 
A SUCROSE PREFERENCE

B SUCROSE INTAKE
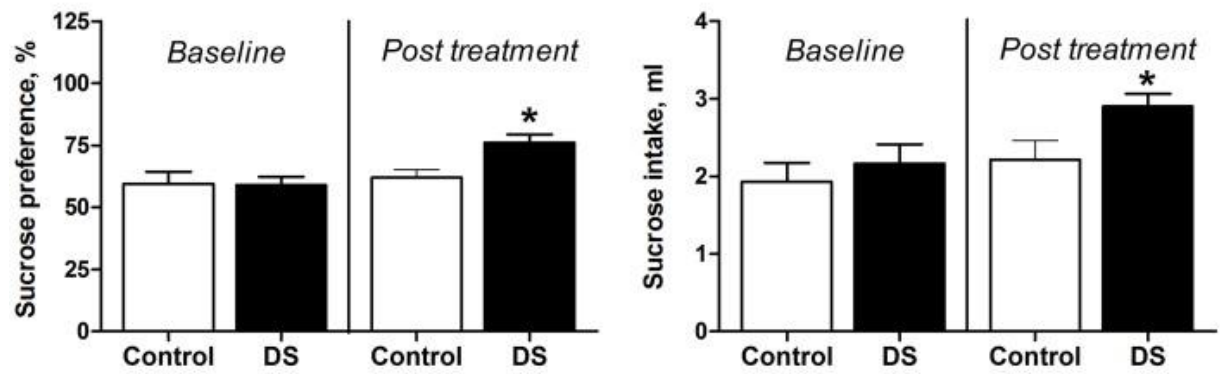

C

WATER INTAKE

D

TOTAL LIQUID INTAKE
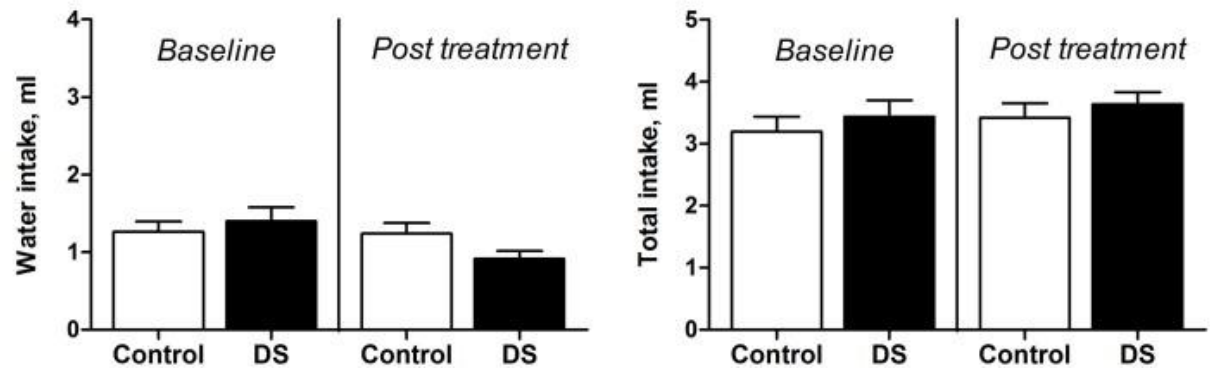

Figure 3 


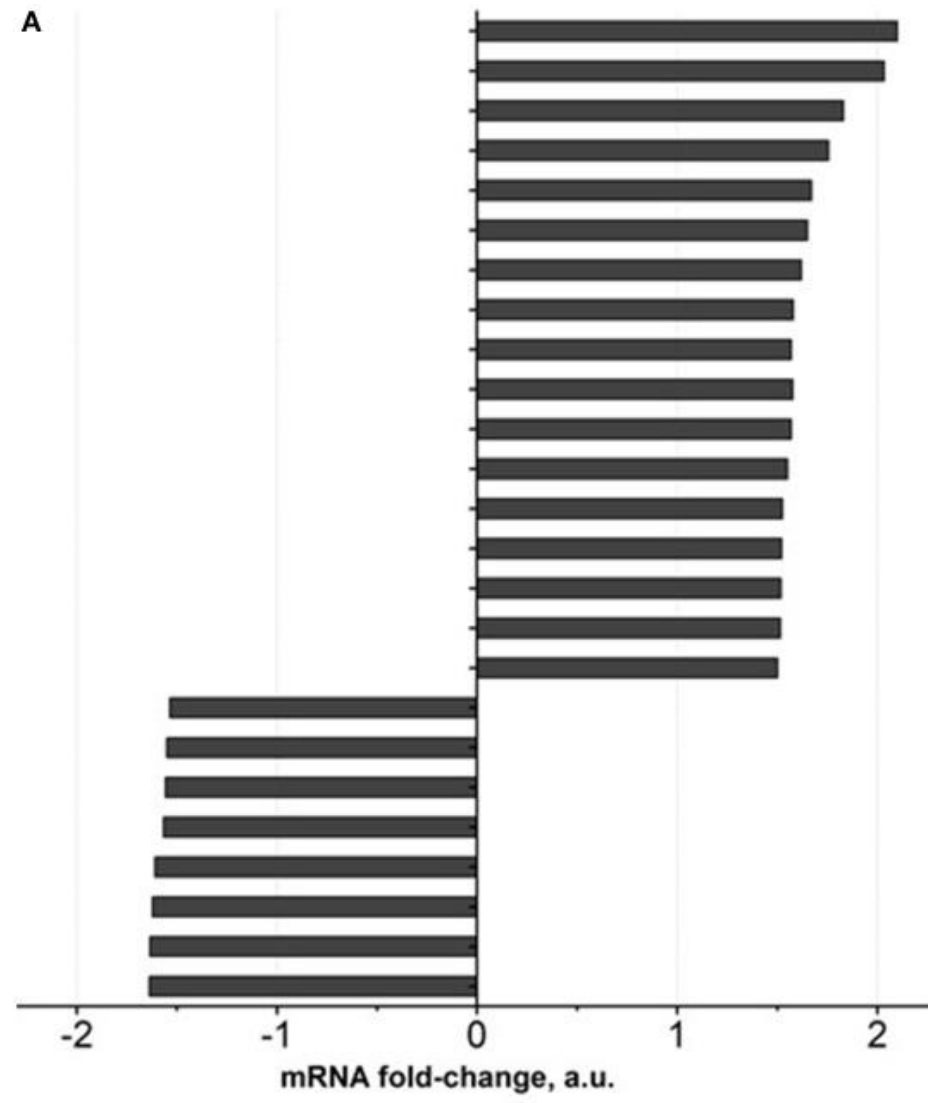

Arc

Nptx2

Sgk1

6430548M08Rik

Taf15

Dctn1

Vgf

Rgs4

Egr1

6030419C18Rik

lqgap2

Bat2

Htra1

Gatad2b

SIpi

Fosb

Slc23a3

Hist1h1c

Gm129

Spag7

Erh

Slc27a1

St3gal5

Cirbp Dbp

B

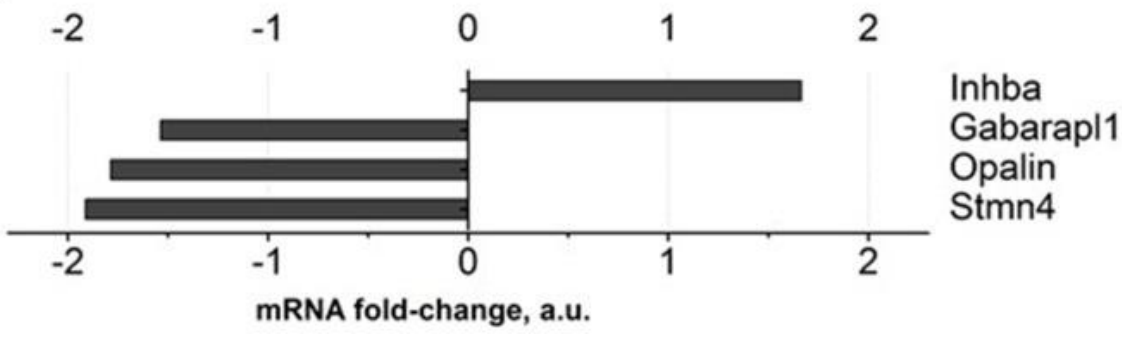

Figure 4 


\section{A FORCED SWIM TEST}
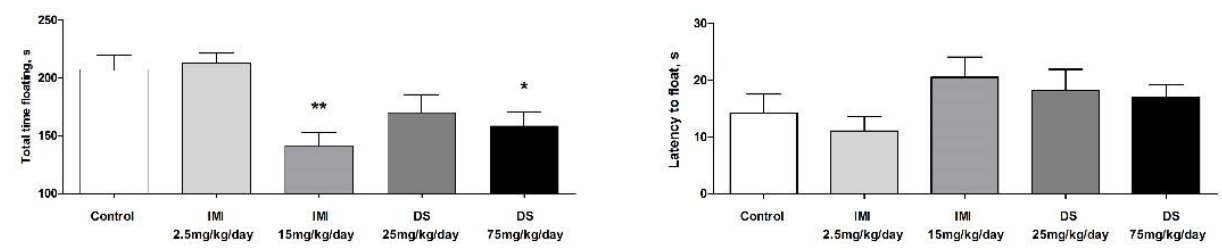

B O-MAZE
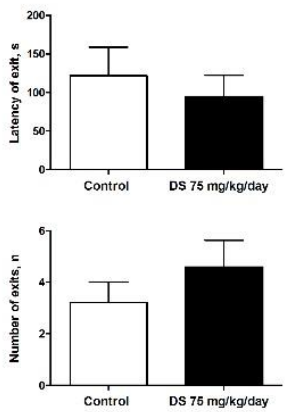

D GSK-3 $\beta$

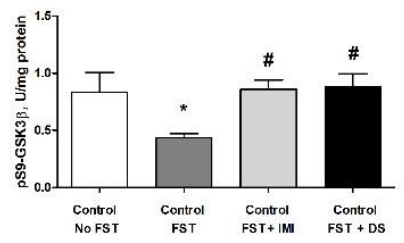

C NOVEL CAGE TEST
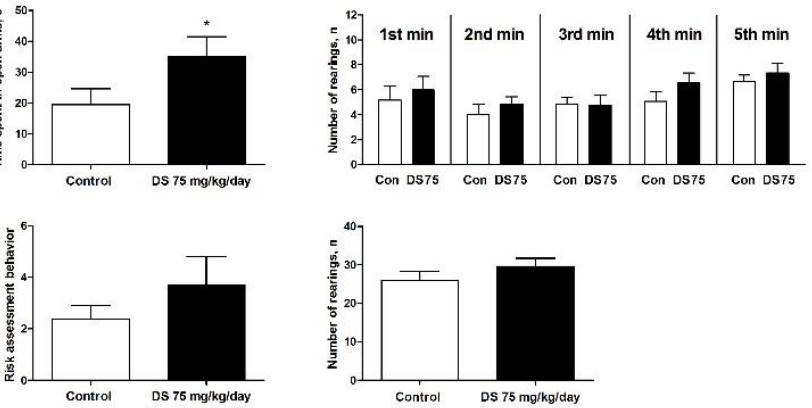

Figure 5 


\section{Supplementary data}

Rat exposure while in a small container

Mice were introduced into cylindrical containers, which were placed into a rat home cage for $15 \mathrm{~h}$ (over-night, from $18 \mathrm{~h} 00$ to 9h00). Containers were made from customized transparent plastic, size $15 \mathrm{~cm} \times \varnothing 8 \mathrm{~cm}$, with holes in covers $(\varnothing<0.5 \mathrm{~cm})$, which ensured protection of the mouse from the rat, but allowed visual and odor contact.

\section{Social defeat stress}

Social defeat took place during the dark phase under red light to enable visual control over the resident-intruder confrontation. In a preliminary test, aggressive individuals of the CD1 mouse strain that were able to attack the counter-partners in less than 60 sec without injuring them were selected for this procedure; these animals were introduced in the home cages of mice from the stress group during social defeat sessions for $5 \mathrm{~min}$. During social defeat stress, test mice typically showed flight response, submissive posture and vocalization. Pairs of animals were carefully observed in order to exclude any physical harm. In rare cases of its incidence, overly aggressive individuals were immediately removed from the cage of resident mice. After a 5-min period of social defeat C57BL/6 mice were introduced into small containers and placed inside the CD1 cage, where they stayed for a 3h-period. Thereafter, a 5-min social defeat procedure was repeated again. In order to randomize the procedure, the same pairs of C57BI6 and CD1 mice were never put together.

\section{Tail suspension stress}

Mice were submitted to the tail suspension procedure by hanging them by their tails. The procedure was done during the dark phase of the animals' light cycle. 
Restraint Stress

Animals were placed inside a plastic tube (internal diameter $26 \mathrm{~mm}$ ) for $2 \mathrm{~h}$ during the dark phase of the light cycle and kept in a dark experimental room.

Real-time PCR assay

RNA extraction was performed as previously described (Costa-Nunes et al., 2014). Cycling conditions and sequences of primers used are indicated in Table 1. 
Table 1. Cycling conditions and sequences of primers used in RT PCR assay

\begin{tabular}{|c|c|c|c|}
\hline $\begin{array}{l}\text { mRNA } \\
\text { target }\end{array}$ & \multicolumn{2}{|r|}{ Primer sequence $\left(5^{\prime} \rightarrow 3^{\prime}\right)$} & $\begin{array}{l}\text { Annealing } \\
\text { Temperature }\end{array}$ \\
\hline \multirow{3}{*}{ NR2A } & Forward & GCTACACACTCTGCACCAATT & \multirow{3}{*}{64} \\
\hline & Reverse & СACCTGATAGCCTTCCTCAGTGA & \\
\hline & TaqManProbe & $\begin{array}{c}\text { 6-FAM } \\
\text { TGGTCAATGTGACTTGGGATGGCAABHQ-1 }\end{array}$ & \\
\hline \multirow{3}{*}{ NR2B } & Forward & CTGCATGCGGAATACAGTC & \multirow{3}{*}{56} \\
\hline & Reverse & TTGATGTAGCCTGGTTCCT & \\
\hline & TaqManProbe & $\begin{array}{c}\text { 6-FAM } \\
\text { CAGAAGCGCATCATCTCTGAGAATBHQ-1 }\end{array}$ & \\
\hline \multirow{3}{*}{ GAPDH } & Forward & TGCACCACCAACTGCTTAG & \multirow{3}{*}{54} \\
\hline & Reverse & GGATGCAGGGATGATGTTC & \\
\hline & TaqManProbe & HEX ATCACGCCACAGCTTTCCAGA BHQ-1 & \\
\hline
\end{tabular}

The qPCR was performed in a $25 \mu \mathrm{l}$ reaction volume containing a 10xPCR Buffer $(2.5 \mu \mathrm{l}), 25 \mathrm{mmol} \mathrm{MgCl} 2(4 \mu \mathrm{l}), 10 \mathrm{mmol}$ dNTPs $(2 \mu \mathrm{l})$, specific forward and reverse primers at $20 \mathrm{pmol} / \mu \mathrm{l}$ concentration $(1 \mu \mathrm{l}), 5 \mathrm{pmol} / \mu \mathrm{l}$ Taq Man probe $(1.5 \mu \mathrm{l})$, cDNA $(2 \mu l), 5 \mathrm{u} / \mu \mathrm{l}$ Taq DNA polymerase ( $1 \mu \mathrm{l})$ (Beagle, st. Petersburg, Russia), and ddH2O $(10 \mu l)$. All samples were run in duplicate. Cycling was performed at $95 \mathrm{C}^{\circ}$ for $5 \mathrm{~min}$ followed by a 45 -cycle amplification at $95^{\circ} \mathrm{C}$ for 10 s, then at the annealing temperature (see Table 1) for $15 \mathrm{~s}$ and at the temperature $72^{\circ} \mathrm{C}$ for $20 \mathrm{~s}$.

Results of the qPCR measurements were expressed as Ct values, where $\mathrm{Ct}$ is defined as the threshold cycle of PCR at which amplified product was $0.05 \%$ of normalized maximal signal. We used the comparative $\mathrm{Ct}$ method and computed the difference between the expression of the gene of interest and GAPDH expression in each cDNA 
sample (2- $\Delta \Delta$ Ct method). Results are expressed as folds of expression compared to the mean values of expression in non-stressed control animals (Couch et al., adapted from Livak and Schmittgen 2001).

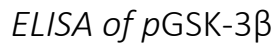

Hippocampus was homogenized in buffer containing $10 \mathrm{mM}$ Tris $(\mathrm{pH} 7,4), 100 \mathrm{mM}$ $\mathrm{NaCl}, 1 \mathrm{mM}$ EDTA, 1 mM EGTA, 1 mM NaF, 20 mM Na4P2O7, 10\% glycerol, 2mM Na3VO4. Protease inhibitor cocktail (Sigma, USA) was added immediately prior to homogenization. The GSK-3B [pS9] ELISA kit (Invitrogen Corporation, USA) was used for detection and quantification of the level of GSK-3 $\beta$ protein phosphorylated at serine residue 9. A monoclonal capture antibody specific for GSK-3 $\beta$ has been coated onto the wells of the 96-well plate provided. During the first incubation, standards of known GSK-3 $\beta$ [pS9] content and unknown samples are pipetted into the wells and the GSK-3 $\beta$ antigen binds to the immobilized (capture) antibody. After washing, a rabbit antibody specific for GSK-3 $\beta$ [pS9] is added to the wells. During the second incubation, this antibody serves as a detection antibody by binding to the immobilized GSK-3 $\beta$ protein captured during the first incubation. After washing, a horseradish peroxidase-labelled anti-rabbit IgG is added. This binds to the detection antibody to complete the four-member sandwich. After a third incubation and washing to remove all the unbound enzyme, a substrate solution (TMB) is added, which is acted upon by the bound enzyme to produce color. The intensity of this colored product is directly proportional to the concentration of GSK-3 $\beta$ [pS9] present in the original specimen. All procedures were done according the instruction manual and the optical density of experimental plates were measured at $450 \mathrm{~nm}$ using a plate reader (Wallac 1420 VICTOR, USA). The results were normalized to total protein level in tissues homogenates. Protein concentrations were determined by the biuret assay using bovine serum albumin as a standard (Gornall, A. G., Bardawill, C. J., and David, M. M. (1949) J Biol Chem 177, 751-766). 
Table 2. EEG power spectra parameters in chronically stressed mice were not affected by DS.

\begin{tabular}{|c|c|c|c|c|c|c|}
\hline $\begin{array}{l}\text { Treatment } \\
\text { SLOW WAVE }\end{array}$ & Delta & Theta & Alpha & Sigma & Beta 1 & Beta 2 \\
\hline $\begin{array}{l}\text { Vehicle } \\
\text { baseline }\end{array}$ & $39.95 \pm 0.5$ & $32.15 \pm 0.8$ & $14.10 \pm 0.9$ & $3.55 \pm 0.4$ & $5.04 \pm 0.2$ & $5.21 \pm 0.7$ \\
\hline $\begin{array}{l}\text { Vehicle } \\
\text { stress }\end{array}$ & $40.40 \pm 0.7$ & $33.10 \pm 1.9$ & $13.40 \pm 0.8$ & $3.19 \pm 0.6$ & $4.72 \pm 0.3$ & $5.19 \pm 0.8$ \\
\hline DS baseline & $41.10 \pm 0.8$ & $32.60 \pm 0.9$ & $14.25 \pm 1.0$ & $3.39 \pm 0.3$ & $4.88 \pm 0.1$ & $3.78 \pm 0.5$ \\
\hline $\begin{array}{l}\text { DS stress } \\
\text { REM SLEEP }\end{array}$ & $40.01 \pm 1.6$ & $34.00 \pm 2.1$ & $13.97 \pm 0.9$ & $3.28 \pm 0.4$ & $4.73 \pm 0.3$ & $4.00 \pm 0.7$ \\
\hline $\begin{array}{l}\text { Vehicle } \\
\text { baseline }\end{array}$ & $24.32 \pm 1.4$ & $41.79 \pm 0.9$ & $17.05 \pm 0.7$ & $3.56 \pm 0.3$ & $5.98 \pm 0.6$ & $7.30 \pm 0.7$ \\
\hline $\begin{array}{l}\text { Vehicle } \\
\text { stress }\end{array}$ & $26.67 \pm 2.3$ & $40.52 \pm 0.45$ & $15.60 \pm 1.2$ & $3.48 \pm 0.4$ & $5.86 \pm 0.5$ & $7.87 \pm 1.1$ \\
\hline DS baseline & $23.65 \pm 1.7$ & $39.86 \pm 1.2$ & $17.87 \pm 0.9$ & $3.64 \pm 0.2$ & $6.53 \pm 0.4$ & $8.45 \pm 1.1$ \\
\hline DS stress & $24.18 \pm 1.9$ & $40.50 \pm 1.0$ & $16.90 \pm 0.9$ & $3.60 \pm 0.3$ & $6.21 \pm 0.5$ & $8.61 \pm 1.4$ \\
\hline
\end{tabular}


Table 3A. List of differentially expressed genes in the hippocampus of old mice treated with DS.

\begin{tabular}{|c|c|c|c|}
\hline Gene name & Gene Symbol & Ratio* & p-Value \\
\hline $\begin{array}{l}\text { Activity-regulated cytoskeleton- } \\
\text { associated protein }\end{array}$ & Arc & 2,097 & 0,0000819 \\
\hline Neuronal pentraxin II & Nptx2 & 2,034 & 0,0000107 \\
\hline $\begin{array}{l}\text { Serum/glucocorticoid regulated } \\
\text { kinase } 1\end{array}$ & Sgk1 & 1,83 & 0,001816 \\
\hline $\begin{array}{l}\text { TATA-binding protein-associated } \\
\text { factor } 2 \mathrm{~N}\end{array}$ & Taf15 & 1,67322 & 0,00019865 \\
\hline Dynactin 1 & Dctn1 & 1,65636 & 0,00115384 \\
\hline VGF nerve growth factor inducible & Vgf & 1,62473 & 0,00047794 \\
\hline Regulator of G-protein signaling 4 & Rgs4 & 1,58555 & 0,00017529 \\
\hline Early growth response 1 & Egr1 & 1,57936 & 3,45E-06 \\
\hline $\begin{array}{l}\text { IQ motif containing GTPase } \\
\text { activating protein } 2\end{array}$ & Iqgap2 & 1,57442 & 0,00069018 \\
\hline proline-rich coiled-coil 2A & Bat2 & 1,5569 & $3,56 \mathrm{E}-05$ \\
\hline HtrA serine peptidase 1 & Htra1 & 1,52536 & $1,02 \mathrm{E}-05$ \\
\hline $\begin{array}{l}\text { GATA zinc finger domain containing } \\
\text { 2B }\end{array}$ & Gatad2b & 1,52186 & $1,42 \mathrm{E}-05$ \\
\hline $\begin{array}{l}\text { Secretory leukocyte peptidase } \\
\text { inhibitor }\end{array}$ & Slpi & 1,51893 & 0,00199586 \\
\hline $\begin{array}{l}\text { FBJ murine osteosarcoma viral } \\
\text { oncogene homolog B }\end{array}$ & Fosb & 1,51512 & $6,34 \mathrm{E}-06$ \\
\hline $\begin{array}{l}\text { Solute carrier family } 23 \text { (ascorbic } \\
\text { acid transporter), member } 3\end{array}$ & Slc23a3 & 1,50125 & $4,12 \mathrm{E}-06$ \\
\hline Histone cluster $1, \mathrm{H} 1 \mathrm{c}$ & Hist1h1c & $-1,5352$ & 0,00180782 \\
\hline $\begin{array}{l}\text { Circadian Associated Repressor Of } \\
\text { Transcription }\end{array}$ & Gm129 & $-1,5496$ & $5,65 \mathrm{E}-05$ \\
\hline Sperm associated antigen 7 & Spag7 & $-1,5573$ & $1,41 \mathrm{E}-05$ \\
\hline $\begin{array}{l}\text { Enhancer of rudimentary homolog } \\
\text { (Drosophila) }\end{array}$ & Erh & $-1,5667$ & 4,47E-07 \\
\hline $\begin{array}{l}\text { Solute carrier family } 27 \text { (fatty acid } \\
\text { transporter), member } 1\end{array}$ & Slc27a1 & $-1,6106$ & $1,63 \mathrm{E}-05$ \\
\hline $\begin{array}{l}\text { ST3 beta-galactoside alpha-2,3- } \\
\text { sialyltransferase } 5\end{array}$ & St3gal5 & $-1,6226$ & $5,94 \mathrm{E}-07$ \\
\hline Cold inducible RNA binding protein & Cirbp & $-1,6348$ & $9,62 \mathrm{E}-06$ \\
\hline $\begin{array}{l}\text { D site of albumin promoter } \\
\text { (albumin D-box) binding protein }\end{array}$ & $\mathrm{Dbp}$ & $-1,6382$ & $4,01 \mathrm{E}-10$ \\
\hline $\begin{array}{l}\text { Oligodendrocytic myelin paranodal } \\
\text { and inner loop protein }\end{array}$ & Opalin & $-1,8266$ & 0,00016628 \\
\hline
\end{tabular}


Table 3B. List of differentially expressed genes in the prefrontal cortex of old mice treated with DS.

$\begin{array}{llcr}\text { Gene name } & \text { Gene Symbol } & \text { Ratio* } & \text { p-Value } \\ \begin{array}{l}\text { Activity-regulated cytoskeleton- } \\ \text { associated protein }\end{array} & \text { Inhba } & 1,66369 & 0,00075 \\ \begin{array}{l}\text { Neuronal pentraxin II } \\ \text { Serum/glucocorticoid regulated }\end{array} & \text { Stmn4 } & -1,9122 & 4,73 \mathrm{E}-06 \\ \text { kinase 1 } & \text { Opalin } & -1,7873 & 0,000254 \\ \text { TAF15 RNA } & \text { Gabarapl1 } & -1,5367 & 1,21 \mathrm{E}-07\end{array}$

*Ratio=(mRNA abundance DISU/ mRNA abundance Control) Unadjusted $\mathrm{p}$ value $<0.001$ and | fold change $\mid>1.5$ (see the text) 



\section{Chapter 4}

\section{Tlr4 upregulation in the brain accompanies depression- and anxiety-like behaviors induced by a high-cholesterol diet}

Strekalova $\mathrm{T}^{1,2,3,{ }^{*}}$, Evans $\mathrm{M}^{1}$, Costa-Nunes $\mathrm{JP}^{2,3}$, Bachurin $\mathrm{S}^{4}$, Yeritsyan $\mathrm{N}^{5}$, Couch $\mathrm{Y}^{1}$, Steinbusch $\mathrm{HWM}^{3}$, Köhler $\mathrm{ES}^{6}$, Lesch $\mathrm{KP}^{3,7}$, Anthony $\mathrm{DC}^{1^{*}}$. ${ }^{*}$ Authors contributed equally to this work

${ }^{1}$ Department of Pharmacology, Oxford University, Oxford, UK; ${ }^{2}$ Institute for Hygiene and Tropical Medicine, New University of Lisbon, Lisbon, Portugal; ${ }^{3}$ Department of Neuroscience, Maastricht University, Maastricht, The Netherlands; ${ }^{4}$ Institute of Physiologically Active Compounds, Russian Academy of Sciences, Moscow, Russia; ${ }^{5}$ Division of Cardiology, University Hospital Magdeburg, Magdeburg, Germany; ${ }^{6}$ Department of Anatomy and Embryology, Maastricht University, Maastricht, Netherlands; ${ }^{7}$ Department of Psychiatry, Psychosomatics and Psychotherapy, University of Würzburg, Würzburg, Germany.

Brain, Behavior, and Immunity 2015, 48: 42-7. 


\section{Abstract}

An association between metabolic abnormalities, hypercholesterolemia and affective disorders is now well recognized. Less well understood are the molecular mechanisms, both in brain and in the periphery, that underpin this phenomenon. In addition to hepatic lipid accumulation and inflammation, C57BL/6J mice fed a highcholesterol diet (0.2\%) to induce Non-Alcoholic Fatty Liver Disease (NAFLD), exhibited behavioural despair, anxiogenic changes, and hyperlocomotion under bright light. These abnormalities were accompanied by increased expression of transcript and protein for Toll-like receptor 4, a pathogenassociated molecular pattern (PAMP) receptor, in the prefrontal cortex and the liver. The behavioural changes and T/r4 expression were reversed ten days after discontinuation of the high-cholesterol diet. Remarkably, the dietary fat content and body mass of experimental mice were unchanged, suggesting a specific role for cholesterol in the molecular and behavioural changes. Expression of Sert and Cox1 were unaltered. Together, our study has demonstrated for the first time that high consumption of cholesterol results in depression- and anxiety-like changes in C57BL/6J mice and that these changes are unexpectedly associated with the increased expression of TLR4, which suggests that TLR4 may have a distinct role in the CNS unrelated to pathogen recognition.

Key Words: Western diet; cholesterol; affective disorders; depression; anxiety; impulsivity; hepatosteatosis; toll-like receptor four (TIr4); CNS; mouse. 


\section{Introduction}

In man the prevalence and coincidence of both depression and obesity are growing steadily (de Wit et al., 2010). An emerging body of clinical and experimental evidence suggests that excessive nutrition, generally attributed to a so-called Western diet (a diet enriched with saturated fat and cholesterol), and the ensuing hypercholesterolemia, obesity and insulin resistance contribute to the pathogenesis of affective disorders and interfere with pharmacotherapy (Sonawalla et al., 2002). Translational studies using this type of dietary challenge in rodents revealed deficient synaptic plasticity and increased production of IL-1 $\beta$ in the hippocampus of Wistar rats after foot shock (Sobesky et al., 2014), blunted responses to antidepressant treatment in a chronic stress depression model (Isingrini et al., 2010), and signs of hepatosteatosis and liver inflammation, such as over-expression of genes of the macrophage activation marker Cd68, and the cytokine Tnf- $\alpha$ in C57BL/6J mice (Comhair et al., 2011). Another study in toll-like receptor 4 (T/r4) deficient mice revealed that these mice were more insulin sensitive, than WT mice after being fed a high-fat diet (Shi et al., 2006). However, these studies did not investigate potential changes of parameters of emotionality and related molecular changes in the CNS, and the link between peripheral and central effects of a high-fat diet was not addressed.

A condition of non-alcoholic fatty liver disease (NAFLD) can be induced by a 3-week exposure of young $\mathrm{C} 57 \mathrm{BL} / 6 \mathrm{~J}$ mice to a diet containing $0.2 \%$ cholesterol (Comhair et al., 2011). In this model, cholesterol and female sex, but not the degree of saturation of the fats was found to be the key factors that determine the degree of hepatic steatosis and inflammation. Here, we used this model to investigate the effects of increased cholesterol intake on depression- and anxiety-like behaviours and on T/r4, Sert (SIc6a4), and Cox1 gene expression to discover whether the changes in TIr4 expression observed in the periphery might also occur in the CNS. 


\section{Methods}

\section{Animals}

Studies were performed on 3-month-old female C57BL/6J from the Gulbenkian Institute of Science, Oeiras, Portugal. Mice were housed in groups of five under a reversed light-dark cycle, under standard laboratory conditions (see Supplementary data). All experiments were carried out in accordance with the European Communities Council Directive for the care and use of laboratory animals.

Study flow with a model of non-alcoholic fatty liver disease (NAFLD)

This study used a recently validated model of non-alcoholic fat dystrophy of the liver (Comhair et al. 2011). Mice were exposed for three weeks either to a regular laboratory diet with an energy content of $4.0 \mathrm{kcal} / \mathrm{g}$ (Mucedola Srl, Settimo Milanese, Italy) or a diet of the similar composition with $0.2 \%(\mathrm{w} / \mathrm{w})$ of cholesterol (HC diet) and an energy content of $4.6 \mathrm{kcal} / \mathrm{g}$ (Research Diets Inc, New Brunswick, NJ, USA; see Supplementary information); their body-weight and 24-h food intake were evaluated throughout the experimental period (see Supplementary information, SI Figure 1). One set of mice received the $\mathrm{HC}$ diet or standard chow for three weeks before behavioural testing and sacrifice, another set was exposed to the same regime, but then a 10-day wash-out period with standard chow followed before further behavioural testing and sacrifice. After this period of refeeding, the NAFLD-like hepatosteatosis has been shown to resolve itself (Itagaki et al. 2013). For more detailed investigation of potential behavioural changes, several tests were used. In order to avoid any interference between the tests on the same animal, different behaviours were studied in different groups of mice. Respective control mice were tested simultaneously with experimental mice (see supplementary information for full details of the testing regime).

The assessment of histological integrity of liver and hepatic triglyceride content was performed as described elsewhere (Comhair et al., 2011). RNA extraction from brain 
and liver tissue was carried out as described previously on animal that had been perfused with sterile heparinised-saline (Blond et al., 2002; Campbell et al., 2005). Quantitative RT-PCR (qPCR) was performed to evaluate expression of T/r4, Sert, TIr2, II-1b, Tnf and Cox1 using glyceraldehyde-3-phosphate dehydrogenase (Gapdh) as the housekeeping gene. Results were calculated as fold increase compared to control animals and normalized to the means of this group (details of all experimental techniques are given in Supplementary data and Table 1). An ELISA for TLR4 was employed to explore protein expression levels and the LAL test for endotoxin was performed on plasma collected immediately prior to perfusion (please see the supplementary information for details).

\section{Statistics}

Data were analysed with GraphPad Prism version 6.0 for Macintosh (San Diego, CA, USA) using unpaired t-tests or 2-way ANOVA with Bonferoni post hoc-testing. The level of confidence was set at $95 \%(p<0.05)$. For the analysis of the metabolic data (weight, food intake, and energy intake) multiple t-tests where used with a FDR set at $1 \%$.

\section{Results}

Mice subjected to a high-cholesterol diet display impulsivity and increased depressive-, and anxiety-like behaviours

Mice exposed to the HC diet displayed signs of elevated anxiety when tested under subtle lighting (5lux); significantly shorter time was spent in the open arms of elevated O-maze ( $p=0.02, t=2.661)$ and lit box of dark/light box $(p=0.02, t=2.365)$, as well as reduced mean distance to the wall in the open filed $(p=0.041, t=2.262)$ (Fig.1B-D). Mice re-exposed to a normal diet spent the same amount of time in the lit box and exhibited the same mean distance to the wall compared to the control group ( $p=0.27, t=1.161$ and $p=0.60, t=0.533$, respectively; Fig. $1 C, D)$. In the forced 
swim and tail suspension tests, animals fed the highcholesterol diet showed a significantly decreased latency to float or to immobility compared to control animals $(p=0.04, t=2.381$, and $p=0.03, t=2.526$, respectively; Fig.1E, $F)$. The duration of floating immobility behaviour in the dietary challenged group were significantly higher than in control animals $(p=0.007, t=3.361$ and $p=0.04, t=2.345$, respectively; Fig.1 E, G). Together these results suggest that increased behavioural despair, a sign of a depressive-like state, is induced in mice that received increased dietary cholesterol.

When the more stressful 25-Lux illumination was used in the dark-light box, open field and novel cage, the high-cholesterol group spent significantly longer time in the lit box and had an increased number of exits therein $(p=0.04, t=2.226$ and $p=0.04$, $\mathrm{t}=2.174$, respectively; Fig. $1 \mathrm{H}$ ). Similarly, increased vertical activity in the novel cage test and mean speed of horizontal movement in the open field was revealed in the animals subjected to a highcholesterol diet, compared to the control group $(p=0.009$, $t=3.082$ and $p=0.03, t=2.354$; Fig.1l, J). Such behavioural changes that are indicative of increased impulsivity and general behavioural invigoration are often associated with an elevated stress response (Strekalova et al., 2005). Ten days after discontinuation of the high-cholesterol diet, both horizontal and vertical activities measured under bright light returned to normal $(p=0.53, t=0.6448$ and $p=0.55$, $\mathrm{t}=0.617$; Fig.11.J).

High-cholesterol diet induces NAFLD-like syndrome and TIr4 upregulation without increasing body mass

Mice assigned to the control or the high-cholesterol diet had similar body weights before (mean: $20.3 \pm 1.4 \mathrm{~g}$ and $19.9 \pm 1.4 \mathrm{~g}$, respectively; $\mathrm{p}=0.577, \mathrm{t}=0.568$ ) and at time points during the experiment (see Supplementary Fig 1, p>0.05; body weight averaged across experiment was $21.1 \pm 1.2 \mathrm{~g}$ and $21.2 \pm 1.4$ in control and highcholesterol diet groups, respectively; $p=0.92, t=0.099$ ). The average daily intake of 
the high-cholesterol diet was significantly lower than that of control diet (averaged food intake across entire period of dietary intervention: $2.89 \pm 0.26 \mathrm{~g}$ and $2.30 \pm 0.35 \mathrm{~g}$, respectively; $\mathrm{p}=0.001, \mathrm{t}=3.670$ ), but the daily intake of calories did not differ between the groups (SI Figure 1). This is likely to reflect an adjustment of the mice to the higher caloric content of the high-cholesterol diet.

Compared with the control mice, the high-cholesterol diet group revealed compromised liver tissue integrity, in agreement with previous observations (Comhair et al., 2011). The appearance of intracellular vacuoles was due to fat deposition in the tissue (Fig.2A, middle image). The liver of the animals re-fed standard chow after the HC diet (bottom image) and control (top image) animals appeared normal. The colorimetric assay showed significantly increased liver concentration of triglycerides in mice on the high-cholesterol diet as compared to control animals ( $p=0.0003, t=6.001 ;$ Fig. $2 A$, middle panel). The liver mRNA concentrations of TIr4 were significantly elevated in the high-cholesterol group as compared to controls ( $p=0.03, t=2.533$; Fig. $2 \mathrm{~A}$,). However, there was no difference in the circulating levels of endotoxin as revealed by the LAL test. In the brain, 2-way ANOVA revealed that diet had a significant impact on T/r4 gene expression (79\% of variation; $p<0.0001)$ that was independent of the brain region $(1.62 \%$ of variation; $p=0.242)$. In the prefrontal cortex $(P F C)(p<0.001, t=5.165)$ and hippocampus $(p<0.001, t=6.89)$, mRNA concentrations of T/r4 were significantly higher than in the control group (Fig 2B, left panel), while mRNA concentrations of Sert ( $p>0.05, t=0.271$ ) and $\operatorname{Cox} 1$ ( $p>0.05, t=1.199)$ were not altered (Fig 2B, middle and right panels). An ELISA revealed that TLR4 protein was significantly upregulated in the PFC $(p<0.05$, $\mathrm{t}=2.130$ ), but not in the hippocampus following exposure to the HC diet compared to control. After a 10-day reversal to the control diet, mRNA concentrations of TIr4 were no longer different in the prefrontal cortex ( $p>0.05, t=1.291$, Fig.2C, left panel) and in the hippocampus ( $p>0.05, t=1.918$ Fig. $2 \mathrm{C}$, left panel) between mice from the high- 
cholesterol group and control mice. As before, expression levels of Sert and Cox1 were unchanged (Fig.2C, middle and right panels). We also examined gene expression for Tnf, $\| 1 b$ and TIr2, but the transcripts were expressed at a very low level and were unaffected by diet (data not shown).

\section{Discussion}

The present study with a recently validated model of NAFLD (Comhair et al., 2011) has demonstrated that a 3-week exposure of young naïve C57BL/6J mice to dietary cholesterol in amounts of $0.2 \%$ of daily food intake can evoke profound behavioural modifications and molecular changes in the brain and liver. This is the first report of the behavioural changes associated with this diet, and these changes are consistent with depression and anxiety-like behaviour. Based on previously validated protocols used in this part of the experiment, the data presented here suggest that mice exposed to high amounts of dietary cholesterol display behavioural changes that are similar to those induced in a model of stress-induced depression (Strekalova et al., 2004, 2005; Couch et al., 2013). The signs of impulsivity observed under bright light have also been shown to be associated with the response to chronic stress in mice (Sanchez, 1997; Strekalova et al., 2005). The diet-induced changes observed here, though unexpected, further support the argument that a high-cholesterol diet can induce a depression-like syndrome in a similar manner to the changes induced by a chronic stress model.

Liver steatosis, dystrophy, and accumulation of triglycerides have been previously described for this model, but the over-expression of a molecular marker of inflammation T/r4 has not. However, it has been shown that fatty acids can interact with TLR4 on adipocytes and macrophages in the periphery, and that $\mathrm{T} / \mathrm{r}^{-\%}$ animals are protected against insulin resistance induced by a high-fat diet. Meanwhile, no previous study has reported that TIr4 is induced in the CNS as a response to a high- 
cholesterol diet. A significant increase of gene expression of TIr4 was found in both the hippocampus and the prefrontal cortex, two important structures of the limbic system, but significant changes in protein were only detectable in the prefrontal cortex. This results were surprising as, in general, we have often found that changes in transcript are usually reflected by downstream changes in protein though not always to the same magnitude. We have previously shown that the prefrontal cortex behaves differently, in terms of cytokine induction, compared to the hippocampus (Couch et al. 2013). As the behavioural changes identified are most likely to reflect molecular changes in the prefrontal cortex than in the hippocampus, the putative relationship between TLR4 expression and the behavioural changes we observed remains consistent with our findings. The level of TIr4 expression returned to normal ten days after reversion to the control diet, and was accompanied by a normalization of vertical activity under stressful testing conditions. Notably, mRNA expression of Sert and Cox1 was not altered in any of the experimental groups. We have previously shown that changes in Sert and Cox1 expression are associated with the occurrence of stress-induced anhedonia (Couch et al., 2013). Thus despite the behavioural similarities in the diet-induced depressive-like state and the chronic stress paradigm there are clear molecular disparities. However, increased expression of T/r4 in the hypothalamus of female hamsters has been shown to be associated with increased anxiety-like behaviour and stress response but the rationale for exploring this gene was not given or discussed (Shannonhouse et al., 2014). Interestingly, the social separation method employed in the Shannonhouse study induced TIr4 expression only in female mice, and it should be noted that we used female mice in the present study because they exhibit a more pronounced phenotype. Pharmacological blockade of TLR4 has been shown to reduce indices of anxiety in the elevated plus maze test (Okun et al., 2012), but LPS-induced activation of TLR4 is known to increase parameters of anxiety (Rico et al., 2010). Taken together our results suggest that 
central upregulation of T/r4 might underlie the changes in the emotionality caused by the exposure to a high-cholesterol diet as reported here.

Hepatic Srebf1 and Fasn are also increased during high intake of cholesterol (Comhair et al., 2011), and are found to increase circulating endotoxins (Cani et al., 2008). This, in turn, can lead to elevated plasma concentrations of TNF- $\alpha, I L-1 \beta, I L-6, I L-10$ and cortisol, and the increased measures of anxiety and worsening of mood (Kullmann et al., 2013). Thus the increased TIr4 expression in the CNS might be the consequence of increased circulating levels of cytokines. However, our failure to detect changes in Tnf, II-1, T/r2, or Cox1 expression argue for a rather more indirect pathway. However, it is important to note that we only examined expression at the selected behavioural time points and it is possible that abnormal cytokine expression may have been induced either before or after these particular points it time. The overexpression of TIr4 can compromise the so-called neural plasticity, a term that was proposed for multiple aspects of aberrant brain plasticity underlying mechanisms of depression (Wainwright and Galea, 2013), since its deficiency enhances proliferation and neuronal differentiation (Rolls et al., 2007) and improves spatial reference memory (Okun et al., 2012). Interestingly, a high-fat diet that caused overexpression of IL-6 was recently reported to impair synaptic plasticity in rats (Sobesky et al., 2014). Thus future studies might explore whether altered brain plasticity as a consequence of TIr4 overexpression may be a cause for the changes in emotionality found in the present study.

Remarkably, in the model employed here, the body weight of mice on the highcholesterol diet remained unchanged. This, together with the fact that the fat content of the diet was normal, excludes the contribution of obesity or excessive amounts of exogenous or endogenous fat, or other pathogenic elements of a Western diet, apart from dietary cholesterol, to the central and peripheral abnormalities found here in the employed NAFLD model. 
In summary, our study demonstrates for the first time that the exposure of naive mice to high amounts of dietary cholesterol can result in depression- and anxiety-like changes, impulsivity and this is associated with systemic and central upregulation of TLR4 mRNA and protein.

\section{Conflict of Interest}

The authors declare no conflict of interest.

\section{Acknowledgements}

We acknowledge the important contribution of Drs. Dinora Lopes, Henrique Silveira and Dolores Bonaparte (New University of Lisbon) and Igor Pomytkin (Buddha Biopharma Oy, Finland). The authors' work reported in this paper was supported by the European Community (EC: AGGRESSOTYPE FP7/No. 602805) and RFBR 15-0403602 to TS. 


\section{References}

Blond, D., Campbell, S. J., Butchart, A. G., Perry, V. H. \& Anthony, D. C., 2002. Differential induction of interleukin-1beta and tumour necrosis factor-alpha may account for specific patterns of leukocyte recruitment in the brain. Brain Res 958, 89-99.

Campbell, S. J. et al., 2005. Central Nervous System Injury Triggers Hepatic CC and CXC Chemokine Expression that Is Associated with Leukocyte Mobilization and Recruitment to Both the Central Nervous System and the Liver. Am J Pathol 166, 1487-1497.

Cani, P.D., Bibiloni, R., Knauf, C., Waget, A., Neyrinck, A.M., Delzenne, N.M., Burcelin, R., 2008. Changes in gut microbiota control metabolic endotoxemia-induced inflammation in high-fat diet-induced obesity and diabetes in mice. Diabetes. 57, 1470-1481.

Cline, B.H., Anthony, D.C., Lysko, A., Dolgov, O., Anokhin, K., Schroeter, C., Malin, D., Kubatiev, A., Steinbusch, H.W., Lesch, K.P., Strekalova, T., 2014. Lasting downregulation of the lipid peroxidation enzymes in the prefrontal cortex of mice susceptible to stress-induced anhedonia. Behav. Brain. Res. doi: 10.1016/j.bbr.2014.04.037.

Comhair, T.M., Garcia-Caraballo, S.C., Dejong, C.H., Lamers, W.H., Köhler, S.E., 2011. Dietary cholesterol, female gender and n-3 fatty acid deficiency are more important factors in the development of nonalcoholic fatty liver disease than the saturation index of the fat. Nutr. Metab. (Lond). 8, 4.

Costa-Nunes, J., Zubareva, O., Araújo-Correia, M., Valença, A., Schroeter, C.A., Pawluski, J.L., Vignisse, J., Steinbusch, H., Hermes, D., Phillipines, M., Steinbusch, H.M., Strekalova, T., 2014. Altered emotionality, hippocampus-dependent performance and expression of NMDA receptor subunit mRNAs in chronically stressed mice. Stress. 17, 108-116.

Couch, Y., Anthony, D.C., Dolgov, O., Revischin, A., Festoff, B., Santos, A.I., Steinbusch, H.W.M., Strekalova, T., 2013. Microglial activation, increased TNF and SERT expression in the prefrontal cortex define stress-altered behaviour in mice susceptible to anhedonia. Brain. Behav. Immun. 29, 136-146.

de Wit L., Luppino F., van Straten A., Penninx B., Zitman F., Cuijpers P. 2010. Depression and obesity: a meta-analysis of community-based studies. Psychiatry Res. 30, 230-235.

Isingrini, E., Camus, V., Le Guisquet, A.M., Pingaud, M., Devers, S., Belzung, C., 2010. Association between repeated unpredictable chronic mild stress (UCMS) procedures with a high fat diet: a model of fluoxetine resistance in mice. PLoS. One. 5, e10404.

Itagaki, H., Shimizu, K., Morikawa, S., Ogawa, K. \& Ezaki, T., 2013. Morphological and functional characterization of non-alcoholic fatty liver disease induced by a methioninecholine-deficient diet in C57BL/6 mice. International journal of clinical and experimental pathology 6, 2683-2696.

Kullmann, J.S., Grigoleit, J.S., Lichte, P., Kobbe, P., Rosenberger, C., Banner, C., Wolf, O.T., Engler, H., Oberbeck, R., Elsenbruch, S., Bingel, U., Forsting, M., Gizewski, E.R., Schedlowski, M., 2013. Neural response to emotional stimuli during experimental human endotoxemia. Hum. Brain. Mapp. 34, 22172227. 
Malatynska, E., Steinbusch, H.W., Redkozubova, O., Bolkunov, A., Kubatiev, A., Yeritsyan, N.B., Vignisse, J., Bachurin, S., Strekalova, T., 2012. Anhedonic-like traits and lack of affective deficits in 18-month-old C57BL/6 mice: Implications for modeling elderly depression. Exp. Gerontol. 47, 552-564.

Markova, N., Chernopiatko, A., Schroeter, C.A., Malin, D., Kubatiev, A., Bachurin, S., Costa-Nunes, J., Steinbusch, H.M., Strekalova, T., 2013. Hippocampal gene expression of deiodinases 2 and 3 and effects of 3,5-diiodo-L-thyronine T2 in mouse depression paradigms. Biomed. Res. Int. 2013, 565218.

Okun, E., Barak, B., Saada-Madar, R., Rothman, S.M., Griffioen, K.J., Roberts, N., Castro, K., Mughal, M.R., Pita, M.A., Stranahan, A.M., Arumugam, T.V., Mattson, M.P. 2012. Evidence for a developmental role for TLR4 in learning and memory. PLoS. One. 7, e47522.

Rico, J.L., Ferraz, D.B., Ramalho-Pinto, F.J., Morato, S., 2010. Neonatal exposure to LPS leads to heightened exploratory activity in adolescent rats. Behav. Brain. Res. 215, 102-109.

Rolls, A., Shechter, R., London, A., Ziv, Y., Ronen, A., Levy, R., Schwartz, M., 2007. Toll-like receptors modulate adult hippocampal neurogenesis. Nat. Cell. Biol. 9, 1081-1088.

Shannonhouse, J.L., Fong, L.A., Clossen, B.L., Hairgrove, R.E., York, D.C., Walker, B.B., Hercules, G.W., Mertesdorf, L.M., Patel, M., Morgan, C., 2014. Female-biased anorexia and anxiety in the Syrian hamster. Physiol. Behav. 133, 141-151.

Sanchez, C., 1997. Acute stress enhances anxiolytic-like drug responses of mice tested in a black and white test box. Eur. Neuropsychopharmacol. 7, 283-288.

Shelton, R.C., Miller, A.H., 2010. Eating ourselves to death (and despair): the contribution of adiposity and inflammation to depression. Prog Neurobiol. 91, 275-299.

Shi, H., Kokoeva, M.V., Inouye, K., Tzameli, I., Yin, H., Flier, J.S., 2006. TLR4 links innate immunity and fatty acid-induced insulin resistance. J. Clin. Invest. 116, 3015-3025.

Sobesky, J.L., Barrientos, R.M., De May, H.S., Thompson, B.M., Weber, M.D., Watkins, L.R., Maier, S.F., 2014. High-fat diet consumption disrupts memory and primes elevations in hippocampal IL-1 $\beta$, an effect that can be prevented with dietary reversal or IL-1 receptor antagonism. Brain. Behav. Immun. doi: 10.1016/j.bbi.2014.06.017.

Sonawalla, S.B., Papakostas, G.I., Petersen, T.J., Yeung, A.S., Smith, M.M., Sickinger, A.H., Gordon, J., Israel, J.A., Tedlow, J.R., Lamon-Fava, S., Fava, M., 2002. Elevated cholesterol levels associated with nonresponse to fluoxetine treatment in major depressive disorder. Psychosomatics. 43, 310-316.

Strekalova, T., Spanagel, R., Bartsch, D., Henn, F., Gass, P., 2004. Stress-induced anhedonia in mice is associated with deficits in forced swimming and exploration. Neuropsychopharmacology. 29, 20072017.

Strekalova, T., Spanagel, R., Dolgov, O., Bartsch, D., 2005. Stressed-induced hyperlocomotion as a confounding factor in anxiety and depression models in mice. Behav. Pharm. 16, 171-180.

Wainwright, S.R., Galea, L.A., 2013. The neural plasticity theory of depression: assessing the roles of adult neurogenesis and PSA-NCAM within the hippocampus. Neural. Plast. 2013:805497. 


\section{Figure Legends}

Figure 1. Study flow and effects of a high-cholesterol diet on parameters of emotionality. (A) Schematic of the study. (B-D) Anxiety-like behavior was increased in animals kept on a highcholesterol diet for 3 weeks in as revealed by the (B) O-maze, (C) dark/light box and (D) open field tests; this anxiety-like behavior returned to normal after the wash-out period in the two latter tests. (E-G) Depressive-like behavior was elevated in mice exposed to high cholesterol diet as revealed by the $(E)$ forced swim and $(F, G)$ tail suspension tests; such depressive-like behviour was no different from control following the wash-out period in the tail suspension test. (H-J) Mice exposed to high-cholesterol diet displayed signs hyperactivity and invigoration in brightly illuminated $(\mathrm{H})$ dark/light box, $(\mathrm{I})$ open field and $(\mathrm{J})$ novel cage that was not found in mice re-exposed to normal diet, in the two latter tests $(I, J) .\left({ }^{*} p<0.05\right.$ vs. control, t-test). Data are shown as mean \pm SEM, $n=6+$.

Figure 2. The effects of a high-cholesterol diet on (A) liver and $(B \& C)$ the brain. (Ai) Photomicrographs of haematoxylin and eosin-stained sections showing the normal appearing liver in animals feed a control diet (top) versus the high-cholesterol diet for 3 weeks (middle) and those re-fed the standard chow for 10 days (bottom). Note the vacuolation in the middel image. Scale bar 20um. (Aii) Concentration of triglycerides in the liver, (Aiii) mRNA expression of T/r4, and (Aiv) the absence of any increase in circulating levels of endotoxin. (B) mRNA concentrations of T/r4, Sert and Cox1 in the hippocampus and prefrontal cortex immediately after a 3-week dietary intervention and ELISA data revealing that there is an increase in TLR4 protein expression in the PFC. (C) Ten days after reversal to the control diet gene expression returned to normal ( ${ }^{*} p<0.05$ vs. control, t-test and ANOVA, see the text). Data are shown as mean $\pm S E M, n=6+$. 


\section{A Experimental design}

\section{$\square$ Standard diet \\ High cholesterol $\square$ Behaviour and tissue}

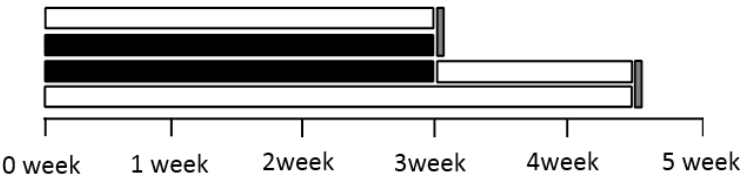

B O-Maze at $5 \mathrm{~lx}$
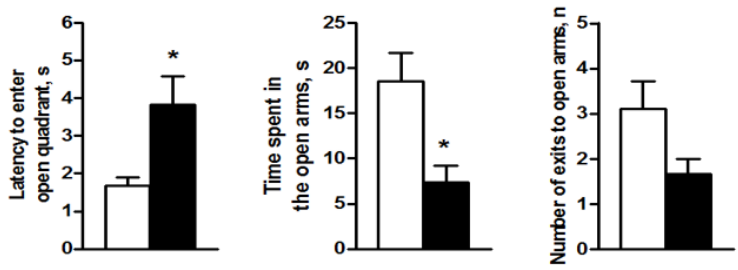

\section{Forced swim test}
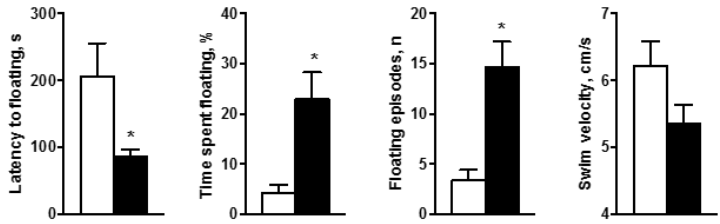

D Dark-light box at $25 \mathrm{~lx}$
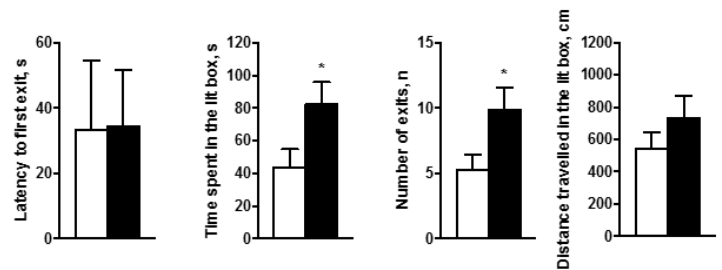

E Novel cage

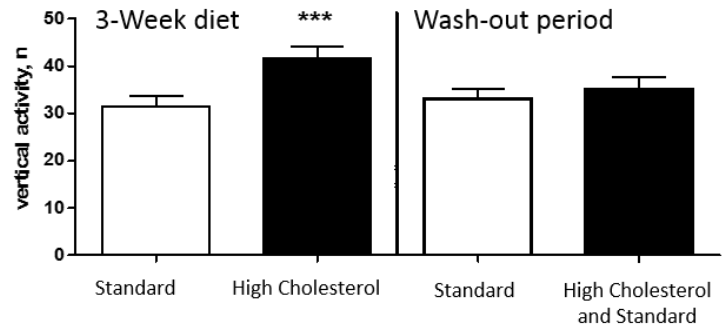

Figure 1 
A Hepatic response to a high cholesterol diet

i.

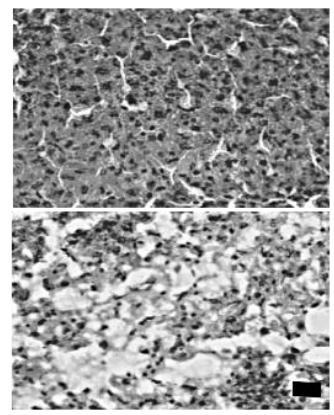

ii.

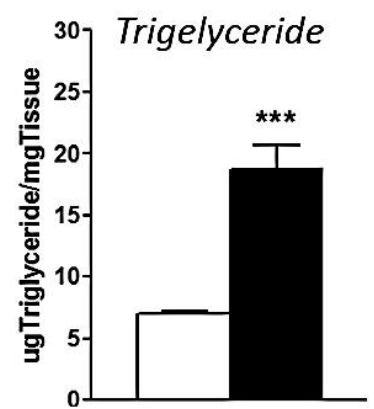

iii.

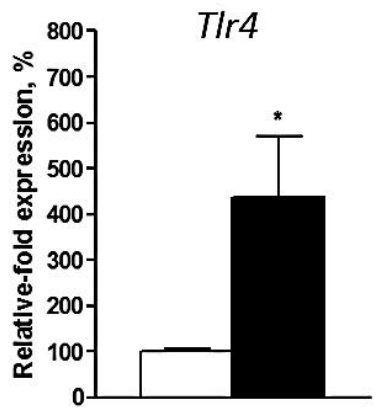

B CNS gene expression after exposure to a high cholesterol diet TIr4 Sert Cox1
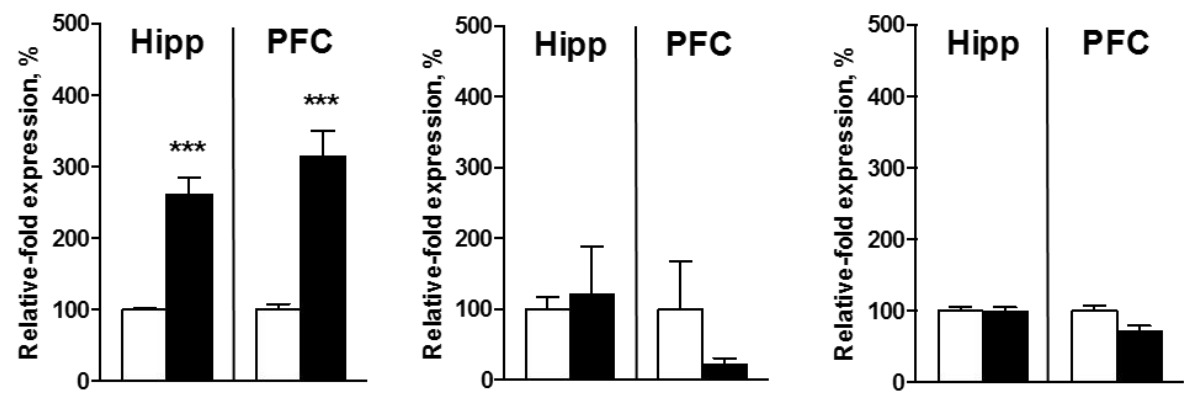

C CNS gene expression after discontinuation of a high cholesterol diet

TIr4

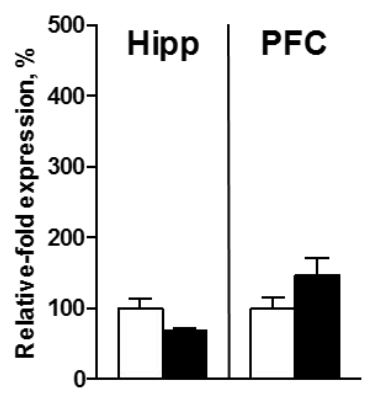

Sert

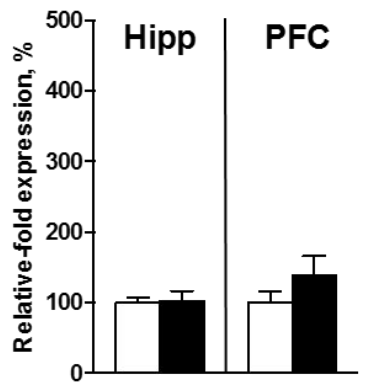

Cox1

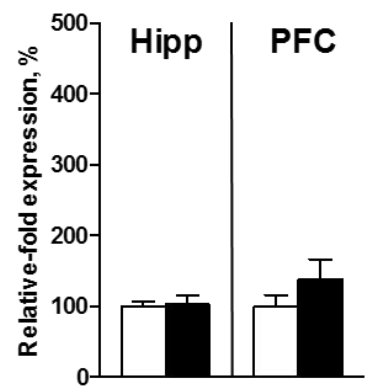

Figure 2 



\section{Chapter 5}

\section{Animal models of depression and drug delivery with food as an effective dosing method: evidences from studies with celecoxib and dicholine succinate}

Costa-Nunes $\mathrm{JP}^{1,2,3^{*}}$, Cline $\mathrm{BH}^{4^{*}}$, Araújo-Correia $\mathrm{M}^{2,5}$, Valença $\mathrm{A}^{2,6}$, Markova $\mathrm{N}^{7,8}$, Dolgov $\mathrm{O}^{9}$, Kubatiev $\mathrm{A}^{7}$, Yeritsyan $\mathrm{N}^{10}$, Steinbusch HWM ${ }^{1}$, Strekalova $\mathrm{T}^{1,2,8}$.

${ }^{*}$ Co-first authorship

${ }^{1}$ Department of Neuroscience, Maastricht University, Maastricht, the , Netherlands; ${ }^{2} \mathrm{CBA}$, Faculdade de Ciencias, Universidade de Lisboa, Lisboa, Portugal; ${ }^{3}$ Instituto de Higiene e Medicina Tropical, Universidade Nova de Lisboa, Lisboa, Portugal; ${ }^{4}$ INSERM U1119, Université de Strasbourg, Strasbourg, France; ${ }^{5}$ Chronic Diseases Research Center, Faculdade de Ciências Médicas, Universidade Nova de Lisboa, Lisboa, Portugal; ' ${ }^{6}$ aculdade de Medicina Veterinária, Universidade de Lisboa, Lisboa, Portugal; ${ }^{7}$ Institute of General Pathology and Pathophysiology, Russian Academy of Medical Sciences, Moscow, Russia; ${ }^{8}$ Institute of Physiologically Active Compounds, Russian Academy of Sciences, Moscow, Russia. ${ }^{9}$ Anokhin Institute of Normal Physiology, Russian Academy of Medical Sciences, Moscow, Russia. ${ }^{10}$ Division of Cardiology, University Hospital Magdeburg, Magdeburg, Germany.

BioMed Research International 2015, 2015:596126. 


\section{Abstract}

Multiple models of human neuropsychiatric pathologies have been generated during the last decades which frequently use chronic dosing. Unfortunately, some drug administration methods may result in undesirable effects creating analysis confounds hampering model validity and preclinical assay outcomes. Here, automated analysis of floating behaviour, a sign of a depressive-like state, revealed that mice, subjected to a three-week intraperitoneal injection regimen, had increased floating. In order to probe an alternative dosing design that would preclude this effect, we studied the efficacy of a low dose of the antidepressant imipramine $(7 \mathrm{mg} / \mathrm{kg} /$ day) delivered via food pellets. Antidepressant action for this treatment was found while no other behavioural effects were observed. We further investigated the potential efficacy of chronic dosing via food pellets by testing the antidepressant activity of new drug candidates celecoxib (30 mg/kg/day) and dicholine succinate (50 mg/kg/day), against standard antidepressants imipramine $(7 \mathrm{mg} / \mathrm{kg} /$ day) and citalopram $(15 \mathrm{mg} / \mathrm{kg} / \mathrm{day})$ utilizing the forced swim and tail suspension tests. Antidepressant effects of these compounds were found in both assays. Thus, chronic dosing via food pellets is efficacious in small rodents, even with a low drug dose design, and can prevail against potential confounds in translational research within depression models applicable to adverse chronic invasive pharmacotherapies.

Key words: pre-clinical models of depression, dosing route, imipramine, citalopram, celecoxib, dicholine succinate, animal welfare, mouse. 


\section{Introduction}

The challenge to propose new powerful therapeutics for neuropsychiatric disorders, including antidepressants, has raised important questions regarding the efficiency of preclinical approaches currently being used (Munos, 2009; Piggot et al., 2010; Araragi and Lesch, 2013). Numerous limitations of the models of human neuropsychiatric pathologies have being intensively discussed during the last years (Insel, 2007; Insel and Sahakian, 2012; Strekalova et al., 2013). Apart from a general problem of translational research, basic practical issues with animal models of neuropsychiatric conditions, however seemingly trivial, can essentially affect the validity of preclinical models, yet these can be addressed and resolved.

As with translational models in small rodents, these issues concern laboratory and procedural settings in animal studies. A number of experimental conditions have been shown to result in potential confounds for the practical application of animal models. The principals of these factors are commonly considered to include: the circadian phase of manipulations (Sato et al., 2005; Beeler et al., 2006), cage enrichment (Frick et al., 2003; Wolfer et al., 2004; Munne et al., 2011), lighting conditions (Strekalova et al., 2005; Fukushiro et al., 2010), handling (Wahlsten et al., 2003; Longordo et al., 2011; Cloutier et al., 2014), vibration (Ringgold et al., 2013), the adverse taste of food or water (Strekalova et al., 2008; Strekalova and Steinbusch, 2010), and a presence of and manipulations by an experimenter (Bohlen et al., 2014; Sorge et al., 2014). They are sometimes believed to result in the remarkable variability in results that are extensively reported by the literature (Crabbe et al., 1999; Mandillo et al., 2008; Strekalova et al., 2008, 2011). The method and duration of dosing of experimental animals is one of the important sources of such confounds (Wahlsten et al., 2003; Sousa et al., 2006; Azar et al., 2011). 
Various types of invasive treatments in rodents were shown to induce pain, inflammation and distress, despite the proper use of standardized methods of application, especially when prolonged dosing is employed (Gärtner et al., 1980; Cloutier and Newberry, 2008; Thiele and Navarro, 2014). Obviously, this raises issues that concern not only the quality of studies, in which such dosing methods are used, but also animal welfare and ethical aspects. Nonetheless, in many cases long and invasive drug administration to small rodents is problematic to avoid. This often applies for instance when non-water soluble compounds have to be chronically administered, for example, during experimental conditions for which the induction of a desirable syndrome in an animal and / or the occurrence of the therapeutic drug's effect require a long time. The latter experimental situations are particularly typical for testing drugs in rodent models of depression where, for example, the induction of some key elements of depressive syndrome may take 2-12 weeks (Willner, 2005; Strekalova et al., 2011; Harro, 2013) and the occurrence of an antidepressant's effect, with most of the classical antidepressants, develop after 3-4 weeks of treatment (Willner, 2005; Strekalova et al., 2006; Overstreet, 2012).

In order to avoid the negative effects of chronic invasive dosing on overall animal welfare and experimental outcomes from standard models of depression, we evaluated the efficacy of drug delivery via food pellets in mice. First, we studied the effects of a three-week daily intraperitoneal vehicle injection in the mouse forced swim test, a common scheme of testing for the antidepressant-like effects of various treatments (Cryan et al., 2005a; Overstreet, 2012; Harro, 2013). As this manipulation resulted in an increase of floating scores, a measure of "behavioural despair", indicating a "pro-depressant" effect of daily intraperitoneal injections for the experimental animals, we probed an alternative way of dosing using food pellets.

Though drug delivery with voluntary consumed food is one of the common methods of dosing, its use in laboratory research is quite limited. While in many cases this 
mode of pharmacological treatment is seen as advantageous because it enables the maintenance of a steady blood concentration for the drug, in contrast to bolus drug administration. However, it is sometimes viewed as insufficiently reliable due to its reliance on food intake and the variable bioavailability of some compounds depending on their delivery route (Pottenger et al., 2000; Volvert et al., 2008).

However, given that, in a reasonable proportion of the experimental situations, the consummatory behaviour of laboratory animals is not altered and the standard pharmaca, whose bioavailability and metabolism are well known not to be sensitive to the treatment method, are used; dosing with the voluntary intake of food pellets can probably be exploited much more frequently. Apart from the obvious benefits of animal wellbeing, the delivery of investigational drugs with food pellets can increase the validity of translational models as it simulates a human equivalent therapeutic dosing route.

In this study we first used, via food pellets, a low dose of a classical antidepressant reference drug, imipramine $(7 \mathrm{mg} / \mathrm{kg} /$ day), for which chronic administration via drinking water for 3 weeks was recently reported to evoke an antidepressant effect in a model of stress-induced anhedonia (Cline et al., 2014). A low dose of antidepressant was selected because we sought to evaluate the usefulness of this dosing method at the lowest possible dosage limit which is used in other means of drug administration, and because imipramine may exert side-effects when applied in higher concentrations (Strekalova et al., 2013). The effects of imipramine delivered with self-made food pellets were tested in the forced swim test, as well as, in order to exclude potential non-specific effects of treatment, in a battery of behavioural tests including: dark/light box, O-maze, novel cage, open field and two-bottle sucrose test. Finally, to verify the applicability of this defined dosing method with food pellets, we tested the effects of new potential antidepressants, celecoxib, a non-watersoluble compound, at the dose $30 \mathrm{mg} / \mathrm{kg} /$ day which was selected based on previously 
published data (Myint et al., 2007; Maciel et al., 2013), and dicholine succinate whose dose was applied at $50 \mathrm{mg} / \mathrm{kg} /$ day based on previous results (Cline et al., 2012) (Strekalova and Anthony, unpublished results), in the forced swim and tail suspension tests. Imipramine, applied at $7 \mathrm{mg} / \mathrm{kg} /$ day (Pottenger et al., 2000; Cline et al., 2012; Malatynska et al., 2012; Strekalova et al., 2013), and citalopram, 15 mg/kg/day (Strekalova et al., 2006, 2013; Cline BH et al., 2014), were used as pharmacological references.

\section{Materials and Methods}

\section{Animals and housing}

Three month old C57BL/6N male mice were supplied by Instituto Gulbenkian de Ciência, Oeiras, Portugal, and housed individually in standard laboratory conditions under a reverse 12:12h cycle (lights on at 21:00). Behavioural tests took place from the onset of the dark phase of the light cycle (9:00h). The testing was carried out in a dark, quiet room in morning hours. All procedures were in accordance to the European Union's Directive 2010/63/EU, Portuguese law Law-Decrees DL129/92 (July 6th), DL197/96 (October 16th) and Ordinance Port.131/97 (November 7th). This project was approved by the Ethical Committee of the New University of Lisbon.

\section{Study flow with chronic intraperitoneal injections}

This study used a broadly applied treatment, in small rodents, of chronic intraperitoneal injections (Gärtner et al., 1980). We have chosen to expose mice to a three-week daily intraperitoneal injections of $\mathrm{NaCl}$ at volume $0.01 \mathrm{ml} / \mathrm{g}$ body weight (for scheme of study flow, see Fig.1A). Control mice were not treated but handled daily. Starting from the next day after this period, mice were tested in the two-day forced swim test as previously described (Malatynska et al., 2012; Cline et al., 2014). Behavioural data were scored using Noldus EthoVision XT 8.5 (Noldus Information 
Technology, Wageningen, the Netherlands). Number of mice per group is indicated in Figure legends.

Study flow with chronic imipramine delivery via food pellets

As a next step, we exposed mice to self-made food pellets (see below) that contained imipramine, for four weeks. Prior to starting treatment, animals were balanced upon body weight. The calculation of the used concentration of imipramine in food pellets was based on a daily food intake of experimental mice that constituted $2.9 \pm 0.26 \mathrm{~g}$, and a desirable dosage of $7 \mathrm{mg} / \mathrm{kg} /$ day. The selection of this dose was based on previously obtained data that showed the efficacy of the dose (Cline et al., 2014) and a lack of such with chronic imipramine delivery via drinking water at a dose of 2.5 $\mathrm{mg} / \mathrm{kg}$ (Strekalova and Markova, unpublished results), in mice. Control mice received a regular diet. Before the start and after four weeks of dosing, all mice were tested in the sucrose preference test, O-maze test and in the Dark/light box, as described elsewhere (Markova et al., 2013; Costa-Nunes et al., 2014) (see below). After two and four weeks of dosing, locomotor activity of all mice was studied in the novel cage and open field tests, as described elsewhere (Cline et al., 2012; Malatynska et al., 2012; Costa-Nunes et al., 2014) (see below). At the end of behavioural testing, a two-day forced swim test with 6 min sessions was performed as previously described (Malatynska et al., 2012; Cline et al., 2014) (see below; for scheme of study flow, see

Fig.1B). Number of mice per group is indicated in Figure legends.

Study flow with chronic delivery via food pellets of new candidates to antidepressants Next, we subjected mice to food pellets that contained imipramine, citalopram, celecoxib or dicholine succinate (see below), for four weeks. Prior to starting treatment, animals were balanced upon body weight. The latter two drugs are regarded as compounds with potential antidepressant activity (Myint et al., 2007; Cline et al., 2012; Maciel et al., 2013). The calculation of drug concentrations was based on daily food intake of experimental mice, and desirable doses: $7 \mathrm{mg} / \mathrm{kg} / \mathrm{day}$, 
$15 \mathrm{mg} / \mathrm{kg} / \mathrm{day}, 30 \mathrm{mg} / \mathrm{kg}$ and $50 \mathrm{mg} / \mathrm{kg}$ respectively. Control mice received regular diet. A two-day tail suspension test and a two-day forced swim test were carried out during four consecutive days after the termination of the dosing period, as described elsewhere (Malatynska et al., 2012; Markova et al., 2013) (for scheme of study flow, see Fig.1C). Number of mice per group is indicated in Figure legends.

\section{Preparation of pellets}

Imipramine Hydrochloride (Sigma-Aldrich, Munich, Germany), citalopram (Lundbeck, Copenhagen, Denmark) or celecoxib (Pfizer, Berlin, Germany) were added to a commercial chow (Mucedola SRL, Milan, Italy) that was turned to powder by a blender. Small amounts of distilled water were added, food pellets of a similar size to commercial pellets were formed and dried overnight (16h) at $60^{\circ}$. New pellets were prepared twice a week in order to refresh the food supply of experimental groups. The content of drugs was adjusted to the dose indicated above and was based on the consumption of normal diet that was averaged over 3 days. Food pellets containing dicholine succinate (Buddha Biopharma Oy Ltd, Helsinki, Finland) were prepared in a similar way, using a $7 \%$ solution of the compound; the content of drug was adjusted to the above-mentioned daily dose of this drug.

\section{Behavioural tests}

Forced swim test. The Porsolt forced swim test has been used as described elsewhere (Malatynska et al., 2012; Cline et al., 2014). Mice were subjected to two 6 min swimming sessions spaced $24 \mathrm{~h}$ apart in a transparent cylinder $(\varnothing 17 \mathrm{~cm})$ filled with water $\left(+23^{\circ} \mathrm{C}\right.$, water height $13 \mathrm{~cm}$, height of cylinder $20 \mathrm{~cm}$, illumination intensity 25 Lux). Floating behaviour was defined by the absence of any directed movements of the animals' head and body and was scored with Noldus EthoVision XT 8.5 (Noldus Information Technology, Wageningen, the Netherlands). Using this method, the latency of the first episode of floating and the duration of floating behaviour were recorded during the 6 min swimming session, on day 1 and day 2 of the test. Latency 
to begin floating was scored as time between introduction of the animal into the pool and the first moment of complete immobility of the entire body for a duration of $>3$ seconds. The total time spent floating, number of floating episodes, mean velocity and distance moved were scored for the entire duration of the test using post-test video footage.

Dark/light box. The dark/light box (Technosmart, Rome, Italy) consisted of two plexiglass compartments, one black/dark $(15 \mathrm{~cm} \times 20 \mathrm{~cm} \times 25 \mathrm{~cm})$ and one lit $(30 \mathrm{~cm}$ $\times 20 \mathrm{~cm} \times 25 \mathrm{~cm})$, connected by a tunnel. Anxiety-like behaviour was assessed by earlier validated measures (Malatynska et al., 2012; Markova et al., 2013). Mice were placed into the dark compartment, from where they could visit the lit box, illuminated by light of 25 Lux intensity. The latency of the first exit to the light compartment, the total duration of time spent in the lit box and the number of visits to this anxiety-related compartment were scored by visual observation over $5 \mathrm{~min}$.

Elevated O-maze. The apparatus (Technosmart, Rome, Italy), which consisted of a circular path (runway width $5.5 \mathrm{~cm}$, diameter $46 \mathrm{~cm}$ ), was placed $50 \mathrm{~cm}$ above the floor. Two opposing arms were protected by walls (height $10 \mathrm{~cm}$ ), and the illumination strength was 25 Lux. The apparatus was placed on a dark surface in order to reduce reflection and maintain control over lighting conditions during testing. Anxiety-like behaviour was assessed using previously validated parameters (Cline et al., 2014; Costa-Nunes et al., 2014). Mice were placed in one of the closed-arm compartments of the apparatus. The latency of the first exit to the anxiety-related open compartments of the maze, the total duration of time spent therein and the number of exits to the open arms were scored during a 5-min observation period.

Novel cage test. The novel cage test was performed to assess vertical activity, as described elsewhere (Cline et al., 2014). Mice were introduced into a standard plastic cage the size of their home cage filled with small amounts of fresh sawdust. The 
number of exploratory rearings was counted under red light during a 5-min period.

Open field. The open-field apparatus consisted in four square arenas $(50 \mathrm{~cm} \times 50 \mathrm{~cm} \times$ $50 \mathrm{~cm})$, made of wood covered by white resopal. Mice were put in the center and their behaviour was recorded on camera for $10 \mathrm{~min}$. The open field was illuminated with white light (25 Lux). Distanced moved and mean instant speed were analysed off-line using the Any-maze software (Stoelting Co, Wood Dale, IL, USA), as described elsewhere (Pawluski et al., 2012).

Sucrose test. Animals were given 8 hours of free choice between two bottles of either $1 \%$ sucrose or normal drinking water, as described elsewhere (Cline et al., 2014). At the beginning and end of the period the bottles were weighed and consumption calculated. The beginning of the test started with the onset of the dark (active) phase of animals' cycle. To prevent the possible effects of side-preference in drinking behaviour, the position of the bottles in the cage was switched at 4 hours, halfway through testing. No previous food or water deprivation was applied before the test. The 1\%-sucrose solution is used in tests performed across the experiment. Percentage preference for sucrose is calculated using the following formula:

$$
\text { Sucrose Preference }=\left(\frac{V_{\text {Sucrose solution }}}{\left(V_{\text {Sucrose solution }}+V_{\text {Water }}\right)}\right) x 100 \%
$$

Tail suspension test. The protocol used in this study was adapted from a previously proposed procedure (Malatynska et al., 2012; Markova et al., 2013). Mice were subjected to the tail suspension by being hung by their tails with adhesive tape to a rod $50 \mathrm{~cm}$ above the floor for $6 \mathrm{~min}$. Animals were tested in a dark room where only the area of the modified tail suspension construction was illuminated by a spotlight from the ceiling; the lighting intensity on the height of the mouse position was 25 Lux. The trials were recorded by a video camera positioned directly in front of the mice while the experimenter observed the session from a distance in a dark area of 
the experimental room. This procedure was carried out twice with a 24-h interval between tests. The latency of the first episode of immobility, the total duration of this behaviour and mean velocity were scored using Noldus EthoVision XT 8.5 (Noldus Information Technology, Wageningen, the Netherlands) according to the protocol that was previously validated (Malatynska et al., 2012). In accordance with the commonly accepted criteria of immobility, the immobility behaviour was defined as the absence of any movements of the animals' head and body. The latency of immobility was determined as the time between the onset of the test and the first bout of immobility.

\section{Statistical analysis}

Data were analysed with GraphPad Prism version 5.00 for Windows (San Diego, CA, USA). Two-tailed unpaired $t$-tests were applied for two-group, two-tailed comparisons of independent data sets, as the distribution was normal. One-way ANOVA was used followed by a post-hoc Dunnett for a comparison of more than two groups with a control; repeated measures ANOVA was used for analysis of repeated measures. The level of confidence was set at $95 \%(p<0.05)$ and data are shown as mean \pm SEM.

\section{Results and Discussion}

\section{Effects of 3-week intraperitoneal vehicle injections on floating behaviour}

Behaviour analysis revealed that animals subjected to injections displayed a nonsignificant decrease of latency to float as compared to control animals (Day 1: $p=0.11$, $t=1.73$; Day 2: $p=0.91, t=0.12$, Fig.2A, unpaired two-tailed $t$-test). The number of floating episodes and the duration of floating in the chronically injected group were significantly higher than in control animals (Day 1: $p=0.0037, t=3.89$ and $p=0.016$, $t=3.06$; Day 2: $p=0.0016, t=4.30$ and $p=0.11, t=1.77$, respectively; Fig.2B, $2 \mathrm{C}$ unpaired two-tailed $t$-test), mean velocity of swimming and distance moved were non- 
significantly decreased (Day 1: $p=0.25, t=1.25$ and $p=0.31, t=1.09$; Day 2: $p=0.18$, $t=1.43$ and $p=0.15, t=1.56$, respectively, Fig.2D,2E, unpaired two-tailed $t$-test). This suggests increased "behavioural despair", a sign of depressive like state, in mice that received chronic manipulations with intraperitoneal injections.

Similar results were obtained in our previous experiments which demonstrated that three and four-week daily injections in chronically stressed mice increased the number of individuals exhibiting signs of anhedonia, a reduced sensitivity to reward, in a sucrose preference test (Strekalova et al., 2008, 2011). Other studies showed that chronic intraperitoneal injections in rats evoke ultrasonic vocalizations at $22-\mathrm{kHz}$ range, indicative of a negative emotional state that was reduced by pre-exposure of experimental animals to handling (Cloutier et al., 2014).These "pro-depressive" like changes found in this study, could be potentially induced by well-recognized pathogenetic elements of depression, such as stress of manipulation (Silverman and Sternberg, 2012) and pain experience (Miller and Cano, 2009; Goffer et al., 2013), repeated situations of unescapable stress and helplessness (Pryce et al., 2011), as well as inflammation (Dantzer et al., 2011).

Effects of chronic imipramine delivery via food pellets on floating behaviours and other variables

In order to assess the efficacy of an alternative chronic dosing design that could preclude the adverse changes in behaviour described above, we evaluated the effects of a four-week dosing of imipramine via food pellets in the forced swim test and supplementary behavioural paradigms. Animals subjected to imipramine treatment, showed a significant increase in the latency to float and decreased immobility time, when compared to control animals (Day 1: $p=0.0002, t=5.19$ and $p=0.0008, t=4.42$; Day 2: $p=0.18, t=1.43$ and $p=0.0011, t=4.28$, respectively, Fig.3A, unpaired two-tailed $t$-test). Thus, an applied low dose of antidepressant treatment delivered with food pellets induced an antidepressant-like effect in the present study. 
This result is in line with our previous findings that showed a 3-week low dose administration of imipramine to C57BL6J mice via drinking water reduced such depressive symptoms as stress-induced decease in sucrose intake and preference, hyperlocomotion and elevated aggressive behavior (Cline et al., 2014). Similar behavioural results were obtained in the chronic stress depression model with CD1 mice (Cline et al., 2012) and in a model of elderly depression in 18-month-old C57BI6N mice (Malatynska et al., 2012). The low dose imipramine antidepressant effects were accompanied by preservation of normal activity of brain peroxidation enzymes which were suppressed by chronic stress (Cline et al., 2014). These effects are typical for antidepressant effect manifestations induced by tricyclics in rodents (Von Frijtag et al., 2002; Cryan et al., 2005a).

Further, in order to rule out potential effects of imipramine administration on anxiety, locomotion and liquid intake that were previously reported in mice treated with this drug at a dose of $15 / \mathrm{mg} / \mathrm{kg}$ in C57BL6N mice, we performed supplementary tests in all mice. In both anxiety paradigms, dark-light box and O-maze, animals treated with imipramine showed no significant differences in their behaviour from the control group: in latency of the exit to the anxiety-related areas, lit box and open arms ( $p=0.94, t=0.08$ and $p=0.59, t=0.55$, respectively; unpaired two-tailed $t$-test), time spent in the lit box and open arms $(p=0.80, t=0.26$ and $p=0.28 t=1.14$, respectively; unpaired two-tailed $t$-test) and numbers of exits to these zones ( $p=0.87, t=0.17$ and $p=0.13, t=1.63$, respectively; unpaired two-tailed $t$-test Fig.3B,3C). In locomotory tests, in comparison with control mice, animals treated with imipramine exhibited normal vertical activity, as shown by the number of rearings in novel cage, (Week 2: $p=0.33, t=1.01$; Week 4: $p=0.54, t=0.63$, unpaired two-tailed $t$-test), as well as unchanged horizontal locomotion in the open field.

In the latter test, no difference between groups was found in distance travelled (Week 2: $p=0.97, t=0.038$; Week 4: $p=0.31, t=1.05$ ) or mean instant velocity (Week 2: 
$p=0.98, t=0.026$; Week 4: $p=0.84, t=0.21$, Fig.3D, unpaired two-tailed $t$-test). In a twobottle sucrose preference test, there were no significant differences in water intake, sucrose solution intake and sucrose preference between the groups ( $p=0.47, t=0.75$; $p=0.32, t=1.04 ; p=0.20, t=1.35$, respectively; unpaired two-tailed $t$-test, Fig.3E). Finally, body weight was not different between control and imipramine-treated groups ( $p=0.20, t=1.37$, data not shown, unpaired two-tailed $t$-test). There are no statistical significance using a repeated measures ANOVA (data not shown).

Thus, the employed dosing with imipramine did not affect basic physiological variables, such as locomotion, liquid consumption and body weight. Also, it did not affect the parameters of anxiety and sucrose ingestion, as reported in some studies that employ higher amounts of tricyclics (File and Tucker, 1986; Mogensen et al., 1994; Willner, 2005; Strekalova et al., 2013). The discrimination between antidepressant- versus antianxiety-like effects, and lack of evidences for general effects on physiological parameters, suggests that low dose imipramine treatment via voluntary food pellet intake can serve as an optimal pharmacological reference in animal models of depression that require prolonged antidepressant treatment of small rodents.

Effects of chronic delivery via food pellets of new candidates to antidepressants in the forced swim and tail suspension tests

Next, we sought to investigate whether the defined method of antidepressant dosing with food pellets can be applicable with the testing of new drug candidates, one of which, celecoxib, is not soluble in water and; therefore, is problematic to deliver to the animals chronically. As such, we exposed a cohort of animals to food pellets containing new drug candidates, dicholine succinate or celecoxib. In addition, we used imipramine or citalopram as the antidepressant references. 
In the forced swim test, one-way ANOVA revealed significant differences between the groups in the latency to float, total time spent floating and velocity (Day 1: $p=0.0054, F=4.24 ; p=0.049, F=2.60$ and $p=0.22 ; F=3.18$, respectively, Fig.4A). Posthoc Dunnett test showed that on Day 1, in comparison with the control group, the latency to swim was increased in animals treated with imipramine or dicholine succinate $(p<0.05, q=3.17$ and $p<0.01, q=3.20)$, the duration of immobility was decreased in the imipramine-treated animals $(p<0.05, q=2.67)$ and velocity was elevated in the dicholine succinate-treated group $(p<0.05, q=2.62)$. On Day 2 of the forced swim test, one-way ANOVA showed a trend to a statistically significant difference in the latency of floating and no differences in the duration of floating or velocity ( $p=0.059, F=2.46 ; p=0.48, F=0.89$ and $p=0.40, F=1.04$, respectively, Fig.4B). Dunnett post-hoc test revealed a significant increase in latency to float in the imipramine-treated group $(p<0.05 ; q=2.96)$. As a reduction of the parameters of floating behaviour in the forced swim test is a well-established measure of antidepressant activity of various compounds (Cryan et al., 2005a; Harro, 2013), these data suggest that the applied treatment with imipramine or dicholine succinate induces an antidepressant effect and that the employed dosing was effective.

With the tail suspension test, one-way ANOVA showed that on Day 1, there were statistically significant differences between the groups in the latency and duration of immobility ( $p=0.007, F=4.09 ; p<0.0001, F=3.43$ and $p<0.0001, F=3.43$, respectively, Fig.4C); a strong tendency to differences in velocity were found ( $p=0.0505, F=2.57$ ). Post-hoc Dunnett test revealed a significant difference in the latency of immobility from the control group in imipramine-treated animals $(p<0.01, q=3.380)$, but not in other treatment groups.

All groups that received pharmacological treatment had significantly reduced duration of immobility in comparison to control mice (imipramine-treated: $p<0.001$, $q=4.50$; citalopram-treated: $p<0.001, q=5.02$; dicholine succinate-treated: $p<0.05$, 
$q=3.07$; celecoxib-treated: $p<0.05, q=2.65$; Dunnett post-hoc test). In comparison to control group, velocity was significantly increased in imipramine- and dicholine succinate-treated groups $(p<0.05, q=2.55 ; p<0.05, q=2.56$, respectively; Dunnett post-hoc test).

On Day 2 of the tail suspension test, statistically significant differences between the groups were found in the latency of immobility, the duration of immobility and velocity ( $p=0.0159, F=3.43 ; p<0.0002, F=6.90$ and $p=0.012, F=3.65$, respectively, oneway ANOVA; Fig.4D). Dunnett post-hoc test showed a significant increase of the latency of immobility in imipramine- and dicholine succinate-treated animals, as compared with controls ( $p<0.01, q=3.48$ and $p<0.05, q=2.75$, respectively). All treated groups had significantly reduced duration of immobility, as compared with control mice (imipramine-treated: $p<0.001, q=4.46$; citalopram-treated: $p<0.001$, $q=4.31$; dicholine succinate-treated: $p<0.01, q=3.39$; celecoxib-treated: $p<0.001$, $q=4.24$ Dunnett post-hoc test). Velocity was significantly increased in comparison with control mice in the imipramine- and dicholine succinate-treated groups $(p<0.05$, $q=2.97 ; p<0.05, q=2.59$, respectively; Dunnett post-hoc test). Since a decrease of immobility behaviour in the tail suspension test is generally considered as a manifestation of the antidepressant activity of various treatments (Cryan et al., 2005b; Harro, 2013), these results evidence an antidepressant-like effect of the applied drugs, and again, the efficacy of the tested method of drug administration.

\section{Conclusions}

Thus, as a desirable alternative to invasive dosing, such as chronic intraperitoneal injections, the administration of various drugs via food pellets can be very efficient. The results from our study are in line with other successful attempts to avoid adverse drug delivery methodologies in translational research that showed, for example, the efficacy of treatment with analgesic therapy delivered via food in rats which were 
subjected to surgery (Jessen et al., 2007). The use of such methods could be particularly needed when repeated drug administration to stressed, operated or immunodeficient laboratory animals is necessary and therefore could greatly improve not only animal welfare but also the validity of animal models.

\section{Acknowledgements}

We would like to thank Dr. Cláudia Oliveira from the CBA and Science Faculty of the University of Lisbon, Dr. Dinora Lopes from the Institute of Hygiene and Tropical Medicine for organizational support and Mrs Margarida Rama for technical support. This work was supported by the Fundação para a Ciência e Tecnologia (FCT) and Internationale Stichting Alzheimer Onderzoek (ISAO), the Netherlands, grant N 09501 and RFBR to TS. 


\section{References}

Araragi N1, Lesch KP. Serotonin (5-HT) in the regulation of depression-related emotionality: insight from 5-HT transporter and tryptophan hydroxylase-2 knockout mouse models. Curr Drug Targets 2013; 14:549-70.

Azar TA, Sharp JL, Lawson DM. Heart rates of male and female Sprague-Dawley and spontaneously hypertensive rats housed singly or in groups. J Am Assoc Lab Anim Sci. 2011; 50:175-84.

Beeler JA, Prendergast B, Zhuang X. Low amplitude entrainment of mice and the impact of circadian phase on behavior tests. Physiol Behav. 2006; 87:870-80.

Bohlen M, Hayes ER, Bohlen B, Bailoo JD, Crabbe JC, Wahlsten D. Experimenter effects on behavioral test scores of eight inbred mouse strains under the influence of ethanol. Behav Brain Res. 2014; 272:4654.

Cline BH, Anthony DC, Lysko A, Dolgov O, Anokhin K, Schroeter C, et al. Lasting downregulation of the lipid peroxidation enzymes in the prefrontal cortex of mice susceptible to stress-induced anhedonia. Behav Brain Res. 2014. pii: S0166-4328(14)00255-1.

Cline BH, Steinbusch HW, Malin D, Revishchin AV, Pavlova GV, Cespuglio R, et al. The neuronal insulin sensitizer dicholine succinate reduces stress-induced depressive traits and memory deficit: possible role of insulin-like growth factor 2. BMC Neurosci. 2012;13:110.

Cloutier S, Newberry RC. Use of a conditioning technique to reduce stress associated with repeated intraperitoneal injections in laboratory rats. Appl Anim Behav Sci. 2008; 112:158-73.

Cloutier S, Wahl K, Baker C, Newberry RC. The social buffering effect of playful handling on responses to repeated intraperitoneal injections in laboratory rats. J Am Assoc Lab Anim Sci. 2014; 53:168-73.

Costa-Nunes J, Zubareva O, Araújo-Correia M, Valença A, Schroeter CA, Pawluski JL et al. Altered emotionality, hippocampus-dependent performance and expression of NMDA receptor subunit mRNAs in chronically stressed mice. Stress 2014;17:108-16.

Crabbe JC, Wahlsten D, Dudek BC. Genetics of mouse behavior: interactions with laboratory environment. Science 1999; 284:1670-2.

Cryan JF, Mombereau C, Vassout A. The tail suspension test as a model for assessing antidepressant activity: review of pharmacological and genetic studies in mice. Neurosci Biobehav Rev 2005b; 29:571625.

Cryan JF, Valentino RJ, Lucki I. Assessing substrates underlying the behavioural effects of antidepressants using the modified rat forced swimming test. Neurosci Biobehav Rev. 2005a; 29:547-69.

Dantzer R, O'Connor JC, Lawson MA, Kelley KW. Inflammation-associated depression: from serotonin to kynurenine. Psychoneuroendocrinology. 2011; 36:426-36.

File SE, Tucker JC. Behavioral consequences of antidepressant treatment in rodents. Neurosci Biobehav Rev 1986; 10:123-34.

Frick KM, Stearns NA, Pan JY, Berger-Sweeney J. Effects of environmental enrichment on spatial memory and neurochemistry in middle-aged mice. Learn Mem. 2003; 10:187-98. 
Fukushiro DF, Benetti LF, Josino FS, Oliveira GP, Fernandes M, Saito LP, et al. Environmental novelty and illumination modify ethanolinduced open-field behavioral effects in mice. Pharmacol Biochem Behav. 2010; 95:13-22.

Gärtner K, Büttner D, Döhler K, Friedel R, Lindena J, Trautschold I. Stress response of rats to handling and experimental procedures. Lab Anim. 1980; 14:267-74.

Goffer Y, Xu D, Eberle SE, D'amour J, Lee M, Tukey D, et al. Calcium-permeable AMPA receptors in the nucleus accumbens regulate depression-like behaviors in the chronic neuropathic pain state. J Neurosci. 2013; 33:19034-44.

Harro J. Animal Models of Depression Vulnerability. Curr Top Behav Neurosci 2013; 14:29-54.

Insel TR, Sahakian BJ. Drug research: a plan for mental illness. Nature 2012; 483:269.

Insel TR. From animal models to model animals. Biol Psychiatry 2007; 15:1337-9.

Jessen L, Christensen S, Bjerrum OJ. The antinociceptive efficacy of buprenorphine administered through the drinking water of rats. Lab Anim. 2007; 41:185-96.

Longordo F, Fan J, Steimer T, Kopp C, Lüthi A. Do mice habituate to "gentle handling?" A comparison of resting behavior, corticosterone levels and synaptic function in handled and undisturbed $\mathrm{C} 57 \mathrm{BL} / 6 \mathrm{~J}$ mice. Sleep 2011; 34:679-81.

Maciel IS, Silva RB, Morrone FB, Calixto JB, Campos MM. Synergistic effects of celecoxib and bupropion in a model of chronic inflammation-related depression in mice. PLoS One. 2013; 8:e77227.

Malatynska E, Steinbusch HW, Redkozubova O, Bolkunov A, Kubatiev A, Yeritsyan NB, et al. Anhedoniclike traits and lack of affective deficits in 18-month-old C57BL/6 mice: Implications for modeling elderly depression. Exp Gerontol. 2012; 47:552-64.

Mandillo S, Tucci V, Hölter SM, Meziane H, Banchaabouchi MA, Kallnik M, et al. Reliability, Robustness and Reproducibility in mouse behavioral phenotyping: a cross-laboratory study. Physiol Genomics 2008; 34:243-55.

Markova N, Chernopiatko A, Schroeter CA, Malin D, Kubatiev A, Bachurin S et al. Hippocampal gene expression of deiodinases 2 and 3 and effects of 3,5-diiodo-L-thyronine T2 in mouse depression paradigms. Biomed Res Int. 2013; 2013:565218.

Miller LR, Cano A. Comorbid chronic pain and depression: who is at risk? J Pain 2009; 10:619-627.

Mogensen J, Pedersen TK, Holm S. Effects of chronic imipramine on exploration, locomotion, and food/water intake in rats. Pharmacol Biochem Behav 1994; 47:427-35.

Munn E, Bunning M, Prada S, Bohlen M, Crabbe JC, Wahlsten D. Reversed light-dark cycle and cage enrichment effects on ethanol-induced deficits in motor coordination assessed in inbred mouse strains with a compact battery of refined tests. Behav Brain Res. 2011; 224:259-71.

Munos B. Lessons from 60 years of pharmaceutical innovation. Nat Rev Drug Discov. 2009; 8:959-68.

Myint AM, Steinbusch HW, Goeghegan L, Luchtman D, Kim YK, Leonard BE. Effect of the COX-2 inhibitor celecoxib on behavioural and immune changes in an olfactory bulbectomised rat model of depression. Neuroimmunomodulation 2007; 14:65-71.

Overstreet DH. Modeling depression in animal models. Methods Mol Biol 2012; 829: 125-44. 
Pawluski JL, Valença A, Santos Al, Costa-Nunes JP, Steinbusch HW, Strekalova T. Pregnancy or stress decrease complexity of CA3 pyramidal neurons in the hippocampus of adult female rats. Neuroscience 2012; 227:201-10.

Pigott HE, Leventhal AM, Alter GS, Boren JJ. Efficacy and effectiveness of antidepressants: current status of research. Psychother Psychosom. 2010; 79:267-79.

Pottenger LH, Domoradzki JY, Markham DA, Hansen SC, Cagen SZ, Waechter JM Jr. The relative bioavailability and metabolism of bisphenol $\mathrm{A}$ in rats is dependent upon the route of administration. Toxicol Sci. 2000; 54:3-18.

Pryce CR, Azzinnari D, Spinelli S, Seifritz E, Tegethoff M, Meinlschmidt G. Helplessness: a systematic translational review of theory and evidence for its relevance to understanding and treating depression. Pharmacol Ther. 2011; 132:242-67.

Ringgold KM, Barf RP, George A, Sutton BC, Opp MR. Prolonged sleep fragmentation of mice exacerbates febrile responses to lipopolysaccharide. J Neurosci Methods 2013; 219:104-12.

Sato Y, Seo N, Kobahashi E. The dosing-time dependent effects of intravenous hypnotics in mice. Anesth Analg. 2005; 101:1706-8.

Silverman MN, Sternberg EM. Glucocorticoid regulation of inflammation and its functional correlates: from HPA axis to glucocorticoid receptor dysfunction. Ann NY Acad Sci. 2012;1261:55-63.

Sorge RE, Martin $\sqcup$, Isbester KA, Sotocinal SG, Rosen S, Tuttle AH, et al. Olfactory exposure to males, including men, causes stress and related analgesia in rodents. Nat Methods 2014; 11:629-32.

Sousa N, Almeida OF, Wotjak CT. A hitchhiker's guide to behavioral analysis in laboratory rodents. Genes Brain Behav. 2006; 5:5-24.

Strekalova T, Anthony DC, Dolgov O, Anokhin K, Kubatiev A, Steinbusch HM, et al. The differential effects of chronic imipramine or citalopram administration on physiological and behavioral outcomes in naive mice. Behav Brain Res. 2013; 245;101-6.

Strekalova T, Couch Y, Kholod N, Boyks M, Malin D, Leprince P, et al. Update in the methodology of the chronic stress paradigm: internal control matters. Behav Brain Funct. 2011; 7:9.

Strekalova T, Gorenkova N, Schunk E, Dolgov O, Bartsch D. Selective effects of citalopram in a mouse model of stress-induced anhedonia with a control for chronic stress. Behav Pharmacol. 2006; 3:271-87.

Strekalova T, Spanagel R, Dolgov O, Bartsch D. Stress-induced hyperlocomotion as a confounding factor in anxiety and depression models in mice. Behav Pharmacol. 2005;16:171-80.

Strekalova T, Steinbusch HW. Measuring behavior in mice with chronic stress depression paradigm. Prog Neuropsychopharmacol Biol Psychiatry. 2010; 34:348-61

Strekalova TV, Cespuglio R, Koval'zon VM. Depressive-like state and sleep in laboratory mice. Zh Vyssh Nerv Deiat Im I P Pavlova. 2008;58:728-37.

Thiele TE, Navarro M. "Drinking in the dark" (DID) procedures: a model of binge-like ethanol drinking in non-dependent mice. Alcohol 2014; 48:235-41.

Volvert ML, Seyen S, Piette M, Evrard B, Gangolf M, Plumier JC, et al. Benfotiamine, a synthetic S-acyl thiamine derivative, has different mechanisms of action and a different pharmacological profile than lipid-soluble thiamine disulfide derivatives. BMC Pharmacol. 2008; 8:10. 
Von Frijtag JC, Van den Bos R, Spruijt BM. Imipramine restores the long-term impairment of appetitive behavior in socially stressed rats. Psychopharmacology (Berl). 2002; 62:232-8.

Wahlsten D, Metten P, Crabbe JC. A rating scale for wildness and ease of handling laboratory mice: results for 21 inbred strains tested in two laboratories. Genes Brain Behav. 2003; 2:71-9.

Wahlsten D, Rustay NR, Metten P, Crabbe JC. In search of a better mouse test. Trends Neurosci. 2003; 26:132-6

Willner P. Chronic mild stress (CMS) revisited: consistency and behavioural-neurobiological concordance in the effects of CMS. Neuropsychobiol. 2005; 52:90-110.

Wolfer DP, Litvin O, Morf S, Nitsch RM, Lipp HP, Würbel H. Laboratory animal welfare: cage enrichment and mouse behaviour. Nature 2004; 432:821-2. 


\section{Figure legends}

Figure 1. Experimental design. A - Schematic timeline of studies with vehicle injections; Chronic delivery with food pellets of imipramine (B) and new drug candidates to antidepressants (C). i.p. - intraperitoneal injection; FST=forced swim test; TST=tail suspension test; $\mathrm{DLB}=$ dark-light box; $\mathrm{OM}=\mathrm{O}-\mathrm{maze} ; \mathrm{NCT}=$ novel cage test; $\mathrm{OF}=$ open field; $\mathrm{ST}=$ sucrose test; d=days.

Figure 2. Chronic intraperitoneal injections increase depressive-like behaviour in the forced swim test. In comparison with control group, mice that received daily intraperitoneal saline injections over the course of three weeks had a non-significantly reduction of the latency of floating $(A)$, significant increase of the total number of floating episodes (B) and total time spent floating (C). There were no significant differences in mean velocity (D) or distance swum (E) between control and injected groups. ${ }^{*} p<0.05 ;{ }^{* *} p<0.01$ vs. control (unpaired $t$-test). Con: control group, $(n=7)$; i.p. injection: a group of mice subjected to intraperitoneal injections with a vehicle $(n=5)$. All data are means \pm SEM.

Figure 3. Effects of dosing with imipramine via food pellets on floating scores and other behaviours. (A) In comparison with control group, mice that received imipramine in food pellets over four weeks showed an increase of latency to float and total duration of floating in the forced swim test. No significant differences between the groups were found in parameters of anxiety (B) in the dark-light box and (C) O-maze tests. (D) Control and imipramine-treated mice showed similar numbers of rearings in the novel cage, distance travelled and mean velocity in the open field test. (E) In the two-bottle sucrose preference test, water intake, sucrose solution intake and sucrose preference were not different between imipramine-treated and control groups. ${ }^{* *} p<0.01, * * * p<0.001$ vs. control (unpaired t-test). Con: control group, $(n=7)$; Imi-food: imipramine-treated group $(n=8)$. All data are means \pm SEM.

Figure 4. Effects of chronic delivery via food pellets of new candidates to antidepressants in the forced swim and tail suspension tests. (A) On Day 1 of the forced swim test, as compared with control, imipramine-treated animals elicited an increase in latency to float and reduced 
time spent floating, and dicholine succinate-treated groups displayed an increase swim velocity. (B) On Day 2 of the forced swim test, imipramine-treated group had higher latency to float in comparison to control mice; no other differences between treated and control groups were found. (C) On Day 1 of the tail suspension test, there was a significant increase of the latency of immobility and velocity in imipramine- and dicholine succinate-treated groups, as compared to controls. All treated groups showed a significant reduction of total time spent immobile, as compared to control animals. (D) On Day 2 of the tail suspension test, in comparison to control group, an increase of the latency of immobility was found in imipramine-treated group and an increase of velocity was observed in both imipramine- and dicholine succinate-treated mice. All animals that received a treatment, demonstrated a significant reduction of total time spent immobile, in comparison to control group. ${ }^{*} p<0.05$, $* * p<0.01, * * * p<0.001$ vs. control (one-way ANOVA with Dunnett post-hoc tests). All groups were $n=10$. Con: control group; Imi-food: imipramine-treated group; Cit-food: citalopramtreated group; DS-food: dicholine-succinate-treated group; Cel-food: celecoxib-treated group. All data are means \pm SEM. 
A

No Treatment - (Control) $\square$ Daily i.p. injections

\section{$\downarrow$ Randomization}

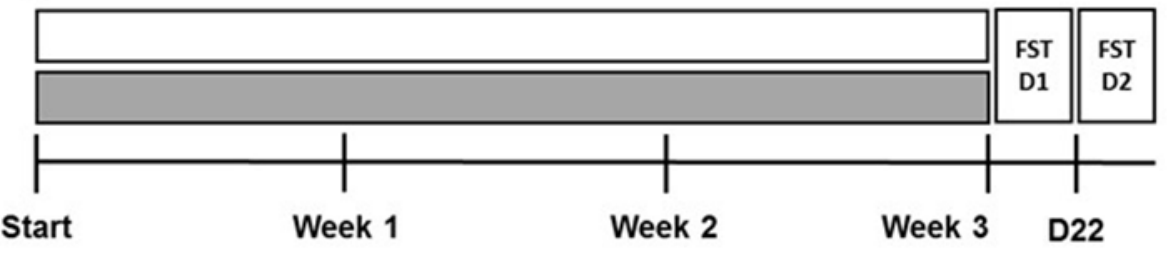

B

Regular diet Imipramine - (Food pellets)

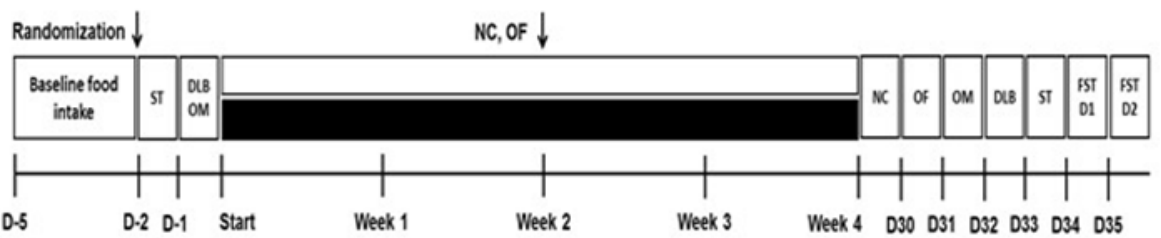

C

$\square$ Regular diet - (Control)

Imipramine - (food pellets)

Citalopram - (food pellets)

Dicholine Succinate - (food pellets)

Celecoxib - (food pellets)

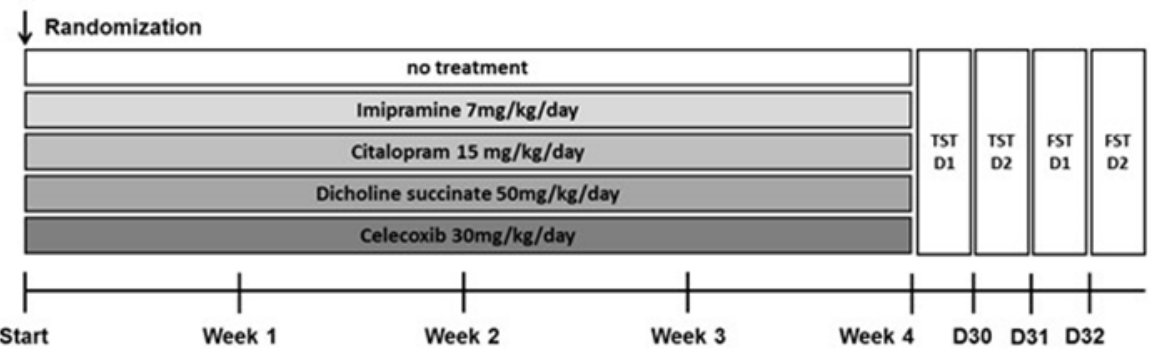

Figure 1 
A

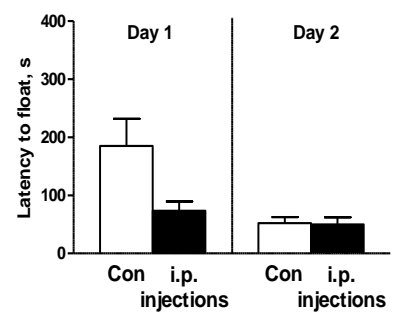

D

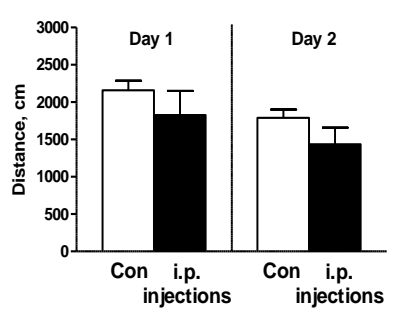

B

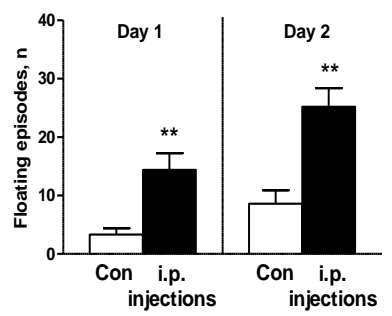

E

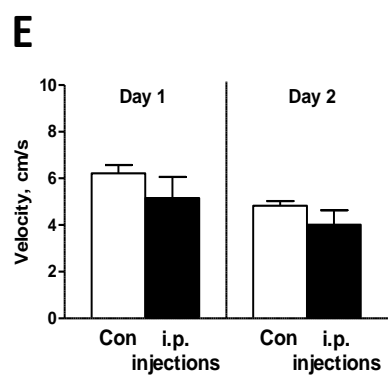

Figure 2
C

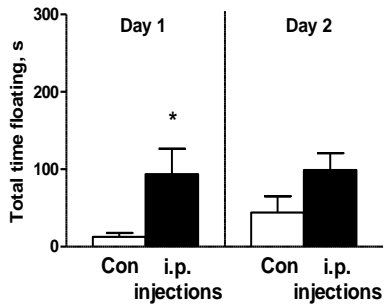


A

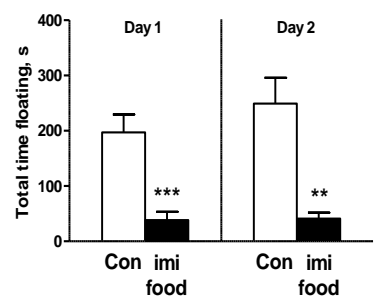

B

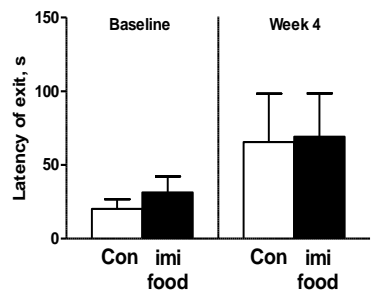

C

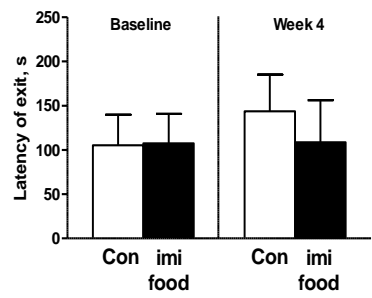

D

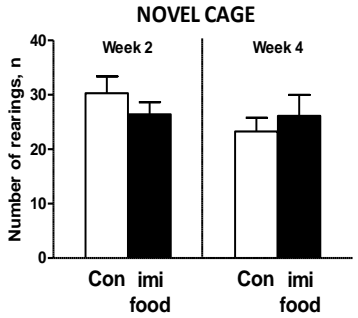

E

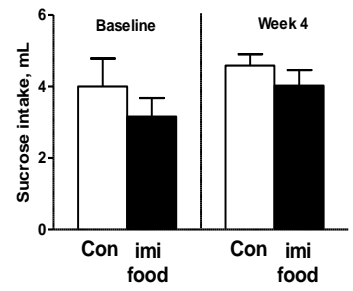

FORCED SWIM TEST

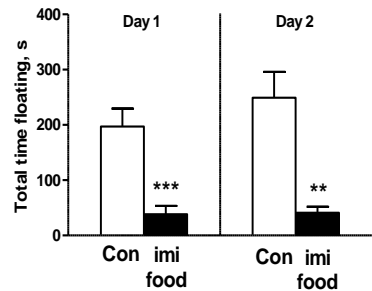

DARK-LIGHT BOX
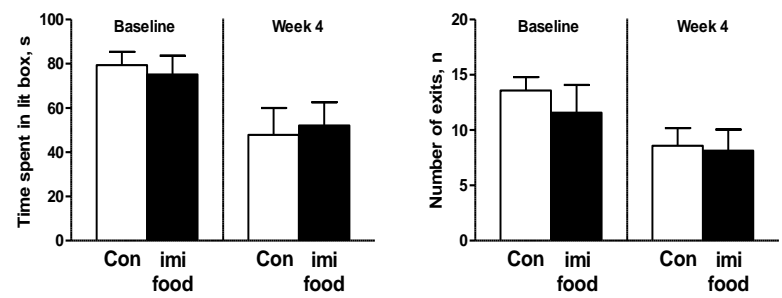

O-MAZE
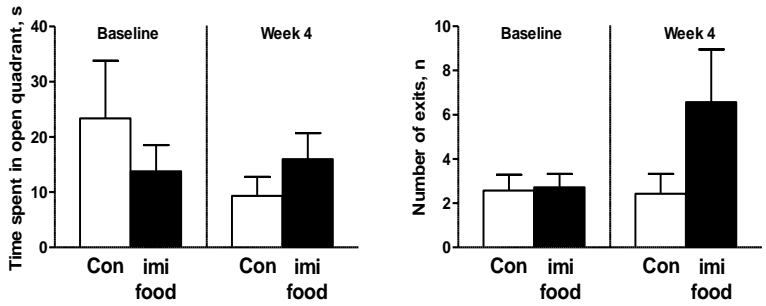

LOCOMOTORY TESTS

OPEN FIELD
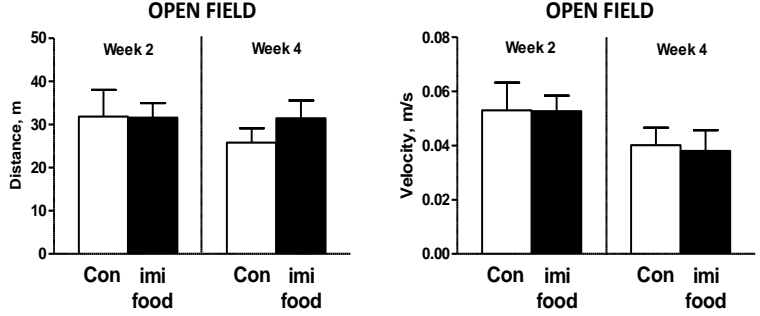

\section{SUCROSE TEST}
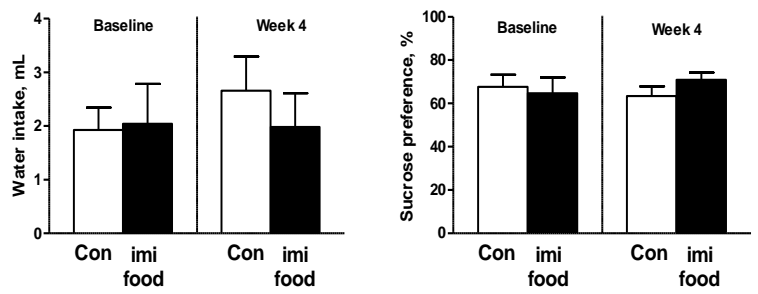

Figure 3 

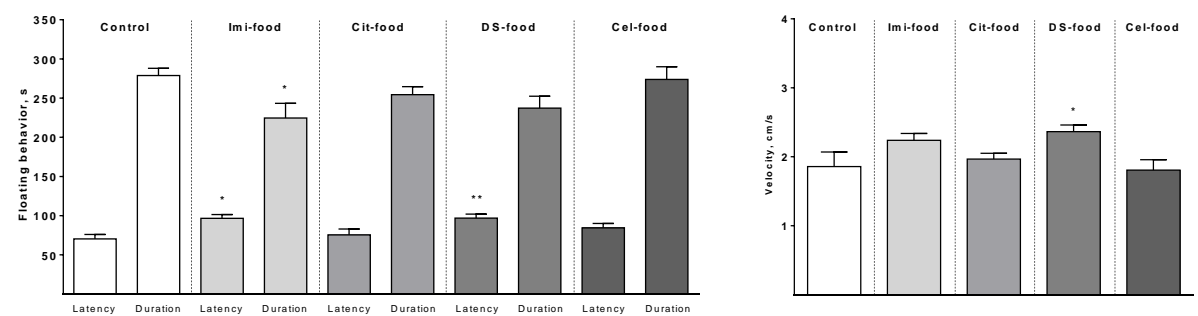

B

FORCED SWIM TEST DAY 2
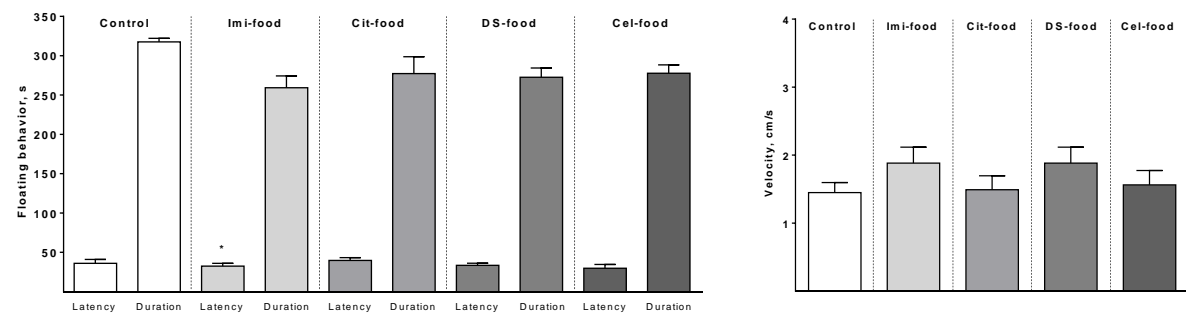

C

TAIL SUSPENSION TEST DAY 1
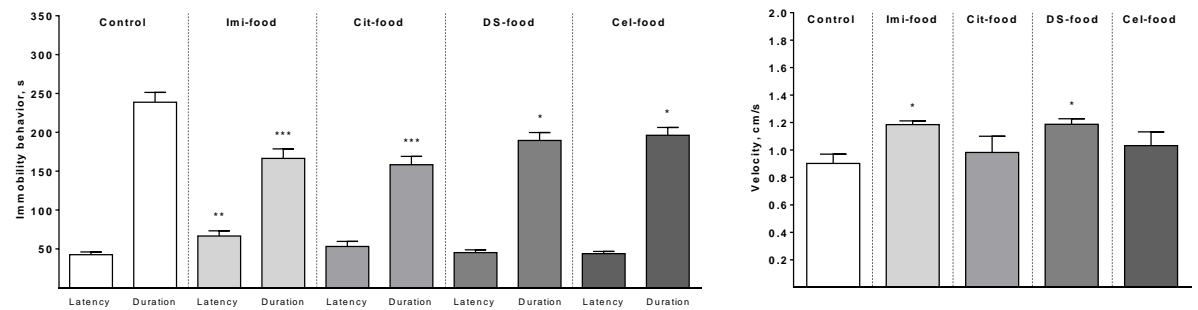

D

FORCED SWIM TEST DAY 2
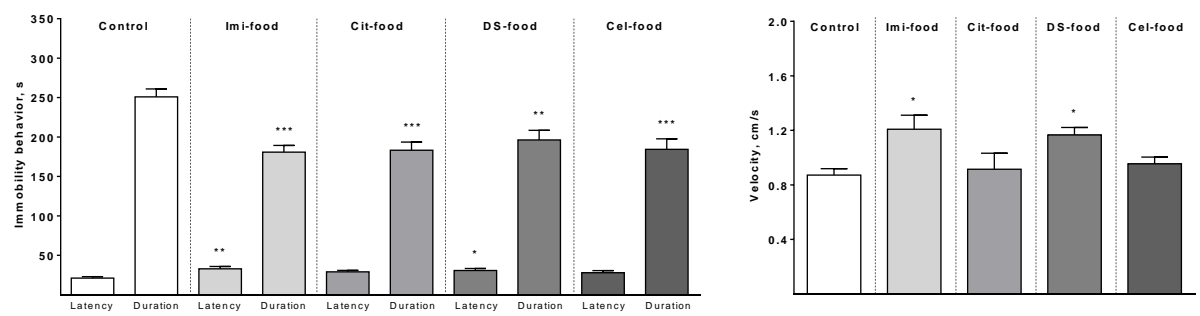

Figure 4 




\section{Chapter 6}

\section{Insulin receptor sensitizer, dicholine succinate, prevents both Toll-like receptor 4 (TLR4) upregulation and affective changes induced by a high-cholesterol diet in mice.}

Strekalova $\mathrm{T}^{1}$, Costa-Nunes $\mathrm{JP}^{1,2}$ Veniaminova $\mathrm{E}^{1,3}$, Kubatiev $\mathrm{A}^{3}$, Lesch $\mathrm{KP}^{1,4}$, Chekhonin $\mathrm{V}^{5}$, Evans $\mathrm{M}^{6}$, Steinbusch $\mathrm{HWM}^{1}$.

${ }^{1}$ Department of Neuroscience, Maastricht University, Maastricht, the Netherlands; ${ }^{2}$ CEDOC, NOVA Medical School, Universidade Nova de Lisboa, Lisboa, Portugal; ${ }^{3}$ Institute of General Pathology and Pathophysiology, Russian Academy of Medical Sciences, Moscow, Russia; ${ }^{4}$ Division of Molecular Psychiatry, Department of Psychiatry, Psychosomatics and Psychotherapy, University of Wuerzburg, Wuerzburg, Germany; ${ }^{5}$ Serbsky National Research Center for Social and Forensic Psychiatry, Department of Fundamental and Applied Neurobiology, Moscow, Russia; ${ }^{6}$ Department of Pharmacology, Oxford University, Oxford, UK 


\section{Abstract}

Background: High cholesterol intake in mice induces hepatic lipid dystrophy and inflammation, signs of non-alcoholic fatty liver disease (NAFLD), depressive- and anxiety-like behaviours, and the up-regulation of brain and liver Toll-like receptor 4 (T/r4). Here, we investigated whether dicholine succinate, an insulin receptor sensitizer and mitochondrial complex II substrate would interact with these effects. Methods: C57BL/6J mice were given a 0.2\%-cholesterol diet for 3 weeks, alone or along with oral DS administration, or a control feed. Outcomes included behavioural measures of anxiety/depression, and T/r4 and peroxisome-proliferator-activatedreceptor-gamma coactivator $1 \mathrm{~b}$ (PPARGC1b) expression. Results: $50 \mathrm{mg} / \mathrm{kg}$ DS treatment for 3 weeks partially ameliorated the cholesterol-induced anxiety- and depressive-like changes. Mice were next treated at the higher dose $(180 \mathrm{mg} / \mathrm{kg})$, either for the 3-week period of dietary intervention, or during its last two weeks. Three-week DS administration normalized behaviours in the forced swim and O-maze tests and abolished the T/r4 up-regulation in the brain and liver. The delayed, 2-week DS treatment had similar effects on the TIr4 expression and largely rescued abovementioned behaviours. Suppression of PPARGC1b, a master regulator of mitochondrial biogenesis, by the high cholesterol diet, was prevented with a 3-week administration, and markedly diminished during a 2-week administration of DS. None of treatments prevented hepatic dystrophy and triglyceride accumulation. Limitations: Other conditions have to be tested to define possible limitations of reported effects of DS. Conclusions: DS treatment did not alter the pathomorphological substrates of NAFLD syndrome in mice, but ameliorated its molecular and behavioural consequences, likely by activating mitochondrial functions and antiinflammatory mechanisms.

Key words: Western diet; depression; anxiety; insulin receptor sensitizers; toll-like receptor four (T/r4); mice 


\section{Introduction}

An emerging body of human and animal experiments has shown that a "Western diet" (high in saturated fat and/or cholesterol) - with ensuing obesity, hypercholesterolemia and insulin resistance - is associated with higher rates of affective disorders, and decreases therapeutic efficacy of antidepressants (Pomytkin et al., 2015; Shelton and Miller, 2010; Sonawalla, 2002; de Wit et al., 2010). Whilst the peripheral mechanisms of the association between metabolic factors and affective disorders has received some attention in the literature (Castanon, et al., 2015; Kishi and Elmquist, 2005), very few studies have addressed the central molecular pathways involved, which could be explored as potential targets for pharmacotherapy (Andre et al., 2014; Lucas and Maes, 2013; Scheen, 2009).

Insulin resistance, including deficient insulin receptor signalling, is regarded as a crucial pathogenic mechanism of affective changes associated with over-nutrition and metabolic syndrome (Kan et al., 2013; Pomytkin et al., 2015; Pyykkönen et al., 2011). Recent studies have shown that insulin itself and "neuronal insulin receptor sensitizers" have anti-depressant-like properties (Eissa Ahmed and Al-Rasheed, 2009; Gupta et al., 2014; Igarashi et al., 2008; Kemp et al., 2011; Mittal et al., 2009; Rasgon et al., 2010; Saubermann et al., 2002). These compounds increase neuronal mitochondrial biogenesis, are anti-inflammatory, and ameliorate neuronal damage (Ali et al., 2006; Asghar et al., 2007; Nuccio et al., 2015; Salehi-Sadaghiani et al., 2012; Strum et al., 2007; Zhao et al., 2006). Given the crucial role of mitochondria in synaptic function (Maeder et al., 2014) and evidence of lowered mitochondrial ATP and enzyme production, and inhibited respiratory chain and glucose metabolism during a depressive-like state (Gardner et al., 2003; Madrigal et al., 2001; Videbech et al., 2000), it is remarkable that insulin receptor sensitizers substantially ameliorate mitochondrial functions in the brain (De Nuccio et al., 2015; Dello Russo et al., 2002; Crenshaw et al., 2015). Notably, mitochondrial effects of insulin receptor sensitizers 
result in increased resting-state functional connectivity of hippocampal CA1 area to the hypothalamus and ventral thalamus (Crenshaw et al., 2015); currently, compromised brain connectivity is regarded as a biomarker of severe depression (Kaiser and Pizzagalli, 2015).

Antidepressant-like effects have also been reported for the non-esterified salt, dicholine succinate (DS), a mitochondrial complex II substrate, which enhances insulin-induced neuronal insulin receptor autophosphorylation in a dose-dependent manner (Persiyantseva et al., 2013; Storozheva et al., 2008; Storozhevykh et al., 2007), a mechanism for receptor activation (Wei et al., 1995). In a model of stressinduced anhedonia, DS, rescued normal contextual fear conditioning, increased hippocampal N-methyl-D-aspartate (NMDA) receptor subunit NR2A expression (and increased the NR2A/NR2B ratio), and increased rapid-eye-movement (REM) sleep rebound after acute predation (Cline et al., 2015, 2012). In a model of elderly depression, DS restored normal hedonic behaviours and increased the expression of neural plasticity factors in the hippocampus (Cline et al., 2015). Also, DS normalized hippocampal levels of the phosphorylated (inactive) form of glycogen synthase kinase three-beta (GSK3- $\beta$ ) during swim test in mice (Cline et al., 2015) and improved tail suspension behaviour (Costa-Nunes et al., 2015).

Given the link between insulin receptor-meditated signalling and nutritional/metabolic factors (Kan et al., 2013; Pyykkönen et al., 2011), we hypothesized that DS can improve the conditions resulting from non-alcoholic fatty liver disease (NAFLD). To test this, we employed recently established NAFLD model, in which young female $\mathrm{C} 57 \mathrm{BL} / 6 \mathrm{~J}$ mice are exposed to a feed containing $0.2 \%$ cholesterol for 3 weeks (Comhair et al., 2011; Strekalova et al., 2015). These changes are accompanied by behavioural despair, anxiety-like and impulsive behaviours, and elevated brain and liver levels of Toll-like receptor 4 (T/r4). The present study 
investigated whether DS could ameliorate the behavioural and molecular changes associated with NAFLD.

\section{Methods}

\section{Animals}

Three-month-old female C57BL/6J mice obtained from the Gulbenkian Institute of Science, Oeiras, Portugal were housed in groups of five under standard conditions and reversed lighting (see Supplementary material). All experiments were carried out in accordance with the European Communities Council Directive for the care and use of laboratory animals.

Study flow, dietary challenge and behavioural testing

Twenty-three mice were exposed for three weeks either to a regular diet (control group), with an energy content of $4.0 \mathrm{kcal} / \mathrm{g}$ (Mucedola Srl, Settimo Milanese, Italy), or a diet of similar composition with $0.2 \%(\mathrm{w} / \mathrm{w})$ cholesterol and an energy content of $4.6 \mathrm{kcal} / \mathrm{g}$ (Research Diets Inc, New Brunswick, NJ, USA; see Supplementary material), using an established protocol (Comhair et al., 2011; Strekalova et al., 2015). Body weight and 24-h food intake was evaluated on Days 0, 14 and 21 of dietary challenge. Eight mice were treated with DS via drinking water at $50 \mathrm{mg} / \mathrm{kg} /$ day (see p. 2.3) on days 1-21 of the dietary intervention. DS-treated mice were tested using the 0-maze on day 21 , along with eight dietary challenged but pharmacologically naïve mice, and seven dietary control mice; lighting intensity was 5Lux (Fig.1A; details of all behavioural paradigms can be found in Supplementary material). Latency of exit to the open arms, time spent therein, and number of exits, were scored in all groups (Strekalova et al., 2015). 3h after the O-maze, all mice were subjected to the 6-min forced swim test and 24h later, on Day 22, they were scored for latency to floating, and total duration of floating (Malatynska et al., 2012; Strekalova et al., 2015). 
Next, seven mice fed a high fat diet were given a dose of $180 \mathrm{mg} / \mathrm{kg}$ of DS (see 2.3), and studied alongside pharmacologically-naïve $(n=7)$ and dietary control $(n=10)$ mice, as described above (Fig.1B). In addition, a group of mice were given high-cholesterol diet alone for 1 week, and then were given DS alongside for the remaining 2 weeks ( $n=8$; Fig.1B). On days 21-22, all thirty-two mice were studied behaviourally as described above. On day 23, mice were sacrificed for brain and liver dissection and subsequent histological, molecular and biochemical analyses; the details of ex-vivo assays (see 2.4) are presented in Supplementary material.

\section{Drug administration}

DS was dissolved in tap water at 50 and $180 \mathrm{mg} / \mathrm{kg} / \mathrm{day}$, and provided for mice to drink ad libitum in water bottles as described elsewhere (Cline et al., 2015; CostaNunes et al., 2015).

\section{Tissue collection and ex-vivo analyses}

Mice were terminally anaesthetised and transcardially perfused with $\mathrm{NaCl}$, liver and brains were dissected, and prefrontal cortex, hippocampus, hypothalamus and dorsal raphe were isolated as described elsewhere for a subsequent in vitro assays, where five animals from each group were analyzed (Couch et al., 2013; Cline et al., 2015). The assessment of histological integrity and triglycerides in livers were performed as described elsewhere (Comhair et al., 2011; Strekalova et al., 2015). RNA extraction was performed from snap-frozen tissue to evaluate expression of T/r4 and PPARGC1b using SYBR green-based technology (Primer Design Ltd.), as described previously (Couch et al., 2013; Strekalova et al., 2015). Results were corrected to the housekeeping gene, glyceraldehyde 3-phosphate dehydrogenase (Gapdh) and expressed as fold increase compared to control animals and normalized to the means of this group. 
Statistics

Data were analysed with GraphPad Prism version 5.0 (San Diego, CA, USA) using oneor two-way ANOVA with Tukey post-hoc testing. The level of significance was set at $p<0.05$.

\section{Results}

Dosing with $50 \mathrm{mg} / \mathrm{kg} /$ day choline salt of succinic acid partially rescued affective changes induced by cholesterol diet

Body weight did not differ significantly between groups, suggesting that the dietary and pharmacological interventions did not grossly alter body composition $(p>0.05$, ANOVA; see Supplementary material, Fig.1A). In line with previous findings, intake of the high-cholesterol diet was significantly lower than that of the control diet, and this was not altered by DS administration ( $p<0.05$, ANOVA; see Supplementary material,

Fig.1B), likely due to the adjustment of mice to the higher caloric value of the highcholesterol diet. In the O-maze, there was a significant difference between the groups with regards to latency to exit into the open arms, time spent therein and number of exits to this zone $(F=3.98, p=0.035 ; F=4.58, p=0.023$ and $F=4.46, p=0.025$, respectively, one-way ANOVA; Fig.2A-C), with increased latency, decreased time spent, and decreased number of exits in mice fed with cholesterol diet compared with control mice ( $p<0.05$, Tukey test, see Supplementary Table 3$)$. Whilst there was a trend to normalizing of these behavioural features with DS treatment, there were no statistically significant differences between DS-treated mice with pharmacologically-naïve mice in terms of latency to exit into open arms, time spent therein and number of exits into open arms ( $p>0.05$, Tukey test).

In the forced swim test, there was a significant difference between the groups in terms of latency and duration of floating ( $F=5.86, p=0.010$ and $F=6.37, p=0.007$ respectively; ANOVA, Fig.2D,E). Post-hoc comparisons revealed shortened latency to 
float in pharmacologically-naive mice fed with the high cholesterol diet compared with dietary control mice ( $p<0.05$, Tukey test) but this was significantly ameliorated in the DS group ( $p<0.05$, Tukey test, see Supplementary Table 3$)$. Conversely, duration of floating was increased in pharmacologically naïve high cholesterol mice $(p<0.05$, Tukey test); there was a tendency to normalization with DS treatment, but this did not meet statistical significance. Due to the borderline effect noted with 50 $\mathrm{mg} / \mathrm{kg} /$ day treatment with DS, we next investigated whether these behavioural effects become more prominent at a higher dose.

Both simultaneous and delayed dosing with $180 \mathrm{mg} / \mathrm{kg} /$ day choline salt of succinic acid ameliorated the affective changes induced by cholesterol diet

As in the previous study, there was no difference between the groups in body weight across the study ( $p>0.05$, ANOVA; see Supplementary material, Fig.3A); similarly, the intake of the high-cholesterol diet was significantly lower than that of control diet and was not altered in DS-treated mice ( $p<0.05$, one-way ANOVA).

The groups differed significantly in terms of time spent in the open arms and number of exits into the open arms of the O-maze $(\mathrm{F}=3.50, p=0.029$ and $\mathrm{F}=3.19, p=0.040$, respectively, one-way ANOVA; Fig.2F-H). Pharmacologically-naïve mice fed the high cholesterol diet spent significantly less time in the open arms compared with dietary control mice ( $p<0.05$, Tukey test, see Supplementary Table 4$)$ and this normalized significantly with 3 week DS treatment at $180 \mathrm{mg} / \mathrm{kg} /$ day $(p<0.05$, Tukey test). Similarly compared with dietary control mice, those given a high cholesterol diet trended to fewer exits to the open arms, but this did not reach statistical significance; however, DS treatment significantly increased the number of exits onto the open arms in mice given DS for 3 weeks compared with pharmacologically-naïve mice ( $p<0.05$, Tukey test). Other differences between the groups did not reach statistical significance ( $p>0.05$, ANOVA, Tukey test). Mice on the high cholesterol diet treated with the delayed DS regime during two last week of dietary intervention did not show 
any changes in any behavioural measure on the O-maze as compared with control group ( $p>0.05$, ANOVA, Tukey test; Fig.2F-H).

In the forced swim test, the groups differed significantly in terms of latency and duration of floating ( $\mathrm{F}=5.38, p=0.005$ and $\mathrm{F}=5.92, p=0.003$, respectively; Fig.2I,J). Post hoc comparison showed that pharmacologically naïve mice fed a high cholesterol diet had a reduced latency to floating compared with dietary controls ( $p<0.05$, Tukey test, see Supplementary Table 4), but DS treatment, either for the three or two-week treatment regime, increased latency significantly compared with naïve mice $(p<0.05$, Tukey test). The duration of floating was significantly increased in pharmacologically naive high cholesterol mice compared with dietary controls ( $p<0.05$, Tukey test), and this was significantly ameliorated with three-week, ( $p<0.05$, Tukey test) but not twoweek treatment with DS ( $p>0.05$, Tukey test). No other comparisons between groups reached statistical significance ( $p>0.05$, ANOVA, Tukey test). Thus, at the dose of 180 $\mathrm{mg} / \mathrm{kg} / \mathrm{day}$, DS administration for the entire 3-week dietary period abolished behavioural changes induced by the high cholesterol diet. By comparison, a delayed, two-week administration of DS only partially ameliorated the behavioural effects of cholesterol supplementation.

Dicholine succinate treatment normalizes TIr4 and PPARGC1b expression, but does not alter cholesterol-induced NAFLD syndrome

High cholesterol diet and treatment with DS had a significant impact on TIr4 gene expression $(F=108.0, p<0.0001)$ that was independent of the CNS region $(p=0.195$, two-way ANOVA; Fig.3A). Expression of TIr4 was significantly higher in mice fed the high cholesterol diet without DS treatment compared with dietary controls, in the prefrontal cortex $(\mathrm{F}=11.99, p<0.0001)$, hippocampus $(\mathrm{F}=8.99, p<0.0001)$, hypothalamus ( $\mathrm{F}=5.66, p=0.009)$, and dorsal raphe $(\mathrm{F}=8.29, p<0.0001$; Fig.3A). This effect was obliterated with DS treatment, with significantly decreased expression in all anatomical regions, for high cholesterol-fed mice treated with DS vs 
pharmacologically naïve mice, including prefrontal cortex, hippocampus, hypothalamus and dorsal raphe $(p<0.0001$, see Supplementary Table 5$)$, but no significant differences between mice fed a normal diet compared with mice fed high cholesterol diet but receiving DS treatment in all these brain areas $(p>0.05$, Tukey test).

Similarly, TIr4 gene expression in the liver was significantly altered $(F=7.56, p=0.002$; one-way ANOVA, Fig.3A). Post hoc comparisons showed significant increased mRNA levels of T/r 4 in the liver of mice exposed to high cholesterol diet $(p<0.05$, Tukey test, see Supplementary Table 5) but not in dietary challenged mice dosed with DS for 3 or 2 weeks ( $p<0.05$, Tukey test), as compared to control. Animals exposed to cholesterol and treated with DS either for 3 or 2 weeks, showed significantly diminished liver TIr4 expression, in comparison with non-treated group fed with cholesterol-containing $\operatorname{diet}(p<0.05$, Tukey test).

There were also significant differences between groups in terms of PPARGC1b gene expression ( $F=123.0, p<0.0001$; one-way ANOVA), which were independent of CNS region ( $\mathrm{F}=0.54, p=0.660$; two-way ANOVA; Fig.3B). In all CNS regions, including prefrontal cortex, hippocampus, hypothalamus and dorsal raphe, PPARGC1b mRNA levels were significantly lower for mice fed with high cholesterol diet and no treatment and mice treated with DS for 2 weeks compared with the dietary control group ( $p<0.0001$, Tukey test, see Supplementary Table 6).

Mice fed with high cholesterol diet and treated with DS had elevated PPARGC1b expression in all above-listed CNS structures compared with both pharmacologically naïve mice fed with cholesterol diet and mice given the delayed 2-week treatment $(p<0.001$, Tukey test). In most CNS regions, including hippocampus, hypothalamus and dorsal raphe, PPARGC1b expression was not significantly different between high cholesterol DS treated mice compared with normal diet control ( $p>0.05$, Tukey test) 
but was decreased in the prefrontal cortex ( $p<0.05$, Tukey test), showing that gene expression was returned to broadly normal levels with 3 week DS treatment. There were no significant differences in PPARGC1b expression between mice fed high cholesterol diet with no treatment, and those given the delayed 2-week regime, in any CNS region studied ( $p>0.05$, Tukey test). No other statistically significant changes in the brain levels of PPARGC1b mRNA were found.

Hepatic PPARGC1b gene expression was significantly different between treatment groups ( $\mathrm{F}=8.50, p=0.001 ;$ ANOVA, Fig.3B). Hepatic PPARGC1b expression was significantly decreased in pharmacologically naïve mice exposed to high cholesterol diet ( $p<0.05$, Tukey test, see Supplementary Table 6) and mice dosed with DS for 2 weeks ( $p<0.05$, Tukey test). However, mice fed the high cholesterol diet with 3 week DS treatment had increased PPARGC1b levels compared with pharmacologically naïve mice ( $p<0.05$, Tukey test), but were not significantly different from mice fed a normal diet ( $p>0.05$, Tukey test).

Compared with mice fed a normal diet, the high-cholesterol diet groups revealed compromised liver tissue integrity, irrespectively to the scheme of dosing with DS (Fig.3C). The appearance of intracellular vacuoles was due to fat deposition in the tissue as previously reported (Comhair et al., 2011; Strekalova et al., 2015). There was limited difference between the four high fat groups, although there appears to be optical amelioration in the two treated groups compared with no treatment (Fig.3C). Dosing with DS for 3 weeks seems to have preserved integrity compared with a 2-week treatment with DS, although variation in tissue made this difficult to establish. Hepatic levels of triglycerides were significantly different between the groups ( $\mathrm{F}=12.56, p=0.0002$, ANOVA; Fig.3D). The colorimetric assay showed significantly elevated levels of triglycerides in mice on the high-cholesterol diet as compared to control animals ( $p<0.05$, Tukey test). This increase was found in mice treated with DS for 3 or 2 weeks as well $(p<0.05$, Tukey test, see Supplementary Table 
7). There was no difference in this measure between treatment groups for mice fed with high cholesterol diet ( $p>0.05$, Tukey test).

\section{Discussion}

In this study we showed that treatment with insulin receptor sensitizer dicholine succinate ameliorated anxiety- and depressive-like behaviours induced by a high cholesterol diet, and normalized expression of pro-inflammatory factor T/r4 and mitochondrial activity marker PPARGC1b, which were expressed abnormally high and low after high cholesterol diet treatment respectively. These effects were most pronounced when the dose of DS of $180 \mathrm{mg} / \mathrm{kg} /$ day was used for the entire period of a 3-week dietary challenge, and appeared to be limited when the onset of this treatment was delayed by one week. Liver steatosis and dystrophy were not significantly changed by the DS administration. As such, the improvement of affective changes in mice exposed to elevated dietary cholesterol and treated with the insulin receptor sensitizer DS was likely realized via the normalization of the secondary mechanisms of NAFLD syndrome, such as inflammation and mitochondrial functions, rather than of its primary features of liver steatosis and dystrophy.

We have previously reported sharply elevated brain and liver mRNA and protein levels of TIr4 associated with increased anxiety, hyperlocomotion and "behavioral despair" using this NAFLD model (Strekalova et al., 2015). Here, both 3- and 2-week administration of DS at the dose $180 \mathrm{mg} / \mathrm{kg} /$ day rescued normal gene expression of TIr4 in a liver and all four investigated brain structures, including the hippocampus and the prefrontal cortex. This was accompanied by a normalization of anxiety- and depressive-like behaviours. Our data and other recent reports in the literature show a link between TLR4 expression, anxiety-like behaviour and stress in rodents (Okun et al., 2012; Rico et al., 2010; Shannonhouse et al., 2014), which suggests that the 
ameliorative behavioural effects of DS shown in this experiment may be due to a suppressive action of DS on T/r4.

In comparison to the behavioural effects of a 3-week treatment with DS, the dosing with DS for 2 weeks with a delayed onset of 1 week had limited efficacy. Both treatments similarly prevented the brain and liver T/r4 overexpression, but no significant restorative action of a 2-week DS administration on the marker of mitochondrial activity PPARGC1b was found, which might explain the abovementioned discrepancy in behavioural results. While this discrepancy can also be due to differing protein levels of TLR4 protein, our data may suggest a partial role of TLR4 in the regulation of affective changes in mice.

PPARGC1b is a member of family of peroxisome proliferator activated receptor gamma coactivators, which induces nuclear-encoded genes regulating mitochondrial oxidative metabolism and beta-oxidation of fatty acids in the brain, liver and other tissues, particularly during over-nutrition (Lin et al., 2003; Scarpulla, 2008; Sonoda et al., 2007). PPARC1b knock-out mice have increased susceptibility to hepatic steatosis induced by high fat diet, insulin resistance, reduced mitochondrial biogenesis and behavioural inhibition (Lelliott et al., 2006; Sonoda et al., 2007; Vianna et al., 2006). In contrast, mutant mice overexpressing PPARGC1b revealed enhanced biosynthesis of mitochondria and basal oxygen consumption, increased energy expenditure and reduced lipid accumulation under these conditions (Kamei et al., 2003; Lin et al., 2002; Meirhaeghe et al., 2003). Available data suggest that the treatment of mice housed on a high cholesterol diet with DS could enhance lipid metabolism and mitochondrial functions via a restoration of basal PPARGC1b expression, and this might preserve normal brain functions and behaviour.

In summary, our study demonstrates for the first time that the dosing with insulin receptor sensitizer DS can ameliorate depressive- and anxiety-like behaviours, as well 
as changes in the molecular markers of inflammation and mitochondrial function, which are evoked by dietary cholesterol. Given data showing a functional relationship between insulin resistance, TLR4 and mitochondrial functions, the precise mechanisms of which are not yet fully elucidated (Shi et al., 2006), we hypothesize that the molecular effects of DS shown in this report are mediated by the stimulation of insulin receptor signalling. They are likely to involve secondary effects associated with increased insulin receptor signalling, such as amelioration of glucose tolerance and neuronal mitochondria functions resulting in normalized brain connectivity, an important factor in depression (Maeder et al., 2014; Pomytkin et al., 2015). While DS induced no significant effects on hepatic histology or triglyceride content, our findings nonetheless suggest a potential therapeutic role of insulin receptor sensitizers, an emerging class of antidepressant remedies, for the treatment of affective symptoms during NAFLD syndrome.

\section{Role of funding source}

The founding source had no influence on any aspect of work presented in this publication.

\section{Conflict of Interest}

The authors declare no conflict of interest.

\section{Acknowledgements}

We acknowledge the important contribution of Prof. Daniel C. Anthony (Oxford University), Dr. Eleonora S. Koehler (Maastricht University) and Dr. Dolores Bonaparte (New University of Lisbon). The authors' work reported in this paper was supported by the European Community (EC: AGGRESSOTYPE FP7/No. 602805) and RFBR 15-04-03602 to TS. 


\section{References}

Ali, F.Y., Davidson, S.J., Moraes, L.A., Traves, S.L., Paul-Clark, M., Bishop-Bailey, D., Warner, T.D., Mitchell, J.A., 2006. Role of nuclear receptor signaling in platelets: antithrombotic effects of PPARbeta. FASEB J. 20, 326-328.

André, C., Dinel, A.L., Ferreira, G., Layé, S., Castanon, N., 2014. Diet-induced obesity progressively alters cognition, anxiety-like behaviour and lipopolysaccharide-induced depressive-like behaviour: focus on brain indoleamine 2,3-dioxygenase activation. Brain Behav Immun. 41, 10-21.

Asghar, S., Hussain, A., Ali, S.M., Khan, A.K., Magnusson, A., 2007. Prevalence of depression and diabetes: a population-based study from rural Bangladesh. Diabet Med. 24, 872-877.

Castanon, N., Luheshi, G., Layé, S., 2015. Role of neuroinflammation in the emotional and cognitive alterations displayed by animal models of obesity. Front Neurosci. 9, 229.

Cline, B.H., Costa-Nunes, J.P., Cespuglio, R., Markova, N., Santos, A.I., Bukhman, Y.V., Kubatiev, A., Steinbusch, H.W., Lesch, K.P., Strekalova, T., 2015. Dicholine succinate, the neuronal insulin sensitizer, normalizes behaviour, REM sleep, hippocampal pGSK3 beta and mRNAs of NMDA receptor subunits in mouse models of depression. Front Behav Neurosci. 9:37.

Cline, B.H., Steinbusch, H.W., Malin, D., Revishchin, A.V., Pavlova, G.V., Cespuglio, R., Strekalova, T., 2012. The neuronal insulin sensitizer choline salt of succinic acid reduces stress-induced depressive traits and memory deficit: possible role of insulin-like growth factor 2. BMC neuroscience 13:110.

Comhair, T.M., Garcia-Caraballo, S.C., Dejong, C.H., Lamers, W.H., Köhler, S.E., 2011. Dietary cholesterol, female gender and n-3 fatty acid deficiency are more important factors in the development of nonalcoholic fatty liver disease than the saturation index of the fat. Nutr. Metab. (Lond). 8, 4.

Costa-Nunes, J.P., Cline, B.H., Araújo-Correia, M., Valença, A., Markova, N., Dolgov, O., Kubatiev, A., Yeritsyan, N., Steinbusch, H.W., Strekalova, T., 2015. Animal Models of Depression and Drug Delivery with Food as an Effective Dosing Method: Evidences from Studies with Celecoxib and Dicholine Succinate. Biomed Res Int. 596126.

Couch, Y., Anthony, D.C., Dolgov, O., Revischin, A., Festoff, B., Santos, A.I., Steinbusch, H.W.M., Strekalova, T., 2013. Microglial activation, increased TNF and SERT expression in the prefrontal cortex define stress-altered behaviour in mice susceptible to anhedonia. Brain. Behav. Immun. 29, 136-146.

Crenshaw, D.G., Asin, K., Gottschalk, W.K., Liang, Z., Zhang, N., Roses, A.D., 2015. Effects of low doses of pioglitazone on resting-state functional connectivity in conscious rat brain. PLoS One. 10.

De Nuccio, C., Bernardo, A., Cruciani, C., De Simone, R., Visentin, S., Minghetti, L., 2015. Peroxisome proliferator activated receptor- $\gamma$ agonists protect oligodendrocyte progenitors against tumor necrosis factor-alpha-induced damage: Effects on mitochondrial functions and differentiation. Exp Neurol. 271, 506-14.

Dello Russo, C., Gavrilyuk, V., Weinberg, G., Almeida, A., Bolanos, J.P., Palmer, J., Pelligrino, D., Galea, E., Feinstein, D.L., 2002. Peroxisome proliferator-activated receptor gamma thiazolidinedione agonists increase glucose metabolism in astrocytes. J Biol Chem. 278, 5828-36.

Eissa Ahmed, A.A, Al-Rasheed, N.M., 2009. Antidepressant-like effects of rosiglitazone, a PPARgamma agonist, in the rat forced swim and mouse tail suspension tests. Behav. Pharmacol. 20, 635-642. 
Gardner, A., Johansson, A., Wibom, R., Nennesmo, I., von Dobeln, U., Hagenfeldt, L., Hällström, T., 2003. Alterations of mitochondrial function and correlations with personality traits in selected major depressive disorder patients. Journal of affective disorders. 76, 55-68.

Gupta, D., Kurhe, Y., Radhakrishnan, M., 2014. Antidepressant effects of insulin in streptozotocin induced diabetic mice: Modulation of brain serotonin system. Physiol Behav. 129, 73-8.

Igarashi, M., Hirata, A., Yamaguchi, H., Jimbu, Y., Tominaga, M., 2008. Pioglitazone reduces atherogenic outcomes in type 2 diabetic patients. J. Atheroscler. Thromb. 15, 34-40.

Kaiser, R.H., Pizzagalli, D.A., 2015. Dysfunctional Connectivity in the Depressed Adolescent Brain. Biol Psychiatry. 78, 594-5.

Kamei, Y., Ohizumi, H., Fujitani, Y., Nemoto, T., Tanaka, T., Takahashi, N., Kawada, T., Miyoshi, M., Ezaki, O., Kakizuka, A., 2003. PPARgamma coactivator 1beta/ERR ligand 1 is an ERR protein ligand, whose expression induces a high-energy expenditure and antagonizes obesity. Proc Natl Acad Sci U S A. 100, 12378-12383.

Kan, C., Silva, N., Golden, S.H., Rajala, U., Timonen, M., Stahl D., Ismail, K., 2013. A systematic review and meta-analysis of the association between depression and insulin resistance. Diabetes care. 36, 480-489.

Kemp, D.E., Ismail-Beigi, F., Ganocy, S.J., Conroy, C., Gao, K., Obral, S., Fein, E., Findling, R.L., Calabrese, J.R., 2011. Use of insulin sensitizers for the treatment of major depressive disorder: A pilot study of pioglitazone for major depression accompanied by abdominal obesity. J. Affect. Disord. 136, 1164-1173.

Kishi, T., Elmquist, J.K., 2005. Body weight is regulated by the brain: a link between feeding and emotion. Mol Psychiatry. 10, 132-146.

Lelliott, C.J., Medina-Gomez, G., Petrovic, N., Kis, A., Feldmann, H.M., Bjursell, M., Parker, N., Curtis, K., Campbell, M., Hu, P., Zhang, D., Litwin, S.E., Zaha, V.G., Fountain, K.T., Boudina, S., Jimenez-Linan, M., Blount, M., Lopez, M., Meirhaeghe, A., Bohlooly-Y, M., Storlien, L., Strömstedt, M., Snaith, M., Oresic, M., Abel, E.D., Cannon, B., Vidal-Puig, A., 2006. Ablation of PGC-1beta results in defective mitochondrial activity, thermogenesis, hepatic function, and cardiac performance. PLoS Biol. 4, e369.

Lin, J., Puigserver, P., Donovan, J., Tarr, P., Spiegelman, B.M., 2002. Peroxisome proliferator-activated receptor gamma coactivator 1 beta (PGC-1beta), a novel PGC-1-related transcription coactivator associated with host cell factor. J Biol Chem. 277, 1645-1648.

Lin, J., Tarr, P.T., Yang, R., Rhee, J., Puigserver, P., Newgard, C.B., Spiegelman, B.M., 2003. PGC-1beta in the regulation of hepatic glucose and energy metabolism. J Biol Chem. 278, 30843-30848.

Lucas, K., Maes, M., 2013. Role of the Toll Like receptor (TLR) radical cycle in chronic inflammation: possible treatments targeting the TLR4 pathway. Mol Neurobiol. 48, 190-204.

Madrigal, J.L., Olivenza, R., Moro, M.A., Lizasoain, I., Lorenzo, P., Rodrigo, J., Leza, J.C., 2001. Glutathione depletion, lipid peroxidation and mitochondrial dysfunction are induced by chronic stress in rat brain. Neuropsychopharmacology: official publication of the American College of Neuropsychopharmacology. 24, 420-429.

Maeder, C.I., Shen, K., Hoogenraad, C.C., 2014. Axon and dendritic trafficking. Curr Opin Neurobiol. 27, 165-70. 
Malatynska, E., Steinbusch, H.W., Redkozubova, O., Bolkunov, A., Kubatiev, A., Yeritsyan, N.B., Vignisse, J., Bachurin, S., Strekalova, T., 2012. Anhedonic-like traits and lack of affective deficits in 18-month-old C57BL/6 mice: Implications for modeling elderly depression. Exp. Gerontol. 47, 552-564.

Meirhaeghe, A., Crowley, V., Lenaghan, C., Lelliott, C., Green, K., Stewart, A., Hart, K., Schinner, S., Sethi, J.K., Yeo, G., Brand, M.D., Cortright, R.N., O'Rahilly, S., Montague, C., Vidal-Puig, A.J., 2003. Characterization of the human, mouse and rat PGC1 beta (peroxisome-proliferator-activated receptorgamma co-activator 1 beta) gene in vitro and in vivo. Biochem J. 373, 155-165.

Mittal, R., Malhotra, S., Pandhi, P., Kaur, I., Dogra, S., 2009. Efficacy and safety of combination Acitretin and Pioglitazone therapy in patients with moderate to severe chronic plaque-type psoriasis: a randomized, double-blind, placebo-controlled clinical trial. Arch. Dermatol. 145, 387-393.

Okun, E., Barak, B., Saada-Madar, R., Rothman, S.M., Griffioen, K.J., Roberts, N., Castro, K., Mughal, M.R., Pita, M.A., Stranahan, A.M., Arumugam, T.V., Mattson, M.P., 2012. Evidence for a developmental role for TLR4 in learning and memory. PLoS. One. 7, e47522.

Persiyantseva, N.A., Storozhevykh, T.P., Senilova, Y.E., Gorbacheva, L.R., Pinelis, V.G., Pomytkin, I.A., 2013. Mitochondrial $\mathrm{H} 2 \mathrm{O} 2$ as an enable signal for triggering autophosphorylation of insulin receptor in neurons. J Mol Signal. 8, 11.

Pomytkin, I.A., Cline, B.H., Anthony, D.C., Steinbusch, H.W., Lesch, K.P., Strekalova, T., 2015. Endotoxaemia resulting from decreased serotonin tranporter (5-HTT) function: a reciprocal risk factor for depression and insulin resistance? Behav Brain Res. 276, 111-117.

Pyykkönen, A.J., Raikkonen, K., Tuomi, T., Eriksson, J.G., Groop, L., Isomaa, B., 2011. Depressive symptoms, antidepressant medication use, and insulin resistance: the PPP-Botnia Study. Diabetes care. 34, 2545-2547.

Rasgon, N.L., Kenna, H.A., Williams, K.E., Powers, B., Wroolie, T., Schatzberg, A.F., 2010. Rosiglitazone add-on in treatment of depressed patients with insulin resistance: a pilot study. Sci. World. J. 10, 321328.

Rico, J.L., Ferraz, D.B., Ramalho-Pinto, F.J., Morato, S., 2010. Neonatal exposure to LPS leads to heightened exploratory activity in adolescent rats. Behav. Brain. Res. 215, 102-109.

Salehi-Sadaghiani, M., Javadi-Paydar, M., Gharedaghi, M.H., Zandieh, A., Heydarpour, P., YousefzadehFard, Y., Dehpour, A.R., 2012. NMDA receptor involvement in antidepressant-like effect of pioglitazone in the forced swimming test in mice. Psychopharmacology (Berl). 223, 345-355.

Saubermann, L.J., Nakajima, A., Wada, K., Zhao, S., Terauchi, Y., Kadowaki, T., Aburatani, H., Matsuhashi, N., Nagai, R., Blumberg, R.S., 2002. Peroxisome proliferator-activated receptor gamma agonist ligands stimulate a Th2 cytokine response and prevent acute colitis. Inflamm. Bowel. Dis. 8, 330-339.

Scarpulla, R.C., 2008. Transcriptional paradigms in mammalian mitochondrial biogenesis and function. Physiol Rev. 88, 611-638

Scheen, A.J., 2009. The endocannabinoid system: a promising target for the management of type 2 diabetes. Curr Protein Pept Sci. 10, 56-74.

Shannonhouse, J.L., Fong, L.A., Clossen, B.L., Hairgrove, R.E., York, D.C., Walker, B.B., Hercules, G.W., Mertesdorf, L.M., Patel, M., Morgan, C., 2014. Female-biased anorexia and anxiety in the Syrian hamster. Physiol. Behav. 133, 141-151. 
Shelton, R.C., Miller, A.H., 2010. Eating ourselves to death (and despair): the contribution of adiposity and inflammation to depression. Prog Neurobiol. 91, 275-299.

Shi, H., Kokoeva, M.V., Inouye, K., Tzameli, I., Yin, H., Flier, J.S., 2006. TLR4 links innate immunity and fatty acid-induced insulin resistance. J. Clin. Invest. 116, 3015-3025.

Sonawalla, S.B., Papakostas, G.I., Petersen, T.J., Yeung, A.S., Smith, M.M., Sickinger, A.H., Gordon, J., Israel, J.A., Tedlow, J.R., Lamon-Fava, S., Fava, M., 2002. Elevated cholesterol levels associated with nonresponse to fluoxetine treatment in major depressive disorder. Psychosomatics. 43, 310-316.

Sonoda, J., Mehl, I.R., Chong, L.W., Nofsinger, R.R., Evans, R.M., 2007. PGC-1beta controls mitochondrial metabolism to modulate circadian activity, adaptive thermogenesis, and hepatic steatosis. Proc Natl Acad Sci U S A. 104, 5223-5228

Storozheva, Z.I., Proshin, A.T., Sherstnev, V.V., Storozhevykh, T.P., Senilova, Y.E., Persiyantseva, N.A., Pinelis, V.G., Semenova, N.A., Zakharova, E.I., Pomytkin, I.A., 2008. Dicholine salt of succinic acid, a neuronal insulin sensitizer, ameliorates cognitive deficits in rodent models of normal aging, chronic cerebral hypoperfusion, and beta-amyloid peptide-(25-35)-induced amnesia. BMC Pharmacol. 8, 1.

Storozhevykh, T.P., Senilova, Y.E., Persiyantseva, N.A., Pinelis, V.G., Pomytkin, I.A., 2007. Mitochondrial respiratory chain is involved in insulin-stimulated hydrogen peroxide production and plays an integral role in insulin receptor autophosphorylation in neurons. BMC Neurosci. 8, 84.

Strekalova, T., Evans, M., Costa-Nunes, J., Bachurin, S., Yeritsyan, N., Couch, Y., Steinbusch, H.M., Köhler E.S., Lesch, K.P., Anthony D.C., 2015. Trr4 upregulation in the brain accompanies depression- and anxiety-like behaviours induced by a high-cholesterol diet. Brain Behav Immun. 48, 42-47.

Strum, J.C., Shehee, R., Virley, D., Richardson, J., Mattie, M., Selley, P., Ghosh, S., Nock, C., Saunders, A., Roses, A., 2007. Rosiglitazone induces mitochondrial biogenesis in mouse brain. J. Alzheimers. Dis. 11, 45-51.

Vianna, C.R., Huntgeburth, M., Coppari, R., Choi, C.S., Lin, J., Krauss, S., Barbatelli, G., Tzameli, I., Kim, Y.B., Cinti, S., Shulman, G.I., Spiegelman, B.M., Lowell, B.B., 2006. Hypomorphic mutation of PGC-1beta causes mitochondrial dysfunction and liver insulin resistance. Cell Metab. 4, 453-464.

Videbech, P., 2000. PET measurements of brain glucose metabolism and blood flow in major depressive disorder: a critical review. Acta psychiatrica Scandinavica. 101, 11-20.

Wei, L., Hubbard, S.R., Hendrickson, W.A., Ellis, L., 1995. Expression, characterization, and crystallization of the catalytic core of the human insulin receptor protein-tyrosine kinase domain. J Biol Chem. 270, 8122-8130.

de Wit, L., Luppino, F., van Straten A., Penninx B., Zitman F., Cuijpers P., 2010. Depression and obesity: a meta-analysis of community-based studies. Psychiatry Res. 30, 230-235.

Zhao, Y., Patzer, A., Herdegen, T., Gohlke, P., Culman, J., 2006. Activation of cerebral peroxisome proliferator-activated receptors gamma promotes neuroprotection by attenuation of neuronal cyclooxygenase-2 overexpression after focal cerebral ischemia in rats. FASEB. J. 20, 1162-1175. 


\section{Figure legends}

Figure 1. Schematics of the study with administration of DS (A) at the dose $50 \mathrm{mg} / \mathrm{kg}$ and at the dose $180 \mathrm{mg} / \mathrm{kg}$ (B), for 3-weeks or for 2 weeks, with late onset.

Figure 2. Effects of DS on behavioral correlates. Partial efficacy of treatment with DS at the dose of $50 \mathrm{mg} / \mathrm{kg}$ on the parameters of anxiety-like behavior: the (A) latency of the first exit (B) time spent in open arms (C) number of exits to open arms, in the elevated O-maze, and on depressive-like behavior: the latency (D) and (E) duration of floating in the forced swim test. Preventive effects of administration of DS at the dose of $180 \mathrm{mg} / \mathrm{kg}$ on the parameters of anxiety-like behavior: the (F) latency of the first exit (G) time spent in open arms (H) number of exits to open arms, in the elevated O-maze, and on depressive-like behavior: the latency (I) and (J) duration of floating in the forced swim test. ${ }^{*} p<0.05$ vs. control, $\# p<0.05$ vs. HC diet, Tukey test). Data are shown as mean \pm SEM.

Figure 3. Effects of DS on gene expression, triglyceride levels and hepatosteatosis. Administration of DS at the dose of $180 \mathrm{mg} / \mathrm{kg}$ precludes dietary-induced (A) T/r4 upregulation in the brain and liver and (B) a suppression of a mitochondrial activity markers PPARGC1b, but does not alter (C) hepatosteatosis (Haematoxylin and eosin-stained sections: scale bar 20um) nor (D) triglyceride levels in the liver. ${ }^{*} p<0.05$ vs. control, \#p<0.05 vs. HC diet, Tukey test). Data are shown as mean \pm SEM. 
A Experimental design. Dosing with $50 \mathrm{mg} / \mathrm{kg}$

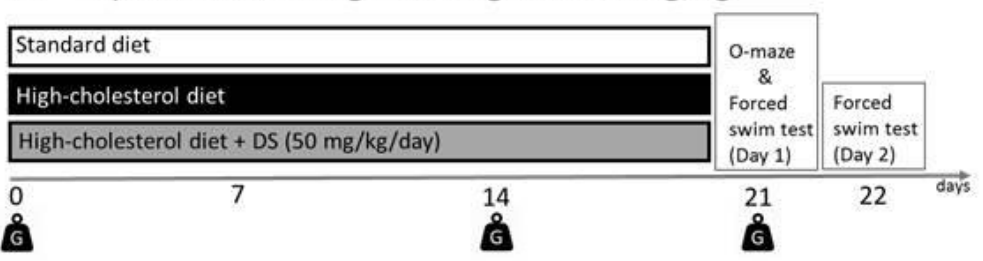

B Experimental design. Dosing with $180 \mathrm{mg} / \mathrm{kg}$

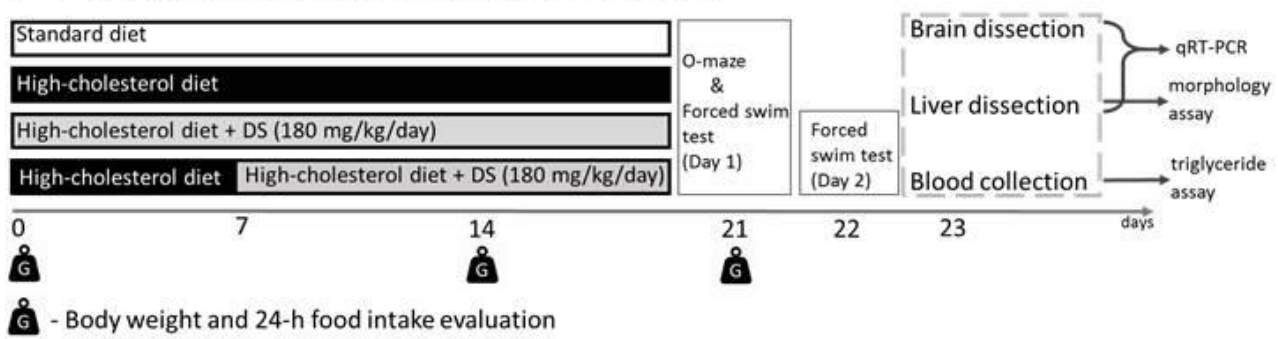

Figure 1 
DOSING WITH 50 MG/KG

O-maze
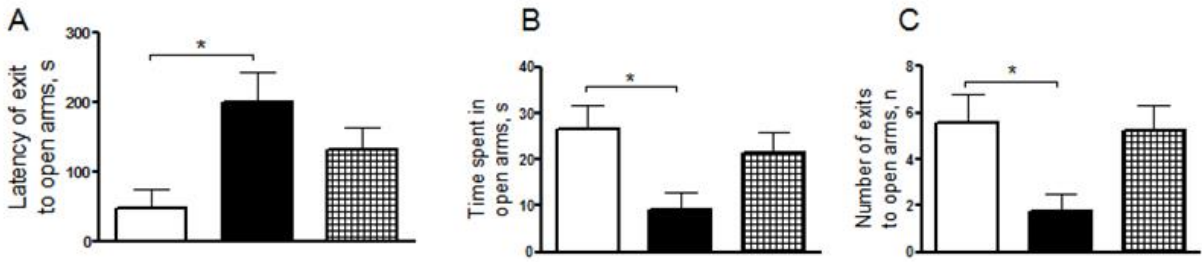

Forced swim test

D

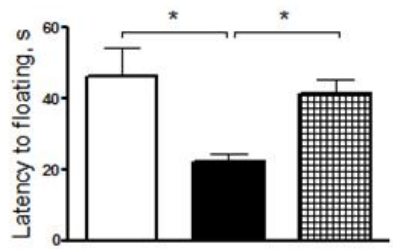

E

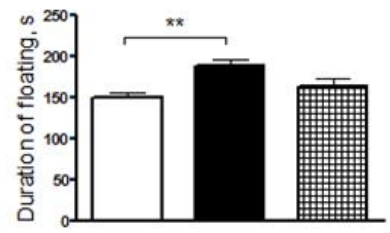

典 HCD + DS (50

$\mathrm{mg} / \mathrm{kg} /$ day,

3-week

treatment)

$\square$ HCD

$\square$ Control diet

DOSING WITH 180 MG/KG

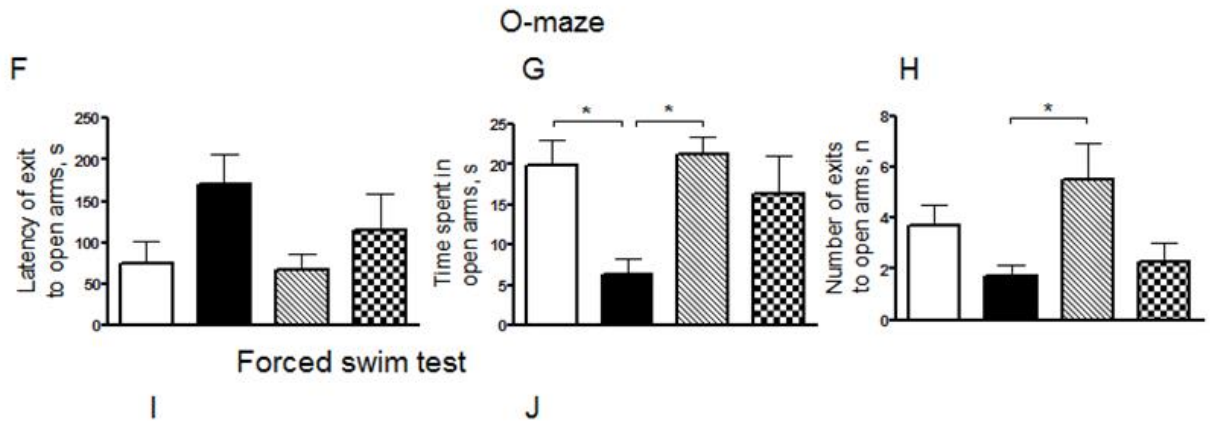

ه HCD + DS (180 mg/kg/day, 2-week delayed treatment)
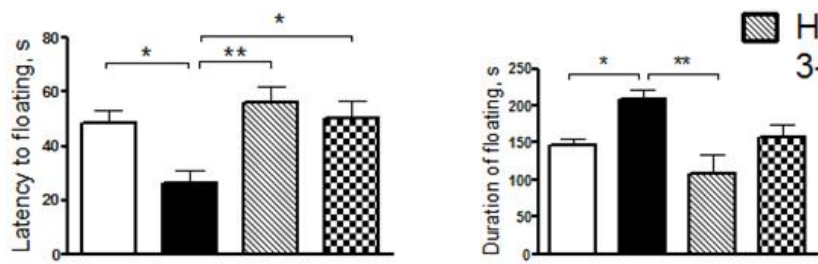

HCD + DS (180 mg/kg/day, 3-week treatment)

$\square$ Control diet

Figure 2 

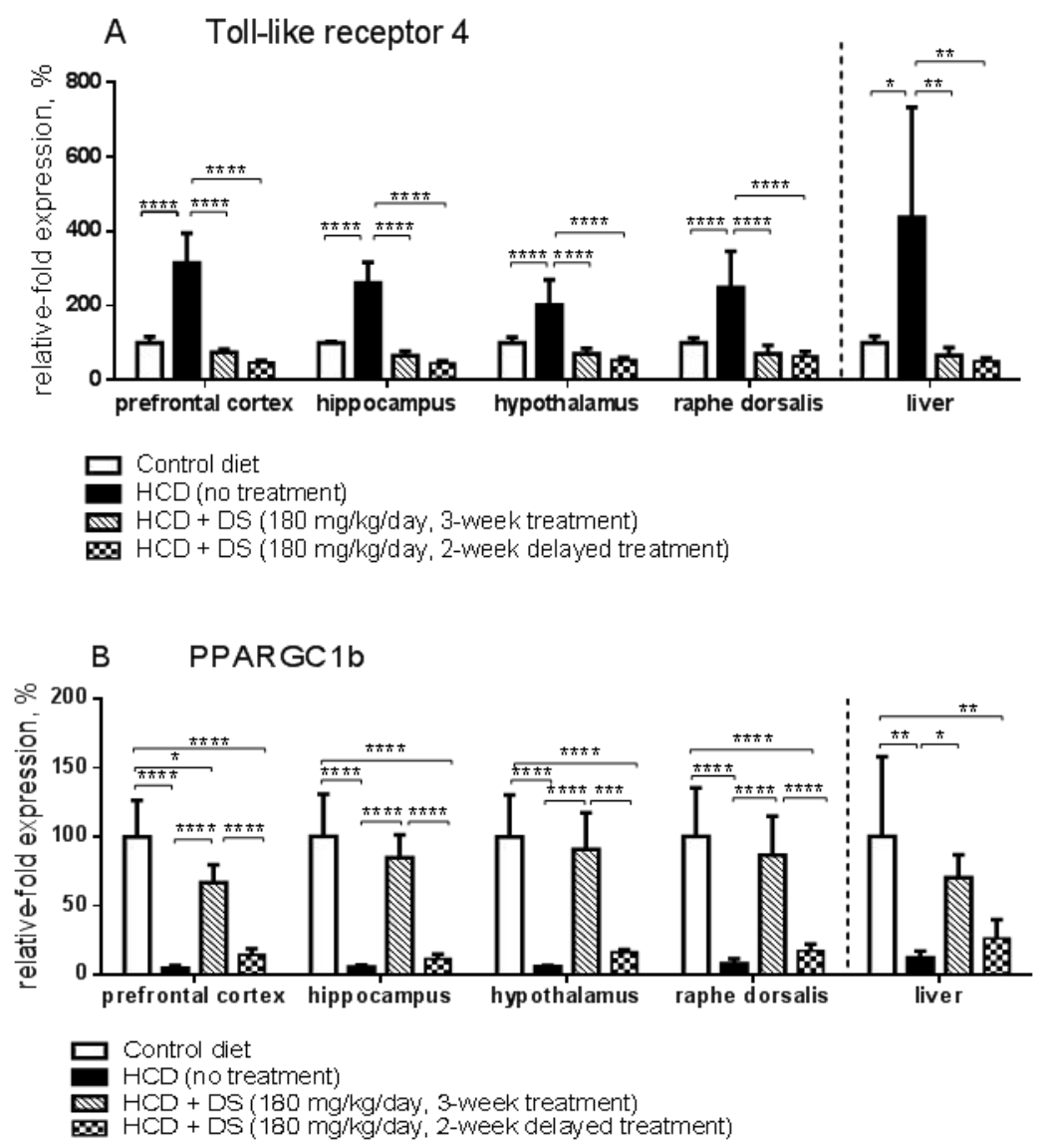

C Liver histology

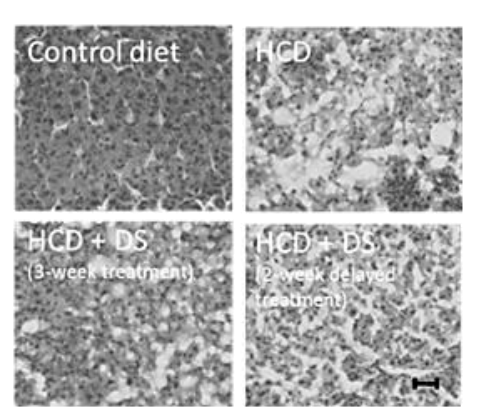

D Triglyceride assay

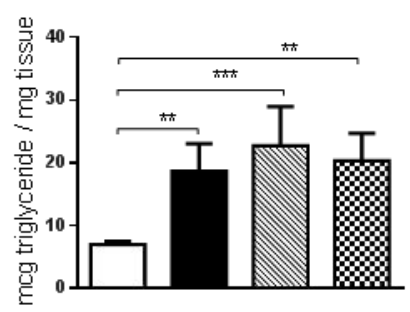

$\square$ control diet

$\mathrm{HCD}$

HCD + DS (180 mgkg/day, 3-meek treatment)

$\mathbf{H C D}+\mathrm{DS}$ (180 mgkgiday, 2-meek delayed tre atment)

Figure 3 


\section{Supplementary material}

\section{Animals}

Studies were performed using 3-month-old female C57BL/6J from the Gulbenkian Institute of Science, Oeiras, Portugal. C57BL/6J mice were housed in groups of five under a reversed 12-hour light-dark cycle (lights on: 21:00 h) starting from the day of animals' transportation in the laboratory with food and water provided ad libitum, under controllable laboratory conditions ( $22 \pm 1^{\circ} \mathrm{C}, 55 \%$ humidity). Animals were handled weekly during the changes of cages by care takers, as well as when experimental procedures were performed. All mice had a tissue paper in their cages and also placed on the bedding material.

All experiments were carried out in accordance with the European Communities Council Directive for the care and use of laboratory animals 2010/63/EU and Portuguese Law-Decrees DL129/92 upon approval by the Ethical and Welfare Committee of the New Lisbon University on animal care and welfare.

\section{Elevated O-maze}

The apparatus (Technosmart, Rome, Italy), which consisted of a circular path (runway width $5.5 \mathrm{~cm}$, diameter $46 \mathrm{~cm}$ ), was placed $20 \mathrm{~cm}$ above the floor. Two opposing arms were protected by walls (height $10 \mathrm{~cm}$ ), and the illumination strength was $5 \mathrm{Lux}$. The apparatus was placed on a dark surface in order to reduce reflection and maintain control over lighting conditions during testing. Anxiety-like behaviour was assessed using previously validated parameters (Cline et al., 2015; Costa-Nunes et al., 2014, 2015, Strekalova et al., 2015). Mice were placed in one of the closed-arm compartments of the apparatus. The latency of the first exit to the anxiety-related open compartments of the maze, the total duration of time spent therein, and the number of exits to the open arms were scored during a 5-min observation period; all behaviours were scored manually. 


\section{Forced swim test}

The Porsolt forced swim protocol has been adapted from previously established method (Malatynska et al., 2012; Strekalova et al., 2015). Mice were subjected to two 6-min swimming sessions, on Days 1 and 2, spaced $24 \mathrm{~h}$ apart, in a transparent cylinder $(\varnothing 17 \mathrm{~cm})$ filled with water $\left(23^{\circ} \mathrm{C}\right.$, water height $13 \mathrm{~cm}$, height of cylinder 20 $\mathrm{cm}$, illumination intensity 25 Lux). Behavior was scored on Day 2. Floating was defined by the absence of any directed movements of the animals' head and body and was scored manually; criteria of scoring were previously validated using Noldus EthoVision XT 8.5 (Noldus Information Technology, Wageningen, The Netherlands) and CleverSys (CleverSys, Reston, VA, USA). Using this method, the latency of the first episode of floating and the duration of floating behaviour were scored. Latency to begin floating was scored as time between introduction of the animal into the pool and the first moment of complete immobility of the entire body for a duration of $>3$ seconds. The total time spent floating was scored for the entire duration of the test using post-test video footage.

\section{Tissue collection and in vitro assays}

Mice were terminally anaesthetised with sodium pentobarbitone and transcardially perfused with $\mathrm{NaCl}$, brains were dissected and prefrontal cortex, hippocampi, hypothalamus, raphe dorsalis and liver were isolated and stored at $-80^{\circ} \mathrm{C}$ until use as described elsewhere (Couch et al., 2013; Cline et al., 2015; Costa-Nunes et al., 2014). Pieces of liver were separately stored for a subsequent histological and triglyceride analysis as previously described (Strekalova et al., 2015).

\section{Quantitative RT-PCR (qPCR)}

RNA Extraction and Quantitative RT-PCR: RNA extraction was performed as previously described from specifically microdissected snap-frozen brain regions (Blond et al., 2002, Campbell et al., 2005). Specific primers were designed by the Primer Design Centre (Roche) and are given in the table below (see Supplementary 
Table 1). Standard curves were generated using synthetically designed amplicons of known copy number (Primer Design Ltd., UK). Quantitative RT-PCR was run using Roche Mastermix and FAM PCR probes. Results are expressed as number of copies of target per $1 \mathrm{ng}$ input RNA corrected to the housekeeping gene, glyceraldehyde 3phosphate dehydrogenase (Gapdh). Data were calculated as fold increase compared to control animals and normalized to housekeeping gene.

\section{Triglyceride assay}

The triglyceride colorimetric assay from Cayman chemicals (Cayman Europe, Tallinn, Estonia) was used for this analysis. In brief, small segments of liver (range: 25.0mg 34.0mg; median: $30.05 \mathrm{mg}$ ) were placed in $100 \mu \mathrm{L}$ of the cell lysis buffer, and homogenized using an electronic tissue disruptor. Samples were then frozen at $-80^{\circ} \mathrm{C}$ to use freeze-thaw for mechanical disruption of the tissue. Once thawed, $10 \mu \mathrm{L}$ of each samples were placed in a 96 well plate, with $150 \mu \mathrm{L}$ of enzyme mixture (lipoprotein lipase, glycerol kinase, glycerol phosphate oxidase and peroxidase). A triglyceride standard curve was used with the following concentrations:

\begin{tabular}{|c|c|}
\hline $\begin{array}{l}\text { Triglyceride } \\
\text { standard }\end{array}$ & $\begin{array}{ll} & \text { Concentration } \\
(\mathrm{mg} / \mathrm{dL}) & \end{array}$ \\
\hline 1 & 200 \\
\hline 2 & 100 \\
\hline 3 & 50 \\
\hline 4 & 25 \\
\hline 5 & 12.5 \\
\hline 6 & 6.25 \\
\hline 7 & 3.125 \\
\hline 8 & 0 \\
\hline
\end{tabular}


This was read using a plate reader with absorbance at $550 \mathrm{~nm}$. The $0 \mathrm{mg} / \mathrm{dL}$ standard was used as a null reference, and the absorbance value of this standard was subtracted from all other samples and standards to give a corrected absorbance value (CA). The standard curve was used to construct the linear equation $y=m x+c$, and the concentration of triglycerides in the samples was calculated using a formula:

$$
\text { Triglycerides }(\mathrm{mg} / \mathrm{dL})=[(\mathrm{CA})-\mathrm{c}) / \mathrm{x}]
$$

This gives the concentration of triglycerides in the samples, which is then divided by 10,000 to give the total amount of triglyceride in the original lysis buffer. This value was then divided by the number of mg of tissue homogenized into the lysis buffer, multiplied to convert to $\mu \mathrm{g}$ triglyceride to end up with a value of $\mu \mathrm{g}$ triglyceride / $\mathrm{mg}$ of liver tissue.

\section{Liver morphology assay}

Small segments of liver tissue were fresh frozen, and stored at $-80^{\circ} \mathrm{C}$ until use. Tissue was attached using embedding medium to the cryostat apparatus (Leica

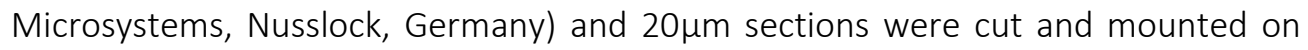
ionized microscope slides. The slides were dried over night at room temperature, and then dehydrated using increasing concentrations of ethanol (70\% - 95\% - 100\%) and placed in xylene. The tissue was subsequently rehydrated using the reverse procedure, and then stained using a basic protocol:

- Haematoxylin solution -5 mins

- Acidified $70 \%$ ethanol $(1 \% \mathrm{HCl})-5$ mins

- Scott's tap water -5 mins

- Eosin Y solution - 5 mins

- Running tap water -5 mins

- Scott's tap water -5 mins 
The slides were then taken through increasing concentrations of ethanol to dehydrate, and then placed in xylene as a clearing agent. Slides were mounted with coverslips using DPX hydrophobic mounting medium, and allowed to air dry at room temperature. Representative images were acquired using Leica firecam software at 20 x magnification (Leica Microsystems, Nusslock, Germany). 
Supplementary Tables

Table 1. Sequences of primers used

\begin{tabular}{|l|l|l|}
\hline $\begin{array}{l}\text { mRNA } \\
\text { target }\end{array}$ & \multicolumn{2}{|l|}{ Primer sequence $\left(5^{\prime} \rightarrow 3^{\prime}\right)$} \\
\hline \multirow{2}{*}{ TIr4 } & Forward & GAGGCAGGAGGTCGAGGT \\
\cline { 2 - 3 } & Reverse & GACAGCCAGCAAGACCAAG \\
\hline \multirow{2}{*}{$\begin{array}{l}\text { PPARGC } \\
1 b\end{array}$} & Forward & CTCCAGTTCCGGCTCCTC \\
\cline { 2 - 3 } & Reverse & CCCTGTGCTCTCACGTCTG \\
\hline \multirow{2}{*}{ Gapdh } & Forward & ACCCCTTCATTGACCTCAACTACATG \\
\cline { 2 - 3 } & Reverse & CCTTCTCCATGGTGGTGAAGAC \\
\hline
\end{tabular}


Table 2. Composition of Control and High Cholesterol diets

\begin{tabular}{|c|c|c|}
\hline & Control diet & High Cholesterol diet \\
\hline Saturated / unsaturated fat & $5.2 \%$ & $7.6 \%$ \\
\hline Saturated (SFA) ,\% of fat & $12.9 \%$ & $14.2 \%$ \\
\hline Monounsaturate(MUFA), \% of fat & $76.3 \%$ & $72.1 \%$ \\
\hline Polyunsaturated (PUFA), \% of fat & $10.8 \%$ & $13.7 \%$ \\
\hline Carbohydrates (en\%) & $70.0 \%$ & $11 \%$ \\
\hline Protein (\%) & $24.6 \%$ & $0.2 \%$ \\
\hline Choline (\%) & $0.2 \%$ & \\
\hline
\end{tabular}

The composition of the diets with respect to the content of carbohydrates, saturated / unsaturated fat, protein were similar in control and high cholesterol diets, apart from a presence of cholesterol. 
Table 3. Summary of group comparisons in O-maze and forced swim behaviors: study with DS administration at the dose $50 \mathrm{mg} / \mathrm{kg} / \mathrm{day}$ (see Figure 2A-F)

\begin{tabular}{|c|c|c|c|c|c|}
\hline \multirow[t]{2}{*}{ Groups } & \multicolumn{3}{|l|}{ O-maze test } & \multicolumn{2}{|c|}{ Forced swim test } \\
\hline & $\begin{array}{l}\text { Latency of } \\
\text { exit }\end{array}$ & $\begin{array}{l}\text { Time spent in } \\
\text { open arms }\end{array}$ & $\begin{array}{l}\text { Number of } \\
\text { exits }\end{array}$ & $\begin{array}{l}\text { Latency of } \\
\text { floating }\end{array}$ & $\begin{array}{l}\text { Duration of } \\
\text { floating }\end{array}$ \\
\hline $\begin{array}{l}\text { Control diet } \\
\text { vs. } \\
\text { HCD }\end{array}$ & $\begin{array}{l}q=4.28, \\
p=0.0176\end{array}$ & $\begin{array}{l}q=3.84 \\
p=0.0343\end{array}$ & $\begin{array}{l}q=3.73 \\
p=0.0401\end{array}$ & $\begin{array}{l}q=4.52 \\
p=0.0121\end{array}$ & $\begin{array}{l}q=4.91, \\
p=0.0065\end{array}$ \\
\hline $\begin{array}{l}\text { Control diet vs. } \\
\text { HCD + DS } 50 \\
\text { mg/kg/day }\end{array}$ & $\begin{array}{l}q=2.37, \\
p=0.2390, n s\end{array}$ & $\begin{array}{l}q=1.11, \\
p=0.7146, n s\end{array}$ & $\begin{array}{l}q=0.31, \\
p=0.9733, n s\end{array}$ & $\begin{array}{l}q=0.95, \\
p=0.7842, n s\end{array}$ & $\begin{array}{l}q=1.63, \\
p=0.4936, n s\end{array}$ \\
\hline $\begin{array}{l}\text { HCD vs. } \\
\text { HCD + DS } 50 \\
\mathrm{mg} / \mathrm{kg} / \text { day }\end{array}$ & $\begin{array}{l}q=1.98, \\
p=0.3611, n s\end{array}$ & $\begin{array}{l}q=2.82, \\
p=0.1402, n s\end{array}$ & $\begin{array}{l}q=3.54, \\
p=0.0531, n s\end{array}$ & $\begin{array}{l}q=3.70 \\
p=0.0419\end{array}$ & $\begin{array}{l}q=3.39, \\
p=0.0649, n s\end{array}$ \\
\hline
\end{tabular}

HCD - high cholesterol diet; ns - not significant ( $p>0.05)$. 
Table 4. Summary of group comparisons in O-maze and forced swim behaviors: study with DS administration at the dose $180 \mathrm{mg} / \mathrm{kg} /$ day (see Figure $2 \mathrm{E}-\mathrm{J}$ )

\begin{tabular}{|c|c|c|c|c|c|}
\hline \multirow[t]{2}{*}{ Groups } & \multicolumn{3}{|l|}{ O-maze test } & \multicolumn{2}{|c|}{ Forced swim test } \\
\hline & $\begin{array}{l}\text { Latency of } \\
\text { exit }\end{array}$ & $\begin{array}{l}\text { Time spent in } \\
\text { open arms }\end{array}$ & $\begin{array}{l}\text { Number of } \\
\text { exits }\end{array}$ & $\begin{array}{l}\text { Latency of } \\
\text { floating }\end{array}$ & $\begin{array}{l}\text { Duration of } \\
\text { floating }\end{array}$ \\
\hline $\begin{array}{l}\text { Control diet vs. } \\
\text { HCD }\end{array}$ & $\begin{array}{l}q=2.88, \\
p=0.1987, n s\end{array}$ & $\begin{array}{l}q=4.06 \\
p=0.0374\end{array}$ & $\begin{array}{l}q=2.34, \\
p=0.3676, n s\end{array}$ & $\begin{array}{l}q=4.27, \\
p=0.0258\end{array}$ & $\begin{array}{l}q=4.08 \\
p=0.0358\end{array}$ \\
\hline $\begin{array}{l}\text { Control diet } \\
\text { vs.HCD + DS } 180 \\
\text { mg/kg/day 3-wk }\end{array}$ & $\begin{array}{l}q=0.243, \\
p=0.9981, n s\end{array}$ & $\begin{array}{l}q=1.13, \\
p=0.9936, n s\end{array}$ & $\begin{array}{l}q=2.02, \\
p=0.4926, n s\end{array}$ & $\begin{array}{l}q=1.39, \\
p=0.7604, n s\end{array}$ & $\begin{array}{l}q=2.38, \\
p=0.3507, n s\end{array}$ \\
\hline $\begin{array}{l}\text { Control diet vs. } \\
\text { HCD + DS } 180 \\
\text { mg/kg/day 2-wk }\end{array}$ & $\begin{array}{l}q=1.24, \\
p=0.8155, n s\end{array}$ & $\begin{array}{l}q=0.37, \\
p=0.8532, n s\end{array}$ & $\begin{array}{l}q=1.77, \\
p=0.5992, n s\end{array}$ & $\begin{array}{l}q=0.36 \\
p=0.9939, n s\end{array}$ & $\begin{array}{l}q=0.72, \\
p=0.9555, \\
\text { ns }\end{array}$ \\
\hline $\begin{array}{l}\text { HCD vs. HCD + DS } \\
180 \mathrm{mg} / \mathrm{kg} / \text { day } \\
\text { 3-week treatment }\end{array}$ & $\begin{array}{l}q=2.88, \\
p=0.1988, n s\end{array}$ & $\begin{array}{l}q=3.94 \\
p=0.0452\end{array}$ & $\begin{array}{l}q=3.95 \\
p=0.0444\end{array}$ & $\begin{array}{l}q=5.22, \\
p=0.0050\end{array}$ & $\begin{array}{l}q=5.83 \\
p=0.0017\end{array}$ \\
\hline $\begin{array}{l}\text { HCD vs. } \\
\text { HCD + DS } 180 \\
\text { mg/kg/day 2-wk }\end{array}$ & $\begin{array}{l}q=1.60, \\
p=0.6719, n s\end{array}$ & $\begin{array}{l}q=2.82, \\
p=0.2145, n s\end{array}$ & $\begin{array}{l}q=0.60, \\
p=0.9738, n s\end{array}$ & $\begin{array}{l}q=4.40 \\
p=0.0208\end{array}$ & $\begin{array}{l}q=3.22, \\
p=0.1281, n s\end{array}$ \\
\hline $\begin{array}{l}\mathrm{HCD}+\text { DS } 180 \\
\mathrm{mg} / \mathrm{kg} / \text { day 3-wk } \\
\text { vs. } \\
\mathrm{HCD}+\text { DS } 180 \\
\mathrm{mg} / \mathrm{kg} / \text { day 2-wk }\end{array}$ & $\begin{array}{l}q=1.37, \\
p=0.7675, n s\end{array}$ & $\begin{array}{l}q=1.35, \\
p=0.7760, n s\end{array}$ & $\begin{array}{l}q=3.49, \\
p=0.0882, n s\end{array}$ & $\begin{array}{l}q=0.99, \\
p=0.8961, n s\end{array}$ & $\begin{array}{l}q=2.92, \\
p=0.1914, n s\end{array}$ \\
\hline
\end{tabular}

HCD - high cholesterol diet; ns - not significant ( $p>0.05)$ 
Table 5. Summary of group comparisons in T/r4 gene expression: study with DS administration at the dose $180 \mathrm{mg} / \mathrm{kg} / \mathrm{day}$ (see Fig.3A).

\begin{tabular}{|c|c|c|c|c|c|}
\hline \multirow{2}{*}{ Groups } & \multicolumn{4}{|l|}{ Brain structures } & \multirow{2}{*}{ Liver } \\
\hline & Prefrontal cortex & Hippocampus & Hypothalamus & Dorsal raphe & \\
\hline Control diet vs. HCD & $\begin{array}{l}q=11.99 \\
p<0.0001\end{array}$ & $\begin{array}{l}q=8.99 \\
p<0.0001\end{array}$ & $\begin{array}{l}q=5.66 \\
p=0.0009\end{array}$ & $\begin{array}{l}q=8.29 \\
p<0.0001\end{array}$ & $\begin{array}{l}q=5.05 \\
p=0.0122\end{array}$ \\
\hline $\begin{array}{l}\text { Control diet vs. HCD + DS } 180 \\
\mathrm{mg} / \mathrm{kg} / \text { day 3-wk treatment }\end{array}$ & $\begin{array}{l}q=1.42, \\
p=0.7491, n s\end{array}$ & $\begin{array}{l}q=1.95 \\
p=0.5181, n s\end{array}$ & $\begin{array}{l}q=1.63 \\
p=0.6596, n s\end{array}$ & $\begin{array}{l}q=1.61, \\
p=0.6676, n s\end{array}$ & $\begin{array}{l}q=0.51, \\
p=0.9836, n s\end{array}$ \\
\hline $\begin{array}{l}\text { Control diet vs. HCD + DS } 180 \\
\mathrm{mg} / \mathrm{kg} / \text { day } 2-w \mathrm{k} \text { late treatment }\end{array}$ & $\begin{array}{l}q=2.93 \\
p=0.1729, n s\end{array}$ & $\begin{array}{l}q=3.02, \\
p=0.1527, n s\end{array}$ & $\begin{array}{l}q=2.58, \\
p=0.2732, n s\end{array}$ & $\begin{array}{l}q=1.99 \\
p=0.4977, n s\end{array}$ & $\begin{array}{l}q=0.73, \\
p=0.9538, n s\end{array}$ \\
\hline $\begin{array}{l}\text { HCD vs. HCD + DS } 180 \text { mg/kg/day } \\
\text { 3-wk treatment }\end{array}$ & $\begin{array}{l}q=13.41 \\
p<0.0001\end{array}$ & $\begin{array}{l}q=10.94 \\
p<0.0001\end{array}$ & $\begin{array}{l}q=7.29 \\
p<0.0001\end{array}$ & $\begin{array}{l}q=9.89 \\
p<0.0001\end{array}$ & $\begin{array}{l}q=5.56 \\
p=0.0059\end{array}$ \\
\hline $\begin{array}{l}\mathrm{HCD} \text { vs. } \mathrm{HCD}+\mathrm{DS} 180 \mathrm{mg} / \mathrm{kg} / \text { day } \\
\text { 2-wk late treatment }\end{array}$ & $\begin{array}{l}q=14.93 \\
p<0.0001\end{array}$ & $\begin{array}{l}q=12.01 \\
p<0.0001\end{array}$ & $\begin{array}{l}q=8.24 \\
p<0.0001\end{array}$ & $\begin{array}{l}q=10.28 \\
p<0.0001\end{array}$ & $\begin{array}{l}q=5.78 \\
p=0.0043\end{array}$ \\
\hline $\begin{array}{l}\mathrm{HCD}+\mathrm{DS} 180 \mathrm{mg} / \mathrm{kg} / \text { day 3-wk } \\
\text { treatment vs. HCD + DS } 180 \mathrm{mg} / \mathrm{kg} / \text { day } \\
\text { 2-wk late treatment }\end{array}$ & $\begin{array}{l}q=1.52 \\
p=0.7078 \\
\text { ns }\end{array}$ & $\begin{array}{l}q=1.07 \\
p=0.8723 \\
\text { ns }\end{array}$ & $\begin{array}{l}q=0.95 \\
p=0.9081 \\
\text { ns }\end{array}$ & $\begin{array}{l}q=0.39, \\
p=0.9929 \\
\text { ns }\end{array}$ & $\begin{array}{l}q=0.22 \\
p=0.9985 \\
\text { ns }\end{array}$ \\
\hline
\end{tabular}

HCD - high cholesterol diet; ns - not significant ( $p>0.05)$ 
Table 6. Summary of group comparisons in PPARGC1b gene expression: study with DS administration at the dose $180 \mathrm{mg} / \mathrm{kg} / \mathrm{day}$ (see Fig.3B).

\begin{tabular}{|c|c|c|c|c|c|}
\hline \multirow{2}{*}{ Groups } & \multicolumn{4}{|l|}{ Brain structures } & \multirow{2}{*}{ Liver } \\
\hline & Prefrontal cortex & Hippocampus & Hypothalamus & Dorsal raphe & \\
\hline Control diet vs. HCD & $\begin{array}{l}q=11.18 \\
p<0.0001\end{array}$ & $\begin{array}{l}q=11.09 \\
p<0.0001\end{array}$ & $\begin{array}{l}q=11.02 \\
p<0.0001\end{array}$ & $\begin{array}{l}q=10.81 \\
p<0.0001\end{array}$ & $\begin{array}{l}q=6.35 \\
p=0.0019\end{array}$ \\
\hline $\begin{array}{l}\text { Control diet vs.HCD + DS } 180 \\
\mathrm{mg} / \mathrm{kg} / \text { day 3-wk treatment }\end{array}$ & $\begin{array}{l}q=3.90 \\
p=0.0371\end{array}$ & $\begin{array}{l}q=1.81, \\
p=0.5790, n s\end{array}$ & $\begin{array}{l}q=1.09 \\
p=0.8665, n s\end{array}$ & $\begin{array}{l}q=1.58, \\
p=0.6824, n s\end{array}$ & $\begin{array}{l}q=2.15, \\
p=0.4479, n s\end{array}$ \\
\hline $\begin{array}{l}\text { Control diet vs. HCD + DS } 180 \\
\mathrm{mg} / \mathrm{kg} / \text { day 2-wk late treatment }\end{array}$ & $\begin{array}{l}q=10.03 \\
p<0.0001\end{array}$ & $\begin{array}{l}q=10.39 \\
p<0.0001\end{array}$ & $\begin{array}{l}q=9.84 \\
p<0.0001\end{array}$ & $\begin{array}{l}q=9.70 \\
p<0.0001\end{array}$ & $\begin{array}{l}q=5.32 \\
p=0.0083\end{array}$ \\
\hline $\begin{array}{l}\text { HCD vs. HCD + DS } 180 \mathrm{mg} / \mathrm{kg} / \text { day } \\
\text { 3-wk treatment }\end{array}$ & $\begin{array}{l}q=7.28 \\
p<0.0001\end{array}$ & $\begin{array}{l}q=9.28 \\
p<0.0001\end{array}$ & $\begin{array}{l}q=9.93 \\
p<0.0001\end{array}$ & $\begin{array}{l}q=9.24 \\
p<0.0001\end{array}$ & $\begin{array}{l}q=4.20 \\
p=0.0408\end{array}$ \\
\hline $\begin{array}{l}\mathrm{HCD} \text { vs. } \mathrm{HCD}+\mathrm{DS} 180 \mathrm{mg} / \mathrm{kg} / \mathrm{day} \\
\text { 2-week late treatment }\end{array}$ & $\begin{array}{l}q=1.15 \\
p=0.847, n s\end{array}$ & $\begin{array}{l}q=0.70 \\
p=0.9593, n s\end{array}$ & $\begin{array}{l}q=1.19 \\
p=0.8355, n s\end{array}$ & $\begin{array}{l}q=1.11, \\
p=0.8599, n s\end{array}$ & $\begin{array}{l}q=1.03 \\
p=0.8859, n s\end{array}$ \\
\hline $\begin{array}{l}\mathrm{HCD}+\mathrm{DS} 180 \mathrm{mg} / \mathrm{kg} / \mathrm{day} 3-\mathrm{wk} \\
\text { treatment vs. HCD + DS } 180 \mathrm{mg} / \mathrm{kg} / \text { day } \\
\text { 2-wk late treatment }\end{array}$ & $\begin{array}{l}q=6.13 \\
p=0.0003\end{array}$ & $\begin{array}{l}q=8.58 \\
p<0.0001\end{array}$ & $\begin{array}{l}q=8.75 \\
p<0.0001\end{array}$ & $\begin{array}{l}q=8.12 \\
p<0.0001\end{array}$ & $\begin{array}{l}q=3.17, \\
p=0.1542, n s\end{array}$ \\
\hline
\end{tabular}

HCD - high cholesterol diet; ns - not significant ( $p>0.05)$ 
Table 7. Summary of group comparisons in hepatic triglyceride levels: study with DS administration at the dose $180 \mathrm{mg} / \mathrm{kg} /$ day (see Fig.3D).

\begin{tabular}{|c|c|}
\hline Groups & \\
\hline Control diet vs. HCD & $\begin{array}{l}q=5.94 \\
p=0.0034\end{array}$ \\
\hline $\begin{array}{l}\text { Control diet vs. HCD + DS } 180 \mathrm{mg} / \mathrm{kg} / \text { day } \\
\text { 3-wk treatment }\end{array}$ & $\begin{array}{l}q=7.96 \\
p=0.0002\end{array}$ \\
\hline $\begin{array}{l}\text { Control diet vs. HCD + DS } 180 \mathrm{mg} / \mathrm{kg} / \text { day } \\
\text { 2-wk late treatment }\end{array}$ & $\begin{array}{l}q=6.77 \\
p=0.0010\end{array}$ \\
\hline HCD vs. HCD + DS 180 mg/kg/day 3-wk treatment & $\begin{array}{l}q=2.02, \\
p=0.4995, n s\end{array}$ \\
\hline $\begin{array}{l}\mathrm{HCD} \text { vs.HCD + DS } 180 \mathrm{mg} / \mathrm{kg} / \text { day 2-wk late } \\
\text { treatment }\end{array}$ & $\begin{array}{l}q=0.93 \\
p=0.8328, n s\end{array}$ \\
\hline $\begin{array}{l}\mathrm{HCD}+\mathrm{DS} 180 \mathrm{mg} / \mathrm{kg} / \text { day 3-wk treatment } \\
\text { vs. HCD + DS } 180 \mathrm{mg} / \mathrm{kg} / \text { day 2-wk late treatment }\end{array}$ & $\begin{array}{l}q=1.19 \\
p=0.8294, n s\end{array}$ \\
\hline
\end{tabular}

HCD - high cholesterol diet; ns - not significant ( $p>0.05)$ 


\section{Supplementary Figures}
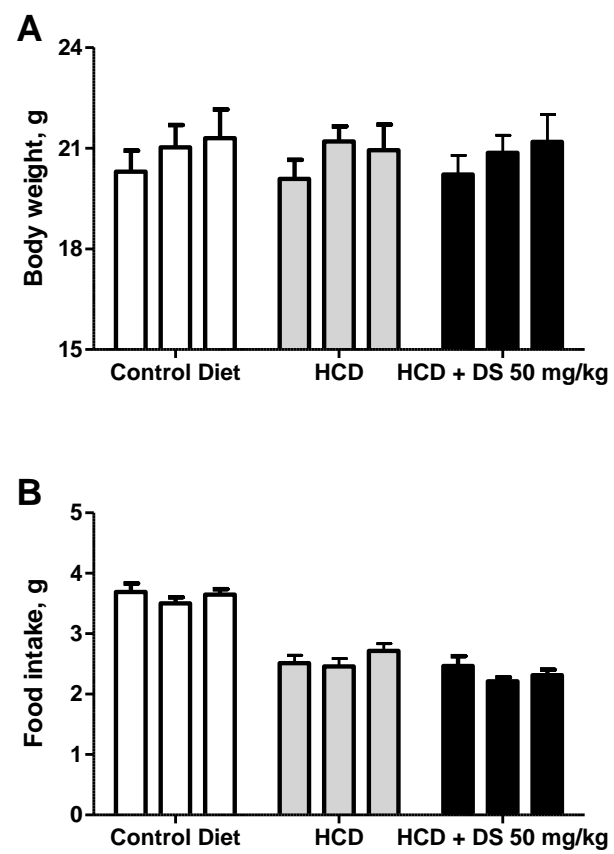

Figure 1. Body weight and food intake during challenge with cholesterol diet and dosing with DS at the dose of $50 \mathrm{mg} / \mathrm{kg} /$ day (A). Body weight was similar between the groups receiving control diet, cholesterol diet, or cholesterol diet and dosing with DS at the dose $50 \mathrm{mg} / \mathrm{kg} /$ day. (B). Food intake was similar in mice that were fed with cholesterol diet regardless the dosing with DS, and was lower in both of these groups than in control animals. Data are expressed as means \pm SEMs. 


\section{A}

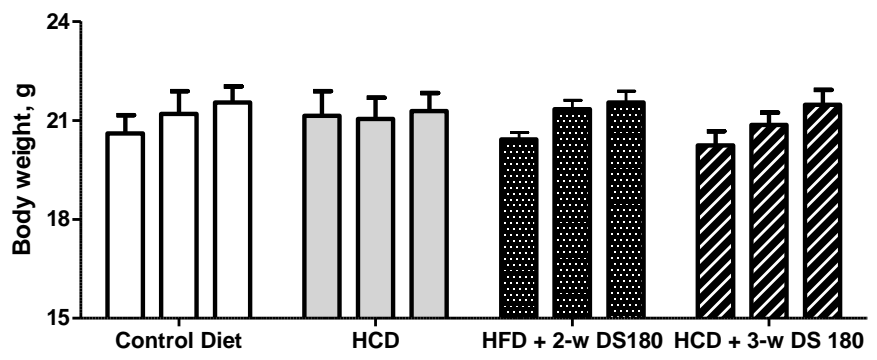

\section{B}

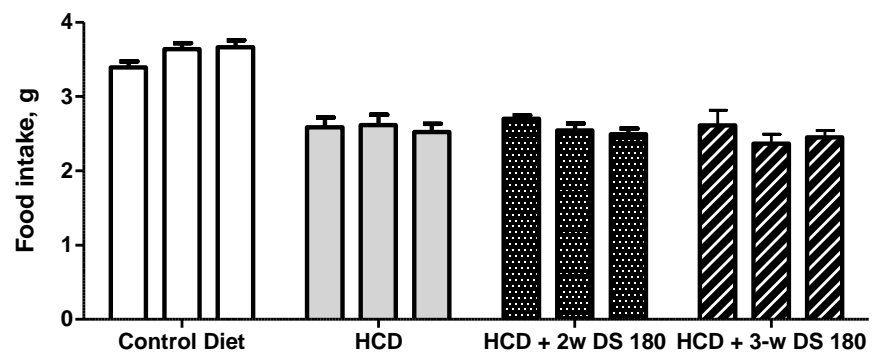

Figure 2. Body weight and food intake during challenge with cholesterol diet and dosing with DS at the dose of $180 \mathrm{mg} / \mathrm{kg} /$ day during two or three weeks. (A). Body weight was similar between the groups receiving control diet, cholesterol diet, or cholesterol diet and dosing with DS at the dose $180 \mathrm{mg} / \mathrm{kg} /$ day, either for two or three weeks. (B). There was no difference in the food intake between the groups that were fed with cholesterol diet, regardless their dosing with DS. All three groups had lower food intake than control mice. Data are expressed as means \pm SEMs. 




\section{Chapter 7}

Discussion and impact 


\begin{abstract}
Affective pathology is a complex construct which encompasses a pathological disturbance in primary emotions, rapidly shifting from neutral to intense perception, associated to dysfunctional coping. In rodents, assessing affective pathology, translated mostly by anxiety- and depressive-like states, is challenging and requires a combined analysis of behavioural, physiological and molecular data in elaborate paradigm constructs. In this regard, we aimed to establish new, reliable and robust models, sensitive to the action of pharmacological compounds such as insulin receptor sensitizers or antidepressants.
\end{abstract}

Knowing the role of NMDA receptor-mediated neurotransmission in the aetiology of stress-related cognitive deficits and behavioural abnormalities, as well as the hypothesis of different roles of NR2A/B receptors regulating the mechanisms of learning and emotion processing, we have employed ethological stressors and 
assessed their effect on building an affective pathology phenotype in mice (Chapter 2).

We found stress-induced increases in hippocampal expression of NR2A and NR2A/NR2B ratio, previously linked to elevated anxiety, impulsivity and aggression, home cage hyperactivity and increases in circulating corticosterone, also present in our behavioural and biochemical data. Moreover, studies have reported a link between these molecular changes and a disruption of long-term memory, but not short-term learning. In summary, our newly validated mouse model of affective pathology accurately resembles the consequences of experiencing chronic stress in humans, and proves useful for translational studies on the effect of putative pharmaca which may compensate or revert this condition.

As diverse etiological factors may contribute to a state of affective pathology, we aimed to characterize the effects of a neuronal insulin receptor sensitizer on a plurality of already established rodent models, which included chronic stress, elderly depression and naïve mice, evaluating several behavioural, molecular and sleep variables, characterized as biological correlates of a depressive state and adaptive response in mice (Chapter 3 ).

Firstly, in the model of chronic stress, pre-treatment with our compound prevented stress-induced memory impairment, possibly through augmented choline acetyltransferase activity, which increases neurogenesis and is considered to be neuroprotective; extended the duration of REM sleep, but not SWS, a mechanism described as an adaptive response to stress, that loses efficacy with ageing and in neuropsychiatric disorders; and increases hippocampal gene expression of NMDA receptor subunit NR2A, as well as NR2A/B ratio.

Secondly, the delivery of this insulin sensitizer in a model of elderly depression has resulted in the restoration of the hedonic deficit similarly to a classical tricyclic 
antidepressant and gene expression profiling demonstrates an upregulation of genes encoding for factors of synaptic plasticity, regulation of sleep and circadian rhythm, known to be implicated in the pathology of depression.

Thirdly, the administration of dicholine succinate to naïve mice has reduced parameters of learned helplessness and decreased anxiety scores in behavioural tests in a similar way to established antidepressants and other thiazolidinediones, without inespecific locomotory side-effects. Furthermore, as insulin regulates GSK$3 \beta$ activity, treatment precluded the reduction of its inactive form similarly to antidepressants, possibly establishing a link to the effects of insulin receptor sensitizers and hippocampal NMDAr expression.

All of the abovementioned effects support the hypothesis of an antidepressant-like role for insulin receptor sensitizers, at different levels and in different contexts for each model. Together with the lack of signs of toxicity in mammals at effective dosage ranges, the enhancement of insulin receptor signalling may be regarded as a potential pharmacotherapeutic target.

A growing body of clinical and experimental data suggests that excessive nutrition conveyed by the so-called Western diet (e.g. high-cholesterol, high-fat, high-salt, high-sugar), and ensuing hypercholesterolemia, obesity and insulin resistance contribute to the pathogenesis of affective disorders and interfere with pharmacotherapy. We considered the use of this type of dietary challenge to investigate the effects of increased cholesterol intake on behaviour and molecular markers, comparing the changes observed in the periphery to those occurring in the central nervous system, and attempting to establish a link to the development affective pathology (Chapter 4).

For the first time, profound behavioural modifications and molecular changes were observed in the brain and liver in association with this diet, along with depression 
and anxiety-like behaviour, and similar to stress-induced depression. A significant increase in T/r4 gene expression was found in both the hippocampus and the prefrontal cortex, albeit increased protein levels were only detectable in the prefrontal cortex. Expression levels returned to baseline values after reversion to control diet, accompanied by a normalization of anxiety- and depression-related behaviours. Unexpectedly, body weight of mice on the high-cholesterol diet remained unchanged, excluding the contribution of obesity or excessive amounts of fat. This methodology was shown to be effective in inducing dietary-associated affective changes, with prospected value in translational pharmacological and preclinical studies.

As a translational approximation to the human clinic and potential use of various compounds as a food supplement, we aimed to evaluate whether it would be effective to deliver compounds by an oral route in mice (Chapter 5). We demonstrated that the delivery of an insulin receptor sensitizer by oral route is effective to elicit antidepressant-like effects similarly to those of the antidepressant imipramine that was used as a reference drug.

Together, we have supported pharmacological delivery of dicholine succinate with food as an effective method of dosing that opens possibilities of the application of this compound with food. Apart from that, our study showed that drug delivery with pellets can be a desirable alternative to invasive dosing, which may greatly improve animal welfare, particularly with the need for repeated or chronic drug administration to physically vulnerable laboratory animals.

Lastly, we investigated the effect of oral delivery of an insulin receptor sensitizer in a non-alcoholic fat liver disease mode induced by a high-cholesterol diet, characterized by hepatic lipid dystrophy, inflammation, depressive- and anxiety-like behaviours and increased expression of TLR-4 (Chapter 6). Treatment with the selected compound 
ameliorated diet-induced anxiety- and depressive-like behaviours, likely linked to the normalized expression of pro-inflammatory factor TLR4 and mitochondrial activity marker PPARGC1b, which were expressed abnormally high and low, respectively.

Our results suggest that the seen improvement is associated with the underlying normalization of the secondary mechanisms of NAFLD syndrome, such as inflammation and mitochondrial functions, rather than of its primary features of liver steatosis and dystrophy, since the use of this insulin sensitizer did not elicit changes on the latter. These evidences support a potential use of insulin receptor sensitizers for the treatment of affective symptoms during NAFLD syndrome.

\section{Concluding remarks}

This work pioneered to robustly use ethological stressors and high amounts of dietary cholesterol as accurate methodologies to reliably mimic cognitive and emotional abnormalities associated with human phenotypes. Combined with these models, age-induced and naïve learned helplessness were successful tools to study the effects of insulin receptor sensitization, gathering evidence which supports the potential to generate effective antidepressant-like effects in various conditions, restoring baseline levels of brain plasticity and function, memory, gene expression and normal behaviours, albeit the underlying mechanisms are not yet fully understood.

Altogether, insulin receptor sensitization has shown a sound potential in rodent models of depression of various etiologies. In line with existing literature, our data supports the vision that enhancement of insulin receptor mediated signallimg may be a new promising strategy of pharmacotehrapy of affective disturbances in human clinic. Thus, the use of compounds of a similar nature to the insulin receptor sensitizer dicholine succinate can be beneficial for future clinical use in a plurality of metabolic and neuropsychiatric disorders. 




\section{Valorization}

\section{Relevance for society}

Diabetes and neuropsychiatric disorders are major health and economic burdens in the next decades. It is estimated that $9 \%$ of the world's adult population suffers from diabetes, and alarmingly, over $13 \%$ are obese and risking developing the disease, which accounts for 1.5 million direct deaths per year. In other hand, recent reports reveal that over 400 million adults suffer of depression and 47.5 million of elderly dementia, $60-70 \%$ directly linked to Alzheimer's disease, the most prevalent neuropsychiatric disorder, recently considered to be "brain diabetes" or a Type III diabetes.

Insulin resistance is the hallmark of diabetes and metabolic syndrome and has been associated with depression. Whereas depression increases the risk for diabetes, people with diabetes are twice as likely to experience depression when compared with the general population. A growing body of evidence in the later years and of the present work has enlightened the role of compromised brain insulin receptor signalling in the aetiology of neuropsychiatric disorders including depression.

Recently, several types of insulin receptor sensitizers have been offered as a potential remedies to tackle affective disturbances. Namely, several classes of pharmacologically active compounds have been developed lately. They include meglitinides and sulfonylureas, which increase a release of insulin by the beta islets in the pancreas; biguanides, which decreases liver gluconeogenesis and increases number of receptors recruited to the membrane and thiazolidinediones, which increase mitochondrial biogenesis and improve lipid metabolism.

Unfortunately, and albeit successful results from the application of these compounds as antidiabetic and even antidepressant agents, associated side effects may vary from 
osteoporosis, cardiovascular complications, increase in body weight and food cravings, kidney failure, cancer, severe hypoglycaemia and other undesirable consequences.

In the present studies, dicholine succinate, an endogenous molecule, has been shown to elicit and antidepressant-like effect in the pre-clinical models of depressivelike state of various origins. This opens the possibilities to consider this substance as a candidate to additive pharmacotherapy of depression, in particular when this disorder is associated with metabolic syndrome. Also, it can be used during obesity as a food supplement to counteract negative effects of high amounts of dietary cholesterol and fat. It is expected that the use of dicholine succine will be not accompanied by significant side effects that are known for the treatment with other insulin receptor sensitizers. The results in this thesis also support the view that dicholine succinate can be used during senile depression. It can be particularly useful for patients suffering from the combination of above listed syndromes that are often co-morbid. Thus, the application of dicholine succinate as a food supplement and as a drug can be of medical and economic importance.

Apart from a discovery of a potential of dicholine succinate being a candidate substance during several forms of affective pathology, our studies have contributed in the optimization and development of animal models of investigated syndromes. A model of affective pathology associated with dietary cholesterol challenge, was newly developed. Models of stress-induced and aging-related affective syndromes were optimized in terms of the use of labour and other resources. Finally, we validated oral ways of chronic dosing with antidepressants, which allows reducing costs for translational studies based on chronic dosing of animals, and significantly ameliorating animal welfare. We have probed and confirm the effectiveness of a delivery of drugs with food or drinking water, which could be particularly useful in future experiments with long protocols and on immunodeficient animals. 


\section{Target groups}

In our studies, we have found beneficial effects of the applications for the insulin receptor sensitizer dicholine succinate as an antidepressant during stress, aging and metabolic conditions associated with consumption of Western-diet type of food. Therefore, we consider our target groups to be 1) patients with depression associated with obesity / metabolic syndrome, 2) patients suffering from elderly depression, with or without metabolic syndrome, 3 ) individuals with a risk of a development of obesity / metabolic syndrome. For the first two target groups, one can anticipate the usefulness of dicholine succinate as a adjustment therapy of depression that can increase the effect of main antidepressant treatment and allow to decrease its dose, thus, leading to a less pronounced side effects of a conventional drug.

As potential outlook of presented work, we foresee a potential interest of pharmaceutical companies to complete necessary tests and develop dicholine succinate as a formulation for pharmacotherapy of depression and associated symptoms, and / or a food supplement, like other endogenous molecules or elements (e.g., fluoride). It is likely that the use of dicholine succinate as a food supplement as for instance, would generally help to improve a public health. It is expected that the production of the compound will be relatively inexpensive and is also widely available for all parts of the population. Nowadays this could be especially important. Given the fact that a lifestyle in developed countries involves lots of stressful life events and the consumption of high-fat, salty and sweet foods is increasing, the use of dicholine succinate can be beneficial in the prevention of metabolic syndrome, obesity and associated with these disturbances depression. Also, a general tendency of a global population to age makes potential use of dicholine succinate a promising tool of prevention with pathological developments related to elderly. 
From an economical point of view, filing of a patent for the use of dicholine succinate could be an option to go for. The use should be defined for conditions where dicholine succinate have shown its efficacy in pre-clinical models, such as depressive pathology associated with metabolic syndrome, senile depression and a risk of the development of these conditions.

\section{Activity / Products}

The major finding in my studies that is described in this dissertation is that the enhancement of insulin receptors by dicholine succinate protects mice from the deleterious effects of a development of affective symptoms during stress, during stress, aging and challenge with high amounts of dietary cholesterol. Also, dicholine succinate is increasing expression of genes related to neuronal plasticity and survival. As the models used have a high translational validity to what has been described in the human clinic, we hypothesize that patients could benefit from the similar properties of dicholine succinate as they are hereby described in pre-clinical experiments.

\section{Innovation}

The work hereby presented has been innovative in various regards. First, we have validated the induction of affective pathological disturbances, characterized by molecular and behavioural phenotypes, in mice models of stress-induced depression, using an optimized protocol that reduces labour and time costs (Chapter 2,3). Second, we have proposed a new model of affective changes that are resulting from a diet with high cholesterol content (Chapter 4 and 6). Third, we have validated the efficacy of chronic dosing with food and water of antidepressant drugs, that, we believe, greatly helps to optimise economic costs for experimental procedure that require such dosing, and contribute to the animal welfare. Finally, we have shown that insulin receptor signalling is a mechanism that is implicated in the affective changes 
during exposure to a Western diet-like diet and that it can be targeted by insulin receptor sensitizers, such as dicholine succinate.

\section{Implementation}

In line with the abovementioned relevance for the scientific and medical communities, society and industry, the implementation of the knowledge generated in the current dissertation is also multidimensional, as already discussed. From an academic perspective, results have been or will be published in peer-reviewed international journals and presented at national and international conferences. 


\section{Biography}

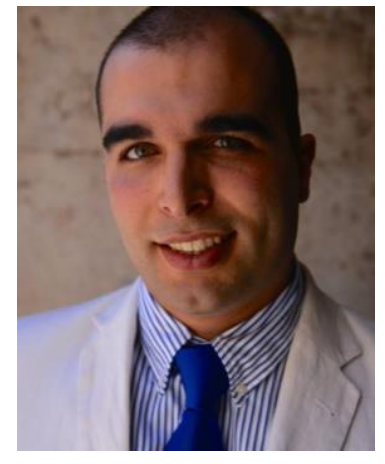

João Pedro da Costa Alvares Viegas Nunes was born on April 26th 1987 in Lisbon, Portugal. In 2004 he has obtained his high school degree in Natural Sciences. Driven by a fascination for biodiversity, he enrolled in a Biology course at the Science Faculty of the University of Lisbon, where an interest in behaviour and neuroscience developed, obtaining his bachelor degree in 2007. For one year, João was intern at cell cycle regulation groups at the Gulbenkian Institute for Science, Oeiras, Portugal to increase his competence in molecular biology techniques. In the fall of 2008, he started his Master courses in Human Biology and Environment, with senior internship at the lab of Dr. Tatyana Strekalova, in a joint collaboration between the University of Lisbon and the School for Mental Health and Neuroscience (MHeNS, from Maastricht University, obtaining his degree from Lisbon in May 2011 with a thesis in the field of neuropsychopharmacology entitled "Behavioural effects of chronic administration of imipramine in food and water regarding anxiety and depression paradigms on naïve C57BL/6N male mice", cosupervised by Dr. Jodi Pawluski, from Maastricht University. Ever since, João has collaborated in multiple research projects, with affiliation to MHeNS as a member of Dr. Tatyana Strekalova. From main collaborations with the University of Oxford, UK, and Prof. Dr. Daniel C. Anthony, University of Wuerzburg, Germany, and Prof. Dr. Klaus-Peter Lesch, also a member of Maastricht University and University of Strasbourg, France, and Dr. Brandon H. Cline, João has produced quality research, published in peer-reviewed journals and scientific meeting, hereby presented, under the main supervision of Prof. Dr. Harry Steinbusch, in order to obtain his doctoral degree. 


\section{Publications}

Strekalova T, Costa-Nunes J, Veniaminova E, Kubatiev A, Lesch KP, Chekhonin V, Evans M, Steinbusch HWM. Insulin receptor sensitizer choline salt of succinic acid prevents both TLR4 upregulation and affective changes induced by a high-cholesterol diet in mice. J Affect Disord. (submitted 15.09.2015, Revised 25.10.2015).

Cline $\mathrm{BH}^{*}$, Costa-Nunes J*, Cespuglio R, Markova N, Santos Al, Bukhman YV, Kubatiev A, Steinbusch HW, Lesch K and Strekalova T. Dicholine succinate, the neuronal insulin sensitizer, normalizes behavior, REM sleep, hippocampal pGSK3 beta and mRNAs of NMDA receptor subunits in mouse models of depression. Front Behav Neurosci. 2015 Feb 26; 9: 37. doi: 10.3389/fnbeh.2015.00037. IF:3.3

Strekalova T, Evans M, Costa-Nunes J, Bachurin S, Yeritsyan N, Couch Y, Steinbusch HWM, Köhler ES, Lesch KP, Anthony DC. TIr4 upregulation in the brain accompanies depression- and anxiety-like behaviors induced by a high-cholesterol diet. Brain Behav Immun. 2015 Aug; 48: 42-7. doi: 10.1016/j.bbi.2015.02.015. IF:5.889

Strekalova T, Evans M, Chernopiatko A, Couch Y, Costa-Nunes J, Cespuglio R, Chesson L, Vignisse J, Steinbusch HW, Anthony DC, Pomytkin I, Lesch KP. Deuterium content of water increases depression susceptibility: The potential role of a serotonin-related mechanism. Behav Brain Res. 2015 Jan 15; 277: 237-44. doi: 10.1016/j.bbr.2014.07.039. IF:3.028

Costa-Nunes JP*, Cline BH*, Araújo-Correia M, A Valença, N Markova, O Dolgov, A Kubatiev, N Yeritsyan, HWM Steinbusch, T Strekalova. Animal Models of Depression and Drug Delivery with Food as an Effective Dosing Method: Evidences from Studies with Celecoxib and Dicholine Succinate. Biomed Res Int. 2015; 2015:596126. doi: 10.1155/2015/596126. IF:1.579

Costa-Nunes J*, Zubareva O*, Araújo-Correia $\mathrm{M}^{*}$, Valença $\mathrm{A}^{*}$, Schroeter CA, Pawluski JL, Vignisse J, Steinbusch H, Hermes D, Phillipines M, Steinbusch HWM, Strekalova T. Altered emotionality, hippocampus-dependent performance and expression of NMDA receptor subunit mRNAs in chronically stressed mice. Stress. 2014 Jan; 17(1): 108-16. doi: 10.3109/10253890.2013.872619. IF: 2.715 
Markova N, Chernopiatko A, Schroeter C, Malin D, Kubatiev A, Bachurin S, Costa-Nunes J, Steinbusch HWM, Strekalova T. Hippocampal gene expression of deiodinases 2 and 3 and effects of 3,5-diiodo-L-thyronine T2 in mouse depression paradigms. Biomed Res Int. 2013; 2013:565218. doi: 10.1155/2013/565218. IF:1.579

Pawluski JL, Valença A, Santos AIM, Costa-Nunes JP, Steinbusch HWM, Strekalova T. Pregnancy or stress decrease complexity of CA3 pyramidal neurons in the hippocampus of adult female rats. Neuroscience. 2012 Dec 27; 227: 201-10. doi: 10.1016/j.neuroscience. 2012.09.059. IF:3.122

Vignisse J, Steinbusch HW, Bolkunov A, Nunes J, Santos A, Grandfils C, Bachurin S, Strekalova T. Dimebon enhances the hippocampus-dependent learning in both appetitive and inhibitory memory tasks in mice. Prog Neuropsychopharmacol Biol Psychiatry. 2011 Mar 30; 35 (2): 510 22. doi: 10.1016/j.pnpbp.2010.12.007. IF:3.247

* Authors contributed equally. 


\section{MHENS}

\section{Thesis defenses from MHeNs - School for Mental Health and Neuroscience}

\section{3}

Rob Havermans: Bipolar disorder in daily life; Mood and cortisol responses to naturally occurring events. Supervisor: Prof.dr. M. de Vries; Co-Supervisor: Dr. N. Nicolson.

Véronique Moers-Hornikx: Deep brain stimulation and the cerebellum. Supervisors: Prof.dr. J. Vles / Prof.dr. Y. Temel; Co-Supervisor: Dr. G. Hoogland.

Nicole Veldhorst-Janssen: Intranasal delivery of rapid acting drugs. Supervisors: Prof.dr. M. Marcus / Prof.dr. C. Neef; Co-Supervisor: Dr. P.H. van der Kuy.

Stéphanie Knippenberg: Vitamin D and Multiple Sclerosis: immunological and clinical outcome. Supervisor: Prof.dr. J. Cohen-Tervaert; Co-Supervisors: Dr. J. Damoiseaux / Dr. Y. Bols.

Erik D. Gommer: Dynamic Cerebral Autoregulation: from methodology towards clinical application. Supervisors: Prof.dr. W.H. Mess / Prof.dr. R.B. Panerai, UK; Co-Supervisor: Dr.ir. J.P.H. Reulen.

Olga A.H. Reneerkens: Can PDE inhibition improve cognition? Translational insights. Supervisor: Prof.dr. H.W.M. Steinbusch; Co-Supervisor: Dr. J. Prickaerts.

Lyzel S. Elias-Sonnenschein: Clinical and biomarker correlates of genetic risk factors for Alzheimer's disease. Supervisor: Prof.dr. F.R.J. Verhey; Co-Supervisor: Dr. P.J. Visser.

Diego F. Mastroeni: Epigenetic Dysregulation and the Pathophysiology of of Alzheimer's Disease. Supervisors: Prof.dr. H.W.M. Steinbusch / Prof.dr. P.D. Coleman, Sun City, Arizona; Co-Supervisors: Dr. B.P.F. Rutten / Dr. D.L.A. van den Hove.

Leonidas Chouliaras: Epigenetic Regulation in Aging and Alzheimer's disease: A translational perspective. Supervisor: Prof.dr. H.W.M. Steinbusch; Co-Supervisors: Dr. B.P.F. Rutten / Dr. D.L.A. van den Hove.

Liesbeth Knaepen: Perinatal events and altered pain sensitivity in later life. Supervisors: Prof.dr. E.A.J. Joosten / Prof.dr. D. Tibboel, EUR; Co-Supervisor: Dr. J. Patijn.

Marisela Martinez-Claros: Hippocampal plasticity and corticosterone: From dendrites to behaviour. Supervisor: Prof.dr. H.W.M. Steinbusch; Co-Supervisors: Dr. J.L. Pawluski / Dr. J. Prickaerts.

Marcus D. Lancé: A circle of improvement in bleeding management: from laboratory to clinic and back. 
Supervisors: Prof.dr. M.A.E. Marcu / Prof.dr. J.W.M. Heemskerk; Co-Supervisor: Dr. Y.M.C. Henskens.

Hilde Braakman: Imaging the brain; neuronal correlates of cognitive impairment in children with frontal lobe epilepsy. Supervisors: Prof.dr. A.P. Aldenkamp / Prof.dr. J.S.H. Vles; Co-Supervisors: Dr.ir. W.H. Backes / Dr. P.A.M. Hofman.

Willem H. van Zwam: Aneurysmal subarachnoid hemorrhage: imaging strategies and cost-effectiveness aspects in diagnostic work-up and post-therapeutic follow-up. Supervisors: Prof.dr. J.T. Wilmink / Prof.dr. J.E. Wildberger; Co-Supervisor: Dr. P.A.M. Hofman.

Klara De Cort: The Pathogenesis of Panic Disorder. Supervisors: Prof.dr. I. Myin-Germeys / Prof.dr. E.J.L. Griez; Co-Supervisors: Dr. K.R.J. Schruers / Dr. I. Van Diest, Leuven.

Kim van Wijck: Mind the Gap; experimental studies on splanchnic hyperfusion and gastrointestinal integrity loss in man. Supervisors: Prof.dr. W.A. Buurman / Prof.dr. C.H.C. Dejong; Co-Supervisor: Dr. K. Lenaerts.

Yvette Roke: Antipsychotic-induced hyperprolactinemia in children and adolescents with mainly autism spectrum disorders. Prevalence, symptoms, clinical consequences and genetic risk factors. Supervisors: Prof.dr. P.N. van Harten / Prof.dr. J.K. Buitelaar (RUN); Co-Supervisor: Dr. A. Boot (UMCG).

Fleur Goezinne: Retinal detachment surgery: pre and postoperative prognostic factors. Supervisors: Prof.dr. F. Hendrikse / Prof.dr. C.A.B. Webers; Co-Supervisor: Dr. E.C. La Heij (Amsterdam).

Ralph L.J.G. Maassen: The Merits of Videolaryngoscopy during Glottic Visualisation for Endotracheal Intubation. Supervisors: Prof.dr. M. Marcus / Prof.dr. A. van Zundert (University of Queensland).

Maria J. de Sousa Guerreiro: The role of sensory modality in age-related distraction. Supervisor: Prof.dr. C.M. van Heugten; Co-Supervisor: Dr. P.W.M. van Gerven.

Ine Rayen: Effects of developmental fluoxetine exposure on neurobehavioral outcomes. Supervisor: Prof.dr. H.W.M. Steinbusch; Co-Supervisors: Dr. J.L. Pawluski / Dr. T.D. Charlier (Ohio University, USA).

Nynke M.G. Bodde: Psychogenic non-epileptic seizures; a separate disorder or part of a continuum? Supervisors: Prof.dr. R. van Oostenbrugge / Prof.dr. K. Vonck (UZ Gent); Co-Supervisors: Dr. R. Lazeron / Dr. A. de Louw (Epilepsiecentrum Kempenhaeghe, Heeze).

Alejandro M. Gomez: Novel strategies for making myasthenia less gravis: targeting plasma cells and the neuromuscular junction. Supervisor: Prof.dr. M.H. De Baets; Co-Supervisors: Dr. M. Losen / Dr. P. Martinez-Martinez.

Mohammad S. Rahnama'i: Prostaglandins and Phosphodiesterases in the Urinary Bladder Wall. Supervisors: Prof.dr. Ph. Van Kerrebroeck / Prof.dr. S. de Wachter (Universiteit Antwerpen); CoSupervisor: Dr. G. van Koeveringe. 
Mariken B. de Koning: Studying biomarkers in populations at genetic and clinical high risk for psychosis. Supervisors: Prof.dr. T. Amelsvoort / Prof.dr. J. Booij (AMC).

Fabien Boulle: Epigenetic regulation of BDNF/TrkB signaling in the pathophysiology and treatment of mood disorders. Supervisors: Prof.dr. H.W.M. Steinbusch / Prof.dr. L. Lanfumey (Universiteit Parijs); CoSupervisors: Dr. D. van den Hove / Dr. G. Kenis.

\section{4}

Iris Nowak-Maes: Tinnitus; assessment of quality of life \& cost-effectiveness. Supervisors: Prof.dr. M. Peters / Prof.dr. B. Kremer; Co-Supervisors: Dr. M. Joore / Dr. L. Anteunis.

Marjolein Huijts: Cognitive function in patients with cerebral small vessel disease. Supervisor: Prof.dr. R.J. van Oostenbrugge; Co-Supervisors: Dr. A.A. Duits / Dr. J. Staals.

Markus Gantert: Fetal inflammatory injury as origin of long term disease: Lessons from animal models. Supervisors: Prof.dr. B. Kramer / Prof.dr. L. Zimmermann; Co-Supervisor: Dr. A. Gavilanes.

Elke Kuypers: Fetal development after antenatal exposures: Chorioamnionitis and maternal glucocorticoids. Supervisors: Prof.dr. B.W. Kramer / Prof.dr. H.W. Steinbusch / Prof.dr. Suhas G. Kallapur (University of Cincinnati, Ohio, USA).

Pieter Kubben: Ultra low-field strength intraoperative MRI for Glioblastoma Surgery. Supervisor: Prof.dr. J.J. van Overbeeke; Co-Supervisor: Dr. H. van Santbrink.

Laura Baijens: Surface electrical stimulation of the neck for oropharyngeal dysphagia in Parkinson's disease: therapeutic aspects and reliability of measurement. Supervisor: Prof.dr. B. Kremer; CoSupervisor: Dr. R. Speyer, Townsville.

Janneke Hoeijmakers: Small fiber neuropathy and sodium channels; a paradigm shift. Supervisor: Prof.dr. R.J. van Oostenbrugge; Co-Supervisors: Dr. C.G. Faber / Dr. I.S.J. Merkies.

Stephanie Vos: The Role of biomarkers in preclinical and prodromal Alzheimer's disease. Supervisor: Prof.dr. F.R. Verhey; Co-Supervisor: Dr. P.J. Visser.

Muriël Doors: The Value of Optical Coherence Tomography in Anterior Segment Surgery. Supervisors: Prof.dr. R.M. Nuijts / Prof.dr. C.A. Webers; Co-Supervisor: Dr. T.T.J.M. Berendschot.

Anneke Maas: Sleep problems in individuals with genetic disorders associated with intellectual disability. Supervisors: Prof.dr. I. Curfs / Prof.dr. R. Didden.

Sebastiaan van Gorp: Translational research on spinal cord injury and cell-based therapies; a focus on pain and sensorimotor disturbances. Supervisors: Prof.dr. B. Joosten / Prof.dr. M. van Kleef; Co-Supervisors: Dr. J. Patijn /Dr. R. Deumens, KU Leuven. 
Andrea Sannia: High risk newborns and brain biochemical monitoring. Supervisor: Prof.dr. J.S.H. Vles; CoSupervisors: Dr. D. Gazzolo, Alessandria, Italy / Dr. A.W.D. Gavilanes.

Julie A.D.A. Dela Cruz: Dopamine mechanisms in learning and memory: Evidence from rodent studies. Supervisors: Prof.dr. H.W.M. Steinbusch / Prof.dr. R.J. Bodnar, New York; Co-Supervisor: Dr. B.P.F. Rutten.

René Besseling: Brain wiring and neuronal dynamics; advances in MR imaging of focal epilepsy. Supervisors: Prof.dr. A.P. Aldenkamp / Prof.dr.ir. W.H. Backes; Co-Supervisor: dr. J.F.A. Jansen.

Maria Quint-Fens: Long-term care after stroke; development and evaluation of a long-term intervention in primary care. Supervisors: Prof.dr. J.F.M. Metsemakers / Prof.dr. C.M. van Heugten / Prof.dr. M. Limburg, Almere; Co-Supervisor: dr. G.H.M.I. Beusmans.

Veronique Moulaert: Life after survival of a cardiac arrest; the heart of the matter. Supervisors: Prof.dr. J.A. Verbunt / Prof.dr. C.M. van Heugten / Prof.dr. D.T. Wade, Oxford, UK.

Feikje Smeets: The hallucinatory-delusional state: a crucial connection in the psychosis symptom network. Supervisor: Prof.dr. J. van Os; Co-Supervisor: Dr. T. Lataster.

Lies Clerx: Alzheimer's disease through the MR-eye; novel diagnostic markers and the road to clinical implementation". Supervisor: Prof.dr. F. Verhey; Co-Supervisors: Dr. P.J. Visser / P. Aalten.

Sonny Tan: The subthalamic nucleus in Parkinson's disease. Supervisors: Prof.dr. Y. Temel / Prof.dr. H.W.M. Steinbusch / Prof.dr. T. Sharp, Oxford, UK / Prof.dr. V. Visser-Vandewalle, Koln.

Koen van Boxem: The use of pulsed radiofrequency in the management of chronic lumbosacral radicular pain. Supervisors: Prof.dr. M. van Kleef / Prof.dr. E.A.J. Joosten; Co-Supervisor: Assoc. Prof.dr. J. van Zundert.

Jérôme Waterval: Hyperostosis cranialis interna. Supervisors: Prof.dr. J.J. Manni / Prof.dr. R.J. Stokroos.

Sylvie Kolfschoten-van der Kruijs: Psychogenic non-epileptic seizures; the identification of neurophysiological correlates. Supervisors: Prof.dr. A.P. Aldenkamp / Prof.dr. K.E.J. Vonck, Universiteit Gent; Co-Supervisors: Dr. J.F.A. Jansen / Dr. R.H.C. Lazeron, Kempenhaeghe.

Wouter Pluijms: Spinal cord stimulation and pain relief in painful diabetic: polyneuropathy, a translational approach. Supervisors: Prof.dr. M. van Kleef / Prof.dr. E.A. Joosten; Co-supervisor: Dr. C.G. Faber.

Ron Handels: Health technology assessment of diagnostic strategies for Alzheimer's disease. Supervisors: Prof.dr. F.R.J. Verhey / Prof.dr. J.L. Severens (EUR); Co-Supervisor: Dr. M.A. Joore / Dr. C.A.G. Wolfs.

Evelyn Peelen: Regulatory T cells in the pathogenesis of Multiple Sclerosis: potential targets for vitamin D therapy. Supervisors: Prof.dr. R.M.M. Hupperts / Prof.dr. J.W. Cohen Tervaert; Co-Supervisor: Dr. J.G.M.C. Damoiseaux / Dr. M.M.G.L.Thewissen, Diepenbeek. 
Reint Jellema: Cell-based therapy for hypoxic-ischemic injury in the preterm brain. Supervisors: Prof.dr. B.W.W. Kramer / Prof.dr. H.W.M. Steinbusch; Co-Supervisor: Dr. W.T.V. Germeraad / Dr. P. Andriessen, Veldhoven.

Maria Wertli: Prognosis of Chronic Clinical Pain Conditions: The Example of Complex Regional Pain Syndrome 1 and Low Back Pain. Supervisors: Prof.dr. M. van Kleef; Co-Supervisor: Dr. F. Brunner, Zürich / Dr. R. Perez, VUmc.

Dagmar Zeef: An experimental model of Huntington's disease: Validation \& Stimulation. Supervisors: Prof.dr. Y. Temel / Prof.dr. H.W.M. Steinbusch; Co-supervisor: Dr. A. Jahanshahi.

Jeroen Decoster: Breaking Down Schizophrenia into phenes, genes and environment. Supervisors: Prof.dr. I. Myin-Germeys / Prof.dr. M. De Hert, KU Leuven; Co-Supervisor: Dr. R. van Winkel.

Eaja Anindya Sekhar Mukherjee: Fetal Alcohol Spectrum Disorders: exploring prevention and management. Supervisor: Prof.dr. L.M.G. Curfs; Co-Supervisor: Prof. S. Hollins, St. George's University of London, UK.

Catherine van Zelst: Inside out; On stereotype awareness, childhood trauma and stigma in psychosis. Supervisors: Prof.dr. Ph. Delespaul / Prof.dr. J. van Os.

Ibrahim Tolga Binbay: Extended Psychosis Phenotype in the Wider Social Environment. Supervisor: Prof.dr. J. van Os; Co-Supervisor: Dr. M. Drukker.

Frank Van Dael: OCD matters in psychosis. Supervisors: Prof.dr. J. van Os / Prof.dr. I. Myin-Germeys.

Pamela Kleikers: NOXious oxidative stress: from head toe too and back. Supervisors: Prof.dr. H.H.H.W. Schmidt / Prof.dr. H.W.M. Steinbusch; Co-Supervisor: Dr. B. Janssen.

José Luis Gerardo Nava: In vitro assay systems in the development of therapeutic interventions strategies for neuroprotection and repair. Supervisors: Prof.dr.med. J. Weis / Prof.dr. H.W.M. Steinbusch; CoSupervisor: Dr. G.A. Brook, RWTH Aachen.

Eva Bollen: Cyclic nucleotide signaling and plasticity. Supervisors: Prof.dr. H.W.M. Steinbusch / Prof.dr. R. D'Hooge, KU Leuven; Co-Supervisor: Dr. J. Prickaerts.

\section{5}

Jessica A. Hartmann: A good laugh and a long sleep; Insights from prospective and ambulatory assessments about the importance of positive affect and sleep in mental health. Supervisor: Prof.dr. J. van Os; Co-Supervisors: C.J.P. Simons / Dr. M. Wichers.

Bart Ament: Frailty in old age; conceptualization and care innovations. Supervisors: Prof.dr. G.I.J.M. Kempen / Prof.dr. F.R.J. Verhey; Co-Supervisor: Dr. M.E. de Vugt. 
Mayke Janssens: Exploring course and outcome across the psychosis-continuum. Supervisor: Prof.dr. I. Myin-Germeys; Co-Supervisor: Dr. T. Lataster.

Dennis M.J. Hernau: Dopayours is not dopamine: genetic, environmental and pathological variations in dopaminergic stress processing. Supervisor: Prof.dr. I. Myin-Germeys; Co-Supervisors: Prof.dr. F.M. Mottaghy / Dr. D. Collip.

Ingrid M.H. Brands: The adaptation process after acquired brain injury Pieces of the puzzle. Supervisors: Prof.dr. C.M. van Heugten / Prof.dr. D.T. Wade, Oxford UK; Co-Supervisors: Dr. S.Z. Stapert / Dr. S. Köhler.

Francesco Risso: Urinary and salivary S100B monitoring in high risk infants. Supervisor: Prof.dr. J.S.H. Vles; Co-Supervisors: Dr. D. Gazzolo, Genoa,Italy / Dr. A.W.D. Gavilanes.

Alessandro Borghesi: Stem and Progenitor Cells in Preterm Infants: Role in the Pathogenesis and Potential for Therapy. Supervisor: Prof.dr. L. Zimmermann; Prof.dr. B. Kramer; Co-Supervisors: Dr. D. Gazzolo, Genoa, Italy / Dr. A.W.D. Gavilanes.

Claudia Menne-Lothmann: Affect dynamics; A focus on genes, stress, and an opportunity for change. Supervisor: Prof.dr. J. van Os; Co-Supervisors: Dr. M. Wichers / Dr. N. Jacobs.

Martine van Nierop: Surviving childhood new perspectives on the link between childhood trauma and psychosis. Supervisors: Prof.dr. I. Myin-Germeys / Prof.dr. J. van Os; Co-Supervisor: Dr. R. van Winkel.

Sylvia Klinkenberg: VNS in children; more than just seizure reduction. Supervisors: Prof.dr. J. Vles / Prof.dr. A. Aldenkamp; Co-Supervisor: Dr. H. Majoie.

Anouk Linssen: Considerations in designing an adult hearing screening programme. Supervisor: Prof.dr. B. Kremer; Co-Supervisors: Dr. L. Anteunis / Dr. M. Joore.

Janny Hof: Hearing loss in young children; challenges in assessment and intervention. Supervisors: Prof.dr. B. Kremer / Prof.dr. R. Stokroos / Prof.dr. P. van Dijk, RUG; Co-Supervisor: Dr. L. Antheunis.

Kimberly Cox-Limpens: Mechanisms of endogenous brain protection; Clues from the transcriptome. Supervisors: Prof.dr. J. Vles / Prof.dr. L. Zimmermann; Co-Supervisor: Dr. A. Gavilanes.

Els Vanhoutte: Peripheral Neuropathy outcome measures; Standardisation (PeriNomS) study part 2: Getting consensus. Supervisors: Prof.dr. C. Faber / Prof.dr. P. van Doorn; Co-Supervisor: Dr. I. Merkies, Spaarne ziekenhuis Hoofddorp.

Mayienne Bakkers: Small fibers, big troubles; diagnosis and implications of small fiber neuropathy. Supervisors: Prof.dr. C. Faber / Prof.dr. M. de Baets; Co-Supervisor: Dr. I. Merkies, Spaarne ziekenhuis Hoofddorp.

Ingrid Kramer: Zooming into the micro-level of experience: An approach for understanding and treating 
psychopathology. Supervisor: Prof.dr. J. van Os; Co-Supervisors: Dr. M. Wichers, UMC Groningen / Dr. C. Simons.

Esther Bouman: Risks and Benefits of Regional Anesthesia in the Perioperative Setting. Supervisors: Prof.dr. M. van Kleef / Prof.dr. M. Marcus, HMC, Qatar / Prof.dr. E. Joosten; Co-Supervisor: Dr. H. Gramke.

Mark Janssen: Selective stimulation of the subthalamic nucleus in Parkinson's disease; dream or near future. Supervisors: Prof.dr. Y. Temel / Prof.dr. V. Visser-Vandewalle, Keulen / Prof.dr. A. Benazzouz, Bordeax, France.

Reina de Kinderen: Health Technology Assessment in Epilepsy; economic evaluations and preference studies. Supervisors: Prof.dr. S. Evers / Prof.dr. A. Aldenkamp; Co-Supervisor: Dr. H. Majoie / Dr. D. Postulart, GGZ O-Brabant.

Saskia Ebus: Interictal epileptiform activity as a marker for clinical outcome. Supervisors: Prof.dr. A. Aldenkamp / Prof.dr. J. Arends, TUE / Prof.dr. P. Boon, Universiteit Gent, België.

Inge Knuts: Experimental and clinical studies into determinants of panic severity. Supervisor: Prof.dr. I. Myin-Germeys; Co-Supervisor: Dr. K. Schruers; Influencing panic.

Nienke Tielemans: Proactive coping post stroke: The Restored4Stroke Self-Management study. Supervisors: Prof.dr. C. van Heugten / Prof.dr. J. Visser-Meily, UMC Utrecht; Co-Supervisor: Dr. V. Schepers, UMC Utrecht.

Tom van Zundert: Improvements Towards Safer Extraglottic Airway Devices. Supervisors: Prof.dr. A.E.M. Marcus / Prof.dr. W. Buhre / Prof.dr. J.R. Brimacombe, Queensland, Australia / Prof.dr. C.A. Hagberg.

Tijmen van Assen: Anterior Cutaneous Nerve Entrapment Syndrome Epidemiology and surgical management. Supervisors: Prof.dr. G.L. Beets / Prof.dr. M. van Kleef / Dr. R.M.H. Roumen / Dr. M.R.M. Scheltinga, MMC Veldhoven.

Rohit Shetty: Understanding the Clinical, Immunological and Genetic Molecular Mechanisms of Keratoconus. Supervisors: Prof.dr. R.M.M.A. Nuijts / Prof.dr. C.A.B. Webers.

Christine van der Leeuw: Blood, bones and brains; peripheral biological endophenotypes and their structural cerebral correlates in psychotic disorder. Supervisor: Prof.dr. J. van Os; Co-supervisor: Dr. M. Marcelis.

Sanne Peeters: The Idle Mind Never Rests; functional brain connectivity across the psychosis continuum. Supervisor: Prof.dr. J. van Os; Co-supervisor: dr. M. Marcelis.

Nick van Goethem: $\alpha 7$ nicotinic acetylcholine receptors and memory processes: mechanistic and behavioral studies. Supervisor: Prof.dr. H.W.M. Steinbusch; Co-supervisor: Dr. J. Prickaerts. 
Nicole Leibold: A Breath of fear; a translational approach into the mechanisms of panic. Supervisor: Prof.dr. H.W.M. Steinbusch; Co-supervisors: Dr. K.R.J. Schruers / Dr. D.L.A. van den Hove.

Renske Hamel: The course of mild cognitive impairment and the role of comorbidity. Supervisor: Prof.dr. F.R.J. Verhey; Co-supervisors: Dr. I.H.G.B. Ramakers / Dr. P.J. Visser.

Lucia Speth: Effects of botulinum toxin A injections and bimanual task-oriented therapy on hand functions and bimanual activities in unilateral Cerebral Palsy. Supervisors: Prof.dr. J. Vles; Prof.dr. R. Smeets; Cosupervisor: Dr. Y. Janssen-Potten, Adelante Hoensbroek.

Yuan Tian: The effects of Lutein on the inflammatory pathways in age-related macular degeneration (AMD). Supervisors: Prof.dr. C. Webers; Prof.dr. A. Kijlstra, WUR; Co-supervisor: Dr. M. Spreeuwenberg; Dr. H. Tange.

Peggy Spauwen: Cognition and Type 2 diabetes; the interplay of risk factors. Supervisors: Prof.dr. F. Verhey; Prof.dr. C. Stehouwer; Co-supervisor: Dr. M. van Boxtel.

Marc Hilhorst: Crescentic glomerulonephritis in ANCA associated vasculitis. Supervisors: Prof.dr. J. Cohen-Tervaert; Co-supervisor: Dr. P. van Paassen.

Martin Gevonden: The odd one out: exploring the nature of the association between minority status and psychosis. Supervisors: Prof.dr. J-P. Selten; Prof.dr. J. Booij, Uva; Prof.dr. I. Myin-Germeys.

Bart Biallosterski: Structural and functional aspects of sensory-motor Interaction in the urinary bladder. Supervisors: Prof.dr. Ph. Van Kerrebroeck; Prof.dr. S. De Wachter, UvAntwerpen; Co-supervisors: Dr. G. van Koeveringe; Dr. M. Rahnama'i.

Alexandra König: The use of information and communication technologies (ICT) for the assessment of patients with Alzheimer's Disease and related disorders. Supervisors: prof.dr. F. Verhey; prof.dr. Ph. Robert, Nice, Fr; Co-supervisors: dr. P. Aalten; dr. R. David, Nice. Fr.

Michelene Chenault: Assessing Readiness for Hearing Rehabilitation. Supervisors: prof.dr. M.P.F. Berger; prof.dr. B. Kremer; Co-supervisor: dr. L.J.C. Anteunis.

Anand Vinekar: Retinopathy of Prematurity. Recent advances in tele-medicine screening, risk factors and spectral domain optical coherence tomography imaging. Supervisor: prof.dr. C.A.B. Webers; Cosupervisor: dr. N.J. Bauer.

Fleur van Dooren: Diabetes and Depression: exploring the Interface between Pathophysiological and Psychological factors. Supervisors: prof.dr. F.R.J. Verhey; prof.dr. J.K.L. Denollet, UvT; prof.dr. F. Pouwer, UvT; Co-supervisor: dr. M.T. Schram.

Gabriëlla Pons van Dijk: Taekwondo and physical fitness components in middle-aged healthy volunteers; the Sekwondo study. Supervisors: prof.dr. J. Lodder; prof.dr. H. Kingma; Co-supervisor: dr. A.F. Lenssen. 
Yara Pujol López: Development and psychoneuroimmunological mechanisms in depression. Supervisor: prof.dr. H.W.M. Steinbusch; Co-supervisors: Dr. G. Kenis; Dr. D. van den Hove; Dr. Aye Mu Myint, München.

Romina Gentier: UBB ${ }^{+1}$; an important switch in the onset of Alzheimer's disease. Supervisors: Prof. H. Steinbusch; Prof. D. Hopkins; Co-supervisor: Dr. F. van Leeuwen.

Sanne Smeets: Insights into insight: studies on awareness of deficits after acquired brain injury. Supervisor: Prof. C. van Heugten; Prof. R. Ponds; Co-supervisor: Dr. I. Winkens

Kim Beerhorst: Bone disease in chronic epilepsy: fit for a fracture. Supervisor: Prof. A. Aldenkamp; Prof. R. van Oostenbrugge; Co-supervisor: Dr. P. Verschuure.

Alex Zwanenburg: Cerebral and cardiac signal monitoring in fetal sheep with hypoxic-ischemic encephalopathy. Supervisor: Prof. T. Delhaas; Prof. B. Kramer; Co-supervisors: Dr. T. Wolfs; Dr. P. Andriessen, MMC. 
